
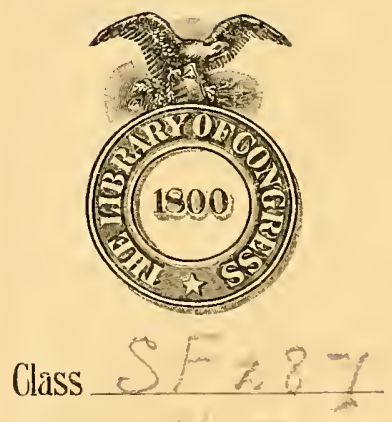

Book

Copyright it N.

COINRIGITT DEPOSIT. 



\section{The Rural :cience Ieries}

EDIted by L. H. BAILEY

\section{THE TRAINING AND BREAKING OF HORSES}




\section{The Ziural Stimen Sertes}

THE SoIL.

The Spraying of Plants.

Milk and its Products.

The Fertility of the Land.

The Principles of Fruit-Growing.

Bush-Frutts.

Fertilizers.

'The Principles of Agriculture. 15th Ed. IRRIGATION AND DRAINAGE.

The Farmistead.

Rural Wealth and Welfare.

The Principles of Vegetable-Gardening. Farm Poultry.

The Feeding of Animals.

The Farmer's Business Handbook.

The Diseases of Animals.

The Horse.

How to Choose a Farm.

Forage Crops.

Bacteria in Relation to Country Life.

The Nursery-Book.

Plant-Breeding. 4th Ed.

THE ForCING-BOOK.

The Pruning-Book.

Fruit-Growing in Arid Regions.

RURAL HYGIENe.

Dry-FARMING.

JaI for the AMERICAN Farmer.

Farm boys and Girds.

The Training and Breaking of Horses.

Others in preparation. 


\section{THE}

\section{TRAINING AND BREAKING OF HORSES}

BY

MERRITT W. HARPER

ASSISTANT PROFESSOR OF ANIMAL HUSBANDRY

NEW YORK STATE COLLEGE OF AGRICULTURE

A T CORNELL UNIVERSITY

AUTHOR OF "MANUAL OF FARM ANIMALS"

Trem 19ork

THE MACMILLAN COMPANY

1912

All rights reserved 


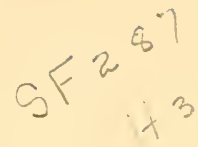

Copyright, 1912 ,

BY THE MACMLLAN COMPANY.

Set up and electrotyped. Published March, Igr 2.

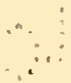

Normood 3 3ress J. A. Cushing Co, - Berwick of smith Co. Norwood, Mass., U.S.A.

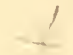

C. CI. A:3(1),53!) 


\section{PREFACE}

THE horse occupies a unique position because he is used as man's principal beast of burden and is constantly associated with him in the performance of his daily work. 'This labor and association establishes a close relationship. The effectiveness with which the work is performed, and perhaps success, depend on their mutual understanding. In performing this work it becomes necessary to trust the horse. This trust is often great, and the safety of the master will depend largely on the understanding he has with his horse.

Since the effectiveness of the horse and the safety of the master and his family depend so largely upon the understanding between man and horse, it seems worth while to give the methods of establishing agreeable relationships careful consideration. It las been with a view of aiding to promote this that the present volume is written. This is done with the thought that the usefulness of the horse depends on his being readily subservient to his master's will, and an attempt is made to set forth the methods that are most likely to bring this about.

Beginning with the foal, each class of horse is considered, and a separate chapter is devoted to the 
education of the more common classes. Special attention is given to the training and subduing of wild horses, as well as to overcoming whims and vicious habits, which often render a horse useless and sometimes dangerous. Many appliances for accomplishing this are described.

While the book is written from a practical point of view, the writer has in mind filling a need met in the classroom, where, owing to lack of time, it is not possible to consider details sufficiently to enable the student to take up the practical work of training horses To facilitate this part of the work, and to avoid repetition, free use is made of cross references.

Recognizing the incompleteness of such a work, the writer will be glad to correspond with those into whose hands this book may fall concerning difficulties in the training of horses, and also to receive suggestions that will aid in perfecting the horse's education.

ITHACA, New YoRk,

II. W. HARPER.

January 29, 1912. 


\section{CONTENTS}

\section{CHAPTER I}

The Horse and his Master • . . . . . 1-25

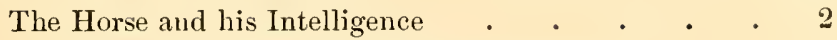

Horses' intelligence often overestinated . . . 3

The horse has a good memory . . . . . 4

Training by Means of the Special Senses . . . 7

The sense of feeling requires patient training . . 8

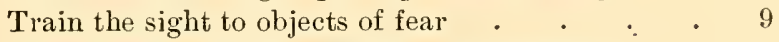

Do not confuse the horse through the hearing . $\quad 9$

Sense of smell also used in training . . . . . 10

Sense of taste indirectly used in training . . . 10

The Objects of Horse Training _ . • • • . 11

Methods of Horse 'Training . . . . . . . . 11

Selecting a method . . . . . . . 12

Rapid methods vs. slow nethods . • • • . 12

Rapid methods permanently effective . . . : 13

Safety in Horse Training . . . . . . . . . 14

Make the Horse understand and respond to Orders and

Signals . . . . . . . . 15

Exact implicit obedience from the horse . . . . 16

Reward and Punishment in Training Horses . . . . 17

The use of the whip . . . . . . . . . 19

Requirements in the Trainer . . . . . . 20

Personal influence of the trainer . . . . 21

General Considerations in Horse Training . . . 22 


\section{CHAPTER II}

Training the Foal . . . . . . . 26-43

Age to begin Training the Foal . . . . 27

Catching and Handling the Foal . . . . . 28

Catch a foal around both ends . . . . . 29

Foals are naturally very timid . . . . . 30

Secure the foal's confidence while young . . . 31

Avoid confusing the foal . . . . . . 32

Make first lessons short and simple . . . . 33

Teach the young foals useful things only . . . 33

Teaching the Foal to Lead . . . . . . 34

Choose a strong, well-fitting halter . . . . 35

The loin-hitch . . . . . . . . . 37

Teaching the Foal to Back . . . . . . . 38

Driving the Foal with Lines . . . . . . 40

Teach the foal "whoa," "get up," and "back" . 40

Value of Early Training . . . . . . . . 42

\section{CIAP'TER III}

Training the Work Horse . . . . . 4t-107

Age to train IIorses for Work . . . . . . 46

Train the IJorse within an Inclosure . . . . 48

Examine the llorse before Training _ . . . 49

Hantle the Horse before Training . . . . . 50

Training the Horse to Lead . . . . . . 51

The tail-hitch . . . . . . . . 52

The quarters-hitch . . . . . . . . . 53

Teach the Horse to follow when Loose . . . . 54

Training to the Ises of the Bit . . . . . 56

Importance of a good month . . . . . 57

Bitting the horse . . . . . . . 57

The hitting-harness . . . . . . . . 60

Driving the Horse with Lines . . . . . . 63 
Teaching the command "whoa" . . . . 65

Teaching the command "get up" . . . . . 67

Teaching the command "back" . . . . . 67

Harnessing, Hitching and Driving the Horse . . 68

Poling the horse . . . . . . . . 69

Harnessing the horse.$\quad$. $\quad . \quad$. 72

Hitching single . . . . . . . . . 74

Training-cart . . . . . . . . . 74

Familiarize the horse with the vehicle . . . $\quad 77$

Teaching the command "steady" . . . . 80

Backing the vehicle . . . . . . . 80

Train the horse to come under the shafts . . . 82

Caressing with the whip . . . . . . 83

Hitching double . . . . . . . . 81

'Training the Horse to Objects of Fear . . . . . 85

"Family-broke" . . . . . . . . 90

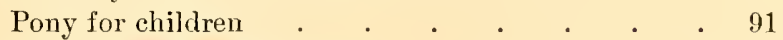

Train the Horse to walk Fast . . . . . . 91

Train the Horse for Heavy Draft . . . . . $\quad$. 93

Training Horses to make Leaders . . . . . . 97

Teaching the commands "haw," "gee" and "yea". 97

Choosing a Vocabulary for the Work Horse . . . 99

Gentling the Feet for Shoeing . . . . . . 101

Training to Mount . . . . . . . . . . 106

\section{CHAPTER IV}

Tranning the Trotter, Coacher and Roanster . 10S-149

Age to begin Training . . . . . . . 109

Method of Training while Young . . . . . 110

The training yard . . . . . . . 111

Plan for training the young colt . . . . 112

Exercising on small track . . . . . . 113

Do not tire the colt . . . . . . . 115

Early Training in Harness . . . . . , 115 
Study individual peculiarities

Training the Two- and Three-year-old • • . . 123

Daily Program for a Horse in Training . . . . 125

'Training for the Race . . . . . . . 127

Preparing for the race . . . . . . . . . 129

Driving . . . . . . . . . . . 129

Improving the Action . . . . . . . . 132

Bitting to improve action - . . . . . . 134

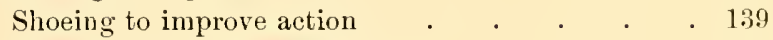

Conditioning to improve action . . . . . 142

Injurious Results of Fanlty Action . • • • • • 143

Over-reaching, forgirg and clicking . . . . . 143

Interfering, striking, cutting and brushing . . 145

Exercise contributes to Action . . . . . 147

\section{CHAPTER V}

Trannisg the Sadde Horse . . . . . 150-185

Lquipment for Training a Saddle Horse . . . . . 151

The riding bridle . . . . . . . 151

The saddle. . . . . . . . . . 151

Whip and spurs. . . . . . . . . 154

Mounting Horse for First Time . . . . . 15.5

Gaits of the Saddle IIorse Described . . . . 15s

The walk . . . . . . . . . 1.59

The trot . . . . . . . . . . 160

The canter. . . . . . . . . 160

The rack . . . . . . . . . . $16 \%$

The ruming walk . . . . . . . 164

The fox trot . . . . . . . . 165

The slow pace . . . . . . . . . 165

The jump . . . . . . . . . 166

Classes of Sutlle Horses . . . . . . . . 167

Training to the Gaits . . . . . . 168

The walk . . . . . . . . . 168 
The trot . . . . . . . . . 170

The canter . . . . . . . . . 171

The running walk . . . . . . . 172

Fox trot . . . . . . . . . 173

The slow pace . . . . . . . . . 173

The rack . . . . . . . . . 173

The jump . . . . . . . . . 174

Training to stand . $\quad . \quad$. $\quad . \quad . \quad . \quad . \quad 176$

Training Horses for the Army . . . . . . 177

The cavalry horse . . . . . . . 178

The scouting horse . . . . . . . $17 \mathrm{~s}$

Picketing . . . . . . . . . . 179

Training Saddle Horses for Special Work . . 179

Polo game . . . . . . . . . . . 179

High-school gaits . . . . . . . 181

Circus tricks $\quad . \quad . \quad . \quad . \quad . \quad . \quad . \quad .183$

\section{CHAPTER VI}

Training Wild and Subdung Vicious Horses . 186-245

Temperament in the Horse . . . . . . . 187

Training and Subduing Appliances . . . . . 188

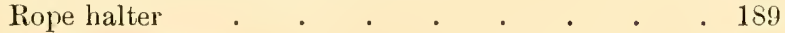

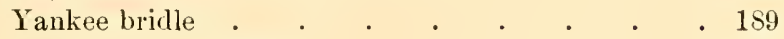

Yankee bridle modified . . . . . . 190

War bridle. . . . . . . . . 191

War bridle modified . . . . . . . 192

Excelsior bridle . . . . . . . . . 193

Pulley bridle . . . . . . . . 193

Pulley bridle modified . . . . . . 195

Hackamore bridle . . . . . . . 196

Caresson halter . . . . . . . . 196

Lip-twiteh . . . . . . . . . 197

Noose-twitch . . . . . . . . 197 
PAGES

Halter-twitch . . . . . . 198

Headstall-twitch . . . . . . . . 199

Bridle-twitch . . . . . . . 200

Rearing-twitch . . . . . . . . . 200

Wooden-gag . . . . . . . . 200

The guy rope . . . . . . . . . . 201

Combination bridle . . . . . . . . . 201

Kicking strap . . . . . . . . . 202

Kicking reins . . . . . . . . . . 202

Kicking harness . . . . . . 204

Self-punishing harness . . . . . . 204

Hobbles . . . . . . . . . 206

Rarey's leg-strap . . . . . . . . . 207

Rarey's safety harness . . . . . . . 208

Rarey's throwing harness . . . . . . . 212

Rope throwing . . . . . . . . . . 216

Galvayne's training harness . . . . . 219

Shackles . . . . . . . . . . . . . . . . . .

Straight-jacket . • . . . . . . . . 221

Training the Wild or Stubborn Horse . . . . . 223

Catching a wild horse . . . . . . . 223

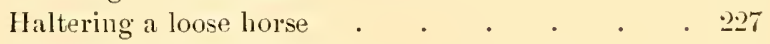

Gentling the wild horse . . . . . . . 229

Teaching the wild horse to lead . . . . . . 231

Teaching the wild horse the uses of the bit and to drive with lines . . . . . . . 293:

'Teaching the wild horse to drive in harness . . 234

'Iraining the will horse to mnfamiliar objects and

to noise. . . . . . . . . 237

Subduing the Vicions Horse . . . . . . . 211

\section{CIIATER VII}

OUTDOOR VICES AND WHIMS . . . . . 246-255

Outdoor Vices, their Cause and how to orercome Them 249

Balling . . . . . . . . . 249 
Jibbing . . . . . . . . . . . 252

Kicking . . . . . . . . . . 251

Shying . . . . . . . . . . . 257

Running away . . . . . . . . . 260

Rumning back . . . . . . . . . 262

Difficult to back . . . . . . . . . 263

Rearing and plunging . . . . . . . 261

Breaking and prancing . . . . . . . . 265

Switching tail . . . . . . . . . 265

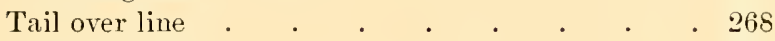

Halter-pulling . . . . . . . . . . 269

Unsteady under whip and spur . . . . . . 273

Difficult to inount . . . . . . . . 274

Buck-jumping . . . . . . . . . . . . 276

Rearing . . . . . . . . . . . 276

Jumping fences . • . . . . . . . . 277

Outdoor Whims, their Cause and how to overcome Them 27s

Tongue-lolling . . . . . . . 278

Striking lips . . . . . . . . . 279

Grasping bit . . . . . . . . . 279

Gnashing teeth . . . . . . . 280

Tossing and shaking the head . . . . . 280

Lugging . . . . . . . . . 281

Boring . . . . . . . . . . 281

Crowding and pulling away . . . . . . 25:

Stripping bridle. . . . . . . . . 288

Refusing to stand over . . . . . . . $28 t$

Tronblesome to catch . . . . . . 285

\section{CHAP'TER VIII}

Stable Vices and Whims . . . . . 286-316

Stable Vices, their Canse and How to Overcome Them 286

Refusing admission into stall . . . . . 286

Difficult to groom . . . . . . . 288 
Difficult to harness . . . . . . . 290

Difficult to bridle . . . . . . . . 291

Difficult to crupper . . . . . . . . 292

Biting . . . . . . . . . . 292

Striking . . . . . . . . . . . . 291

Kicking in stable . . . . . . . . . 295

Hanging back in stall . . . . . . 297

Difficult to lead into a doorway . . . . 298

Cribbing . . . . . . . . . . . . 299

Wind-sucking . . . . . . . . . 300

Difficult to shoe . . . . . . . . 300

Stable Whims, their Cause and How to overcome Them 306

Rolling . . . . . . . . . . . 306

Tearing blankets . . . . . . . . . 307

Stripping the halter . . . . . . . . 308

Pawing with the forefeet . . . . . . . 309

Rubbing the tail . . . . . . . 810

Rubbing harness . . . . . . . . . . 311

Lying down cow-fashion . . . . . . . . 311

Lying down in harness . . . . . . . . . . . . . .

Chewing tie-strap . . . . . . . . 312

Eating the bedding . . . . . . . . 312

Resting one hind foot upon the other . . . . 313

Sleeping standing . . . . . . . . 313

Trotting in stable . . . . . . . . 314

Weaving . . . . . . . . . . . . 311

Switching tail in stable . . . . . . . $31 t$

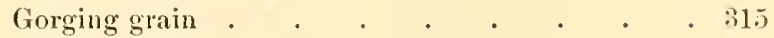

Dificult to drenclı . . . . . . . . . 315

\section{CHAPTER IX}

HAlinessing the COLT . . . . . . . 317-318

The Bit and the Bridle . . . . . . 318

The hit . . . . . . . . 318

Head-stall . . . . . . . . 32.5

Blinds . . . . . . . . 325 
PAges

Centerpieces, earbobs, tassels and brass fixtures . $\quad 326$

The check-rein . . . . . . . . . . . . . . . .

The Lines . • . . . . . . . . 329

Multiple hitch . . . . . . . . 330

The Collar and Sweat-pads . . . . . . . 331

Sweat-pads . . . . . . . . . 335

Breast harness . . . . . . . . . . . . . . . . .

The hame-tug . . . . . . . . . . . 336

The Crupper and Back-straps . . . . . . . 336

The Saddle and Back-bands . . . . . . 337

The Breeching and Hold-backs . . . . . 338

Choosing Harness . . . . . . . . 343

Caring for Harness . . . . . . . . 344

Fly-nets and Fly-blankets $\quad . \quad$. $\quad . \quad$. . 347

\section{CHAPTER $\mathrm{X}$}

\section{Care of Colt in Training}

$319-375$

Exercise and Development . . . . . . . 350

Feeding and Development . . . . . . . 352

Grooming and Development . • . . . . . 357

Clipping and blanketing . . . . . . . . 361

Care of the colt's feet . . . . . . . 363

Care of the colt's teeth . . . . . . . . 365

Accidents Likely to occur in Training • • • . . 366

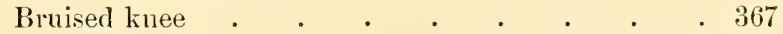

Broken knee . . . . . . . . . . 367

Bruised fetlock . . . . . . . . . 365

Calking . . . . . . . . . . . 369

Puncture of the foot and frog . . • . . . 369

Wounds and stabs . . . . . . . 370

Sprains . . . . . . . . . . 372

Wind-galls, wind-puffs, blood-spavin, bog-spavin

and thorough-pin . . . . . . . . 378

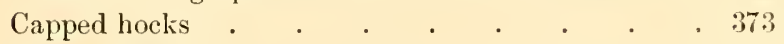

Harness galls . . . . . . . . . . . 373

Chafed legs . . . . . . . . . . 375 



\section{LIST OF ILLUSTRATIONS}

Hackney-colt, showing high knee and hock action. . . 5

Catching foal the first time . . . . . . 29

The loin-hitch used in teaching foal to lead . . . . 37

Teaching the foal to back . . . . . . . 39

Teaching the foal to drive with lines . . . . . 41

The tail-hitch, used in teaching the young horse to lead . 53

The quarters-hitch, used in teaching the young horse to lead . . . . . . . . . 54

The bitting-harness for teaching the uses of the bit . . 61

Running side reins, useful in bitting the horse . . . 63

Teaching the horse to drive with lines . . . . . 64

Poling the head and nose . . . . . . . 70

Poling the body and legs. . . . . . . . 71

The young horse becoming familiar with the harness . . 73

Driving in harness previous to hitching to a vehicle . . 75

Acquainting the horse with the training cart . . . 75

Acquainting him with the top buggy . . . . . $\quad 77$

Hitched for the first time, kicking straps attached . . Ts

Teaching to back with the lines . . . . . . 81

Teaching the horse to back a vehicle . . . . . 82

Young horses hitched double for the first time . . . $\$ 5$

Familiarizing the young hor'se with strange objects . . 88

First position in picking up a front foot . . . . 101

Second position in picking up a frout foot . . . . 102

First position in picking up a rear foot . . . . . . 10 :

Second position in picking up a rear foot . . . . 104

Third position in picking up a rear foot. . . . . $10 \mathrm{~J}$ 
Boots for protecting the feet and legs . . . . . 114

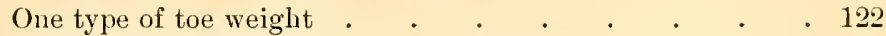

Hackney coach team of proper conformation . . . . 135

Coach horse properly bitted to favor action . . . . 137

Improving action with curb-bit . . . . . . 138

Types of saddles . . . . . . . . . . . . 152

Types of saddle-stirrups . . . . . . . . . 153

Types of spurs . . . . . . . . . . . . 151

The walk . . . . . . . . . . . . 159

The trot . . . . . . . . . . . . 161

The canter . . . . . . . . . . 162

The rack . . . . . . . . . . 163

The running walk . . . . . . . . 164

The fox trot . . . . . . . . . . . 165

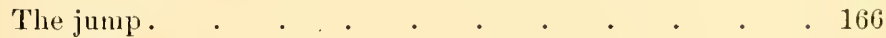

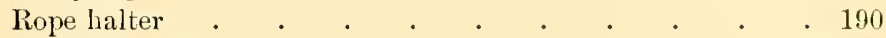

Yankee bridle . . . . . . . . . . . . . . . 191

Yankee bridle modified . . . . . . . . 191

War bridle . . . . . . . . . . . . 192

War bridle modified $\quad . \quad$. $\quad . \quad$. . . . 192

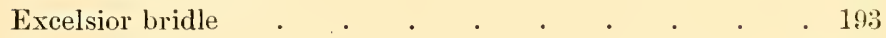

Pulley bridle . . . . . . . . . . . 193

Pulley bridle with three rings . . . . . . . . . 194

Pulley bridle modified . . . . . . . . . 195

IIackamore bridle . • . . . • • . . 196

Noose-twitch . . . . . . . . . . . 197

Halter-twiteh . . . . . . . . . . 198

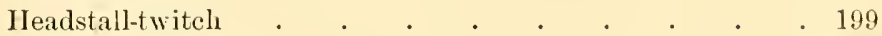

Guy rope . . . . . . . . . . . . 201

Combination bridle . . . . . . . . . 203

Self-punishing harness . . . . . . . . . 205

Hobbles . . . . . . . . . . . . 207

Rarey's siugle safety . . . . . . . . 208

Rarey's double safety with guy rope . . . . . 209

Rarey's single safety restraining one foreleg . . . . 210 
Rarey's double safety restraining the forelegs

Rarey's double safety, horse on knees . .

Rarey's throwing harness

- 213

Rarey's throwing harness, first position . . . . . 214

Rarey's throwing harness, second position . . . . 215

Rarey's throwing harness, third position . . . . 216

Rope throwing harness . . . . . . . . 217

Rope and ring throwing harness . . . . . . . . 219

Nethod of securing rope to tail . . . . . . 220

The Galvayne appliance in use . . . . . . 221

The straight-jacket . . . . . . . . . 222

Snaring a loose horse . . . . . . . . 224

Gentling a loose horse . . . . . . . . . 206

Haltering a loose horse, first position . • . . . 228

Haltering a loose horse, second position . . . . . 229

Arrangement of double safety when hitched . . . . 235

Familiarizing wild horse with objects . . . . . 238

Crupper anti-switching appliance . . . . • . 267

Hip-strap anti-switching appliance . . . . . . 268

Loin-hitch to overcome halter pulling . • • • . 270

Tail-hitch to overcome halter pulling . . . . . 273

Galvayne tail-rope on horse difficult to mount $\quad$. $\quad .275$

Noose-twitch on horse difficult to groom a . . . . 285

Appliances to prevent cribbing . . . . . . . 300

Gentling front foot with rope. . . . . . . 301

Gentling front foot with leg-strap . . . . . . 302

First position in gentling hind foot . . . . . 304

Second position in gentling hind foot . . . . . 305

Third position in gentling hind foot . . . . . 305

Neck-cradle . . . . . . . . . 308

Muzzle to prevent tearing blanket . . . . . . 308

Appliances to prevent pawing • • . . . . . 309

Bits . . . . . . . . . 320

Beery bit. . . . . . . . . . . . . . . . . 33

Patent collars. . . . . . . . . 332 
PAGE

Leather collars. . . . . . . . . . . 333

An inexpensive but neat driving harness . . . . 340

Light work harness . . . . . . . . . . 341

Heavy work harness . . . . . . . . . 342

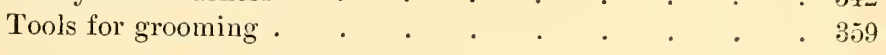




\section{THE TRAINING AND BREAKING OF HORSES}





\title{
THE TRAINING AND BREAKING OF HORSES
}

\author{
CHAPTER I \\ THE HORSE AND HIS MASTER
}

In common usage, the term "training a horse" implies educating him for some special work, while the expression "breaking a horse" signifies preparing him for common everyday work and overcoming whims, faults and vices. This usage of the word "breaking" is very unfortunate. Only too often the average horse is simply broken in spirit and obeys or more accurately does not resist his master because he is worked down and worn out and does not have the energy to refuse. This is the kind of horse that frequently surprises his master by rearing, kicking, running away and the like when permitted to regain his former condition. A horse well educated to perform the more common work of his life requires careful training. This is particularly true at the present time when there are so many self-driven vehicles on the highways.

In this book, therefore, the term "training" is employed to signify the educating of the horse both for common everyday work and for special work, as it 
conveys the proper meaning, the object being to train the horse so as to increase his efficiency, and not to break the high and superb spirit that makes him the most desirable of all animals.

The usefulness and value of a horse depend on his training and on his being readily subservient to his master's will. With few exceptions, such as in high-acting coach work, fast work on the race-track, saddle work and the like, training the horse for his life-work is not difficult. Yet much of the meanness and viciousness existing among horses is due to improper training, poor management and injudicious care. The trainer and the driver, though innocent of the fact, are at fault more often perhaps than the horse. To avoid this deplorable state of affairs, a careful study of the horse and his surroundings should be made in order that the animal may be trained, managed and cared for in a way to enable him to develop his greatest usefulness.

\section{THE HORSE AND HIS INTELLIGENCE}

In horse training, the two most important factors to be considered are the horse and his master. Of these, the master - his nervous disposition, temper, and personal habits - is of vital importance. While knowledge of the methods employed in training is not difficult to obtain, the successful application calls for certain qualities in the master. The lack of such 
qualities accounts for many of the bad habits existing among horses. With a little patience, however, most horse owners can acquire both the knowledge and qualities of temper necessary to train a horse to do his work very satisfactorily.

In order to be efficient in horse training we must know something of the mental capabilities of the horse. We should make therefore a careful study of the animal in order to determine what he can understand. It must be apparent if the horse does not understand what is wanted of him, if he does not comprehend the meaning of the commands and signals, he cannot be taught to obey, but will be much confused, and hence all attempts to train him will fail. First, then, make a careful study of the horse's intelligence.

Horse's intelligence often overestimated. - The horse is often accorded man's most faithful servant, and because of this, no doubt, his intelligence is often greatly overestimated. The horse cannot reason. He lacks the ability of acquiring knowledge by drawing conclusions. This being true, he can be taught only by the association of ideas. As, for example, a touch of the whip on the hindquarter will imply, at first, to go forward, but by giving the command "get up" just before the horse is struck with the whip he soon learns to go at the command. This should be repeated until the habit becomes fixed, when the whip may be discarded. As the horse 
forms habits without difficulty, much care should be exercised in establishing only desirable ones. If a desirable act is repeated, a good habit is formed, whereas if the act is undesirable, the habit is bad. To the horse, however, the habit is neither good nor bad, but only his method of responding to treatment or suggestion.

When a habit is induced generation after generation, it has a tendency to be transmitted from parent to offspring. There are many examples of this among horses, such as the saddle gaits among saddle-bred horses and high action among Hackney coach horses. It is a comparatively easy matter to teach a saddlebred horse the various saddle gaits, whereas it would be practically impossible to teach such gaits to a trotting-bred horse. Hackney coach horses, having been bred for action for many generations, often possess much high knee and hock action from colthood (Fig. 1).

The horse has a good memory. - A habit when fully established implies the use of the memory; that is, the horse must remember that certain commands or signals call for certain acts. The horse has such a good memory that what he fully understands he seldom forgets. The vividness with which erents are retained depends on the intensity of the impression and on repetition, or both. Intensity of impression is more serviceable than repetition in fixing ideas in the horse's mind. Painful lessons are long remem- 
bered. It is this principle that is involved in the short, rather severe methods of training. Repetition, however, is extremely useful in all horse training and is absolutely essential when training for special work, as racers, coachers, saddlers and the like.

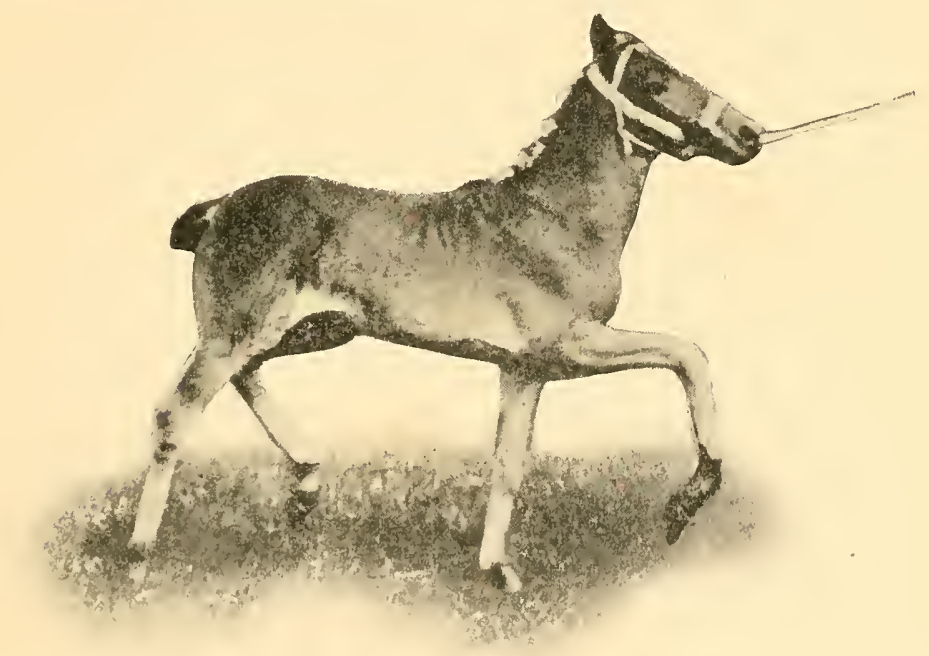

FIg. 1. - Hackney colt, showing high knee and hock action.

In training the horse there are three factors influencing the rapidity with which events may be memorized and thus with which habits are formed. First, with mature horses the power of memorizing or making new associations decreases with increasing age. Therefore we should begin with young ani- 
mals. Second, fatigue, either mental or physical, impairs the memory; hence we should not continue the work so long as to tire out the animal in mind or muscle. Third, the greater the number of ideas associated with the same event the weaker each becomes. Thus, each response should be developed by a different event. That is, to teach a horse to stop, have him do so at the command "whoa"; in teaching him to back, have him do so at the command "back"; and never give the command "whoa-back" when we wish him to stop, or when we wish him to back, as this confuses the animal.

In training the horse's memory, there are two other factors that must be kept constantly in mind. First, there seems to be but slight connection between the two sides of the horse's brain. A horse may be very familiar with an object from one side but when such object is viewed from the other side he may become frightened and much confused. To avoid this confusion, train him to objects first from the "near" or left side, and when thoroughly familiar" with them on this side repeat the process on the "off" or right side. Second, the horse, in his natural state, lives in droves or herds and is never found alone. Because of this tendency to flock together it is easier to drive a number of wild horses than a single wild animal. The domestic horse has not lost this characteristic habit. In view of this, the horse's memory can be more efficiently trained when 
worked alone. If worked with another horse, the colt has a natural tendency to imitate rather than to learn, and thus relies on the other horse and not on his own memory. Further, it is not possible to train a horse while angry, sick or otherwise out of condition, as he does not memorize under such circumstances.

It is interesting to note that the mule possesses greater intelligence, in some things at least, than the horse. A very good example of this is the case of kicking animals. If a kicking horse, when in harness, gets his leg over the trace, he continues to kick until free, even though the legs are injured in the process. On the other hand, if the mule becomes thus entangled, he will remain perfectly quiet and allow himself to be released. The mule seems to be sufficiently intelligent to recognize the folly of needlessly hurting himself, which is not true of the horse when he becomes confused or excited.

\section{TRAINING BY MEANS OF THE SPECIAL SENSES}

Like man, the horse receives his training and education through the special organs of feeling, seeing, hearing, smelling and tasting. It is by these special senses that the horse acquires a knowledge of what is expected of him, and no system of training can be successful that fails to take into account the impressions that the animal receives by these means. 
The sense of feeling requires patient training. In the beginning the horse must be accustomed to handling by his master. The horse should permit every part of the body to be rubbed, but care should be exercised in touching the back of the front legs, the belly and the front of the hind legs, as these parts are very sensitive. Early in life he learns that pressure applied at the halter indicates that he should move forward, and later he learns that a backward pressure on the bit indicates to move backward. The horse familiarizes himself with external objects by the touch, particularly with the nose.

Often horses show much alarm at strange objects in familiar places, such as an empty bag lying in the paddock or a hat by the roadside. The horse will usually walk a few steps toward the object and then circle round and round it, gradually reducing the circle, getting nearer and nearer, until finally he puts his nose on the object. He does this to touch the object, and not primarily to smell it. After thus touching the object the horse's alarm disappear's. This is simply the animal's method of getting acquainted with the strange object. Because of this the horse should be permitted to feel strange objects, such as the harness, the shafts and the like, in order that he may become familiar with them. If this precaution is taken before the harness is placed on the horse's back or before being hitched into the shafts, much needless confusion may be avoided. 
Train the sight to objects of fear. - While the sense of sight is of great importance in training horses, it is second to that of feeling. The horse must be taught to recognize his master and to allow him to approach from either side without resentment. With respect to sight, there are two factors that must be kept in mind. First, train the horse to watch where he is going so that he will not stumble over objects in his path. Second, train the sight so that he will not fear objects likely to. make him start with terror, such as robes, umbrellas, cars and the like. The horse has a great aversion to robes and it is of importance that he be taught, very early in his life, that such objects are harmless, and thus avoid much confusion later. The horse's range of vision is much more limited than that of man. While there is much discussion as to the advisability of using blinds in training, yet it seems very unwise still further to restrict the sight of the animal. This is especially true while he is being trained, as it is the business of the master to familiarize the animal with all objects he is likely to see later in life. Because of the great importance of having the horse view objects from either side and at all angles, the training should be accomplished with an open bridle.

Do not confuse the horse through the hearing. The sense of hearing is often called into use in training horses. While the horse hears readily, it must be borne in mind that too many commands only serve 
to confuse him. Further, one command should never be given for two acts. It is a very common thing to hear a driver use the term "back" when he wishes the animal to stop and to give the same command when he wishes the horse to move backward. Give few commands and have each stand for a certain act. Do not shout at the horse, as this only serves to confuse him. Speak gently but firmly, and if properly trained, he will obey.

Sense of smell also used in training. - Because the sense of smell is not used in the same manner as feeling, seeing and hearing it is often neglected altogether. In horse training, the sense of smell can be made useful, as is suggested by the readiness with which the young horse will take a bit and permit himself to be bridled with a bit and bridle formerly worn by an animal with which the young horse is familiar. In view of this it is well, when convenient, to use harness previously worn by an animal of the horse's acquaintance. (See Fig. 13.)

Sense of taste indirectly used in training. - In rewarding the young horse for obeying our commands, the sense of taste is useful. Thus, if convenient, when the horse obeys he should be rewarded by a bite of grass, a carrot or a lump of sugar. It is a rather common practice to use a measure of grain or an ear of corn to catch a horse out at pasture. While this is a reward only for an act completed, it often serves to fix the idea in the horse's mind. 
THE OBJECTS OF HORSE TRAINING

There are four principal objects sought in training a horse: First, to render him quiet both in and out of the stable; second, to teach him to obey the signals and orders of his master with promptness and precision; third, to create and establish in the animal the habit of applying his powers to the best advantage; and fourth, to correct any fault, whim or vice that detracts from his usefulness.

It is the business of the trainer to guide the horse in such a way as to make it difficult for him to do wrong and exceedingly easy to do right. Since the horse cannot reason, he naturally does those things that are easiest to accomplish. If these acts are bad, we say the horse has bad habits, and if good, we say he has good habits; whereas, with the horse, such acts are simply his way of responding to certain events. Hence we should be ever on the alert to prevent the bad acts by making them very difficult for the horse to accomplish.

\section{METHODS OF HORSE TRAINING}

As horses are exceedingly variable in temper and intelligence, to be successful we must take account of this fact. We should be in possession of various methods for enforcing our commands. This is particularly true of semi-wild horses, or of horses with a tendency to develop certain whims, faults or 
vice, since the removal of the cause of such ailments is the best treatment. The more resourceful the trainer and the greater the number of methods he has at his command, the more successful will be his work.

Selecting a method. - The method to select in training a horse is the one that will give the desired results and establish the proper habits. To determine this we must make a careful study of the animal. Note the temper, the disposition, the general action; in fact, nothing is too insignificant to be considered in this preliminary study of the animal whose habits, either for good or bad, are soon to be established. In the process of developing a horse it may be necessary to employ many methods. This is particularly true in training for the more exacting work, as fast trotting or pacing, high acting coach work, saddle work, and the like.

Rapid methods vs. slow methods. - The methods of training may be divided, in a general way, into two classes: the rapid method and the slow method. In America, the rapid method is usually employed, whereas in the Old World the slow method predominates. A study of these methods reveals the fact that the rapid mode relies on intensity of impression in fixing ideas in the horse's mind, while the slow method depends on repetition to fix the ideas.

The most.common rapid methods are the "Rarey method" (p.20s) and the "Galvaynemethod"(p.219), 
taking their names from the men who first introduced them into practice. In either method the object is to impress the horse that we are superior and that he must do as commanded. Both methods are very simple. Rarey used harness for laying the horse down (Fig. 66), while Galvayne tied the animal's head to his tail in such a way that he was compelled to go round and round until stupefied (Fig. 71). Both methods have been extensively used, particularly on semi-wild horses and on animals that have been spoiled or have contracted some whim, fault or vice. While either method is fairly efficient, one must not make the mistake of thinking it to be infallible. This is an error frequently made by the professional "horse trainer." At best bad habits are often difficult to overcome, and when the horse gets back into his former condition the old tricks also are likely to return. This is especially true of horses that have been spoiled by bad tempered and irritable men who have not the patience to handle a horse. Horses thus spoiled may be cured by changing drivers.

Rapid methods permanently effective. - Some persons have objected to the rapid method of training on the ground that because it takes only one tenth of the time of the slow method, it is not so permanent in its effect. Such is not the case. As has been pointed out, there are two ways of fixing events in the horse's mind; one is by intensity of impression, the other by repetition, of which the former is the more 
effective. In fact, without intensity, repetition has but little effect in fixing an impression on the mind.

In order to insure permanency of effect in training a horse, one must first establish the habit of obedience. Many fail because they do not understand how to enforce obedience, while many others fail because they do not repeat the act until it becomes fixed in the horse's mind. First make the horse obey, then repeat the process as may be needed. Do not rely upon fixing an event in the horse's mind by having him do the act but once or twice. No matter how strong the act was impressed, in the majority of cases it will soon wear off unless repeated. Therefore continue the act until the habit is formed; then it is likely to remain permanently.

It is important to note that no matter how well a horse may have been cured of a bad habit, he is likely to acquire it again if subjected to the same treatment or management that caused it in the first place. The owner of such a horse, therefore, will do well to change him about after training to overcome the bad habit, which in connection with judicious management is very likely to prove permanent in its effect.

\section{SAFETY IN HORSE TRAINING}

In training horses, the methods adopted should be free from physical danger to the horse as well as 
the man. The liability of injuring the animal is one objection to some of the rapid methods. Among horses that are very headstrong and unmindful of the signals, it is safer to risk the horse than ourselves. Thus in the case of horses that are very self-asserting it is best to use methods that afford ample protection, even though they are rather severe on the animal.

The slow, Old World methods are, as a rule, much more likely to result in injury to the trainer than some of the rapid American methods. Thus in some of the slow methods the trainer goes boldly up to the horse, to impress upon him that he is not afraid. Such methods are never to be advised, as the risk is too great. We should never give the animal a chance to do that which is likely to result in injury to ourselves or to any one else. If the trainer is exceedingly careful and painstaking, and, as previously suggested, makes it difficult for the horse to do that which he should not and easy to do that which he should, there is very little risk in horse training.

MAKE THE HORSE UNDERSTAND AND RESPOND TO ORDERS AND SIGNALS

Since the horse cannot understand our spoken language, we must establish certain signals and commands that will render him capable of knowing our 
wishes. These should be very simple, and of such a nature as to be understood easily by the horse. From this it follows that in training horses one should not talk to the animals; this only confuses them. Give few signals and give them as clearly and uniformly as possible. Do not complicate them with other influences, such as the presence of other horses, or undue excitement and the like. Fear and anger also detract from the horse's understanding, and he should not be handled roughly when thus excited.

Even with the simplest of signals, much patience is often required to get the horse to comprehend what is wanted. The moment he understands and completes the act desired, quiet him and repeat until the idea becomes fixed. If the horse does not understand and we continue to force signals upon him, as a rule he will become stubborn, impatient and perhaps violent. The thing to do, therefore, is to make the signals very simple, so simple that he cannot do other than as commanded, and when he does understand and completes the act, to repeat until the habit is formed.

Exact implicit obedience from the horse. - From the beginning the horse must be taught that he cannot resist us. This is very important in the training of a horse, as he takes no interest in obeying. The safety of the trainer as well as the usefulness of the horse requires that he yield himself completely to the guidance of his master. This implicit obedience 
must be exacted even though it is not in keeping with the horse's natural instincts. The method of trying to induce obedience by petting and humoring is not often practical. Such methods often result in the establishment of undesirable whims.

Until he does his work well, the less petting he gets the better animal he will make. This does not mean to punish resisting animals with a whip, - far from it, as such punishment will only make matters worse and is certain to result in the establishment of vicious habits. It does mean, however, to be firm with the horse. Do not attempt too much at one time, but go through with whatever is begun. Give him to understand that you are his master and your will must be done. There are many ways of accomplishing this, as stated later in the text.

\section{REWARD AND PUNISHMENT IN TRAINING HORSES}

Since the horse can acquire knowledge only by the association of ideas, it is necessary to establish methods whereby he may know when he has done as he should; also that he may know when he has not acted in accordance with our wishes. Thus when the animal obeys, he should be rewarded, and when he refuses to obey, he should be punished.

Reward for obedience may be administered in many ways, such as by the voice, by patting, by giving dainty food, by resting, and the like. The use of 
the voice as a means of rewarding animals for obedience is very efficient. The horse readily understands the meaning of a soft tone, and is likely to take a harsh tone for a rebuke. Patting and stroking the horse with the hand, particularly in the region of the mane and along the neck and shoulders, affords a very expressive means of rewarding him for obedience. Giving a handful of hay, or better still of green grass, a carrot or a lump of sugar, often has the desired effect of associating the command or given signal with the event desired. Resting or ceasing the discipline is also a very efficient means of gaining the good will of the horse, and may be used to advantage in the management of the reins.

Punishing the horse for disobedience is much more difficult than rewarding the animal for obedience. There are many ways of rebuking a disobedient animal, the most common being the voice and the whip. The horse will take a harsh tone for a rebuke in much the same manner that he takes a soft tone for a caress. The words used, however, should be few, distinct and significant. No matter what form of punishment is used, we must remember that the benefit to be derived is to induce the horse mentally to associate with it the particular event that we wish to convey. From this it follows that we are justified in inflicting pain only as a means of educating the animal, and never as a penalty for doing wrong. 
The use of the whip. - While the whip is very useful in training and in the subsequent management of the horse, there is perhaps no one thing in connection with horse training so often misapplied as the whip. This is due, in part at least, to the ease with which it can be applied and to the fact that it is used for two very different purposes: First to induce the animal to go forward, and second as a warning that he should not behave in an undesirable manner. This is oftentimes confusing, and the matter is still further complicated when the horse is punished as a penalty for wrong-doing. To avoid this confusion we should give the uses of the whip much consideration.

The whip should always be applied at the rear end of the horse when used to encourage him to go forward. The use of the whip should always be preceded by a command, as "get up." Never strike the horse before giving the command. To be most efficient the lick should succeed the word so elose that the horse cannot help feeling that when the command is given the whip is to follow at once. To avoid the pain of the whip the horse soon learns to start forward at the command alone, when the whip should be put aside.

The whip should always be applied along the side of the horse, when used as a warning. One rather sharp cut, depending on the individual, is usually sufficient to bring a horse to his senses. Never whip 
a horse past an object that is causing him fright. Since he can think of but one thing at a time and since he learns by association of ideas, he may associate the pain with the object or he thinks the object is causing the pain. In horse training, a free use of the whip will break the spirit of highcouraged animals and increase the sulkiness of stubborn ones. One sharp cut, or at most a few, immediately following the command "take care," is sufficient punishment to warn him against wrongdoing.

The horse should never be punished by striking with the whip and jerking on the lines at the same time. This punishing the animal at both ends serves to confuse him, and if he possesses a high spirit some desperate act is likely to follow. To avoid such confusion, administer punishment at but one end at a time.

\section{REQUIREMENTS IN THE TRAINER}

The most important essential in the trainer is that he either possess or acquire complete control over himself and his temper. Without complete control over himself it is not possible for him to attain the ability to control a horse. Horse training is partly an art and partly a science. To execute the work efficiently requires much patience. Horses vary widely both mentally and physically. Some are quick and docile, while others are stupid and 
stubborn. If their lack of understanding or willful disobedience causes their trainer to lose his temper, he will frighten the timid ones out of their senses and provoke the stubborn ones to resistance and perhaps to retaliation. Thus a quick-tempered or irritable trainer is quite likely to develop a bad-tempered horse, while the trainer with an uncontrollable temper is equally as likely to develop a really vicious and dangerous horse. To be most successful in training horses, one should possess an even temper, much patience, readiness of resources, sympathy, skill and pluck, all of which can be attained and developed, in part at least, by thoughtful study and much practice.

Personal influence of the trainer. - In practical horse training the influence of the trainer is often significant. It often happens that the animal is completely taken up by the one in charge. When the trainer is the only one to work the horse subsequently, the possession of such personal influence over the animal is often of much advantage. On the other hand, if the trainer is only to educate the animal, then such influence may be a positive hindrance. The horse may be perfectly safe while under the influence of the trainer, but become refractory or even resent interference from any one else. It is the work of the trainer to render the horse perfectly obedient to the commands of his master. No horse can be said to be thoroughly 
trained until he can be managed under all circumstances by any one familiar with horses.

\section{GENERAL CONSIDERATIONS IN HORSE TRAINING}

Having considered the horse's low degree of intelligence and the fact that he can neither reason nor draw conclusions and must learn therefore by association of ideas; that he possesses an excellent memory which can be easily trained; that the only means of communicating information to him is by the special senses, particularly those of feeling, seeing and hearing; and having considered the objects of training, as well as the more important methods, we may now note some of the more important underlying principles in the practice of horse training.

The earlier in life the training begins the more useful animal he will make. The young horse has fewer ideas of his own and is more willing to accept the direction of a superior intelligence than the older animal. It is therefore of advantage to begin the training in early colthood when at all convenient.

In training, we endeavor to increase the horse's serviceability by rendering him readily subservient to our will. In doing this we exaggerate the horse's idea of those of his powers which are useful and at the same time deceive him as to those attributes which if realized might impair his usefulness. Thus the first time a draft horse is hitched to a load much 
care should be exercised not to overload him, with a view of developing in him the idea that he can pull anything that has both ends loose. On the other hand, the first time he is tied up by the head, equally as much care should be taken to see that the halter is strong enough to hold him in case he pulls. If the horse pulls and fails to free himself at the first few attempts, he is not likely to try it again, and a string would probably serve as well as a chain to keep him in place thereafter. If, however, he succeeds in freeing himself at the first attempt, he will never cease trying to repeat it until put through a system of training to cure the habit of pulling back.

In developing the spirit of obedience, we should not work the horse too long at a time. If the animal is fatigued, his powers of learning are decreased, and if the training is continued, he becomes confused. Fifteen minutes to one half hour is sufficient for a young horse. Five to ten half-hour lessons given in systematic order will accomplish more in preparing the horse to stand severe tests than two years of haphazard training.

Since horses differ in temper and disposition, we are obliged to use various methods in rendering them obedient. No set of rules can be laid down that will apply in all cases. While such methods as were employed by Galvayne and Rarey are very effective in subduing semi-wild horses, neither of them will cure many whims, faults or vices to which 
horses are subject. We should make a careful study of the horse and adopt that method which will prove most efficient with the animal in hand.

Whatever system of training is employed, to be successful we must exact implicit obedience from the horse at all times. Be gentle yet firm, and go through with whatever is attempted. If at any time, however, the horse cannot be induced to do exactly what is required, make him do something else. Enforce obedience of some kind at the time to prevent him from conceiving the idea that he can dispute his master. If at all possible, however, do not rest until he does that which was asked of him.

We should devote our entire attention to the horse in hand and should strive to obtain and keep his attention that he may get an idea of what is expected of him. As soon as he understands what is wanted, repeat in the same manner until the lesson is fixed in his mind. Do not hurry from one lesson to another, and do not try to teach too many things at one time, as such only serves to confuse the hor'se.

In training the stubborn, refractory and wild horse, or in subduing the vicious horse, it is of the utmost importance that he be given to understand that he is to obey or suffer accordingly. From the beginning we must use such appliance as will give us the advantage. This can be accomplished in two ways: First by the employment of such appliance as will consume the animal's strength, and by 


\section{General Consideration in Horse Training 25}

the use of self-punishing harness, which will inflict the punishment at the instant he violates our wish. As soon as he completes the act desired, whether of his own will or because forced to do so, he should be caressed by feeding a dainty, as this serves to fix the idea in his mind. 


\section{CHAPTER II}

\section{TRAINING THE FOAL}

THE foal should be handled and taught a few simple lessons while young. As a rule, the farmer or horse breeder is so very busy at the time the foal is born that the youngster is neglected. He is not given an opportunity to become acquainted with his master. Often he is treated as an outcast. Because he gets in the way or does that which he should not, he is punished. Such treatment may be continued until weaning time, when the youngster is turned out to rough it until three years of age. At this age he is caught up, "broken," and put to work. Soon the owner begins to wonder why his hor'se did not attain the size of that of his neighbor's; why the animal cannot accomplish the work he should; why he developed such whims as lolling his tongue, stripping his bridle, tearing his blanket, cribbing, wind-sucking, and the like; and such vice as switching the tail, biting, kicking, balking, rumning away, and so on, all of which are due to lack of training, care and management while young. 
AGE TO BEGIN TRAINING THE FOAL

As it is much easier to train the young tree, or to mold the clay before it sets, so it is much easier to train the foal while young, as he has fewer ideas of his own and fewer fixed habits. If he is thrifty and strong, the very first day of his life is none too soon to begin training. The earlier in life the training begins the easier the task, and the longer it is postponed the greater are the chances of a hard struggle. We can show, rather than force, him to do that which he does not understand. While it is true, no doubt, that at this early age the animal's power of memorizing is undeveloped, it must be remembered that the horse learns by association of ideas only and beginning at so early an age has many advantages aside from training the memory.

Perhaps the most important advantage gained by early training is that the youngster becomes acquainted with his master at a time when man is the - animal's physical superior. This is significant. As has been stated, the horse obeys commands because he feels obliged to do so, and not because he likes to accomplish a task. It is, therefore, of advantage to fix the idea in the foal's mind that he is our mental and physical inferior and must obey. The earlier he comes into possession of this idea the better horse he will make. On the other hand, horses which 
have roughed it from birth to maturity, having come to know their strength and having their instinct of independence strongly developed, are proportionately more difficult to teach to obey.

\section{CATCHING AND HANDLING THE FOAL}

It is of much importance the first time the foal is caught that he be held in such a manner as not to cause him fright. The common practice is to catch the youngster around the neck, which usually frightens him, and as he has never been fast before he runs backward and either frees himself or falls, with the result that he is more difficult to approach the next time. To avoid this, the trainer should make a careful study of the factors governing the movements of the animal. For example, if we touch his hindquarters, he moves forward, and as we have just seen, if we touch his forequarters, he moves backward. If a horse gets his front foot over an obstruction of any kind and feels the pressure on the foot or leg, he goes backward until he frees himself, even though he seriously injures himself in doing so, whereas he could very easily step over the obstruction by a forward movement. If the hind foot is fast, he goes forward in much the same way. Thus we see that pressure in front stimulates a backward movement, while pressure behind stimulates a forward movement. This is a very important obser- 
vation and should always be kept in mind when training a horse.

Catch a foal around both ends. - In catching the foal for the first time, gently place one arm under the

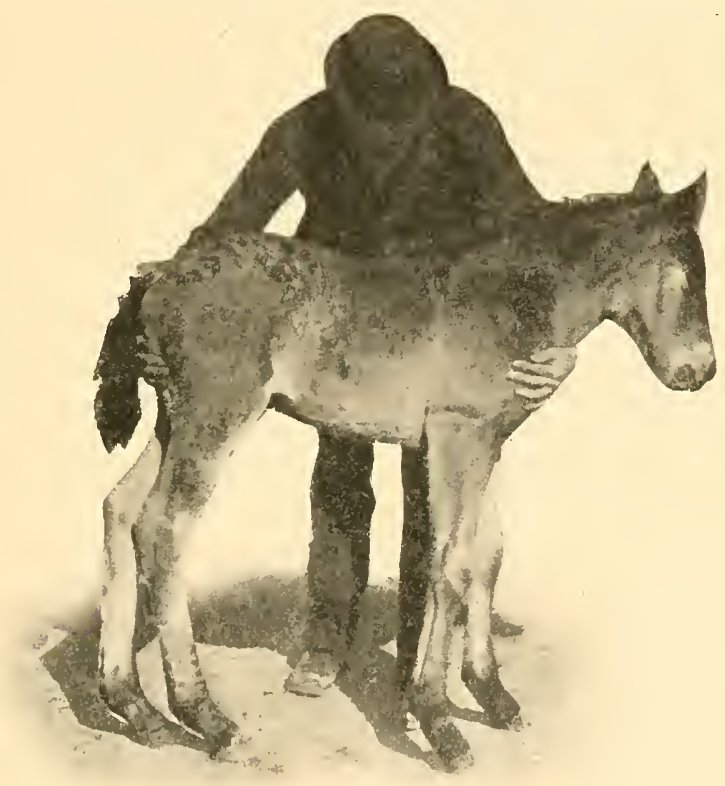

F1G. 2. - Catehing foal the first time.

neck and the other under the hams (Fig. 2). If he attempts to go forward, apply pressure at the neck, or if he attempts to go backward, apply the pressure at the hams. If it is desired to have him step forward, relieve the pressure at the neck and apply it at 
the hams, or if it is desired to have him step backward, relieve the pressure at the hams and apply it at the neck. If caught in this manner, he will soon become quiet, then he should be handled all over the body and legs. Extra care should be taken when handling the ears, the back of the forelegs, the flanks, and the front of the hind legs, as these parts are extremely sensitive to the touch. This requires only a few minutes and the foal, in all probability, will come to meet you the next time you enter the stall instead of fleeing from you, as he will if you attempt to catch him by the neck or even if you pay no attention to him the first time you enter the stall.

Foals are naturally very timid. - Perhaps the treatment horses have received since their domestication, as well as the brutal treatment their ancestors suffered before domestication, has had much to do with rendering the young naturally timid. Foals of the lighter breeds are more nervous and timid than those of the draft breeds, and require more effort to gain their confidence. If the animals are to reach their greatest usefulness, this natural timidity must be overcome and confidence in man established. This can be accomplished by kind, firm treatment. The occasional use of some relished morsel, such as a lump of sugar, will be of material benefit in overcoming timidity and in establishing confidence.

No sudden movements should be made in approaching the foal, as these will make him start and 
jump away. In this way, he will soon learn that he can escape being caught. To avoid this we should always go about the young animal in a very quiet manner. Never make a quick movement in catching him, as this will serve to frighten him and make him more difficult to catch the next time. Never attempt to catch him unless sure of success, for if he succeeds in getting away, it is not at all likely that he will forget it soon.

Children and thoughtless persons often try to make the youngster show off by doing something to frighten him, as throwing sticks, "shooing," running at him and the like. This should never be done. Such actions serve to make the animal more difficult to catch and handle, and in fact may so frighten a highly nervous one as to cause him to injure himself in an attempt to get away. If it is desired to see the foal in action, lead the mare away and the youngster will follow, when his action may be noted.

Secure the foal's confidence while young. - After catching the foal and handling him as suggested, it is important that we secure his complete confidence before he is set free. If for some reason the youngster should make his escape after being caught and held fast, but before his confidence is secured, he will be very difficult to catch the next time. In view of this fact much care must be taken to dispell all fear. Loving kindness is an important factor in securing this confidence. Feeding sweets from the 
palm of the hand, such as a little granulated sugar pressed between the lips, will aid materially in securing the youngster's confidence. Sugar, being sweeter than the dam's milk, seems to give him the idea that we are his friend, and instead of fleeing as we enter the stall he will come to meet us, placing as much confidence in us as in his mother. The importance of securing the colt's confidence at this eariy age is very significant, as he is likely to retain the pleasant recollection throughout life.

Avoid confusing the foal. - In handling the foal, we should go about the work coolly and with confidence. We should be careful to avoid confusing or exciting him. It must be remembered that there is little connection between the two sides of the animal's brain, and he may be perfectly familiar with us from one side and yet become greatly excited if caught from the other side. To avoid this confusion, handle the foal from both sides. He should become familiar with strange objects from every quarter.

In training the youngster, it is important that the first lessons be of such a nature that they can be understood very easily and even more easily accomplished. The foal of course must understand what is wanted before he can be expected to accomplish the task. When he fully understands what is expected of him, he will do it with surprising rapidity. Confusion resulting from not understanding what is wanted often so excites or frightens the animal 
that he is likely to do anything, even to fatally injuring himself by running into telephone poles, gate posts, buildings and the like. Since it is not possible to teach an excited or frightened animal, we must first of all make it clear to him what he is expected to do.

Make first lessons short and simple. - In handling the foal, the first few lessons should not exceed fifteen minutes in length, as this is sufficient time to impress an idea on his mind. These early lessons should be exceedingly simple, so as to avoid confusion. Take up one thing at a time, and be sure the colt fully understands what is wanted and how to do it before passing to another. As advancement is made, teach the lessons in the most useful order and always repeat each in the order taught. Soon the foal can be relied upon to go through the list in order given without a break. On the other hand, if the work is given in a haphazard manner, then all is uncertain as to just what the animal can be depended upon to accomplish. If the work is continued too long and the colt fatigued either mentally or physically, his power of memorizing is weakened, and if the work is complicated, he may become confused. To avoid this make the work short and simple, particularly in the beginning.

Teach the young foal useful things only. - As a rule the foal is full of life, bright and easily taught, and for these reasons he is often taught mischievous 
tricks, such as rearing, kicking, biting, and the like. Since he is likely to remember, throughout life, the impressions made on his mind while young, it goes without saying that such should never be permitted. It is such things that restrict the horse's usefulness.

Teach the young animal only such lessons as will be useful to him later in life. As stated, he should be taught to be handled from both sides and at every angle; teach him the use of the halter so that he will follow wherever you wish him to go; the meaning of the term "whoa," that is, to stop and stand quietly; the meaning of the term "get up," that is, to move forward, and teach him the meaning of the term "back," that is, to move backward. In addition, familiarize the youngster with objects that are likely to cause him fright, show him that such objects will not hurt him, and that he can trust himself to your care with perfect assurance that he will be protected from all harm.

\section{TEACHING THE FOAL TO LEAD}

The best time to teach the foal the use of the halter is when he is about ten days or two weeks old. This is a very important matter, as it is the first time the youngster has been in any part of the harness, and he should be given to understand from the very beginning that such will not hurt him and that he must obey the signals given by means of the halter. Many 
animals which have been very teachable up to this time are often spoiled by improper methods of training to lead, and thus the first impressions they receive as to the use of the halter are bad. In this way the foundation is laid for a confirmed halterpuller, a vice which will materially lessen the future usefulness of the animal (p. 269). This comes about because we are not mindful of the natural tendency of the horse to move backward when pressure is applied at the front and to move forward when the rear end is touched. Without thinking, the halter is placed on his head and we begin to pull on the strap. True to his instincts the foal goes backward. Occasionally the face and neck are deformed in this manner, as the harder we pull the harder the colt pulls back. It is not necessary to drag the foal by the halter in order to suggest to him that his business is to follow. To avoid all this we need but to remember the animal's natural instinct - pressure in front implies a backward movement, whereas pressure behind implies a forward movement.

Choose a strong, well fitting halter. - For the foal a web halter is preferable to a leather one, as it is much lighter and softer and not so likely to injure or frighten him. Never use a rope halter on the young foal. An old halter that has been in constant use is better, all things considered, than one that has been hanging up or even a new one that smells of a lot of things that are strange to the animal. 
It is very important to have the halter fit the head perfectly. Because the foal's head grows so rapidly, colt halters are, as a rule, made too large for the very young animal in order that they may fit later on. The head-stall, brow-band, throat-latch and noseband should be taken up until they fit, otherwise the pressure will not be applied properly, the cheekstraps may be pulled around against the animal's eyes, the chin-band slip over the nose and the like, all of which must be avoided. It often happens that in taking up the halter, long straps are left hanging about the head to annoy the foal. These should be fastened up in some way. It is often rather difficult to adjust the halter to a nervous foal's head, but to be successful one must have patience. Do not be in a hurry, but let the youngster get acquainted with everything as you proceed. With the halter properly adjusted coax the youngster along behind his mother or some accustomed route, as to the water trough and back. If one has sweets available, such as sugar, and permits the youngster to taste of them occasionally, he will soon follow promptly. If he resents, however, other means must be tried. Do not stand in front and try to pull his head off, for he will only roll his eyes, shake his head and move back; and above all do not give up. We must now take advantage of the animal's natural instinct and apply pressure at the rear end as we wish him to move forward. 
The loin-hitch. - Secure a small rope or sash-cord, about ten feet long, tie a loop or fasten a ring in one end, gently place the rope over the foal's back just in front of the hips with the loop or ring on the under

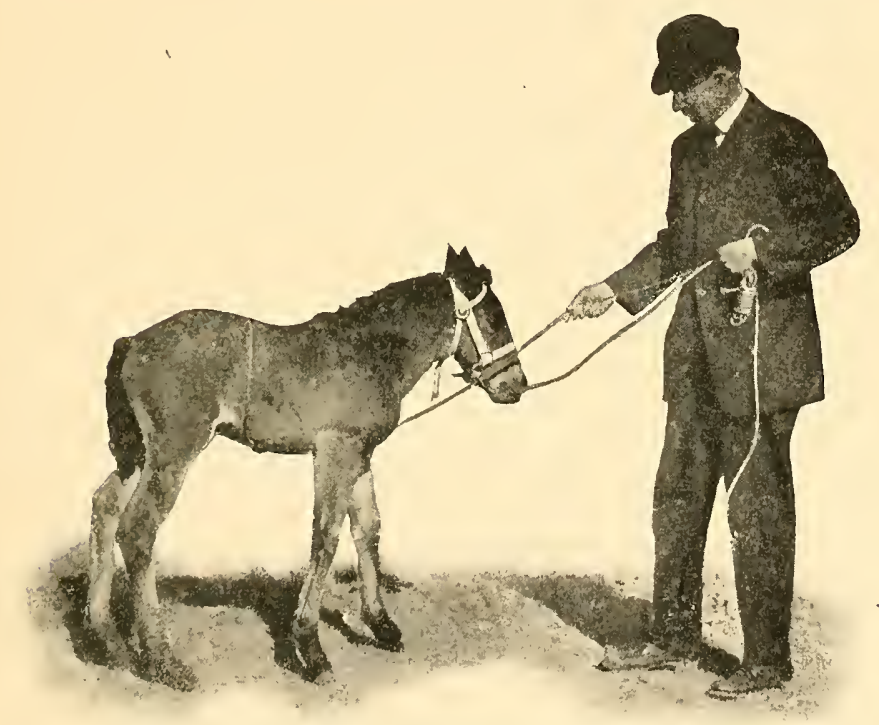

F1G. 3. - The loin-hitch used in teaching foal to lead.

side of the body, so that when the free end of the rope is run through the loop the rope can be closely drawn around the loins and flanks; pass the rope along under the body between the fore legs, and then up through the ring on the halter or under the jaw strap (Fig. 3). 
Take the halter strap in one hand, the loin-hitch rope in the other, and stand in front and a little to one side of the foal. Pull gently on the halter strap and as he begins to shake his head give the loin-rope a sharp pull and he will immediately move forward. In fact, he is likely to move forward so rapidly that he will run into you if you stand squarely in front of him. Do not be in a hurry, but give the animal time to get used to the lesson. If he is excited, give him sweets or caress him until he quiets before attempting to give the loin-rope a second pull. When his confidence has been restored, try again, using the loin-rope again if need be. Soon he will follow wherever you lead. All of this requires only five to fifteen or twenty minutes, whereas by the old method - pulling on the halter alone - we have little or no assurance when the foal will follow.

\section{TEACHING THE FOAL TO BACK}

As soon as the foal fully understands the use of the halter and will follow wherever we lead, he should be taught to back. Do not attempt to teach him to back the same day he is taught to lead, but put it over until the next day. Teaching the colt to back is a very important lesson, as it adds materially to his usefulness in later life. All that is required is pressure in front. Take the halter strap in one hand so as to guide the foal in a straight line or in any 
desired direction, extend the fingers of the other hand between the points of the shoulders and press gently against the animal, and he will step back (Fig. 4).

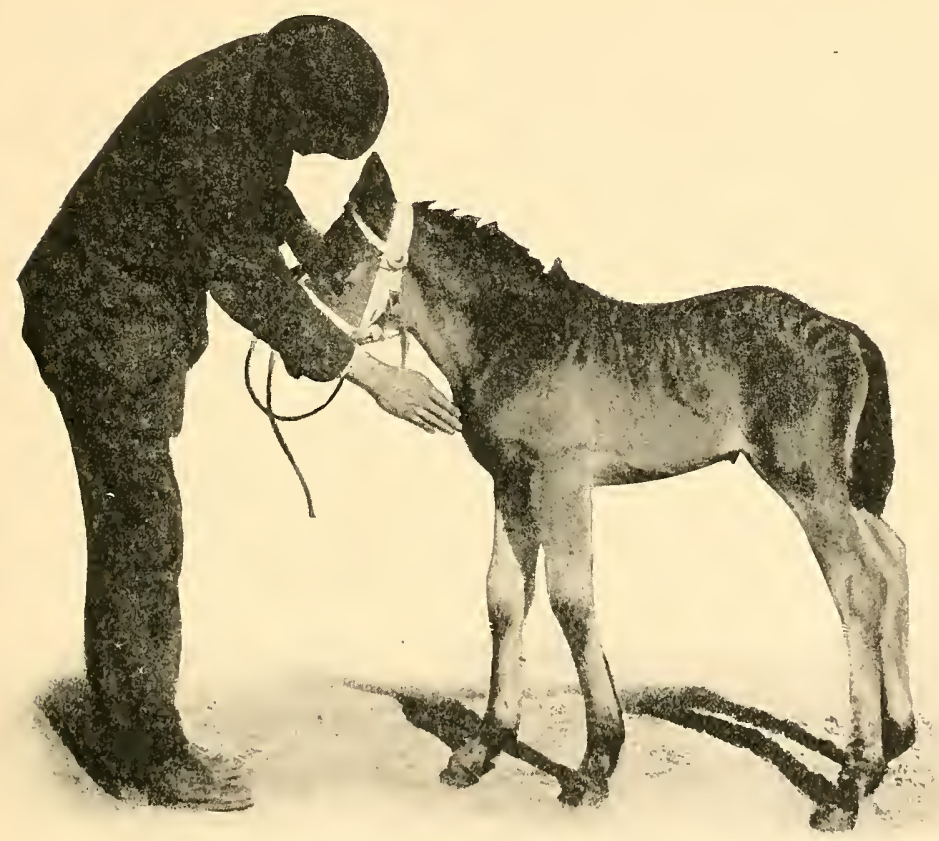

FIG. 4. - Teaching the foal to back.

Reward him for his action and repeat until he will move backward by applying the pressure at the halter alone. Never force the animal by jerking on the halter strap; simply apply pressure in the sensitive chest cavity with the ends of the fingers. In fifteen 
minutes' time, in addition to leading wherever desired, the foal should be willing to back any distance or in any direction.

\section{DRIVING THE FOAL WITH LINES}

By the third day after haltering, if all has gone well and the colt will lead and back, he should be driven with lines. To do this most successfully, a surcingle properly adjusted is required. The surcingle must be provided with a loop on each side, placed well below the center of the body, the lines passed through the loops and fastened to the ring on either side of the halter. Never use a bit in the mouth of a very young animal. Now the lines will pass the hind quarters low and thus prevent the foal from turning with his head toward us, which he will do occasionally if the surcingle is not used. It is very important to keep the reins low in turning to make the guiding process easy. At first, walk close to the animal so as to encourage him to go forward by occasionally touching the rump with one hand while the guiding is done with the other. As soon as he becomes accustomed to being driven he may be touched up with the lines, guided to the right and left, but should be stopped often to assure him that he is doing well (Fig. 5).

Teach the foal "whoa," "get up," and "back:" Since these three terms are to be used so very much 
in the animal's later life, he should be taught their meaning very early. For best results these terms should be taught one each day, beginning the next day after the foal has been driven with the lines. After driving for a short time or until the excitement

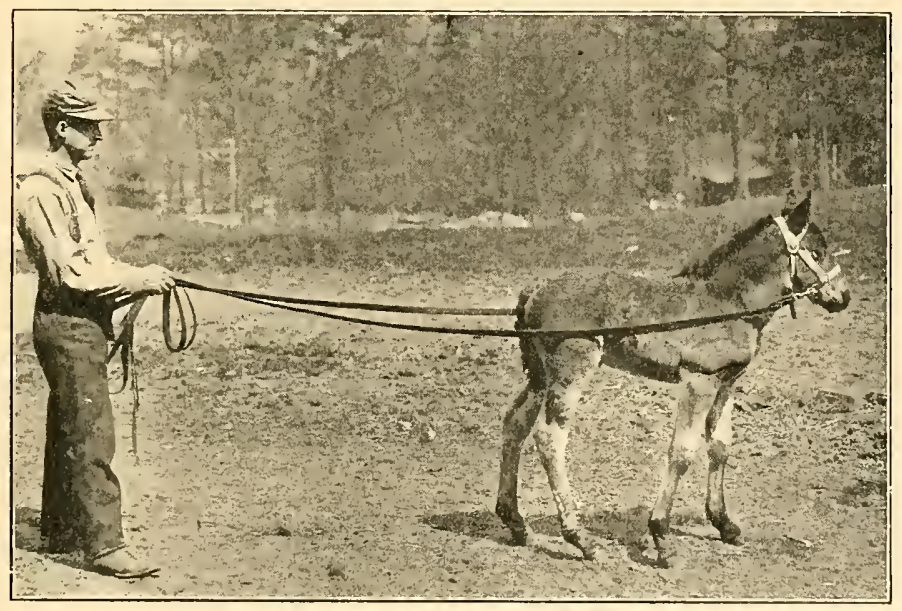

FIG. 5. - Teaching the foal to drive with lines, the surcingle removed.

has worn off, give the command "whoa," following immediately with a sudden and positive pull on the lines (p. 66). Do not speak loud, but rely more on the pressure applied with the lines. The foal should be rewarded. After waiting a short time start by applying pressure on the rump, and after going until all is right, repeat the command and the pull as before. As soon as he shows indication of stopping 
at the command, do not pull on the lines. When he stops at the command alone, reward him.

The next day, after driving for a short time and stopping at the command "whoa," the foal should be taught the meaning of the term "get up." To do this, start the animal by the command "get up," followed immediately by a rather sharp tap upon the rump. Tap the animal according to what he will stand and not so as to frighten him. As soon as he is going normally, stop by the command "whoa" and caress him. Repeat the process until he will start at the command alone.

The following day teach the foal the meaning of the term "back." This should first be done in the way already suggested; that is, by holding the halter in one hand and applying pressure between the shoulder points with the other, at the same time giving the command "back." Repeat until the youngster will move back at the command alone. Now you are ready to snap on the lines and teach him to back from behind. At first it may be necessary to pull on the lines following the command. Repeat and reward him until he will back at the command. By the third day the foal should respond to all three commands.

\section{VALUE OF EARLY TRAINING}

The time required to carry out the above suggestions is but fifteen minutes for six consecutive days, 
or ninety minutes in all, during which time the youngster has been taught to lead, to drive, to stop at the command "whoa," to start at the command "get up" and to back on command. While he is not yet three weeks of age yet he will obey commands better than the average horse will ever obey them. The value of training begun thus early cannot be overestimated. It fixes the idea of subordination in the horse's mind at a time in life when no subsequent treatment can shake it, and even though the time consumed in such training is quite insignificant, it adds as nothing else can to the future usefulness of the animal.

There are two objections to training the colt while young. First, want of time on the part of the owner, and second, being trained, the youngster is likely to be driven or put to hard work before he is properly developed. For these reasons the colt is usually permitted to enjoy his independence until such time as he is needed for work, with the result that his general usefulness in many cases is much impaired. A horse should be reasonably mature before he is called upon to do service, but any time spent in his education prior to the date at which he goes to work will be repaid many times in the more satisfactory service that he will render. 


\section{CHAPTER III}

\section{TRAINING THE WORK HORSE}

In training or hitching horses, young or old, there are a few general considerations that should be kept constantly in mind. A horse should never be trusted more than is necessary. Children, women or incompetent men should never be left in charge of horses unless the animals are thoroughly acquainted with them. Many distressing accidents occur from trusting old family horses. A good horseman never runs risks when they can be avoided.

In handling horses, the safest way is for the attendant to remain close to the animal's left shoulder, grasping the bridle close to the mouth with the right hand. In this position the horse is unable to injure him. If the horse becomes fractious, the attendant should stay close to the animal's left shoulder or get entirely out of his reach, for many serious accidents have resulted from horses rearing, striking and kicking in play, when being led by an attendant at the end of the lead strap. Never attempt to lead a fractious horse with a halter without looping the rope or tie-strap and slipping it into his mouth in the place of a bit, then running the rope or tie- 
strap through the nose-band, thus forming a loop around the lower jaw, in which condition the horse can be easily controlled (p. 199).

In bridling, harnessing and saddling a horse the work should be done from the left side. The harness should be gently but firmly placed upon the animal. The harness and other equipment should be of good quality and in good repair, and so adjusted as to fit the animal snugly. In hitching a horse into a pair of shafts, the shafts always should be raised and the animal led under or backed into them, or the vehicle drawn forward, as the horse is likely to step on a shaft and break it if backed in while they are on the ground. In hitching, the lines should be fastened into the bit and then placed where they can be reached easily before attaching the horse to the vehicle. In unhitching, the lines should be the last disengaged, and care should be taken that the animal is free from the vehicle before he is led away. Serious accidents often result from leading the horse out of the shafts before the holdbacks are unfastened.

In tying to a post or hitching-rack, the horse should be secured by a strong rope or strap placed around his neck, then passed through the ring of the bit and on to the post. It is good practice to obtain a short strap about six inches long, provided with a loose ring and a snap at either end to secure in the bit-ring on either side so the loose ring will remain 
under the lower jaw. Now by snapping the leadrein or running the tie-strap through this ring, pressure is brought to bear equally on either side in case the horse should pull. A horse should always be tied short, otherwise he may get his foot over the tie-strap, be unable to disengage it, break the tiestrap or the check-rein, become frightened and an accident result.

AGE TO TRAIN HORSES FOR WORK

At the present time there is much discussion as to the most profitable age at which to train horses for work. Some good horsemen state that they prefer not to have the horse worked until coming four years old, while others think a more useful animal will result if put to light work at two and one half or three years of age. Each of these methods may prove equally successful, depending on conditions. It would seem that these ages might well represent the extremes. As a rule, the horse should not be put to work under two and one half years of age, and even then the work should be light and the working hours short. If the work is too severe, or continued for too long a time, the animal will be retarded in his growth and he will not make as useful a horse as if the training had been delayed a few months. On the other hand, if the horse is thrifty, it is poor economy to keep him in idleness after he is four year's of age. 
The breed, the individuality and the work performed all have a bearing upon the age to begin training. As a rule, the draft breeds mature younger than the lighter breeds, and therefore may be put to moderate work younger. Some individuals develop more rapidly than others, and as they mature earlier they may be put to work younger. The work performed likewise has a bearing on the age of training. Thus in the case of the draft horse, where force applied.at the collar is required, or in the case of the saddle horse, where the weight is borne upon the horse's back, the animal should be reasonably mature. On the other hand, when the horse is intended for fast work on the race track, many good horsemen feel that the training eannot begin too soon; thus we often find these men constructing miniature tracks around which the animals are led or driven by means of a long line by the time they are weaned, sometimes before.

The breed and the work performed exert an influence on the amount of training required. As a rule, the draft breeds are much more easily trained than the lighter breeds. There are two reasons for this: First, the draft breeds are larger, quieter and neither so active nor so high-strung as the lighter types. They are much more easily handled and not so likely to go wrong as the lighter types. Second, the work that draft breeds are called on to perform does not require the continuous training that is required of 
the lighter breeds; the tasks are not numerous or difficult to learn, whereas the saddle or coach horse may be called upon to do a number of tasks, each of which is hard to learn and requires long and severe training.

\section{TRAIN THE HORSE WITHIN AN INCLOSURE}

In training the horse, it is of great advantage to provide an inclosure, varying in size according to the nature of the training or the temperament of the horse, but for most work twenty-five to fifty feet square will suffice. All obstructions likely to injure or attract the horse's attention, such as wagons, barrels, posts, bricks, stones, sticks and the like, should be removed. If the inclosure is within a barn or under a shed, the ceiling should be at least twelve feet high. No matter where the inclosure, the floor should be of soft earth. Never begin training the horse on cement, brick or even a hard wood floor. Not only is the horse likely to slip and injure himself or the man in charge, but it is often found necessary to lay the horse down to convince him that we are his master, and the likelihood of injury is great if this is attempted on a hard floor, particularly cement or brick. Within such an inclosure it is much easier to get the horse's entire attention, and should anything go wrong whereby he should free himself, he will be unable to get away. 
Many advise turning the horse loose within the inclosure in order that he may become accustomed to the place in which he is to receive his early training.

\section{EXAMINE THE HORSE BEFORE TRAINING}

The horse should be carefully examined to see that he is in good physical condition before the training begins. In order to be effective in training, it is necessary to gain the hor'se's confidence and hold his attention. This is not possible with the animal in poor physical condition. Note the teeth to see if they are uneven or possess sharp edges, which are likely to injure the tongue or jaws. Such edges should be removed with a guarded rasp, otherwise the pain will detract the animal's attention from the lessons we are trying to teach. Note the condition of the feet, and if they are out of proportion, level them with the rasp, otherwise the horse will be irregular in his action and may injure himself by interfering. Examine the horse for impaired vision and defective hearing. If his vision is impaired, he may run into objects, or seeing them but dimly may become frightened and uncontrollable. If his hearing is defective, he is at the disadvantage of not being able to understand spoken commands. The disadvantages under which such a horse labors are great, and it is important that such defects be noted in order that we may not ask him to do that 
which is impossible for him to accomplish. If we proceed with such a horse as if he was normal, he may become confused, frightened, difficult to control and may endanger his own life as well as that of his master.

\section{HANDLE THE HORSE BEFORE TRAINING}

In many cases the horse breeder will not feel warranted in taking the time to train the foal as suggested in the previous chapter, even though the animal's future usefulness is materially lessened by such neglect. The horse may be given his freedom until old enough to work, perhaps never being taught the use of the halter. Such a horse should first of all be made gentle, so that he will permit his entire body to be handled. Some untrained horses are so quiet that they will readily submit to any amount of handling, whereas others offer resistance, even when lightly touched. Familiarizing some horses to the touch requires much patience. Most horses are particularly sensitive about the ears, the underline and the legs.

It is a common practice to use some form of twitch to attract the horse's attention while handling these sensitive parts. While the use of the twitch is recommended in training vicious or spoiled horses, it should be used on the untrained horse only as a last resort. Kind treatment, well-directed effort 
and patience are preferred to the use of the twitch, and will overcome most horses. In case the horse is very sensitive to the touch and it is not safe for one to get near to caress him with the hand, other means must be devised. The English use a socalled "third hand," which is a stick somewhat similar to a walking stick or cane. With such a stick rub the horse along the top of the neck. The dandruff collecting about the base of the mane often irritates the part so that it itches, and the horse enjoys having it rubbed or scratched. After he has become familiar with the stick on top of the neck, pass it back, touching the withers lightly or not at all, and rub the back, the sides, the rump and the like. After a few minutes' work with the stick, the horse learns that he is not going to be harmed and will permit himself to be rubbed with the hand.

The horse is now ready for the halter. Choose a strong leather halter, preferably one that has been in constant use, place it on the animal's head and tie securely in the stall. He should be left in the stall for some time in order that he may become familiar with the halter.

\section{TRAINING THE HORSE TO LEAD}

After the horse becomes accustomed to being handled, and familiar with the halter, he should be taught to lead. As this is a very important matter, 
due care should be exercised to avoid a misunderstanding between the horse and his master. The advice given in teaching the foal to lead (p. 34) applies here, but it may be necessary to employ other methods, particularly if the horse is rather stubborn. While the loin-hitch, which was recommended for use on the foal, is often successfully employed on older horses, it sometimes happens that better results can be secured by the use of the tail-hitch or the quarters-hitch.

The tail-hitch. - Secure a small rope or sash-cord about ten feet long, tie a stationary loop at one end, place the tail through this loop and bring the free end of the rope forward and pass through the ring on the halter or under the jaw strap. To prevent this slipping over the tail when it gets slack, take a small rope and make a surcingle, placing a ring at the top through which the rope leading from the tail to the halter may pass (Fig. 6).

Take the halter strap in one hand the rope in the other, pull gently on the former, and as the horse begins to shake his head or to step back give the latter a sharp pull and the animal will move forward. Caress him until he quiets, and when his confidence has been restored repeat the process, using the rope when needed. In a few minutes the horse will follow where led and the rope may be removed.

While this hitch is a very effective method of teaching a horse to lead, care should be exercised in its 
use. The under side of the tail is very tender and the roughened surface of the rope sometimes provokes the horse to kick, particularly if nervous. With such horses the quarters-hitch is to be preferred.

The quarters-hitch. - Secure a small rope, or sashcord, and tie a large loop at one end. This loop

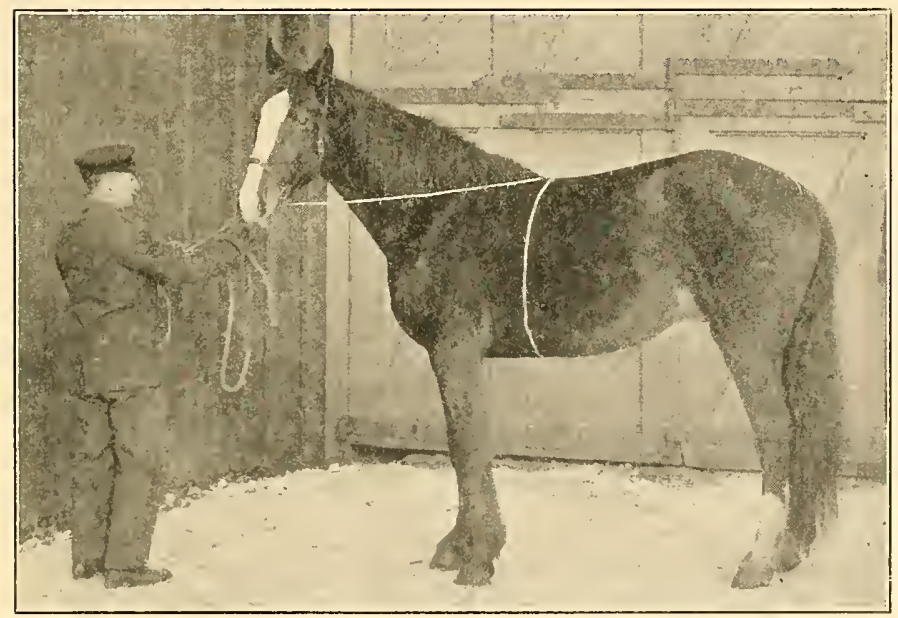

FIG. 6. - The tail-hitch used in teaching the young horse to lead.

should be of sufficient size so that when placed in position on the horse it surrounds his quarters, leaving the knot well forward, on the back. Pass the free end along the back and through the ring on the halter (Fig. 7). By pulling on this rope pressure is brought on the quarters, and the animal moves forward. This hitch has the advantage that the 
pressure is brought to bear at a place where there is little or no likelihood of injuring the horse, and yet the pressure stimulates a forward movement as well if not better than either the loin- or tail-hitch.

\section{TEACH THE HORSE TO FOLLOW WHEN LOOSE}

In order to facilitate catching the horse when loose, as at pasture, it is of advantage to have him

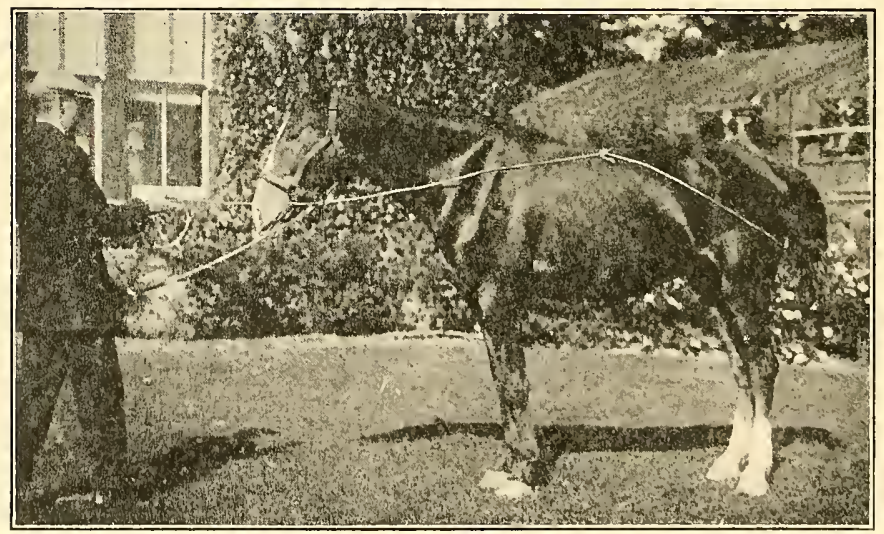

FIG. 7. - The quarters-hitch, used in teaching the young horse to lead.

trained to come up to us, and to follow. While there are many methods of teaching the horse to follow, only two are here given, one to be employed on teachable and gentle horses, the other on horses rather stubborn in their disposition. As soon as the teachable horse has been taught to lead, procure a 
whip, and facing the animal, take a position in front, or slightly to the left, caress him by gently rubbing the whip over his back and rump. When ready to start, say "come here," and immediately follow the command by striking the horse on the rump with the whip, which will induce him to walk forward. Walk backward at the same rate as the horse walks forward, giving the command "come here" to induce him to follow. When he follows at command, place the whip under the left arm. This method may require some time, but with a little patient effort the teachable horse will follow you without the use of either halter or whip.

Some horsemen in teaching a horse to follow prefer to turn the animal loose in a small inclosure, say twenty-five feet square. It is important that the floor be of earth, and that all objects be removed, as they may attract the colt's attention. If the horse is two years old, or more, some prefer to teach this lesson before training to the use of the halter. When ready, turn the horse loose in the inclosure and snap the whip a few times to attract his attention. Remaining near the center, follow him around a few times, occasionally snapping him about the heels with the whip. Soon he will stop in the corner farthest from you. Walk directly to him, giving him an opportunity to turn to you. If he turns his heels as if to kick or run away, strike him severely about the hind legs. Soon he will understand that 
he exposes himself to punishment by turning away from you. Repeat until he turns his head toward you when approached.

As this was the way you wished the horse to turn, he should be rewarded by having his crest scratched with the end of the whip, and if convenient by feeding a carrot or other dainty. You are now ready to teach him to follow by the method described above. If he refuses to obey the command "come here" and runs away, strike him sharply about the heels. If he obeys, caress him. Soon the animal will understand that he is punished for running away and caressed for following. When he understands this he will follow and you may discard the whip.

\section{TRAINING TO THE USES OF THE BIT}

Perhaps no other factor in the training of horses, whether for work or pleasure, is of greater importance than that of educating to the uses of the bit. The thoroughness with which this is accomplished will go far towards determining their usefulness. Inasmuch as the conveyance of the master's desire to the horse's mind for execution is largely through the hands, reins, bit and mouth, little progress can be made and none should be attempted until this means of communication has been established.

Before bitting, the mouth should be examined for sores, as it is not possible properly to train a 
horse to the uses of the bit while suffering from sore mouth. Such an examination is not difficult. Place the horse where there is good light. To examine the left side, pass the left hand into the right side of the mouth, grasp the tongue gently, and pull it to one side, but not out of the mouth, which will expose the bar, or branch of the lower jaw on the left side. The thumb of the right hand may now be placed in the roof of the mouth so as to separate the jaws, when the left side of the mouth may be observed. The other side should be examined in a similar way.

Importance of a good mouth.- No factor contributes so much to the pleasure, comfort and safety of either rider or driver as a responsive mouth - one that always obeys promptly the slightest instruction from the master. A good mouth - one with sensitive bars - is natural to the horse. "Tender," "hard," and all kinds of "spoiled" mouths result from improper handling. Such spoiled mouths are very aggravating and often the cause of many other imperfections - tongue lolling, crossing the jaws, hobbling, kicking, balking, running away and the like - many of which when well established are very difficult to overcome (p. 249).

Bitting the horse. - The object of correct bitting is to preserve, instead of diminish, the natural sensitiveness of the bars of the horse's mouth. The kind of bit to use, therefore, is important. Because of 
the importance of correct bitting, many kinds of bits have been devised for training the horse as well as for subsequent use (p. 320). Many of these bits irritate the tender parts and destroy rather than preserve the natural sensitiveness of the lips and bars. While any bit may slightly abrade the lips and bars of the mouth, many of these patent bits produce deep sores. This, of course, renders training to the uses of the bit unnecessarily painful, and may produce a spoiled mouth.

The proper bit to use depends on the object sought. Thus in training the saddle horse one type of bit is demanded (p. 151); in the coach horse another type (p. 134); in the trotting horse still another; and the work horse responds more readily to a bit differing from any of the above types. Whatever kind of bit is used it should be strong, without being heavy and cumbersome. In training the work horse a straight or slightly curved barbit with leather guards, and covered with rubber or leather in case the horse's mouth is tender, cannot be improved upon.

Many training bits are provided with keys attached to the mouthpiece, which encourage the horse to champ and thus familiarize himself with the bit (Fig. 94, 26 and 27). While key-bits are useful, especially for those horses which persist in keeping a dry mouth, sulkily refusing to champ the bit, as the keys assist in the work of bitting such an ani- 
mal, they should never be used on nervous horses that champ the straight bit. Occasionally the mouth of a nervous horse is spoiled by the use of the key-bit. In case the horse refuses to champ the bit and the key-bit is used, its usefulness may be increased by smearing the keys and mouthpiece with honey or other sweets, as such materials encourage the horse to lick and champ the bit.

When placing the bit in the horse's mouth for the first time, carefully lift the bridle with the left hand until it is above the eyes, then pass the right hand over the animal's head, quietly lift the poll-piece and place the bridle in position. At the same time open the horse's mouth slightly by pressing the bars under the lower lip with the thumb and forefinger of the left hand and guide the bit into the mouth. If the horse refuses to open his mouth, insert the fingers of the left hand into the mouth and tickle the roof. The bit will then slip into the mouth, and it should be arranged so as to lie on the bars.

The adjustment of the bridle and the length of the bit are important. The length of the headstall must be adjusted so as to bring the bit in mild contact with the bars of the mouth. If the headstall is too short, the bit is drawn up into the mouth. too far and the bars as well as the corners of the mouth soon become sore and the animal may become vicious; on the other hand, if too long, the bit drops in the mouth, and the animal becomes care- 
less. The bit should be of proper length for the horse. If it is too long it will pull through the mouth so that the pressure will not be equal on either bar and the horse may become confused (p. 321).

The bitting-harness. - The horse can usually be made familiar with the uses of the bit by the application of the bitting-harness. This harness consists of an open bridle with a large, smooth, guarded bit and check-rein, surcingle and çrupper and two side lines running from the bit to rings on either side of the surcingle (Fig. 8). If the horse is of a nervous disposition, it will often allay his fear to permit him to smell and feel this harness before placing it on his back (Fig. 13). Arrange the harness with much care.

With the bitting-harness properly adjusted, turn the horse into the training paddock to familiarize himself with the bit. The check and side-reins should be left slack at first. During the first few lessons the bit should not be retained in the animal's mouth for more than half an hour at a time. He may be given two or perhaps three lessons a day. Subsequently the lessons may be longer. Gradually from day to day the reins should be shortened, care being taken that they are never made so short as to place the head in an uncomfortable position, or draw the bit so tightly as to make the corners of the mouth sore. The number of lessons necessary to familiarize 
the horse with the uses of the bit will depend entirely on the individual. Some horses will drive after one or two, while others will require a week or more before they fully understand its uses.

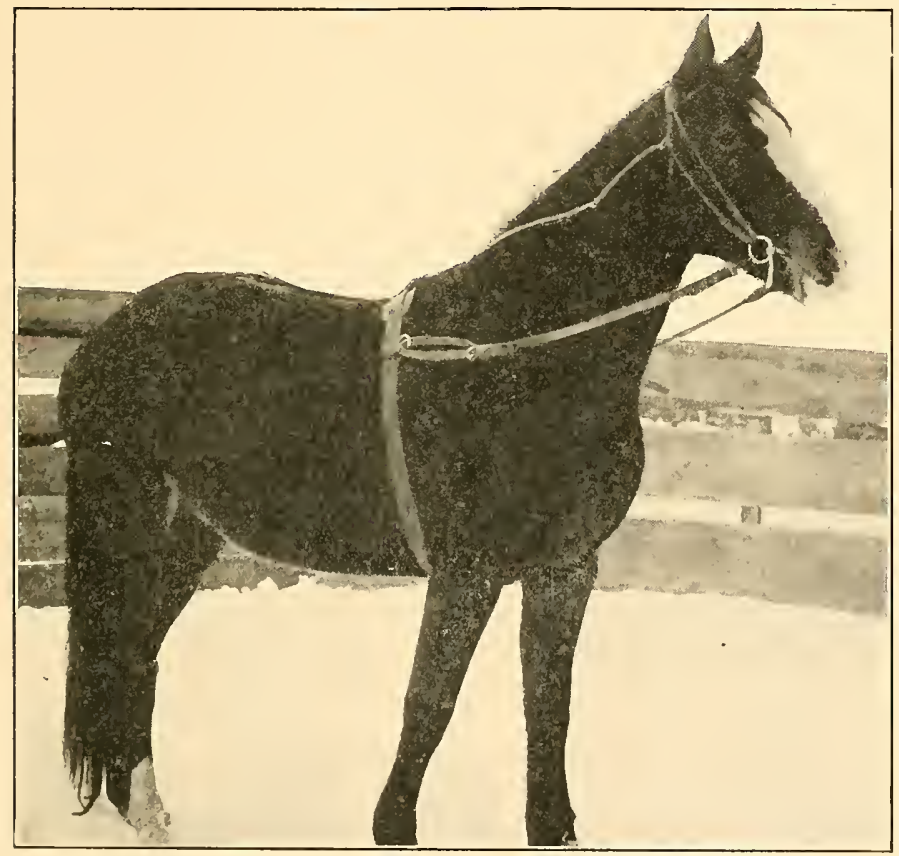

FIG. 8. - The bitting-harness, for teaching the uses of the bit.

During this bitting process some horses acquire the habit of throwing their heads up and down, a habit which when once established is very annoying and often difficult to overcome. Among saddle 
horses the habit is dangerous to the rider. To overcome this, one must use a martingale and an over-draw check-rein (p. 327). Occasionally a horse shows a disposition to carry his head too low, in which case the over-draw check-rein should be used.

In common practice there are two other forms of side-reins used on the bitting-harness, the "elastic" rein, and "running" rein. The elastic rein is composed of rubber and is attached the same as the leather side-rein described above. The leather siderein is often spoken of as the "fixed rein." The running rein is made from a small rope or sash-cord and is attached as follows: The surcingle and bridle are similar to those described above save both side- and check-rein are removed. Tie the cord or rein in the lower ring of the surcingle on the offside, pass it through the bit and back through the ring at the top of the surcingle, then down through the bit on the near-side and back to the lower ring on the near-side and tie fast. Instead of tying the ends fast to the rings on the surcingle, this rein is sometimes modified by passing one end up through the ring at the top of the surcingle then down to the other end and tying the two ends together in such a way that they will slip through the rings on both the bridle and surcingle (Fig. 9). Each of these reins has its advantages and disadvantages: the fixed rein sometimes produces horses with "lugging" mouths; the running rein sometimes produces 
"unresponsive" mouths, and the elastic rein sometimes creates a "boring" horse - one that thrusts

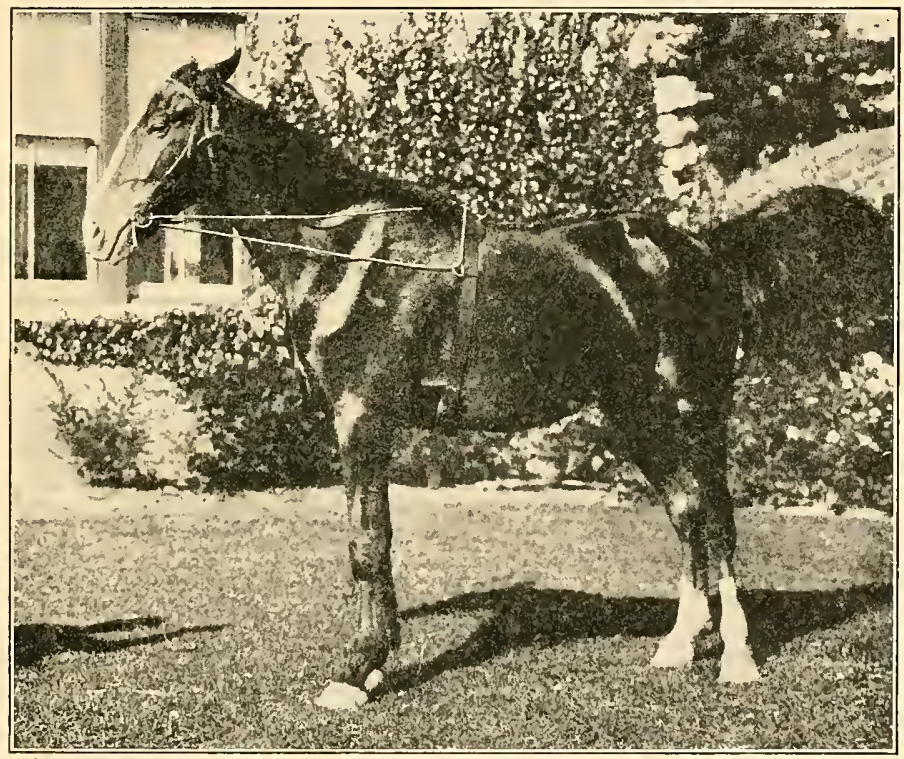

F'IG. 9. - Running side-reins, useful in bitting the horse.

his nose forward and drops his head at the same time and often snatches the lines through the hands of the driver.

\section{DRIVING THE HORSE TVITH LINES}

As soon as the horse becomes familiar with the bit, the side-reins may be substituted for lines and he may be driven about the inclosure. It is important 
to pass the lines through the rings on either side of the surcingle, as the lines will then pass the hind quarters low and thus prevent the horse from turning with his head towards us. It is very important to keep the lines low in turning to make the guiding

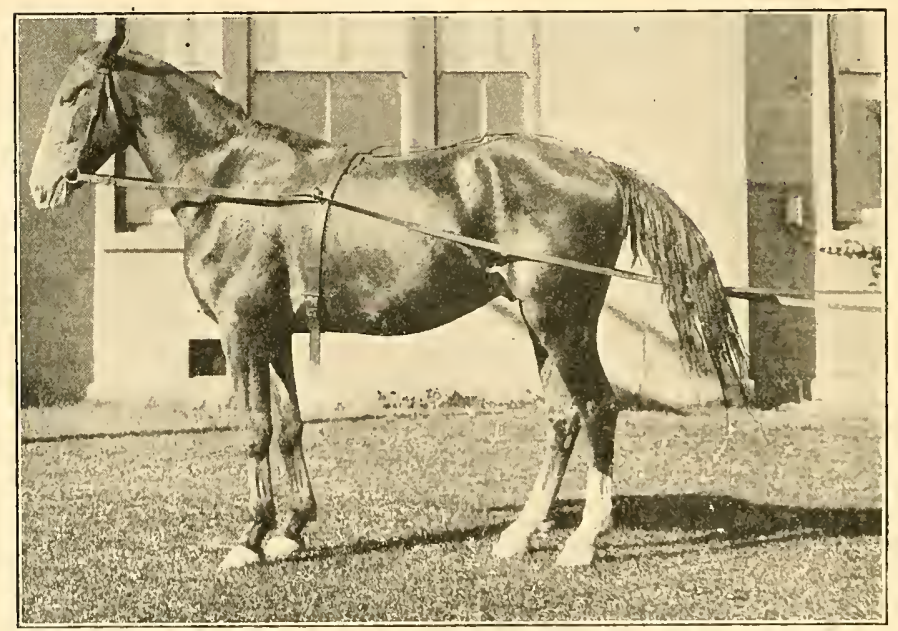

FIG. 10. - Teaching the horse to drive with lines.

process easy (Fig. 10). To avoid a mishap at this time, some suggest the use of a long rein to serve as a lead rein if perchance the animal should turn his head towards us while driving.

During the first driving lesson the horse should be reined but mildly if at all, since if tight, the rein will have a tendency to induce him to run backward, which should by all means be prevented. Further, 
the horse is liable to lower his head and give himself a jerk and thus distract his attention from the work in hand. For a few minutes allow the horse considerable liberty, in order that he may become accustomed to going away from you, at the same time permitting you to walk behind. This first driving lesson should not last long, and the horse should be started by tapping him with the line, and he should be stopped by gentle pressure on the bit. Avoid using spoken language until ready to teach the meaning of the words.

The horse should now be taught to guide to the right and to the left. To teach him to turn to the left, slacken the right line and pull smartly on the left one, not with a jerk, but with a swinging pull. If the horse comes around too far, hold the whip on the left shoulder. Do not pull him back with the right line, and do not strike him with the whip, as either movement will confuse him. If, however, the horse does not respond when the left line is pulled, tap him on the right shoulder with the whip to induce him to turn away quickly and not to give him time to fight the bit. After he has turned a few times to the left, slacken the left side-line and give a swinging pull on the right one to induce him to turn to the right, taking the same precautions as above. Repeat this process, using less and less force as the animal learns to turn.

Teaching the command "whoa." - If all has gone 
well, the next day after teaching the horse to drive with the lines, he should be taught the meaning of "whoa." This word should be used only when we wish the animal to stop and stand. This is an important matter in the education of the horse. The horse that continues to move after the command is given, or that is continually stepping about when you wish him to stand quietly, is very aggravating, and his usefulness as well as his value is lessened. The safety, comfort and pleasure in handling a horse that promptly obeys the command "whoa" are emphasized by the fact that he will command a higher price on the market.

After driving the horse about the inclosure a few times, or until he is going smoothly, give the command "whoa," followed by a strong swinging pull on both lines, and the moment the horse stops slacken the lines, otherwise he may become a confirmed lugger. If necessary to stop the horse, repeat the word and action. As he has done what you wished him to do, he should be caressed before starting again. It will aid the horse in fixing the impression, if he is stopped in the same place for a few times. The second or third time he will stop there at the command alone. Do not stop too many times at one place or there will be difficulty in getting him to pass. About the third or fourth time, therefore, try him at a new place. It may be necessary to follow the command with the action of 
the lines at this new place. Repeat until the horse will stop at any place when commanded.

Teaching the command "get up." - The next day after teaching the horse the meaning of the term "whoa," he should be taught the command "get up." Previous to this time the horse should have been started by tapping him on the rump with the line. Drive the horse about the training inclosure several times, frequently stopping him at the command "whoa." When going smoothly, stop him preparatory to teaching the meaning of the command "get up." When ready to start, give the command "get up," pausing a moment, then striking him a tap with the whip. This will start him forward. When going smoothly, stop him at the command "whoa." Repeat as before, starting with the term "get up" and stopping with the term "whoa," until he will stop and start at the command alone. It is good practice to impress the meaning of these terms so thoroughly that the horse will obey, even though he be running loose in the inclosure and the commands be given by one standing in the center of the paddock.

Teaching the command "back." - The meaning of the term "back" may be taught immediately following that of "get up." With the horse standing, draw the near line tight, give the command "back" and follow immediately with a sharp swinging pull with the off line. This will induce the horse to step backward. Follow with the command and 
give the see-saw pull. Stop at the command "whoa." Do not tire the horse by continually backing him for a prolonged period. Start him forward at the command "get up"; stop him at the command "whoa" and repeat the backing lesson at the command "back" until he obeys the voice promptly.

\section{HARNESSING, HITCHING AND DRIVING THE HORSE}

To be harnessed is a very important part of the horse's education. Animals that have behaved well up to this time often become confused and not only disobey commands but may become uncontrollable. This comes about naturally when the horse is harnessed and hitched without proper preparation. We have seen that pressure in front induces the horse to go backward, and that pressure behind induces him to move forward (p. 28). Thus when the horse is harnessed and hitched without proper preparation, and started forward at the command "get up," the pressure from the breast-harness or collar induces him to step backward. Now he has received the command to go forward and the stimulus to move backward, which confuses him, as he cannot do both. If he disregards the command and obeys the stimulus of the pressure and moves backward, the breeching presses against the quarters, thus inducing him to go forward. The hor'se's confusion is now greater than before. While he is moving back and forth 
between the pressure of the collar and the breeching, he is so excited that he does not heed the commands of the driver, who often becomes aggravated and strikes the animal a sharp cut with the whip. This frightens the already excited horse, and he moves forward with a bound. The driver then jerks him backward and holds a tight line. Thus the horse is punished both at the mouth and in the rear. By this time the animal's confusion is complete, and he is likely to rear, kick, run away or do anything to free himself.

A little patient effort spent in familiarizing the horse with the pressure of the harness and shafts, and in teaching him what is expected of him, will avoid all such confusion and risk.

Poling the horse. - Before harnessing or hitching, the horse should be made familiar with the pressure caused by the harness and shafts. To do this, procure a light pole five or six feet long, and let the horse smell and feel it with his nose (Fig. 11). Gently rub the pole over the nose, the side of the face and up to the mane and crest. After scratching the crest pass the pole back to the withers, down over the shoulder, and along the outside and inside of the forelegs. Pass the pole along the back to the hind quarters, down along the outside and inside of the hind legs. Repeat the process first on one side, and then on the other, rubbing every part of the body (Fig. 12). 
If at any time the horse should become excited and refuse to stand, allow him to touch the pole with his nose, and gradually work back over him again. After he has become perfectly submissive to the pressure on all parts of his body, it is a good

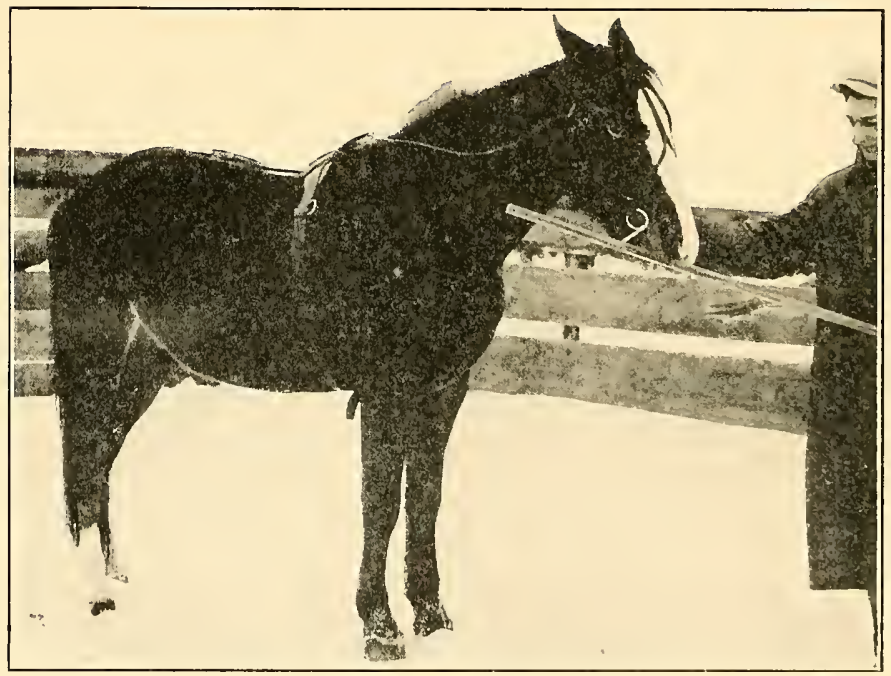

Fig. 11. - Poling the head and nose.

plan to place the pole under the tail, as this will teach him to stand while the crupper is being arranged. To do this, stand a little to one side and with the pole touch both hind legs a short distance above the hocks. With the left hand, carefully raise the tail, and with the right hand gently work the pole upward a few inches; pause a moment and 
repeat, until the pole rests directly under the tail, lying across the quarters. After a moment, carefully raise the tail and gently remove the pole, so as not to frighten the horse. A few repetitions of

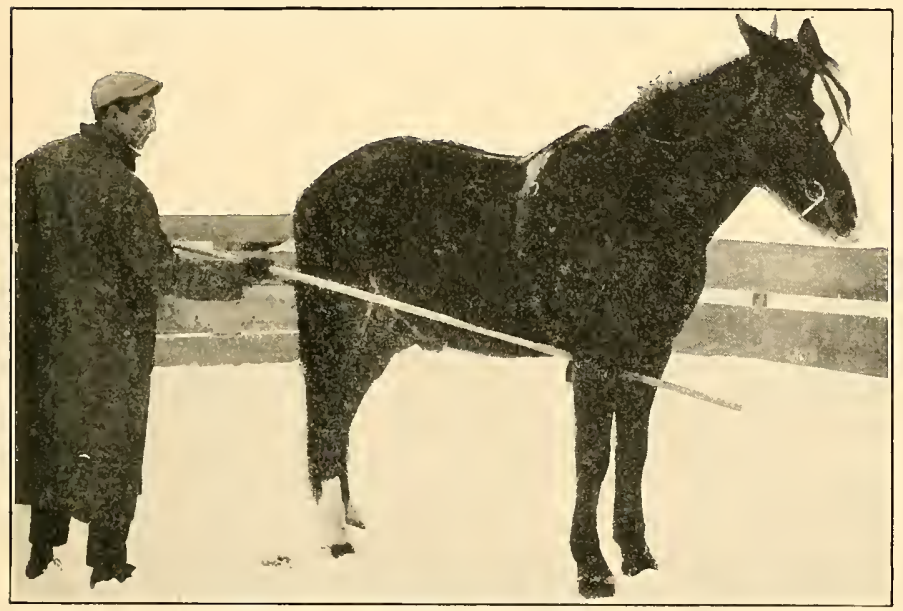

FIG. 12. - Poling the body and legs.

this process will render most horses very easy to crupper.

Poling has a very desirable effect upon the horse, especially if the animal is of a nervous and sensitive disposition. It will render him gentle to the touch of the harness, shafts or any other object coming in contact with the body. After harnessing, some continue the poling process by arranging two poles, one on either side of the body, similar to shafts, 
securing the front end by strapping to the hame tugs, and the rear end to the hip-straps and breeching, and then driving the horse about the inclosure a few times. The rear end of the poles is then unstrapped from the hip-straps and permitted to drag on the ground as the horse is being driven about the paddock. This has the added advantage of familiarizing him with the position and pressure of the shafts as well as to the pressure of the collar and the breeching, while in motion.

Harnessing the horse. - With the horse properly poled, harnessing is an easy task. Put him in his accustomed stall and allow him to smell and feel the harness (Fig. 13). This is important, for occasionally horses are frightened out of their senses by the careless driver throwing the harness over their backs before allowing them to feel and smell it. In this manner, the bands and loose straps striking the animal on the legs and abdomen often provoke kicking. Such excitement can be avoided easily by permitting the horse to smell and feel the harness and by gently lifting it over his back. Carefully raise the tail, and gently put the crupper strap on, then step to the side and fasten the bands. With care, work the breast harness or collar over the head as suggested in bridling (p. 59).

While the harness should not be new, smelling of things unfamiliar to the horse, it should be of good quality and in good repair, for if a part breaks there 
may be trouble and the horse ruined for all time. When convenient, use harness that has been in constant use. It should be so adjusted as to fit perfectly. The collar should receive attention, as it is

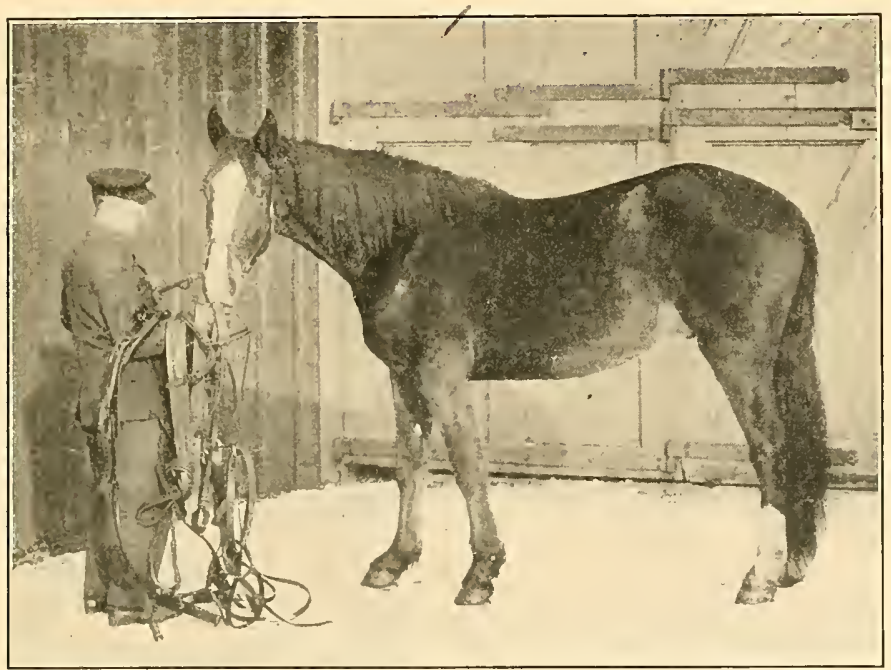

FIG. 13. - The young horse becoming familiar with the harness.

by means of this that the horse exerts his power. (For discussion on fitting harness see page 317. )

A careful examination of the shoulders and quarters of the horse must be made from time to time. Oftentimes the collar that fits perfectly in the beginning soon becomes too large, due to the horse losing flesh. The untrained horse's flesh is very tender, and the friction of the harness often produces sore- 
ness. The parts likely to become abraded are the shoulders, caused by the collar; the back, caused by the saddle of the harness; the tail, caused by the crupper ; and the quarters, caused by the breeching. At the slightest sign of any abrasion, the training must temporarily cease. Bathe the sore parts with soap and water, then apply an astringent, as salt and water, or alum and water, to harden and heal them. As soon as the soreness has disappeared, the training should be resumed (p. 373).

Hitching single. - After harnessing, but before hitching, tie the traces to the ring on each side of the breeching, thus causing a slight pressure on the collar and breeching, and drive the horse about the inclosure. Start him at the command "get up," stop him at "whoa" and have him move backward at the command "back." Turn him to the right and left, and when he is going smoothly take him out on the highway. At first, because of the new environment, the horse may act strangely, but go through with all the commands and signals that he has thus far been taught. The horse is now ready to be hitched to a vehicle (Fig. 14).

Training-cart. - If at all convenient, the first time the horse is hitched, a training-cart - one with long shafts, substantially constructed, and the seat so arranged that the driver can get off and on quickly should be employed (Fig. 15). Such a cart can be constructed from the rear wheels and the axle of a 


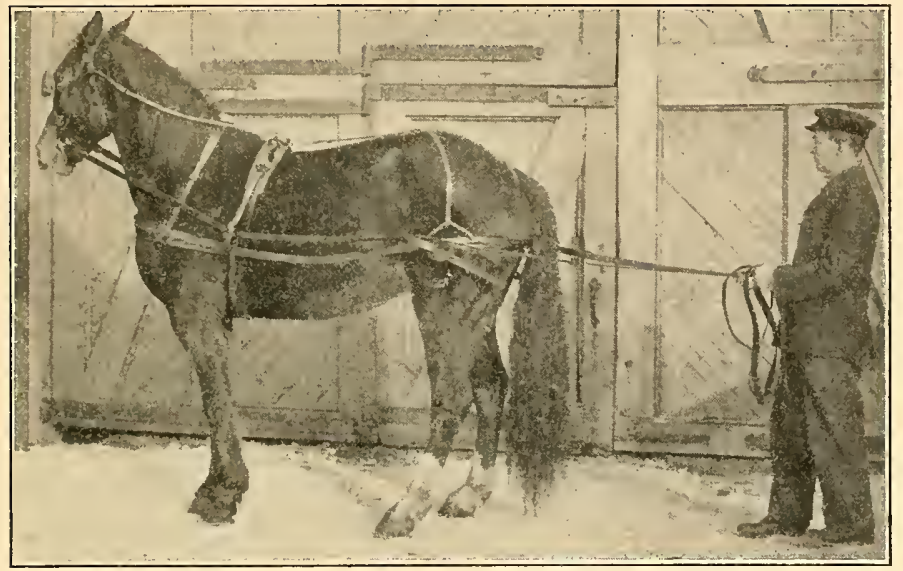

FIG. 14. - Driving in harness previous to hitching to a vehicle.

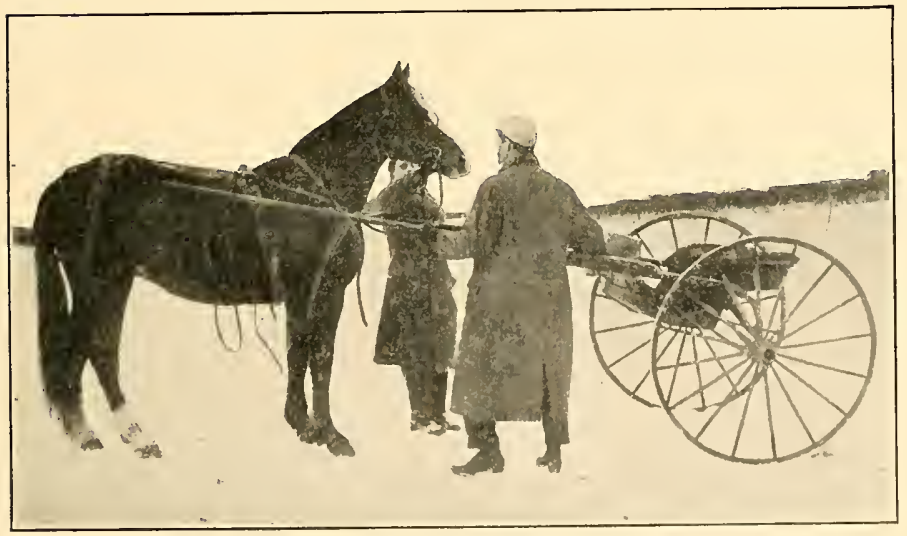

Fig. 15. - Acquainting the horse with the training-cart. 
buggy or carriage by fastening two long poles, hickory or any tough, springy wood, to the axle and by fastening a cross-bar and whiffletree in front and a board seat in the rear. The shafts should be twelve or fourteen feet long, with provision at the ends for the attachment of a strap across from point to point to prevent the horse, in rearing, from throwing his front legs over the ends of the shafts. Training-carts can be purchased on any market where buggies are sold. Many of these carts are provided with steps in the rear, which add to the utility.

Such a cart possesses many advantages, particularly in the training of stubborn and unruly horses. In rearing, the horse strikes his front legs against the strap in front and goes no higher; in kicking, he is so far ahead of the vehicle and driver that he does little or no damage; in turning around suddenly, he is obliged to make so large a circle that he either gets over his fright or becomes discouraged before going far; in throwing himself, the shafts are so long and springy that little or no damage is done; in running away, all that need be done is to give him his head a moment until the muscles of the neck are relaxed, and then, by giving a swinging pull with one line, his head is turned so far to one side that he must either stop or fall; and should the horse refuse to obey the bit in turning around, we have but to dismount, pull gently on one rein and at the same 
time carry the cart around, which will point him in the direction we wish to go.

Familiarize the horse with the vehicle. - The horse should be poled again before hitching. Lead the horse up to the vehicle and allow him to smell and feel the shafts. Rub them along his head, neck,

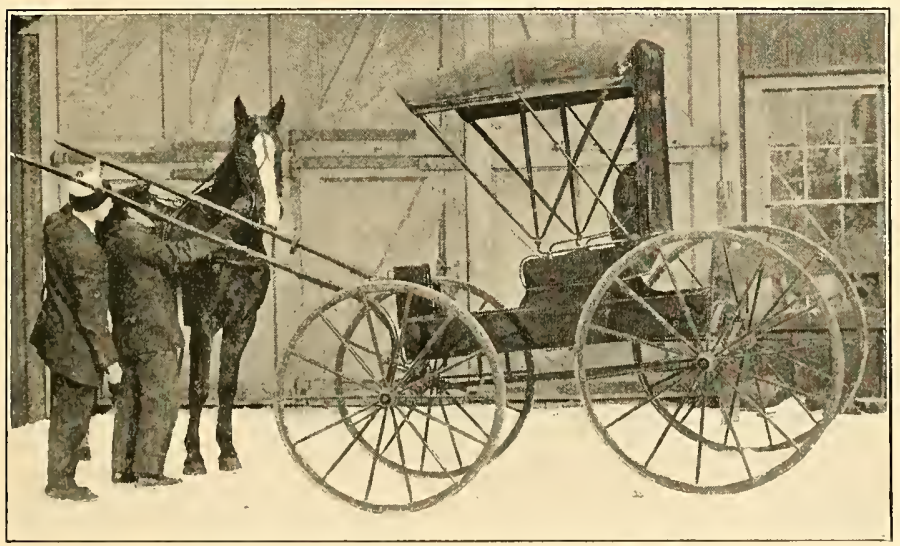

F1G. 16. - Acquainting him with the top buggy.

shoulders and forelegs, both inside and outside. Lead him up between the shafts, allowing them to rest on his back, then drop them at his feet. Repeat this process several times and let him smell and feel the cross-bars, dash-board and the like (Figs. 15 and 16). 'Turn the horse around, draw the vehicle up so that the shafts are even with his heels, and drop them as before. Pull the rig forward and place the shafts on his back, then back it, rubbing 
the shafts over the rump, down along the hind legs both on the outside and inside, dropping them occasionally. Finally bring the rig forward until the cross-bar touches the horse's quarters, first gently and then more forcibly.

Now the horse may be hitched to the vehicle with

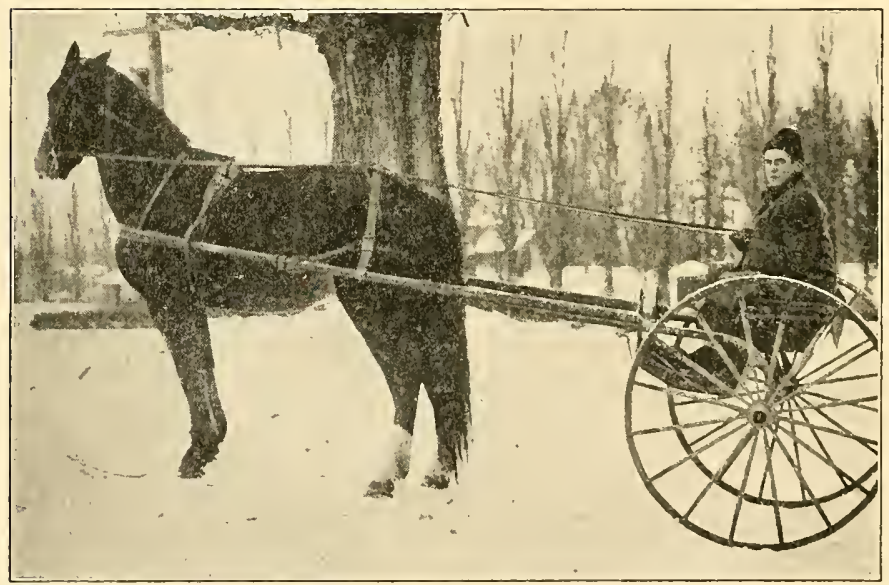

Frg. 17. - Hitched for the first time, showing method of attaching the kicking-strap.

perfect safety. While there is little or no likelihood that a horse trained as suggested above will give trouble, as a precautionary measure the use of the kicking-strap is suggested. This is a heavy strap placed above the rump just back of the hips and one end buckled to each shaft (Fig. 17). As a further safety measure, it is also recommended that an 
assistant remain at the horse's head to aid in starting, stopping and turning if need be. When all is ready, the driver should take his position behind the cart, not on it at first, and start the horse at the command "get up." At the same time, the assistant should aid by pulling the cart forward. After the horse takes a few steps, stop at the command "whoa." Repeat until the horse understands what is expected of him. At first it may be necessary for the driver to aid in turning by carrying the cart around, especially if the training inclosure is small. As soon as the horse will obey the commands "get up" and "whoa" and will guide to the right and left, the driver may mount the cart and drive out on the highway. The assistant should be provided with a long lead strap and should walk along beside the horse until the latter becomes familiar with the new environment. He may then mount the vehicle with the driver, retaining the long lead strap so as to be ready to meet any emergency.

The horse should be stopped and started often to assure him that he is doing what is expected of him. After driving at a walk until all is going smoothly, the horse may then be touched up into a trot. Slow down to a walk and repeat. On the return to the training paddock the horse should not go out of a walk. It is not good practice to drive back and forth past the barn during the first lesson, as the colt is likely to want to turn in and he may give some trouble. 
Teaching the command "steady." - As the command "whoa" should be given only when we wish the horse to stop and stand, so is it very important that he be taught the use of the term "steady" very early in his career. While this term is to be used under a variety of conditions, its general meaning should be to slacken and pay attention. Thus if we wish the horse to maintain a certain speed, we say "steady" in a soothing tone; if we wish him to slack the speed, the same term is used but in a stronger tone; if the horse is frightened and we wish him to quiet down, the command "steady" is given in a high tone and the lines are used in a characteristic see-saw manner; and if the horse is about to pull a heavy load and we wish him to pay attention, we give the command in a rather deep tone and hold evenly on the lines.

The first usage of the command "steady" that should be taught is that of slackening the speed, as this applies when the horse is excited and we wish him to calm. This requires both judgment and patient effort. When all is going smoothly, encourage the horse until he is going at a very lively rate, then give the command "steady," followed by a gentle see-saw motion of the lines. When he slows down to an even trot, caress him by rubbing or stroking him over the rump with the whip. Repeat until he will slow down at the command alone.

Backing the vehicle. - After the horse has been 
driven several times and is going smoothly, he should be taught to back the rig. To do this, repeat the lesson on backing (p. 67) before hitching. Some prefer to take a position in front (Fig. 18). This has the advantage that should the horse refuse

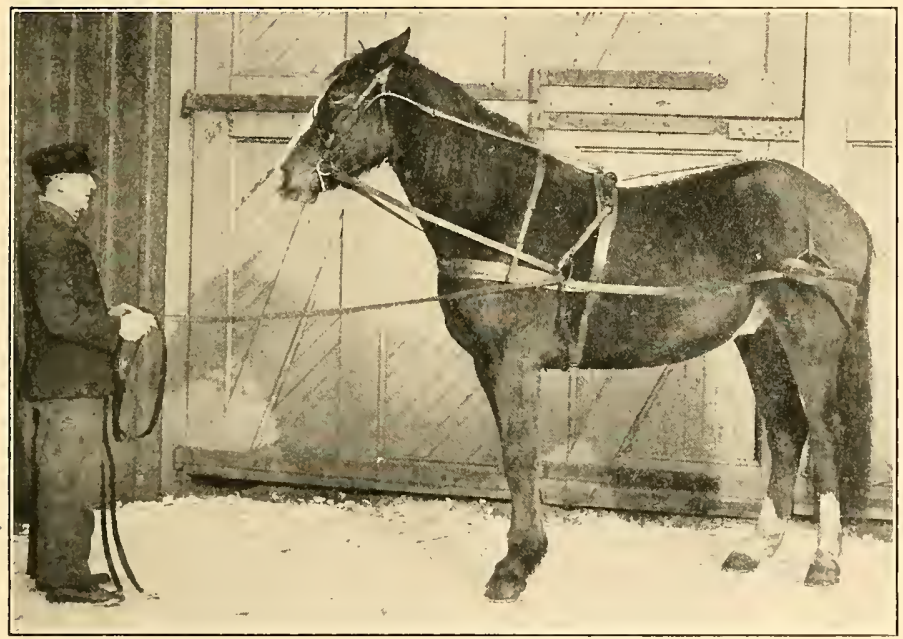

FIG. 18. - Teaching to back with the lines.

to obey the command and the lines, you can assist him (as in Fig. 19) by applying pressure on the chest with the ends of the fingers when, according to the natural impulse, he will step backward. While working in this position, the driver applies the pressure with the right hand, pulls the lines with the left, and gives the command "back" at the same time. After the horse learns to back with the 
driver in front, he then takes his position behind the horse and proceeds as in teaching to back (p. 67). Now that the horse obeys the command readily, hitch him to the vehicle and drive part way up a slight elevation. Stop him and give the command "back," followed by a see-saw motion of the lines.

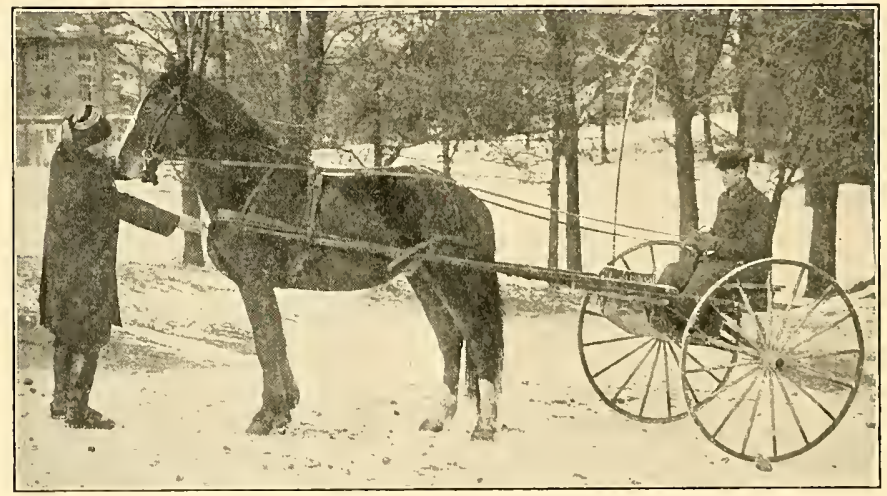

F1G. 19. - Teaching the horse to back a vehicle.

To back the rig down such an elevation requires little or no pressure on the breeching. If more convenient, have an assistant take a position in front of the horse (Fig. 19). By employing some such methods as these the animal learns to back the vehicle in a natural manner. Repeat, stop, start, back, turn to the right and left until the horse is familiar with every detail.

Train the horse to come under the shafts. - It is very aggravating to be obliged to lead the horse in front of the vehicle, leave him and go back and pull 
the rig forward, especially if he keeps stepping up and occasionally walks off and leaves us tugging at the shafts. To avoid this, train the horse to come under the shafts from the beginning. Take the horse to the training paddock, hold the whip up to one side and over him and try to make him go under it by pulling his head toward the whip. If he obeys, caress him; if he refuses, lays back his ears or steps back, reach over and tap him rather lightly with the whip, return it to its former position, and ask him to go under as before. If he refuses, repeat. When he goes under the whip at the signal, hold the shafts up and he will walk under them. If he should refuse, hold the whip in the hand with the shafts. After he steps under the shafts, lower them and arrange the shaft tugs, traces and hold-backs.

Caressing with the whip. - Early in the horse's training he should become familiar with the uses of the whip, not only as a means of punishment, but as a means of reward. The way to caress the horse with the whip is to place it gently on the body and carefully stroke or rub the animal. To teach the horse this usage of the whip, take a position in front of him similar to teaching him to follow (p. 54). Begin by rubbing or stroking his mane and crest, then his back, sides, rump and lastly the quarters. As you are stroking him, feed him dainties, as sugar or a carrot. Ask the horse to follow you to some object at the command "come here," as suggested. 
This object should not be such as to frighten him, as a robe, but something familiar to the horse. Keep caressing him as he follows along by stroking with the whip and by an occasional taste of sugar. After following to a few familiar objects try a strange one, as a robe, since horses are naturally afraid of robes. This time care must be exercised. It may be necessary to try several times before he will touch the robe with his nose, but by constant caressing and occasional tastes of sweets he will walk up to it. By this time he has come to look upon the constant stroking as a signal that no harm is to come to him.

Hitching double. - If the horse is to be worked in a team, his training should be similar to that suggested above. When ready to hitch double, get a well-trained, gentle, but active horse, if the one you are training is active, for it is a mistake to hitch a quick, active one with a slow, lazy horse. The vehicle to which they are attached should be provided with a good brake. The horse in training should be hitched to the off side and the team should be driven at first in a closed field. When hitching double for the first time, it is a good practice to keep a pair of single lines on the horse in training, which can be handled by an assistant. If one has two horses in training that he wishes to work together, they can be hitched together at this time if each has been trained as suggested above. If they do not 
match well in disposition, the impulsive one should be restrained and the slower one urged, so that when hitched together they will have nearly the same gait and respond similarly to the commands (Fig. 20).

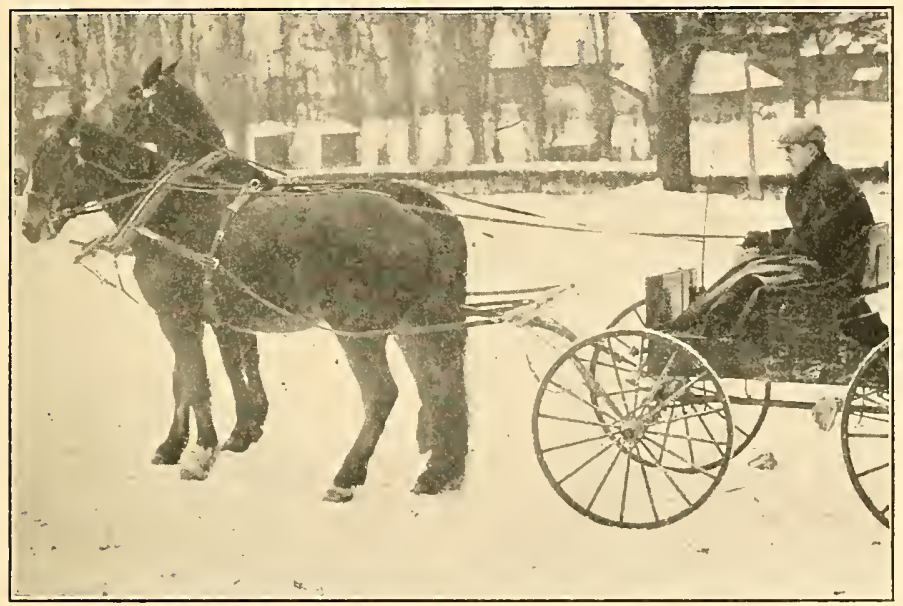

FIG. 20. - Young horses hitched double for the first time.

TRAINING THE HORSE TO OBJECTS OF FEAR

The horse should be made familiar with the various sounds and objects he is likely to meet, particularly along the busy thoroughfares of cities. Noise, such as is produced by brass bands, street car gongs, and the fierce shrieking whistles of the railroad engine, and objects such as traction engines, motor cars, trains and the like, is likely to frighten the 
untrained horse out of his senses and he may prove a source of real danger.

The horse should be driven once or twice before going through the course to familiarize him with frightful objects. At first his attention is taken up by the pressure of the harness, shafts and the vehicle following, and he gives little or no attention to objects along the road, which later may frighten him.

For best results in giving this lesson use nothing but the bridle, surcingle and lines. Since the horse should have the free use of his head he should not be reined. To train the horse to endure strange sounds, stand him in the center of the inclosure and at first have an assistant hold the lines. If the horse has not received the command "whoa" at various angles, he should at this time. To do this, circle around the horse, giving the command "whoa" every few steps. Procure an old tin pan or anything that will make a noise and walk around the horse as before. When in front of him gently start the noise. The first time or two around, it may be necessary to stop the noise as you pass behind the horse, particularly if he is very nervous. Gradually increase the racket until by the fourth or fifth round he will stand while you make all the noise you can. You may now give the pan to the assistant and have him walk in front, making all the noise he can while you drive the horse after him, frequently stopping and 
starting at the commands. Next have the assistant run, while you drive after him in a trot.

To teach the horse to endure strange objects, have the assistant take a position about a rod in front of the horse, facing him, and with his uplifted hands full of old papers. Drive the horse toward the assistant, who should move backward as the animal approaches. Drive the animal between the outstretched arms, and have the assistant carefully close in and gently touch either side of the neck with the papers. Rub them over the head and along the neck to convince the horse that they are harmless. Drop the papers a few at a time and drive over them, permitting him to stop and touch them with his nose if he likes. The papers may now be placed in a large pile and the horse driven through them with perfect safety (Fig. 21).

In some such manner, the horse should be familiarized with other objects, such as umbrellas, flags, objects along the road and the like that are likely to frighten him. In fact, he should be driven up to anything that frightens him in the least and permitted to touch it with his nose. It is rather important that the horse very early in his career be made familiar with motor cars, street cars, trains, engines and the like. After he understands the meaning of the term "steady" (p. s0) and to be caressed by stroking with the whip (p. 83), this should not be difficult to teach. The street car is 


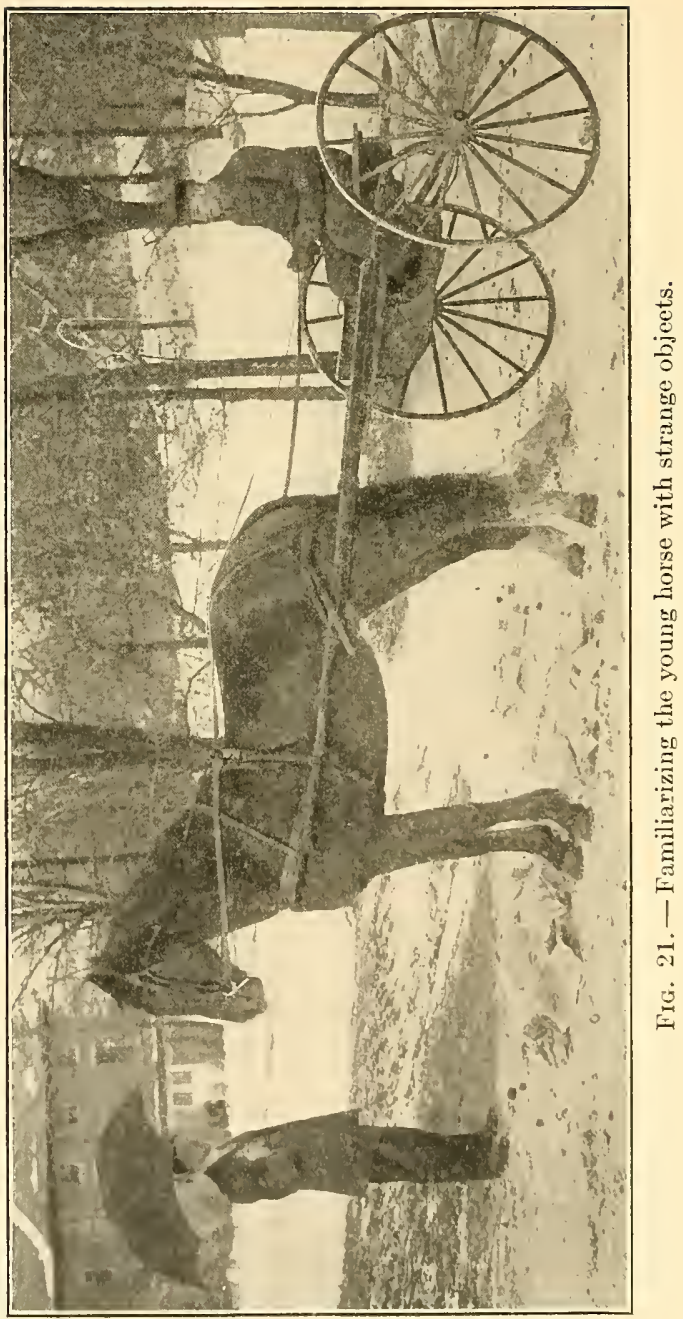


the best object with which to train the horse to strange things, as we know when it is coming and where it is going, which we are never sure of in the case of an automobile. Choose a road or street where the car-line crosses, drive the horse up to within, say approximately, one hundred yards of the track and stop until a car passes. If he seems nervous, caress him with the whip by stroking or rubbing his back, and by the command "steady." Drive over the tracks and something like an equal distance beyond, and stop while another car passes. This time the noise is in the rear. Repeat this process, working the horse closer as each car passes, until he will stand within a few feet of the tracks as it passes. If perchance the car should stop at the crossing, drive the horse up to it and let him feel it with his nose.

Never whip the horse past an object that causes him fright. At the time he probably is so frightened that he does not notice the blows of the whip until the object is past, in which case he may associate the pain with the object which caused his fright; or if he does feel the whip, he knows that it cannot do him great injury; whereas he does not know the possibilities of the object and prefers the blows of the former to facing the latter. In any event whipping a frightened horse only increases his excitement and makes him more difficult to drive past the object. The better way is to caress him with the whip and 
command him to go "steady," when he will calm, if the signal and command have been taught properly. Then he should be made to face the object, and if convenient, to feel it with his nose. Never let the horse hurry past an object or noise that frightens him. It may take some skillful manipulation and much patient effort to familiarize him with all the objects that cause him alarm, but without such training his education is essentially incomplete and at any time he may be frightened out of his senses, become uncontrollable and a serious accident may result.

"Family broke." - In the show ring, on the horse market, in the sale stables and in fact wherever horses are shown or dealt with the terms "family broke" and "family horse" are used. These terms signify that the horse has been trained so that he is perfectly safe to drive by any one accustomed to handling horses. Such animals are easily harnessed - bridled, cruppered and the like - often will follow at the command "come here," go under the shafts at the signal, stand while being hitched, while mounting the vehicle, arranging the robes and until commanded to go forward. In addition they are familiar with all noise, such as brass bands, car gongs and the like, as well as with all objects, such as automobiles, motor cars, engines, trains and objects by the roadsicle. The importance of such training is emphasized with horses of this class, since, other 
things being equal, such animals command the higher price on the market. So popular are such horses that most town, county and state fairs as well as horse shows provide special classes for their convenience.

Pony for children. - Before attempting to educate a pony for the children, we should be sure that the animal possesses an inherent docile and sweet temper. Train only such a pony as takes kindly to the children and seems to enjoy their company. The work of educating such a pony will be essentially the same as outlined above. He should be taught to obey as suggested for the "family horse." For best results the children should be permitted to handle and feed him, as he will become attached to whomever feeds and grooms him.

\section{TRAIN THE HORSE TO WALK FAST}

There is no gait so valuable or so much appreciated and so practically useful in a horse as a fast square walk. This is as true of the work horse as of the driving or saddle horse. And yet this most practical of all gaits is often entirely neglected in training the horse for his life-work. Perhaps this is due, in part at least, to the fact that we have no figures available as to the rate of speed the average work horse attains at the walk. Consider the case of a man plowing with a 16 -inch plow and assuming that it cuts on the average its full capacity. To plow 
one acre the team must travel a little over six miles. Now if we assume that the team walks two miles an hour for a 10-hour day, or twenty miles in all, then the man will plow something over three acres a day. If the team walks three miles an hour for the same length of time, then he will plow almost five acres a day. While it is not possible, perhaps, for one team to pull a 16-inch plow through all kinds of soil at the rate of three miles an hour for ten hours each day, yet this serves to illustrate the value of fast walking. Consider the case of a man harrowing with a 12-foot harrow and the team traveling first at the two-mile and then at the three-mile gait. As he must travel a little over two thirds of a mile in harrowing one acre, in the former case he will harrow approximately twenty-nine acres a day, while in the latter case almost forty-four acres will be covered in the ten hours. Or consider the case of a man cultivating corn with a single-rowed cultivator where the rows are three and one half feet apart and the team traveling at the same gaits as before. As the team must travel approximately two and one third miles to cultivate one acre, at the two-mile gait almost eight and one half acres will be cultivated, while at the three-mile gait almost thirteen acres will be covered in the ten hours. Further, there is nothing, perhaps, that will cause a road horse to be driven harder and kept so continually at the trot as a deficiency in the walking gait. 
It is not difficult to train the average horse to walk fast providing the proper methods are employed early in his training. From the very beginning keep the horse walking up to his limit. We should never allow him to mope along at this time, or the habit will become so strongly fixed that it will be difficult to overcome. During the entire training process, therefore, urge him to his limit. If he breaks into a trot, steady him but do not allow him to fall back into a slow walk. Do not ask him to walk too far at a time, but give him practice each day. When one has a fast walking horse available it is a very good plan to place the green horse beside the fast walker and work them together, as this aids in fixing the habit of fast walking.

\section{TRAINING THE HORSE FOR HEAVY DRAFT}

Because of the desire of all horse owners to have their driving horse in presentable condition, much time and patient effort are spent in his education, whereas the slow plodding draft horse that does much of his work in the fields and on back streets is neglected. Though his work is very hard, he is very often left in the hands of incompetent drivers, who either do not know how to lighten the animal's burden, or do not take sufficient interest. In the fields we often see plow-horses dragging along the plowman, who has the lines around his body, in addition to the 
plow, and since they must pull the former by their mouths, he is by far the more fatiguing. In like manner, on the streets, we often see the driver perched upon the heavily loaded van, holding the lines with extended arms and pulling on the horses' mouths with all his strength, while the already overloaded animals tug away at the load. On the other hand, we often see careless drivers who permit the lines to hang, thus leaving the horses to stumble along as best they can while at their burdensome task.

It is not possible for draft horses to accomplish their maximum usefulness while so driven. In the first case much energy is lost by the constant pulling of the driver, and in the second case the horses are not held together and hence lose energy pulling against each other. Never pull at a horse's mouth one ounce more than is necessary, as the energy is lost, and never drive him without a light touch of the lines so you can just feel the bit and hold him steady. In case the horse is a lugger - one whose mouth has been pulled on until it has become calloused - relief can often be gained by dropping the bit into a new place or by changing to a large smooth rubber or leather covered bit, and some even go so far as to recommend the bitless bridle. The better plan is to put the horse into competent hands and then he will be trained properly from the beginning, and his usefulness increased. 
In training the draft horse, extra care must be exercised to see that he is in good health and entirely free from abrasions likely to give him annoyance. Thus if the animal has a slight sore on the shoulder, back or tail, the draft increases the pain and he associates the effort to pull with the pain and refuses to go into the collar, and the foundation for a balker is laid. It is also important to see that the harness fits perfectly, and that the pressure is equally distributed over the bearing surface (p. 317). Hitch the horse on the off side of an active even-puller, one that will go into the collar at the command and stay until the command "whoa" is given. Choose a smooth, hard road, avoiding soft ground, and if convenient let the first few loads be of bulky material, as hay or straw. This will serve to fix the idea in the horse's mind that he can pull anything that is loose.

Never overload the draft horse in training. The first attempt should be made with a load not exceeding 300 pounds. After driving a short distance this may be doubled. Do not ask the young horse to pull more than his share of 1200 or 1500 pounds until the idea of going up against the pressure of the collar has become thoroughly fixed in his mind.

Never train the young draft horse by hitching to a dragging load, as a plow, harrow, drag or wagon on soft earth. Such loads require constant pressure and serve to discourage the animal. In the case of the low hitch the pressure on the shoulders 
and back is at a disadvantage; he cannot see the results of his efforts; the constant pressure is likely to cause sore shoulders and in the case of the plow the horse may be severely jerked in case the plow strikes a stone or root, all of which serves to discourage and to break his spirit rather than to encourage and inculcate the idea that he can draw anything.

As the training continues, the driver should adopt signals to warn the horse of approaching difficulties, and when he should get ready for superb effort. Excellent drivers use different terms; some whistle, some cluck and some give one command, others another, any of which will serve if properly used, but best usage prefers the command "steady" given in a rather deep tone. At this command the horses square themselves and make ready for the effort. The draft horse should be trained so as gradually to go into the collar and stay there until commanded to cease, as it is the long swinging pull that brings the load. There are many methods of teaching this. When at all convenient, a good way to train the horses to make long steady pulls is to hitch them to a freight car. It requires a constant pull to start the car and the movement is very slow at first but gradually comes faster and easier, which gives the horse much encouragement. This requires patient and cool-headed effort on the part of the driver, but horses thus educated are of great service to mankind. 


\section{TRAINING HORSES TO MAKE LEADERS}

The term "leader" is used in two ways; first it signifies the near or "lead" horse of a team, and second it is applied to the front or leading team when two or more teams are driven tandem, one following the other. The former is employed largely on the farm, the latter in the large cities. To be efficient in either position requires extra training. On the farm the driver's hands are often needed to operate the machinery and he is obliged, therefore, to rely on one line, which is attached to the near horse, and on commands, to drive his team. The off horse is attached to the near one by means of a tiestrap and crowding-stick in such a way that the one is obliged to keep even with the other. Since the driver must rely, in part at least, upon spoken words to convey his desires, the leader must be taught these extra signals and commands, such as "haw" and "gee." In the large cities the merchants find it more profitable to use heavy vans drawn by two or more teams and driven by one man. Since the leading team is so far forward that the driver cannot control it readily with the lines, he is also obliged to rely, in part, on signals and commands, the principal one, in addition to those above, being "yea."

Teaching the commands "haw," "gee" and "yea." - When we wish the team to turn to the left, the command "haw" is given, or a steady pull is made 
on the lead line. When it is desired to turn to the right, the command "gee" is given, or a slight jerk is made on the line. These terms are best taught by providing a pair of lines and placing them on the lead horse and proceeding as suggested for teaching him to turn to the left and right (p.65), giving the command "haw," followed by a steady pull on the near line as we turn to the left, and the command "gee," followed by a slight jerk on the off line as we turn to the right. Caress and repeat until the horse will turn either way at the command or at the motion of the line.

Because of the position of the lines on the leading team, when driving two or more teams the driver is unable often to square the horses on turning, particularly when six or more horses are used, as the slack in the lines is so great that he cannot take it up fast enough; therefore, when the leading team has gone far enough and he wishes it to square itself and go forward, he gives the command "yea." This command should be taught to the leading team according to the suggestions outlined above for teaching "haw" and "gee," by employing long lines and a long whip. When the horse has turned sufficiently, he is squared about with the long whip, immediately followed by the command "yea." These multiple teams are guided to the left and right by the commands, by the movement of the lines, or other signals, each driver having a code of his own. 
CHOOSING A VOCABULARY FOR THE WORK HORSE

The work horse should be taught few words and each should stand for a definite action. It would be of advantage if a standard vocabulary could be adopted and used all over the land, especially where horses pass from one owner or driver to another. As it is now with each driver using commands and signals of his own, the horse is greatly confused whenever there is a change of drivers. In fact, if all drivers would agree to use a few of the more common commands for the same actions, the situation would be greatly relieved. Thus far we have suggested six words for general use; they are short, easily taught, and answer most conditions, at least for the work horse. Any teachable horse can be taught to obey all six commands in as many days if a little patient effort is put into the training.

The six words that have been recommended for general use, and the actions they stand for, are as follows :-

"Whoa" means to stop and stand still. This is the most important word of the group and should never be spoken except when the above action is desired, and the horse should understand that he is to remain quiet until commanded to move. Do not use the word to slacken the animal's speed, or to calm him, or when you wish him to move backward. 
"Get up" means to move forward. The tone should be modified for prompt or deliberate action. This term should be used for increasing the speed. There is no use of employing the words "hurry" and "faster" for the draft horse. There is no objection to the "cluck" or "chirrup," but if they are to be used, the horse should be trained to obey them promptly.

"Back" means to move backward. Because of the great amount of backing that must be done, this is likewise an important word and the horse should be taught its significance. Do not use this word to slacken or stop the animal. Do not use "whoaback" or "back-up," - simply "back." The command may be followed by a see-saw motion of the lines, but in no case jerk or yank on the animal's mouth.

"Steady" means to give attention to the work in hand. It applies to a variety of conditions; thus, when the horse is going fast and we wish him to slow down, this term is used; or when the animal becomes frightened and we wish him to calm; or when we wish to warn him of approaching danger or difficulty we employ this command, but the voice should be modified to meet the attendant condition (p. s0).

"Haw" means to turn to the left, and is preferred to the command "left."

"Gee" means to turn to the right, and is preferred to the command "right." 


\section{GENTLING THE FEET FOR SHOEING}

To avoid bad habits at shoeing, the horse's feet should be handled before going to the shop. A few

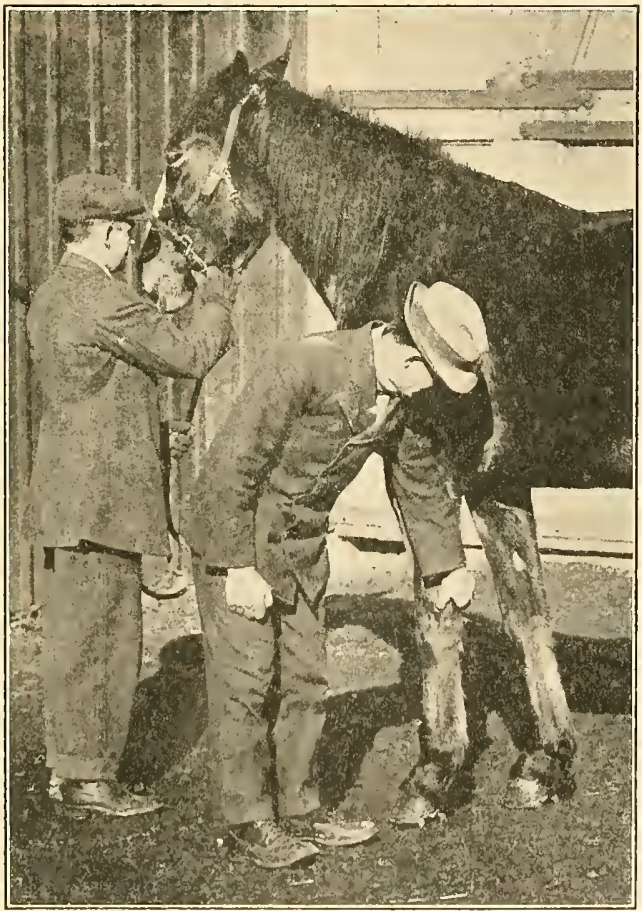

FIG. 22. - First position in picking up a front foot.

horse owners impose upon the blacksmith by sending their horse to the shop to have him shod in order to assist them in training. The blacksmith cannot 
take the time properly to train the horse. The surroundings, the noise and the flying sparks are new to the horse and he becomes excited. Under such

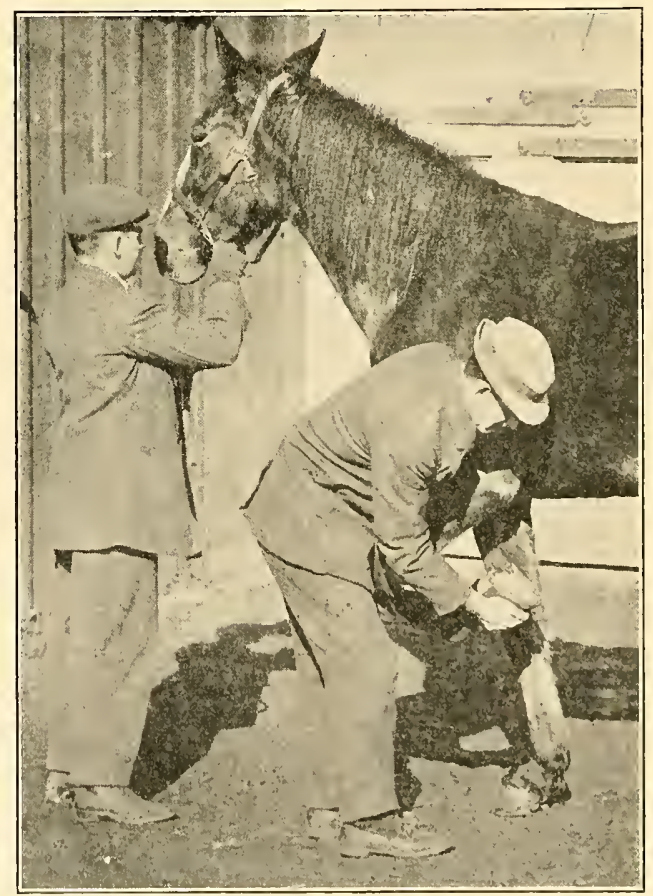

Fig. 23. - Second position in picking up a front foot.

conditions, when the blacksmith picks up the foot for the first time, the horse struggles, but since he was sent there to be shod the blacksmith retains his hold and after much excitement succeeds in shoeing 
him, but not until the animal has acquired a general dislike to having his feet handled, and a particular hatred of blacksmith shops. This excitement and distrust can be avoided by a little patient effort in

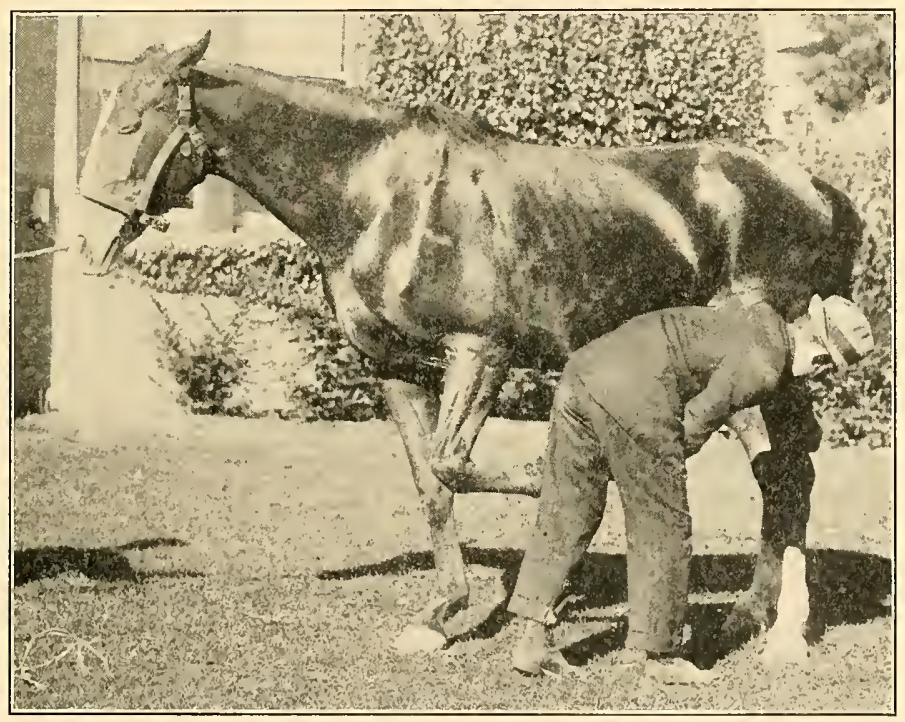

FIG. 24. - First position in picking up a rear foot.

educating the horse to stand while his feet are being handled.

The best way to pick up the foot is to run your left hand down over the shoulder, the fore arm, grasping, say, the near foreleg just above the knee, and to the rear (Fig. 22), and pinching the flexor muscle, which stimulates the horse to pick up the foot. 
At the same time press the point of the shoulder with your left elbow, thus throwing the weight from the near to the off leg, and reach down and pick up

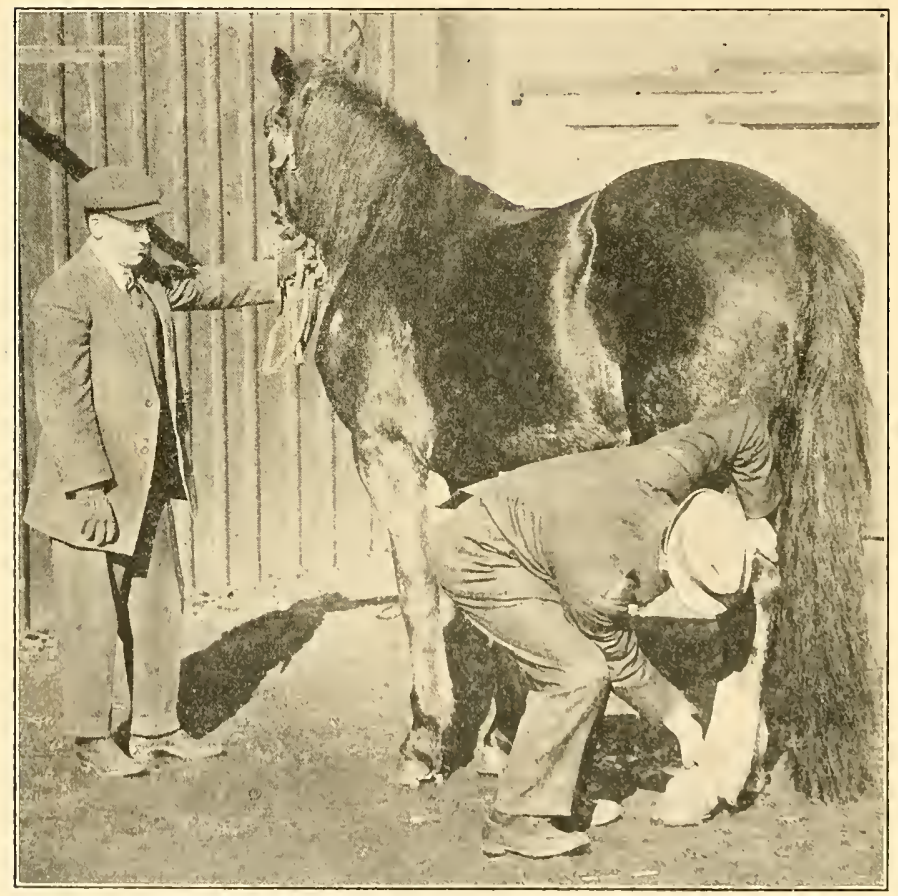

FIG. 25. - Second position in picking up a rear foot.

the horse's foot with the right hand. Hold the foot in the right hand (Fig. 23) for a moment, and then put it down carefully. Never drop the foot, but put it down. Pick it up again as before by the toe and 
hold with the right hand. With the left hand reach over, rub the quarter and pinch the flexor muscle just above the hock (Fig. 24). Gently lower the

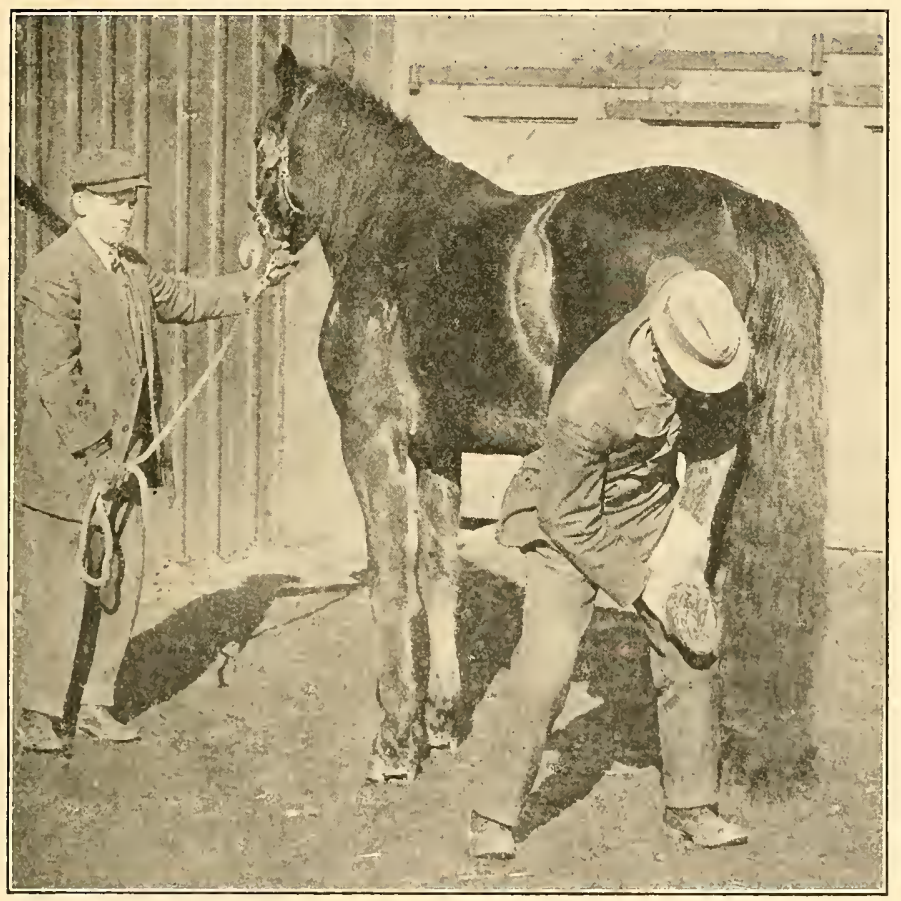

Frg. 26. - Third position in picking up a rear foot.

front foot with the right hand and reach down and pick up the hind foot (Fig. 25). Hold for a moment (Fig. 26) then gently place on the ground. Repeat the same process on the off side. Work only as 
fast as the horse understands. If he becomes excited and resists, do not attempt to hold him, but let him have his foot and begin all over again.

In handling the feet never allow the horse to bear his weight on you, as he is big and strong enough to hold himself, and will do so when he understands what is expected of him. After handling the feet once it is a good plan to take the hammer and gently tap the hoofs as in shoeing. This gentling requires perhaps fifteen minutes, and after going through the course the horse will never be any trouble to shoe (p. 300).

\section{TRAINING TO MOUNT}

Since the work horse is seldom worked under the saddle, and not much time or effort is spent in training him to mount, a short and quick method is given here, though the matter is taken up at some length, and modern methods are given, in the chapter on training the saddle horse (p. 155). In training a horse to mount be very careful that he does not succeed in dislodging you, for if once he succeeds in getting you off his back, it will take some time to convince him that he cannot do it again. The best time to take the horse is after he has been exercised vigorously and while tired. The best place is on soft ground, where the horse can hurt neither himself nor the rider. Put on the saddle as suggested in harnessing (p.72), and make sure that it is fastened 
securely. Have an assistant hold the horse's head while you mount. To steady the animal, some recommend the use of the noose- or rope- twitch (p. 197). The horse may rear, bound forward, buck or lie down. In any event, the rider must stay on, remembering that the horse is already tired and on soft ground. It is often an endurance trial, and this is the reason why one must have the horse tired to begin with, for otherwise he may be able to bound and buck till the rider is so exhausted that he can no longer maintain his position on the saddle. When the horse calms, caress him and repeat until he stands quietly while you mount. 


\section{CHAPTER IV}

\section{TRAINING THE TROTTER, COACHER AND ROADSTER}

Training horses for speed, high action and style requires much patient effort, unlimited tact and native ability. No set of rules can be laid down that will apply in every case. No two horses are of the same disposition or temperament, and the successful training of each is a law unto itself. While study and the experience of others may serve to increase one's skill, he will never be relieved of the necessity of using his own resources. The method is still further complicated by the fact that while there are many horses that have a tendency to show speed, action and style, and which can undoubtedly have the same very much improved by the adoption of a proper system of training, there are a great many others without this inclination and which it is hopeless to try to develop to a degree that makes it worth while spending time and effort on them. Since the method employed must be modified to meet the needs of the animal'and the convenience of the trainer, only a general plan is given, which applies especially to the trotter, but which is to be modified as circumstance 
demands. The plan is followed by a discussion of factors important in training horses of all classes.

\section{AGE TO BEGIN TRAINING}

There is much difference of opinion among horsemen as to the proper age to begin training the colt in order to develop maximum speed, style and action. Some say to begin before the colt is born, which, of course, would lead to a discussion of breeding, while others say that the youngster should be well developed before his training begins, particularly when high action is desired, as in the coach horse. There is a general feeling, however, especially in the case of the trotting horse, that the training cannot begin too soon, especially if the animal is to be raced while young. Some excellent horsemen are strong in their belief that the prejudice against early training in the past has hindered the progress in breeding horses for speed. The fact that early breeders were obliged to wait many years for returns from the capital invested, no doubt diverted attention from breeding trotters. Horse breeders desire quick returns, hence they breed animals that trot young. There can be no doubt that the younger a trotter makes a good record and a coacher shows his style and action, the quicker the breeder can turn his investment into cash and if they go wrong at two years old, they are a cheaper 


\section{Training the Trotter, Coacher and Roadster}

failure than if they go wrong at five or six years of age.

The effect of breeding for early maturity and early training upon the future usefulness of the horse is a much discussed question. Formerly many breeders were of the opinion that such practice had a tendency to weaken the horse, while others were equally as certain that both early maturity and early training better fitted the animal to perform his life-work. Volumes have been written upon this particular question. As a rule at the present time, practical men favor early maturity, though they agree that early training calls for much more tact and judgment than the training of a mature animal. They are strong in the conviction that the colt can be trained for speed from his infancy and that such training, if judiciously given, will prove a great and lasting benefit and make him a better aged horse.

\section{METHOD OF TRAINING WHILE YOUNG}

The youngster should be trained much as suggested in the discussion on training the foal (p. 26). With the lighter and more active types of horses it is very important that they be handled and taught to lead with halter and drive with lines as suggested. It is essential that the colt's entire confidence be secured and maintained, otherwise the trainer must work at a disadvantage. 'To be successful, a mutual 
understanding must exist between the animal and his master.

The training yard. - Since the youngsters are to be put into training very early in life, ample provision should be made for their accommodation. A small training track is almost indispensable for the young trotters, and a yard or track for the coachers. The small track should be laid off oblong similar to a race track, with proportionate turns and stretches. The length over all should not be less than 140 feet and the width not less than 65 feet. The track itself should be 10 to 12 feet wide and if convenient should be covered so as to be of service the year around. It should be made of earth good for the feet and should be kept deep and soft. At the turns, the earth should be thrown up two or three inches to the foot, to facilitate turning.

The construction of the inside fence requires special consideration. The posts should be few in number so as not to obstruct the view of the colt's legs when in action. They should be inclined toward the track in such a manner that the inner rail will prevent the colt from injuring his legs by striking the fence. As a further precaution the posts and railing should be slightly rounded by removing the sharp edges. This inner rail, which should be about six inches wide and of good material, should be placed about as high as the yearling's body. There is no need of a wheel board as the little track is not in- 


\section{Training the Trotter, Coacher and Roadster}

tended for vehicles, but simply for the exercise of the youngster before hitching.

Plan for training the young colt. - Very early in the colt's life one should decide upon a method of procedure. This should include the daily routine work as well as a consideration of the time it is desired to race him, since this will modify the method, as racing at two years old calls for a different plan of preparation than if not raced until later in life. Thus the daily feeding, watering, grooming and exercising should be so arranged as to meet the conditions. The importance of an orderly procedure in all that pertains to the care and management of the colt in training for speed or high action cannot be overestimated. He must be so skillfully handled as to bring out the best there is in him.

The colt should be fed regularly and up to the limit of his appetite from the beginning, in order to keep him strong. It is not possible to get the colt, under fiftcen months of age, too fat if properly groomed and exereised. He should be provided with fresh water at all times, in order that he may not drink to excess (p. 355).

Grooming the colt requires special attention. The colt should be thoroughly cleaned each morning, giving extra care to the legs and feet. The hoofs should be cleaned twice daily by removing all foreign materials that have collected in the clefts and about the frog. They should be kept level and so 
trimmed as to preserve the natural attitude of the colt's legs, otherwise he is likely to develop unsound legs. This trimming should be done with a rasp (p. 357).

In order to develop strength and endurance, it is important that the colt be exercised regularly. This will increase his heart and lung capacity and harden his muscles so that he will be able to endure the hardships of later life. In exercising the colt to develop speed and action, extra attention must be given to the protection of the legs. At any time the youngster "may become excited and strike himself, often inflicting serious injury. To avoid this the colt's legs should be well protected by shin-and quarter-boots, properly fitted so that they will not chafe the legs (p. 375). Such boots can be obtained at the harness shop (Fig. 27).

Exercising on small track. - When all is in readiness, lead the colt around the track a few times until he becomes familiar with it, then unsnap the lead-strap and follow him around several times. Do not hurry, but give him time to become reconciled to his new surroundings. On the other hand if he wants to run, let him do so at first, or until he has had his frolic; then endeavor to keep him at a trot as much as possible. The colt should now be taught to use the miniature track. This can best be accomplished by two men, provided with whips to which are attached long lashes. One man should 


\section{Training the Trotter, Coacher and Roadster}

stand near either end inside the inclosure and by holding up the whip teach the colt to go around the
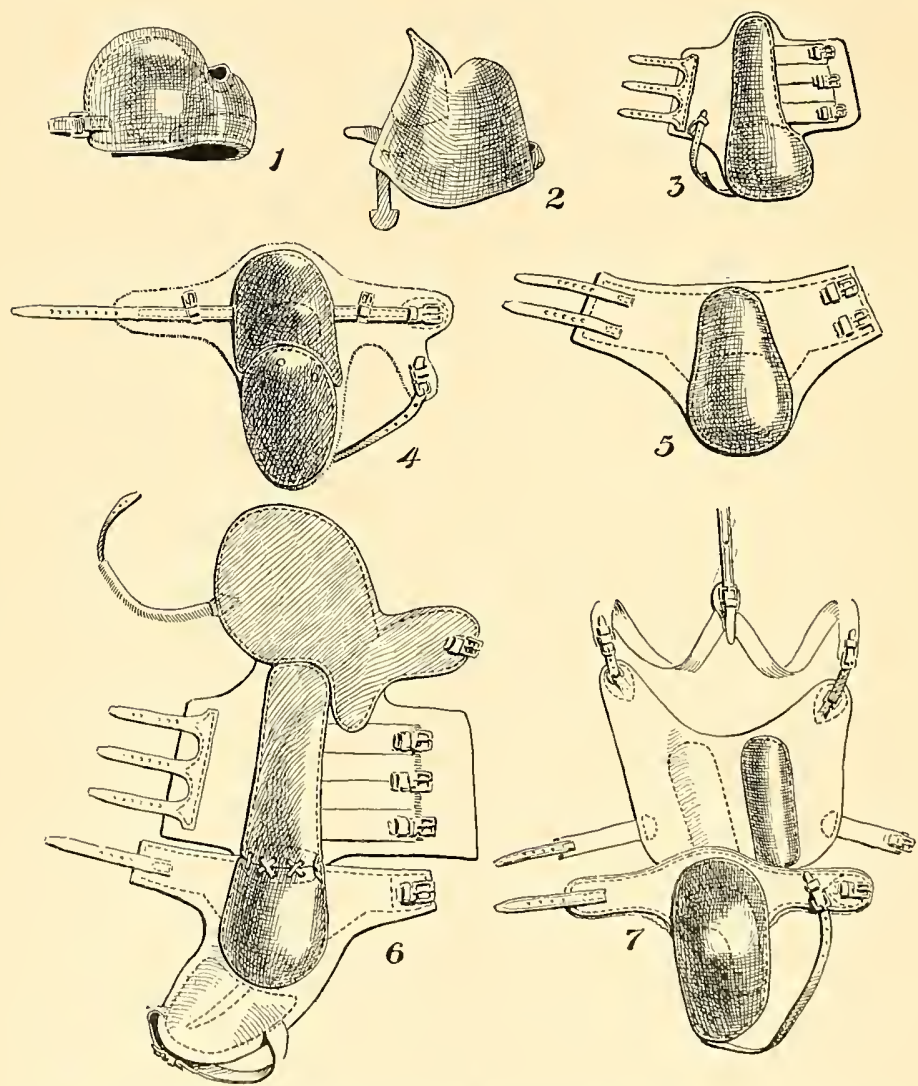

FIG. 27. - Boots for protecting the feet and legs of the horse. 1, Quarterboot; 2 , hind leg sealping-boot; 3 , shin-and-ankle-boot ; 4 , knee-boot ; 5 , front leg ankle-boot ; 6 , hock-and-hind-leg-boot ; $\gamma$, knee-and-armboot. 
turns rather slowly, and by cracking the whip urge him through the stretches. After the colt understands what is wanted do not allow him to run; if he should break go toward the rail and hold the whip out before him, and if he refuses to slow down to a trot slash it across the track in front of him, exercising due care never to strike him about the head. By using a little tact the colt will soon understand what is expected of him and you will be surprised to see how he will take the turns slowly but go through the stretches up to his limit.

After a few rounds, with two or three sharp brushes through the stretches, let him stop to rest if he wishes. This affords a good opportunity to caress him in order to assure him that he is doing as we wish. After a moment start the colt around the other way. Do not permit him to make the turns always in one direction, as this has a tendency to make his action irregular. Care must be exercised in starting the colt or in urging him, to prevent scaring him. Teach him to respond to the crack of the whip and do not "shoo" him or make any unnecessary noise to get him to show his action.

Do not tire the colt. - About fifteen minutes is sufficient time to keep the youngster on the track. The object sought is to create in the colt's mind a love for the exercise, rather than a dread or a disdain for the track. This can be done by permitting the colt some freedom and by caressing him often 
to assure him he is doing well. At this age his mind is receptive, the trotting habit is easily fixed and at the same time he acquires speed and steadiness of action. To overwork the colt at this age not only stops the progress of his education, but he really goes back in that he loses directness of action so essential to horses of speed and high action.

While the colt should not be exercised too long at a time, he may be worked safely two times a day if convenient. In the beginning it is a much better plan to give him two fifteen minute periods, one in the morning and the other in the afternoon, than to work him for one half-hour period. As the colt acquires strength and endurance the length of the exercise period may be increased gradually, but always keep on the safe side and underwork rather than overwork the youngster.

It is a good plan to let the colt rest two or three days each month and if convenient to turn him to pasture where he can have perfect freedom. This serves to break the monotony of the daily exercise and freshens him. After a few days of such freedom he will take his exercise more keenly and with greater vim. The few days of idleness seem to stimulate a desire for the daily exercise so that the colt will gain faster than if he be worked continuously.

During these early exercising periods the colt should be studied critically. Note carefully the carriage of the head, as this will be of advantage in 
adjusting the check-rein when put in harness. Observe his natural action and balance that you may know how to treat him in the future. The gait must receive much careful attention and any hitching or roughness in the action be immediately remedied. In order to develop maximum speed and action, this early training calls for coolness, watchfulness and tact. A study of the peculiarities of the individual colt is a very important part of the trainer's work.

If the colt is thrifty and strong, he may be worked in some such manner until about fifteen months of age, when he should be trained to harness. While such work requires time and calls for patient effort and native ability, if properly conducted it will bring out many peculiarities of the colt. In the first place it will indicate his possibilities, and one can form a fair idea of the kind of a horse he is going to make; or at least, if there is nothing in him he will have demonstrated the fact long before he is fifteen months of age. In the second place, it will bring out his natural carriage and action. Up to this age he must rely upon himself, and such action as he possesses he has acquired without assistance, and if studied carefully one can form an idea of how properly to balance him. Furthermore, early training develops a good disposition. The colt grows up under control and never knows absolute freedom. Before he is strong enough to make stubborn resistance, he is taught that there is nothing to resist and hence he never 
feels subjection. This serves to keep him in good spirit and he develops an even temper. On the other hand, if the colt is given his freedom until quite mature, he resents control and often becomes so headstrong that he may be physically and mentally ruined in training.

\section{EARLY TRAINING IN HARNESS}

The colt may be taught the uses of the bit and made familiar with the pressure of the harness as suggested for training the work horse (pp. 56 to 84). It is important to have him thoroughly obedient to the lines and perfectly accustomed to the harness before hitching.

In order to improve the action and to increase the steadiness of the gait many excellent horsemen recommend hitching double the first few times. They think that the training-cart with its long shafts and constant jarring motion interferes with the action, and throws the colt out of balance. On the other hand, many trainers use nothing but the cart and experience no more difficulty in balancing than those who use the double rig.

In case the colt is worked double, procure a vehicle of light construction and hitch by the side of a gentle, reliable and well-balanced horse. The first few lessons in harness must be short. Drive the team through the stretches of the track, or over a soft 
earth road, at an easy, steady gait for about fifteen minutes, then take the youngster out of the harness. Continue these lessons twice daily, morning and afternoon, for some time, gradually increasing the work, and hitching the colt alternately each time on either side of the staid mate. This part of the training is not to increase the speed, but to educate the colt to harness and at the same time to improve his action.

The colt is now ready for work in single harness. For the first few lessons in single harness, many prefer to use the skeleton wagon, as it interferes less with the action. After a short drive by the side of the staid mate, quietly take the colt out of the double rig and hitch to the single vehicle. Drive at an easy and steady gait for about fifteen minutes. Continue this work until the colt is thoroughly familiar with the vehicle and can be depended on to obey the voice and lines. Now he may be hitched to the cart or sulky with little or no risk.

The amount and kind of training will depend on the object sought. If the colt is to trot as a yearling, he will require work twice daily. This work should be short but sharp and speed-making. Colts and yearlings require little or no jogging. Drive the youngster a good fast gait for about 200 yards. Turn him slowly, giving ample time to catch his breath and let him go back a little faster. After going about the same distance, slow down, turn slowly as before and drive him up the stretch again, 
this time gradually increasing the speed until he is going his limit at the end of the 200 yard brush. After this sharp brush give him a little longer to breathe than before. Now let him out and drive back, carrying him to his limit again. This will be sufficient work for the morning exercise. Take the youngster to the stable, remove the harness and boots, give him a very little water to drink, rub him off lightly and then walk him a few minutes. This part of the work should be done in a stable, shed or protected area free from cold drafts. After walking, place him in a well-ventilated box-stall and leave him undisturbed so that he may lie down and rest.

Since young animals recover from the effect of work more rapidly than older ones, the former may be exercised twice daily with little or no risk until two years of age, providing, of course, good judgment is used and the work never overdone. In the afternoon put the colt through the same course as suggested for the morning, which will provide sufficient exercise for the day. In this early training much care must be exercised not to overwork the colt. The first sign of track-weariness should be followed by a few days' rest.

Continue the work daily as outlined, with little or no increase for the first two weeks, after which the number of brushes and the speed may be increased gradually. With young colts it is thought best not to increase the length of the brushes, as they will 
prove too fatiguing. It is a good plan to continue the practice of giving the colt two or three days' rest each month (p. 116).

Young animals do not need to be blanketed, sweated, scraped or physicked. They do not take on fat internally like mature ones and do not need to be reduced. Such practice has a tendency to stop growth and muscular development, whereas the youngsters require conditions favorable to physical development in order that they may increase in strength and endurance.

Study individual peculiarities. - The one fixed rule, that applies in training all horses, is to study each individual critically. It is this one characteristic more than any other that makes successful horse trainers. At this time the colt is beginning his track work and it is of the utmost importance that he be directed properly. The bitting, checking, harnessing and shoeing are all important factors in balancing and gaiting. If the youngster is not traveling perfectly square, if there is any roughness in his gait, or if he is in any way out of halance, he is not developing that smooth, steady and direct action so essential in the attainment of maximum speed or stylish action. Study the individual and adopt such methods as will keep him going true, smooth and level. Never drive him faster than he can go squarely, and he will develop speed and action if it is in him. 
The shoeing of each colt requires special attention. While much has been written on shoeing and weighting to improve action, experienced horsemen state that each colt is an experiment and that no rule can be made that will apply to all. To be successful, therefore, one must make a careful study of the

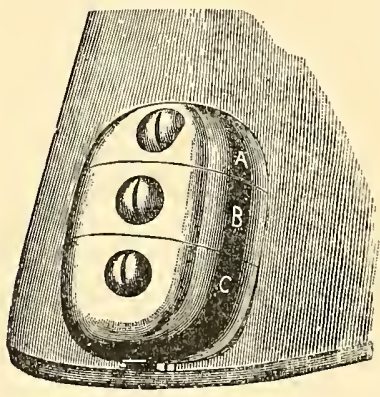

FIG. 28. - One type of toeweight. needs of each individual. If toe-weights improve the action, apply them; if not, disregard their use (Fig. 28). It is often necessary to shoe behind very early in order to boot properly. In such cases a very light shoe or plate should be used. Much care must be exercised in fitting the shoe, for should the colt strike or interfere, he will not extend himself, thus limiting or interfering with his action (p. 139).

Another individual peculiarity is the amount of work the colt can stand. Some can endure twice the work of others, so that it requires constant vigilance not to overwork. When the colt is going nicely the tendency is to drive him another brush, which is continued until he is fatigued. This should not be done. Never continue the exercise beyond the point where the colt can improve with the next step. The tired colt loses control of his legs and feet; his 
action is irregular; he falters in his gait, hitching and hobbling along; he may even strike and injure himself or he may break and run. No progress can be made in training a tired horse, and in fact, he loses precision in action.

If the training is conducted properly, the first year in harness will have a marked effect upon the colt. The lungs will develop with the muscles, and the legs will attain a hard, clean substance capable of enduring great strain. His speed and action will improve with his physical development and he will move with clock-like precision. On the other hand, if the training is not properly conducted, if each individual is not critically studied and his needs supplied, the consequence will be as far-reaching, though with disastrous results.

\section{TRAINING THE TWO- AND THREE-YEAR-OLD}

As the colt increases in age and strength the work may be increased gradually, the exact amount depending on the endurance of the individual. To improve the speed, many trainers continue the short brushes, though the distance driven is gradually increased, starting at about 200 yards with the youngster, working up to three-eighths-mile brushes with the two-year-old, and one half mile brushes with the three-year-old horse. The number of brushes given at each exercise likewise depends on the indi- 


\section{Training the Trotter, Coacher and Roadster}

vidual. By careful observation one can soon learn to judge when a horse has sufficient work.

The number of lessons given daily will depend on the amount and severity of the work. If the exercise is rather light and not too fatiguing, two short lessons are preferred, whereas if the work is fast and severe one is recommended. The often-repeated sharp brushes are the speed-makers and should be employed when convenient. When this system is used, it is important that the brushes be driven at various places along the track. If the work is continued too long in one place, the colt acquires the habit of slowing down and turning at this particular place. Another annoying habit youngsters often acquire is that of turning out every time they pass the gate leading to the stables. To overcome this, avoid slowing down or turning near the gate and brush past it, then turn and walk back.

As the time approaches for the horse to enter the race, his endurance must be improved. Thus far it has been a matter of developing speed, without which no horse can win. While the brush system - going a short distance at a fast rate rather than a long distance at a slow rate - develops the muscles and lungs and improves the speed, it does not prepare the horse to withstand the numerous heats of a longdrawn race. To illustrate one method of increasing the endurance a daily program is given. 


\section{DAILY PROGRAM FOR A HORSE IN TRAINING}

Give the horse a drink the first thing in the morning, or if preferred keep a bucket of water in his box over night. For the morning ration, feed one fourth of the daily allowance. It should be in condition to be easily and rapidly consumed. Nothing is better than clean, sound oats and sweet, well-cured timothy hay harvested rather early. Never feed new oats or new hay. After breakfast thoroughly groom the horse, giving special attention to the legs and soles of the feet. If convenient, walk him in the dew. Now hitch him to the sulky and give him an early jog of a few miles. Take him to the stable, remove the harness and boots and bandage his legs. Walk him a few minutes, remove the bandages and hand-rub the legs. Give him a drink of fresh water and place him in the box-stall with his head loose and leave the animal undisturbed.

In two or three hours, some trainers give the horse his real work for the day, while others prefer to work out in the afternoons. The amount and kind will depend on the individual. At this time give him three or four rather sharp brushes, carrying him well up to his limit at the close of the last one. Take him to the stable, remove the harness, blanket him, and remove the boots. Next scrape him off lightly, exercising much care not to let him get cold or to keep him so warm as to require a second scraping. 
After scraping, quickly rub the loins and muscles of the shoulders with a lotion of arnica, rum and water. Rub the legs, especially the joints and tendons, with the following application: sugar of lead 2 ounces, laudanum 2 ounces, and water 1 quart. After this they should be carefully bandaged. If the horse shows distress, some prefer a body-wash made of warm water and Medford rum, to which a little salt has been added. This lotion is applied over the muscles of the shoulders and loins. Blanket at once, place a light hood over the head and walk slowly for fifteen minutes to half an hour, permitting the animal to stop occasionally if he likes. When dry or nearly so take him to his stall and rub him out.

Bandaging the legs properly calls for some skill. The function of the bandage is to support the ankle and tendons until they have rested after the strain of hard work. Many persons leave the heels and under part of the ankles exposed, whereas the lower part of the ankle needs the support furnished by the bandage equally as much as the upper part of the leg. The bandage, therefore, should be set fairly tight and wrapped well down around and under the fetlock. It should be left on one or two hours.

Now that the animal is dry and thoroughly cleaned, he is ready for the noon meal. First give him a drink of fresh, cool water and then feed him another quarter of his daily allowance. He should now be left 
quiet until time for the afternoon walk, at which time he should be watered again. Some time during the afternoon give him a good walk, and if convenient, allow him to eat a little green grass.

In the evening, offer him another drink and feed the remainder of the day's ration. Thus the heavy feeding comes at night when there is sufficient time to consume the ration and no exercise to follow immediately after feeding. In about two hours after giving the evening ration, water again and arrange the bedding for the night. Before leaving for the night, however, the feet and legs should receive extra attention. The feet should be cleaned carefully and washed out. If dry, they should be packed with clay mud. Avoid the use of such material as cow-dung, as it often causes such diseases as thrush, canker and the like; also avoid using oil, as it has a tendency to make the hoof brittle. The legs should be hand-rubbed, and if slightly inflamed, witchhazel or the sugar-of-lead-laudanum lotion should be applied.

\section{TRAINING FOR THE RACE}

In preparing a horse for the race, first make a thorough physical examination, as good health is essential, and without it no horse can win, even though his breeding be of the best and his training perfect. If the physical condition is satisfactory, begin the preparation by working from three to five 


\section{Training the Trotter, Coacher and Roadster}

miles daily at a very moderate gait. Gradually increase the number of miles to suit the individual. After a time, if the horse conditions nicely, let him go twice each week, Tuesday and Friday, and finish the exercise by carrying him well up to his limit for a quarter mile. Continue this until fair weather in the spring, and then begin giving slow repeats.

During this part of the training, it is a good plan to score (driving under the wire) the horse a few times each day. By a little patient effort he can be trained so that there will be no difficulty in getting off properly at any time it is desired to start him.

About the first of May it will, be necessary to begin working the horse in mile heats at regular intervals of twenty to twenty-five minutes. This should be done twice each week, say Tuesday and Friday. While the number of heats to be given will depend on the endurance of the individual, it is recommended that he be worked in at least five. At first some of these heats should be finished by carrying him well up to his limit for a quarter or half mile.

As a rule, successful horsemen do not like much fast work after the horse is ready. They usually work him three to eight seconds from where he is to start, and continue the brush work, often finishing at the top of the horse's speed, but exercising much care never to push him off his feet. This calls for judgment of the gait on behalf of the trainer, but the successful chiver will have studied 
his horse so critically that by this time he knows just what to depend on.

Preparing for the race. - The evening before and the morning of the race, feed the horse his usual ration. After breakfast give him his morning jog of three or four miles and care for him much as suggested in the daily program (p. 125). Be sure to give a light feed after the jog, exercising care that he does not gorge. In the case of horses that eat their bedding, it may be necessary to provide a muzzle. About eleven o'clock give a fresh drink and feed the usual noon ration. In two hours, or shortly before the time for calling the race, hitch him to the sulky and jog two or three miles. Now let him out, carrying him well within himself for one mile, but at some point driving him to the limit to see that he has his speed. Take him to the stable, and by the time he has been cooled out as suggested in the daily program, the hour for the race will have arrived.

\section{DRIVING}

Now that we have followed the education of the trotter from the time he was foaled to the sound of the bell calling him to the race, we will consider factors of more general application, such as driving; improving the action by bitting, shoeing and conditioning ; injurious results of defective action, as interfering, forging, overreaching, hitching and like topics. 
Attention has already been directed to the necessity of preserving the sensitiveness of the colt's mouth, when educating him, by the use of a bit covered with leather (p. 57) and of the desirability of educating the draft horse to a light rein (p. 93). Such training is commonly known as "mouthing," and is of much importance. The manner in which the lines are held in driving is commonly known as "hands," and designated "good hands" or "bad hands" as the case may be.

Good hands signifies the delicacy of touch that never pulls at a horse's mouth more than is necessary, and never, on any account, when it is not necessary. To acquire this, calls for natural adaptation and skill. A light but firm, an elastic but steady hold on the line is what is desired. Good hands are rather indefinable, and methods of acquiring them cannot be imparted by written or spoken words. The importance of good hands and the necessity of preserving the natural sensitiveness of the horse's mouth become apparent when we consider that our every wish or command is communicated to the horse along the lines to a bit in his mouth, and especially when we take into account the fact that man's strength is insignificant when compared to that of a horse.

On the other hand, bad hands signify all other methods of holding the lines. As a rule, we drive with too tight a line. Pulling hands make lugging horses. 
When the driver pulls on the mouth it hurts. The horse finds, however, if he gives in and slows down, that he is touched with the whip to make him "drive up to the bit." He soon learns, also, that the harder he makes the driver pull at his mouth the less painful it becomes. This is due to the pressure shutting off the circulation, which numbs or deadens the mouth to the pain. The other extreme, that is, permitting the lines to hang, is equally as bad. The horse, being left to stumble along as best he can, becomes careless in his action. Many drivers have the habit of nagging or jerking at the lines when they wish the horse to increase his speed. This likewise destroys the natural sensitiveness.

Bad hands resulting in bad mouths are responsible for much of the undesirable action in driving horses. When we recall the extreme tenderness of the mouth, the cruel manner in which it is handled, the irritation thus produced from the resulting sores, we can understand why a horse may lag behind until the parts become numbed, then begin to pull, holding the head to one side, going with the mouth open, lolling the tongue, slobbering, tossing the head and crossing the jaws; how he loses control of his legs, so to speak, and "hitches," hobbles, forges, overreaches, interferes, and in many other ways shows evidence of the discomfort he is suffering.

To hold the lines when driving, take them in the left hand, the left line coming into the hand over 
the forefinger and the right one between the middle and ring finger. The manipulation of the lines and the guiding should be done with the right hand, which also carries the whip. The arms of the driver from shoulder to elbow should hang naturally, with forearms held at right angles and the hands meeting in front of the body in a perfectly natural position, with thumbs uppermost. This position of the hands and lines gives the best possible control of the lines and at the same time enables him to keep a light touch on the horse's mouth. With the horse properly mouthed and the natural sensitiveness preserved, the slightest touch on either line will be pressure sufficient to guide the horse.

\section{IMPROVING THE ACTION}

In the training of the coach horse, action is paramount. It is prized because the proper kind is so difficult to secure. Training horses of this class is complicated by many factors, chief of which are the conformation and the natural adaptation of the horse. Some horses are so defective in form as to prevent high action. There are others, however, seemingly of the correct conformation to produce excellent action but lacking the nervous adaptation; and still others somewhat lacking in conformation but possessing the proper nervous development to make them excellent performers in their class. In 
the conformation of the pasterns, for example, length and obliquity usually favor lightness and elasticity of the tread, yet this is not always the case, as we find many heavy-going horses of this conformation; in the case of a horse with short pasterns and straight shoulders, which as a rule produce heavy movements, this is not always true, as we not infrequently find straight-shouldered, short-pasterned horses that step lightly. These exceptions are undoubtedly referable to the nervous system. In the former case the horse is of a lymphatic temperament, lacking zest in his labors for the want of tone in his nervous system, while in the latter case he is of a nervous disposition and is a willing and enduring worker in his range.

With few exceptions, however, the action is referable to the conformation, and defects in the legs show themselves with almost unvarying regularity in their effect upon the action. Thus the horse that stands with his front feet placed wide apart has a tendency to straddle; the knock-kneed one generally dishes; the one that toes-in winds out, while the one that toes-out winds in. The horse with his hocks wide apart and his feet close together winds his hocks outward; the sickle-hocked one winds his feet outward; while the horse with his hocks placed too far behind has a peculiar dragging movement of the hind legs. Not only the conformation of the legs but that of the body also indi- 


\section{Training the Trolter, Coacher and Roadster}

cates the action and the ease with which the horse can be balanced. Thus the horse with thick withers and wide chest is likely to roll his feet outward in traveling. In the case of a horse with a short neck and heavy head, much difficulty is experienced in bringing out his action because of the poor relation between the head and neck. In this case the action will be short and stilted. The first requirement, therefore, for straight, undeviating action is that the horse be of proper conformation (Fig. 29).

The action of any horse can be improved by adopting the proper system of training, although but little progress can be made without good conformation and a tendency to show action. Without the conformation, or the inclination, it is hopeless to try to develop action to a degree that will make it worth the time and effort. On the other hand, a horse with head and neck of proper relation and well joined, that has a responsive mouth and some ambition, that has the various parts of the body in correct proportions and stands squarely on his legs, will when urged get his head up and nose in, and if restrained at the same time, by the use of the proper bit, will show superior action.

In training the horse for high action there are three factors that require special attention : bitting, shoeing and conditioning.

Bitling to improve action. - Now that we come to the special study of bitting to improve action, it 


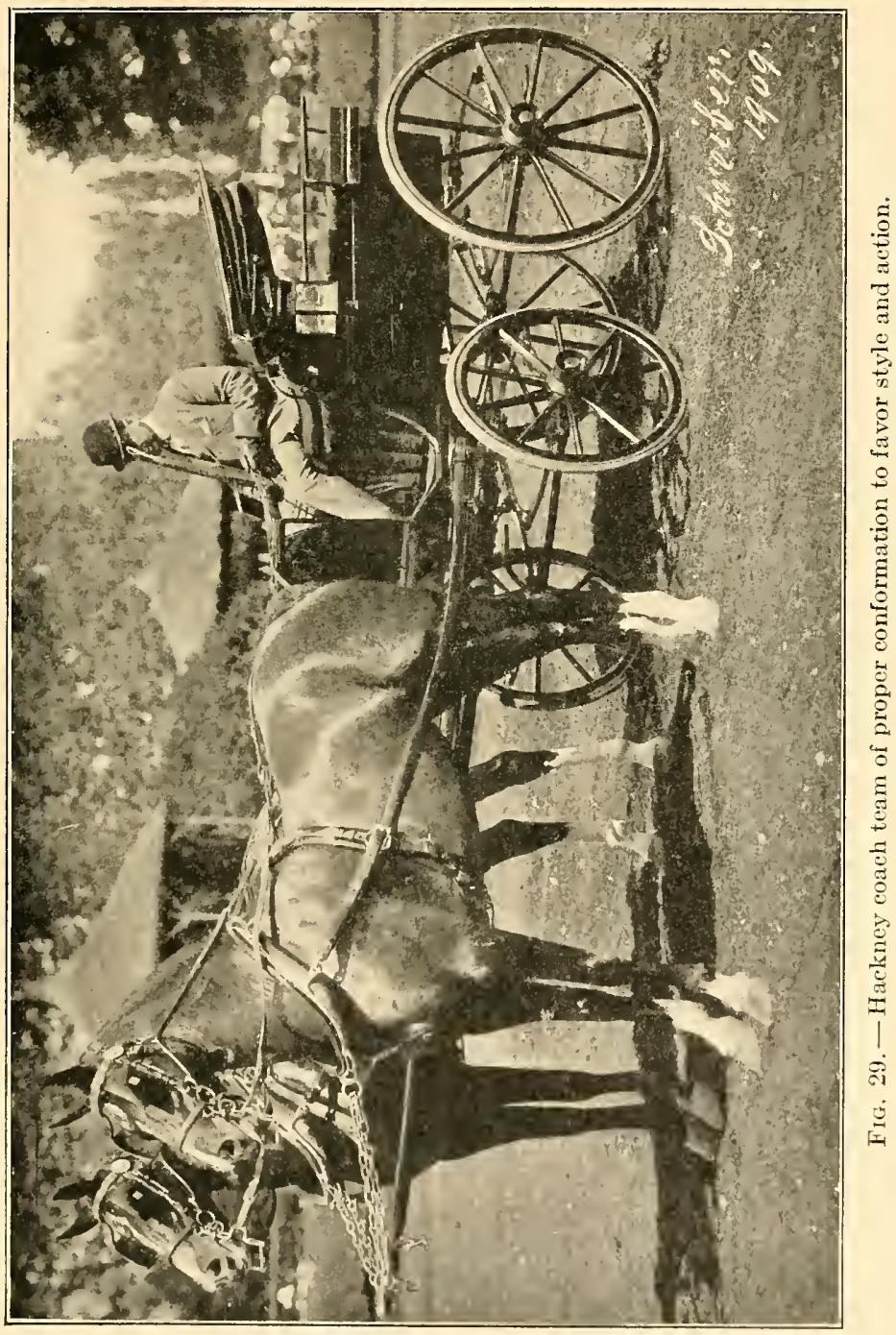




\section{Training the Trotter, Coacher and Roadster}

is important that we scrutinize the mouth, as there is much variation in shape and in the natural sensitiveness among individuals. Some horses possess small tongues and rather narrow sharp bars, which are very sensitive to pressure and call for much care in training to the pressure of the bit. Because of the extreme tenderness, such a mouth is easily spoiled, whereas if properly trained to pressure it is likely to develop into a delightfully responsive one. On the other hand, there are horses that possess thick, leathery tongues and heavy, coarse bars which are very difficult to make responsive, owing to their lack of sensitiveness. A close examination of the mouth, therefore, will give some idea of the method to employ in bitting to improve action.

After familiarizing the coach horse with the uses of the bit by employing an easy bit much as suggested (p. 57), he should then be educated to the curb-bit. Instead of using common lines, as has been suggested, many prefer long ones, so they can remain near the center of the training paddock while driving the horse around, as this gives a better view of the action and saves many steps. The curb-bit is made so as to divide the pressure between the inside and the outside of the mouth, the chain under the lower jaw exerting pressure in such a way as to bend the head on the neck, or rather bend the nose in. By holding the horse's head up with an 
overdraw check-rein and by holding his nose in with the curb-bit, he will when urged and restrained "step up" instead of stepping forward.

Curb-bits are so constructed that different degrees of leverage can be exerted, and they may become instruments of torture in the hands of the inexperienced (Fig. 94, 34 to 36). If properly used,

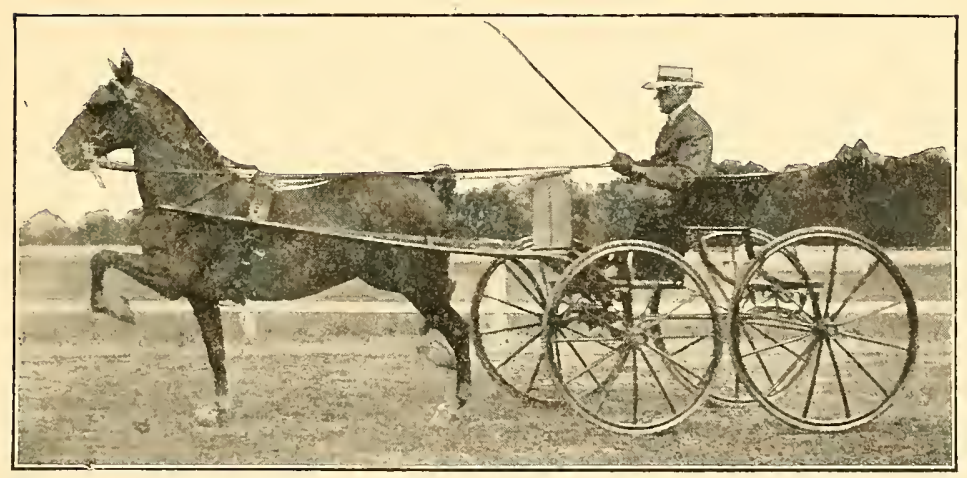

Fig. 30. - Coach horse properly bitted to favor action.

however, they are really easier in many mouths than less severe bits, as the leverage they bring to bear will make some horses bend that cannot be made to do so without them. As soon as the horse bends his head, very little pressure need be exerted to hold the nose in. Never pull more than the exigency of the case requires, for injury and irritating sores will result. To encourage high stepping, simply exert sufficient pressure on the lines to hold the head up and the nose in (Figs. 30 and 31). 
138 Training the Trotter, Coacher and Roadster

To familiarize the horse with the curb-bit, place. it in his mouth a few hours each day and let him stand in the stable. This gives an opportunity to become accustomed to the shape of the new bit in quiet, after which the pressure may be brought to

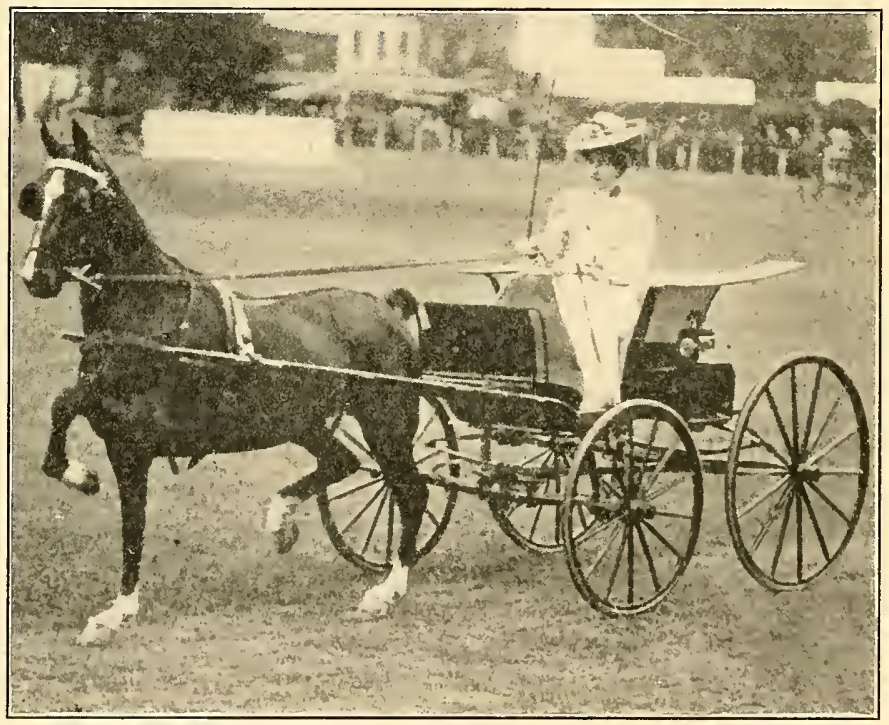

FIG. 31. - Improving the action with a curb-bit; head up and nose in.

bear by degrees. This is very important, as many horses' mouths are spoiled the first day the curb-bit is used. The bit improves the style and action to such an extent that the driver feels encouraged, and he urges the horse against the bit and curbs him in until the mouth becomes abraded. As the parts be- 
come sore the animal begins to hold his head to one side, to toss it up or carry it unsteadily, to pull on the lines and finally to go irregularly in his gait, to hitch, to interfere and the like.

When the horse is made familiar with the uses of the curb-bit by using the dumb jockey or the bittingrig as described (p. 60), if at any time he shows evidence of discomfort, loosen the side-reins and then tighten them gradually. It is important to have the bit of the correct length and properly adjusted. If he draws his tongue up in his mouth, or puts it over the bit, it is because the bit is too low, in which case it should be raised. If he gets his head too low, it should be held in the proper position by using a check-rein. Training to the uses of the curb-bit requires patience, perseverance and tact. The tendency is to hurry this part of the work too rapidly. If the mouth becomes sore, rest it by keeping the bit out until it is better; then begin over again, using extra caution. The trainer will be rewarded for his time and effort, as it is remarkable how much the knee and hock action can be increased by cultivating a responsive mouth.

Shoeing to improve action. - Shoeing and weighting are very important factors in properly balancing the driving horse, but one cannot shoe or weight a horse correctly until making a critical study of his movements.

In training the trotting horse, it is often necessary 
that he be shod very early in life, in which case a very light, plain shoe should be used. It is important to keep the shoes as light as possible, for every additional ounce has a detrimental influence upon the horse. The extra weight may occasionally be necessary, but it is none the less an evil because a necessary one.

In shoeing, the aim should be to keep the foot elastic, yielding and natural. Fitting the shoe calls for careful study, - the old shoe will often furnish valuable information. In trimming the foot, be careful with the knife, cutting only the horn and wall. Leave the frog, the sole and the bars alone. They will care for themselves. When the foot is properly leveled and made as nearly natural as possible, then fit the shoe to the foot and not the foot to the shoe. The shoe should be fitted cold. The nails should not be placed too near the edge of the hoof, nor too far back toward the quarters, thus leaving the heel free. In smoothing the clinched nails, do not rasp the outside of the hoof, as it will remove the natural protective covering. The shoes should be reset at least once each month, otherwise the hoofs will grow out so as to destroy the natural form of the legs.

The importance of weight on the horse's feet is often overestimated. While it is true that extra weight will often make him show more action for a time, particularly if he is well driven and in fine fettle, yet if he is called on to exert himself for 
any length of time, especially if the going is heavy or if he is drawing a load, his movements will soon become labored, he will pound the ground, very likely overreach and forge, and the character of his action will be destroyed. When extra weight is necessary to bring out the action, it should be reduced as soon as possible. This should be done gradually. Since wear lightens the shoes, it is a good plan when replacing them to have the new shoes the weight of the old ones after being reduced. If the horse continues to go well, reduce until the proper weight is reached. One has to be guided by the individual in determining the amount of weight to be put in the horse's shoes in order to bring out the best results in the way of action.

In training for high action it is often of advantage to permit the hoofs to grow to a fair length, thus causing the horse to exert extra effort in raising and extending the legs. Though fatiguing to the animal, this has a tendency to increase the action. This extra growth of the hoof, like extra weight in the shoe, is often a necessary evil when extreme action is desired.

Defects in action can be corrected, in a measure, by modifying the shoe and the shape of the hoof. The horse that winds his feet outward may often have his action improved by having the inside branch of the shoe slightly the heavier, whereas the one that winds in should have the outside branch slightly 


\section{Training the Trotter, Coacher and Roadster}

increased in thickness. In case the horse extends too much and fails to bend his knees sufficiently, it is often advantageous to have the toes of the shoes fairly light and to increase the weight gradually toward the heels; or in case the horse folds or bends the knees too much and fails to extend the feet sufficiently, increase the weight toward the toes and lighten it toward the heels. This of course must be done so as not to interfere with the level of the foot. If the true position of the leg is interfered with, the wear will not be equally distributed and lameness is likely to follow. In shoeing and balancing to improve action, however, it is most important that each animal be critically studied and the method adopted that will yield the best results.

Conditioning to improve action. - To bring out the action, it is essential that the horse be in fine fettle. He must be full of nervous energy and his muscles well developed. No matter what his conformation, how thoroughly trained, or perfectly balanced, it is not possible for the horse that is run down in flesh and lacking thrift to come into the bit with that rhythmical, frictionless action that commands the respect of all. He must not only know how to do it and feel like doing it, but must also have the power. The making of a responsive mouth, the correct balancing and toning up of the system, should proceed together"; one should never be permitted to go ahead of the others in making high-acting horses. 
Horses differ in the amount of food required to produce best results, just as they do in other ways. No rule can be made that will apply to all. One horse may keep strong and in fine condition on hay alone, while another may require ten or fifteen quarts of oats daily, in addition, to keep him right. In cases in which action contributes to the horse's value, he must also look well. This often complicates the feeding question, as an excess of hay in the ration sometimes distends the abdomen and gives the horse an unsightly appearance, particularly if he be slightly cow-bellied. To avoid this, one should feed a nutritious ration, rather concentrated in its nature, then give regular exercise to prevent the spirits from becoming exuberant (p. 147).

\section{INJURIOUS RESULTS OF FAULTY ACTION}

Not only is faulty action unsightly, but it results in many disagreeable, annoying and injurious defects. For convenience these may be divided into two classes: those caused by the hind and fore feet striking, variously referred to as over-reaching, forging and clicking; and those due to the feet on either side hitting, referred to as interfering, striking, cutting and brushing.

Over-reaching, forging and clicking. - These defects result from any cause that prevents the horse from getting his forefeet out of the way of the hind ones 


\section{Training the Trotter, Coacher and Roadster}

while traveling. In some cases, the horse is predisposed to the trouble, in which case it is often difficult to overcome, while in others it is excited by a number of conditions which can be remedied, as a rule, by rational treatment. Undue shortness of body, fore pasterns disproportionately long, withers lower than the croup and low heads are frequent predisposing causes. Lack of strength, or fatigue due to hard or fast work, a hard, unyielding, unresponsive mouth due to bad hands, and soft footing or heavy going, such as driving on soft earth roads, particularly if the horse is used to the hard footing of the city pavement, are frequent exciting causes.

To overcome the difficulty, first seek out and remove the cause if possible. In the large majority of cases, after the horse is put in good condition, the mouth well made and the feet properly shod, there will be no further difficulty. In some cases it may be necessary to employ artificial means, though this should be done only as a last resort. To remedy over-reaching and kindred faults, the principle to pursue is to hasten the action of the forefeet and to encourage a slow or dwelling movement of the hind ones, in order to allow the former to get out of the way of the latter. The action of the forefeet can often be hastened by slightly rounding off the toes of the front shoes, as this has a tendency to encourage the hor'se to raise his feet quickly. On the other hand, the action of the hind feet can often be retarded 
by raising the toes of the hind shoes and lowering the heels.

Interfering, striking, cutting and brushing. - Like over-reaching, these defects also result from a number of causes, some of which are predisposed, while others are due to exciting conditions. Defective conformation, such as narrow chests, legs and particularly fetlocks deviating inward, and feet of poor conformation are the principal predisposing causes. Improper mouthing, fatigue, poor shoeing, uneven and slippery footing, and the like, are frequent exciting. causes.

Of the many defects resulting from faulty action, interfering is one of the most troublesome. It is, however, one that admits of a large measure of prevention, and the ill effects of it can be remedied to a very considerable extent by proper bitting, shoeing or balancing, and by the use of boots.

The treatment to overcome interfering and kindred troubles is much the same as that suggested for over-reaching. First, find the cause and remove it if possible. Then put the horse in good condition, and see that his mouth is properly bitted and his feet correctly shod. When the difficulty is due to defects in the conformation of the hoof, it may, in a measure, be overcome by shoeing. If the horse toes-out, shorten the outer part of the toe to a greater extent than the inner, or if he toes-in, trim the hoof in the opposite way. When the injury is inflicted 
by the inner part of the hoof, as it often is in the hind feet, the difficulty can be remedied, in a degree, by rasping the inner side to reduce slightly its convex form and by placing the inner branch of the shoe under the foot as far as possible without running too much risk of bruising the sole. Relief is often gained by shortening the inside of the hoof more than the outside, in which case the inner branch of the shoe is thickened to keep the foot level. The inner part of the shoe should be well rounded so that there will be as little danger as possible of inflicting injury. In other cases, relief is gained by shoeing with a three-quarter shoe - one coming about halfway round on the inside and not covering the surface of the inner quarter. Shoeing to remedy interfering requires careful study of each individual.

In the training of young horses for speed or high action, boots are strongly recommended to prevent injury, should the animal interfere. It is of very common occurrence for youngsters to interfere until they become familiar with the bit, after which no difficulty is experienced. Furthermore, the colt may become frightened at any time, lose his stride, strike himself, and inflict serious injury. From the very beginning, therefore, boots should be used as a safeguard and as a preventive against possible injuries (Fig. 27). 


\section{EXERCISE CONTRIBUTES TO ACTION}

Faulty action is often due to irregular or insufficient exercise. The periods of enforced idleness occasioned by lack of business engagements of the master or by inclement weather, are often followed by long drives and hours of over-exertion. This is accompanied by many faulty movements, such as irregular and indirect action, hitching and hobbling, interfering and over-reaching, and the like. The matter is still further complicated by the owner, who, desiring to keep his horse in presentable condition, often overfeeds during the enforced idleness. Irregular work weakens the constitution, and the horse thus exercised generally has but a brief career.

Regular and judicious exercise stimulates the appetite, promotes digestion, encourages assimilation and helps the system to remove material for which it has no further need and which, if allowed to remain, would prove injurious. Such exercise improves the muscular tone and keeps the animal in good spirits, thereby enabling him to control his nervous and muscular action. The amount of work necessary to keep the animal in condition will depend on the individual.

This brings us to a discussion of the rather common practice of horse owners in large cities turning their horses out for a part of the year. There is much 
difference of opinion as to the advantages of such practice, particularly if the horse is in good condition and going sound. Some one has said that "two let-ups are as bad as a break-down," and there seems to be considerable truth in the statement. To throw a horse into complete or comparative idleness for any length of time causes his tendons to lose strength, his muscular system to lose tone and his nervous system to lose power of application. True, such a horse may be worked back into condition, but it will take months to restore muscular tone and nervous energy. As a rule, the horse is taken up and put to work at once, with the result that he suffers from muscular soreness and may develop faulty action very difficult to remedy. With the horse that is sound and in good condition, the better plan is to provide regular exercise.

On the other hand, if the horse is run down, slightly lame, or otherwise out of condition, comparative idleness is almost essential. Such animals are already in poor condition, and there is nothing better than a good blue-grass pasture, well watered and well shaded, especially in the early summer before flies become troublesome. Such pastures provide natural conditions, as the horse in feeding will take some exercise, the morning dew will improve the physical condition of his feet, and pasture constitutes the best of food. If convenient, he should be fed grain in addition, as this aids in regaining 
muscular tone and nervous energy. After the horse has regained his strength, he should be worked gradually into condition again. The mistake is often made of putting the animal to work too quickly, thus offsetting the good effect of the rest. 


\section{CHAPTER V \\ TRAINING THE SADDLE HORSE}

THE saddle-bred colt should receive much the same training as that suggested for the foal (p. 26). The saddle work, however, should not begin until the colt is at least two years of age, and in most cases it is preferable not to begin the real training until three years old. The reason for this delay is apparent, as the saddle horse is obliged to bear the weight of the rider and, therefore, should be well matured to avoid straining the muscles of the back and the tendons and ligaments of the legs. If the saddlebred colt seems good enough to make a show horse, and is stout and rugged, the training may begin early, but extra care must be employed to prevent injury.

When the colt is sufficiently mature to begin the saddle work, he should be taught the uses of the bit much as suggested in bitting the work horse and the coach horse (pp. 56 and 134). As with high-acting horses this is a very important part of the saddle horse's training, and the work should be thoroughly accomplished before mounting. 
EQUIPMENT FOR TRAINING A SADDLE HORSE

The riding bridle. - After teaching the saddle horse the uses of the bit with a common bridle, the riding-bridle should be employed. This bridle is similar to the common bridle except the bit and reins. The bit is similar to a curb-bit with provision for the attachment of two sets of reins, one set to the snaffle, the other to the curb (Fig. 94, 31 to 33). Some riders prefer two bridles, one provided with a snaffle, and the other with a curb-bit. It is not considered good practice to use the curb without the snaffle, as the refractory horse may become difficult to control by the former. Before attempting to mount, the horse should be made familiar with the bits, much as suggested in the case of the curb-bit (p. 138). If the horse has a tendency to throw the head upward, the martingale should be used, as the rider is liable to injury.

The saddle. -- There are many makes of saddles, some devised especially for men (Fig. 32, 1 and 2) and others for women (Fig. 32, 3 and 4). A rather light and flexible saddle is preferable to a very heavy and stiff one. The pommel - upward projection in front - and the cantle - upward projection behind - should not extend too high, especially for the horse in training. Care should be exercised to see that the saddle fits properly and that the weight is equally distributed. The stirrups and stirrup- 
straps should receive much attention. Stirrups are made in many forms (Fig. 33). Whatever the form
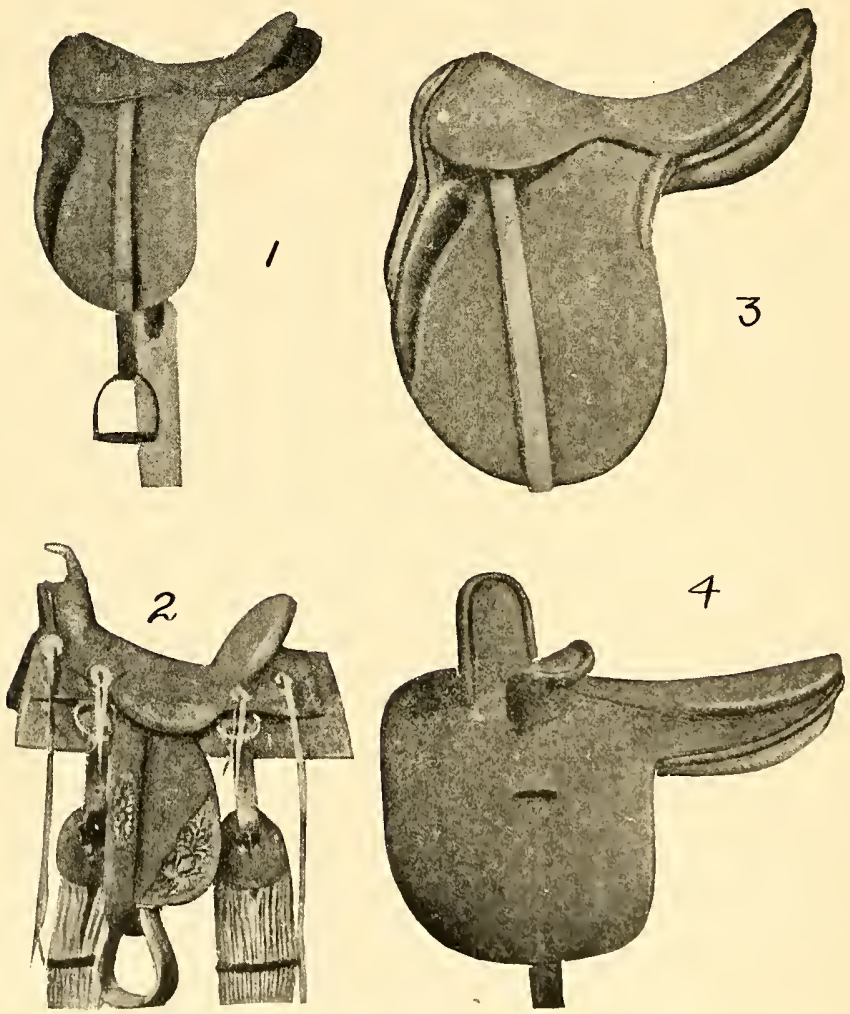

Fig. 32. - Types of saddles. 1 and 2 for men, 8 and 4 for women.

chosen, they should be of light, neat construction, and so arranged as to admit the feet easily. Some 
riders prefer the safety stirrups, so that in case of accident there will be no danger in getting the feet fast, as the safety stirrups are provided with latches which spring open when the pressure is removed, thus freeing the feet (Fig. 33, 3). The stirrup-straps should be properly adjusted. If too short, the legs of the rider will be held in a cramped and tiresome position, and if too long, the rider cannot properly balance himself. The saddle-girth should be arranged moderately tight so as to prevent the
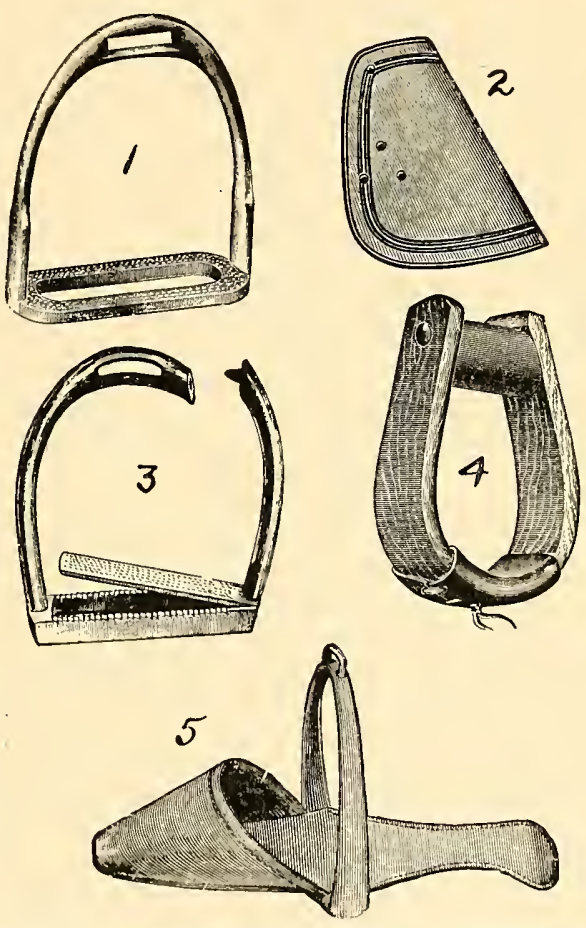
saddle from turning. There is much difference of opinion as to the advisability of using a saddle-blanket, some rec- 
ommending its use, while others state that with a properly fitted saddle it is useless.

Whip and spurs. - These are important articles in the training of a saddle horse. They may be used as aids in bringing out the gaits or as stimulants; hence, it is important to teach their uses very early in the training period. In teaching the horse to

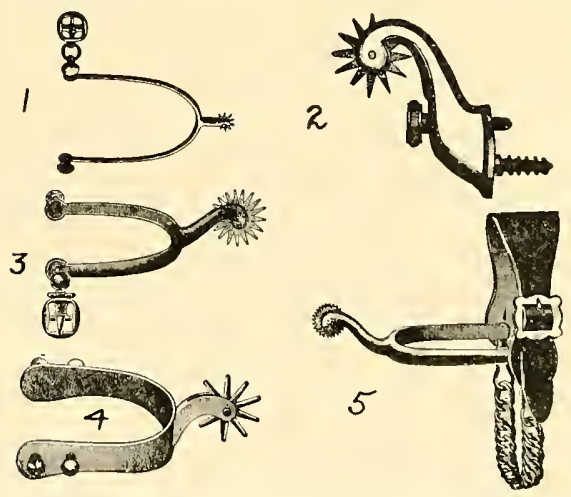

Fig. 34.-Types of spurs. 1, Racing ; 2 , patent ; 3, English ; 4, Plain ; 5, Army spur.

obey the whip, either as an aid or a stimulant, one should be careful to use it in such a way that the horse will not become unsteady in the event of his rider carrying anything in his hand (p. 19).

In teaching the horse to obey the spurs, care must be exercised to avoid making him regard them as instruments of torture. Many spurs are so constructed as to injure the horse if improperly used (Fig. 34, 2). For use in training the saddle horse, a light, mild spur is recommended (Fig. 34, 1). Gradually the horse should be made familiar with the uses of the spurs, at first by pressure of the flat of the foot or heel, then by that of the spurs without a 
rowel, or with a blunted rowel, and lastly by the pressure of the common spurs. The horse should be made so thoroughly obedient to them that when riding him we may dispense with their use, the contact of the heel being sufficient to produce the desired results.

\section{MOUNTING HORSE FOR FIRST TIME}

After the saddle horse has been taught the uses of the bit, he should be educated to stand while being mounted. This is an important part of the saddle horse's training, for it is very provoking to have a horse continually stepping about or starting while one is mounting. Many horses otherwise well trained possess this aggravating habit.

After driving the horse about the training paddock, as suggested in teaching the commands (p. 63), take him to his stall and carefully place the saddle on his back, first permitting him to feel and smell it, if he likes. Draw the girth moderately tight and leave him in the stall until he becomes familiar with the object on his back. If unsteady, he should be caressed. Then cautiously remove the saddle and carefully replace as before. Repeat until he exhibits no uneasiness on being saddled.

Next take the horse into the training paddock, place across the saddle a half-filled sack of sand or earth, secure firmly and drive him about the inclo- 
sure until he becomes steady. We may now remove the sack, and if the horse has exhibited any unsteadiness, apply the noose- or rope-twitch (p. 197). Let an assistant hold the horse and correct any uneasiness by using the twitch while the animal is being mounted. Quietly mount and dismount several times, rewarding or punishing the horse according to his conduct. The assistant may lead the horse about the inclosure to familiarize him, while in motion, with the weight on his back. Now the rider should take a short and firm hold on the reins, so as to be able to meet any emergency, while the assistant removes the twitch. Ride the horse first about the inclosure, and then in the field, until he becomes perfectly familiar with the extra weight and will obey the voice and reins.

Some horsemen mount for the first time by gradually educating the horse to bear the weight of a man's body. They begin by handling and caressing the animal, then catching hold around the neck well back toward the withers, and by degrees familiarizing him with the weight by hanging on to the back part of the neck. After he learns to bear weight at the withers, pass to the back, and in a like manner educate him to bear weight, first by simply leaning on him, gradually increasing the weight, and lastly by taking a position astride. The horse is frequently caressed to assure him that he is doing well. This method works well with the gentle horse. In case 
the horse is difficult to mount, more strenuous methods must be adopted (p. 274).

To mount the trained horse, grasp the reins in the left hand and catch hold of the mane just in front of the withers. With the right hand, first aid the left foot into the stirrup, then catch hold of the pommel. Now by a springing leap pull yourself up and stand in the left stirrup, then place the right leg over the saddle and into the right stirrup. Assume a comfortable position, with the arms hanging naturally, the left one, which supports the reins, being held about even with the top of the pommel (for method of holding the reins see page 131).

The horse should now be educated to the uses of the spurs and the rider's legs in guiding and controlling. Closing the knees without pressure by the lower parts of the legs tends to steady the horse while in action. Placing the lower part of the legs slightly to the rear, and closing them equally, thus causing slight pressure on either side, prepares the horse to move, or if already in action, has a tendency to encourage him to keep up to the bit. Closing the lower legs with considerable pressure behind the girth stimulates the horse to move forward. Placing the right leg to the rear and closing with considerable pressure stimulates the horse to move his hind quarter's to the left, while a corresponding action with the left leg stimulates the horse to move his hind quarter's to the right. Each of these movements should be 
taken up separately and taught the horse until he will obey without the aid of the voice, rein or whip.

It is important that the saddle horse be taught to guide to the right and left when you apply pressure with the knees and incline the body in the desired direction. This is accomplished most efficiently by guiding on the neck. To do this, first cross the snaffle reins under the lower jaw; now as you pull on the left snaffle ring, slight pressure is brought to bear on the right side of the neck, which induces the animal to guide to the left; simultaneously clamp his body with your knees and incline your body to the left. Repeat until the horse will guide to the left when you clamp the knees and inchine to the left. Next teach the animal to guide to the right by reversing the process. When thoroughly familiar with the method, teach him to guide to the right and left in rapid succession as you incline either to the right or left.

\section{GAITS OF THE SADDLE HORSE DESCRIBED}

Before attempting to teach the various gaits, we should have a clear conception of each and know exactly what movements the horse must make in performing the same. The gaits of the saddle horse are much confused in the popular mind because a few are designated by several terms. There are three natural gaits, - the walk, trot, and gallop, and several artificial ones, being more or less varia- 
tions of the natural gaits, such as the running walk, fox trot, slow pace, rack and the like.

The wall. - This may be considered the foundation of all saddle gaits. It is a gait of four flat beats, each foot being planted in regular order. If the right forefoot comes first to the ground, the left hind foot

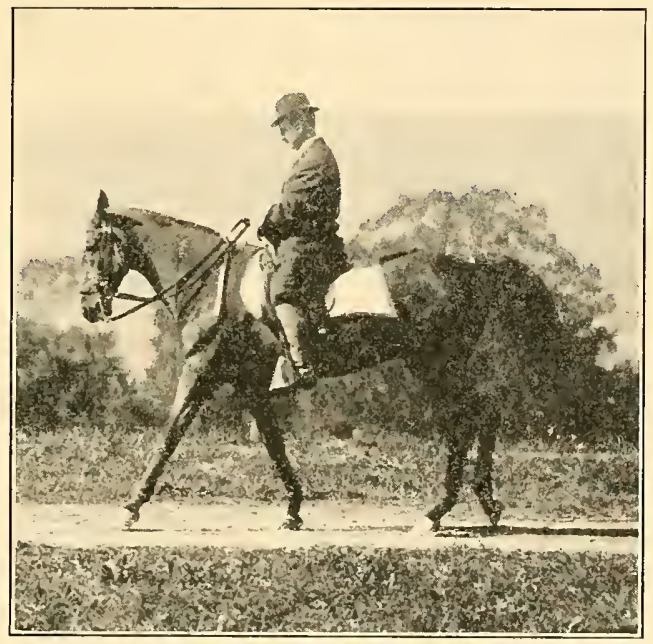

Fig. 35. - The walk.

is next planted; then the left forefoot and finally the right hind foot. The horse has never less than two, and never more than three feet bearing weight on the ground at the same time. The weight is borne first by the two forefeet and right hind foot; then by the right forefoot and left hind foot; then by the two hind feet and right forefoot; and lastly by the 
left forefoot and right hind foot (Fig. 35). When the movement is quickened the horse does not at once change his gait, but extends his strides and makes them more uniform, until further extension becomes difficult, when he will break into a trot.

The trot. - In the common trot the footfalls mark two sharp beats, and the hor'se moves from one pair of diagonally disposed legs to the other pair. In the common and long trot there is a short interval between each step when all four feet are free from the ground. During the short trot; however, one pair of diagonal legs is on the ground all the time. The trot depends simply upon the united action of a foreleg and a diagonal hind leg, hence the weight is borne by the diagonally disposed legs alternately (Fig. 36). The trot is not as fast a gait as some others, but it is one in which the average horse is capable of traveling farther in a day's journey with less fatigue than any other, on account of the diagonal pairs of legs being used as weight bearers and propellers. This diagonal movement makes the gait a rough one for saddle work. If the movement is hurried, the horse extends himself until further extension becomes difficult, when he will break into a gallop or canter.

The canter. - In common usage there are three words describing this gait, according to its speed the canter, the gallop or lope, and the run. When the horse is going fast it is called a rum; when going at a moderate speed it is called a gallop or lope, and 
when he is going slow the gait is called a canter. There are two other terms sometimes used in this connection, the hand-gallop and the three-footed canter. The former comes between the canter and the gallop, but is more nearly like the canter, while the latter is really a canter in front and a rack behind.

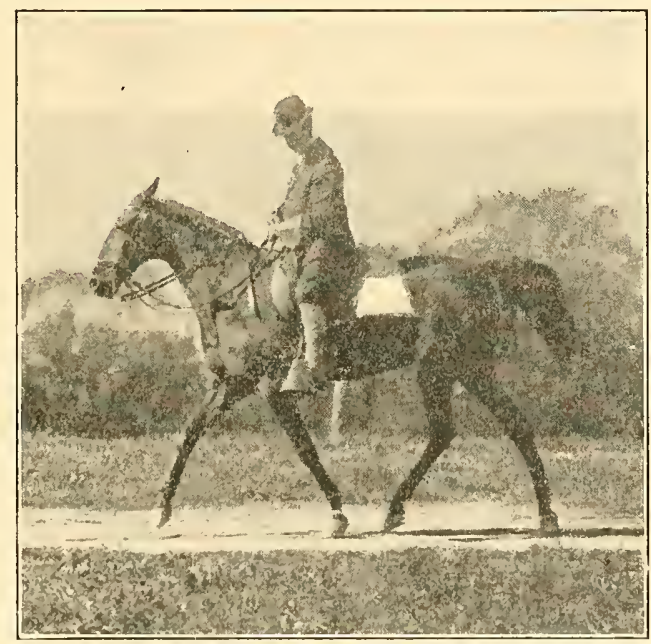

FIG. 36. - The trot.

In other words, it is a mixed gait and is considered undesirable. The gallop and the run are rough to ride, while the hand-canter and the canter are very pleasant.

The true canter is a gait of three beats. If the weight is received upon the left hind foot, it next falls upon the right hind foot and left forefoot, and then 
upon the right forefoot. The horse works on his haunches, with his legs well under him; he bounds up in front gracefully and drops to the ground lightly, sustaining his weight on his hind legs and haunches in such a manner as to prove delightful riding. The slower the gait, so long as performed with animation

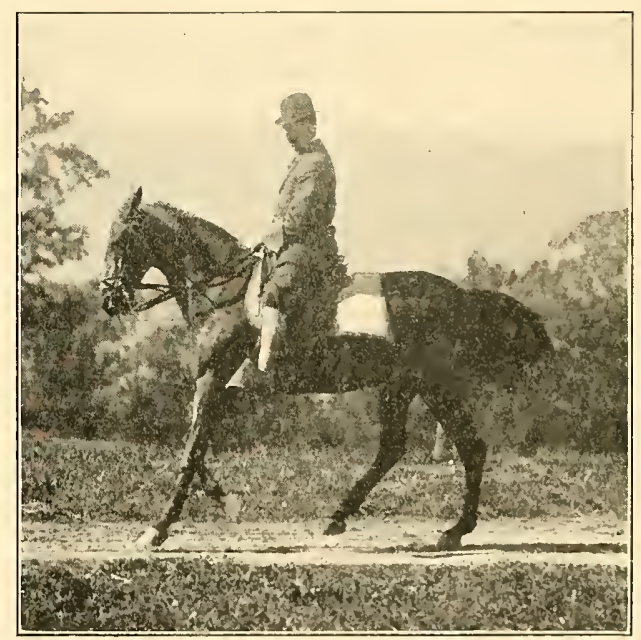

Fig. 37. - The canter.

and exactness, the better, about five miles an hour being the most desirable (Fig. 37).

When the horse goes into the air from his left foreleg, followed by the other legs in the regular order of succession, he is said to be leading with the near or left foreleg and to be galloping left; when he goes into the air from his right foreleg he is said to be 
leading with his off or right foreleg and to be galloping right.

The rack. - Formerly this gait was designated by the term "single foot." It was so named because each foot falls upon the ground separately, thus making it a four-beat gait. The rack and the single-

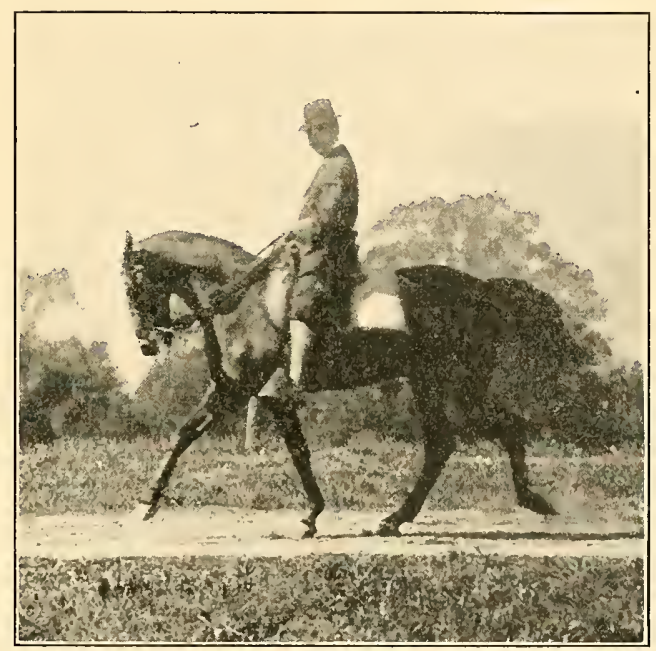

FIG. 38. - The rack.

foot, therefore, are terms designating the same gait. The term "rack" has come into more common use because of action taken by the American Saddle Horse Breeders' Association.

While the true rack is a gait of four beats, it seems to be difficult for some horses to perform, and they amble or pace instead. These gaits, though per- 
formed by the alternate moving of the pair of legs on either side, hence often called "side wheelers," and when true consisting of two beats only, are nevertheless closely associated with the rack; in fact the

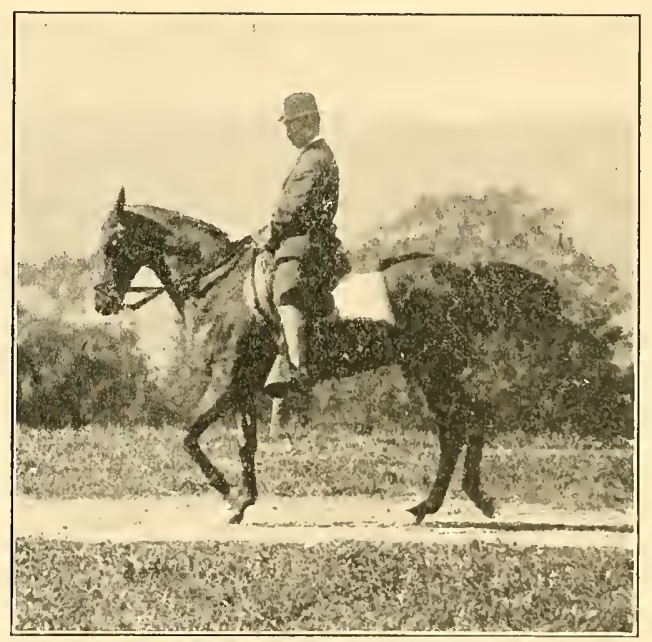

FIG. 39. - The running walk.

rack seems to be a very fast amble, in which the feet follow each other in very rapid succession, thus breaking up the two beat side wheeled motion (Fig. 3S).

The running walk. - The name fittingly describes the gait. It is simply an accelerated walk, the footfalls following each other in rapid succession. It is a four beat gait. The running walk is an easier gait than the walk, and is very much faster, though slower than the rack. It is spoken of as a slow gait (Fig. 39). 
The fox trot. - This gait is simply a slow, rather loosely jointed trot. Some one has fittingly described it as a "dog trot." The action is somewhat similar to the trot described above except that it is much

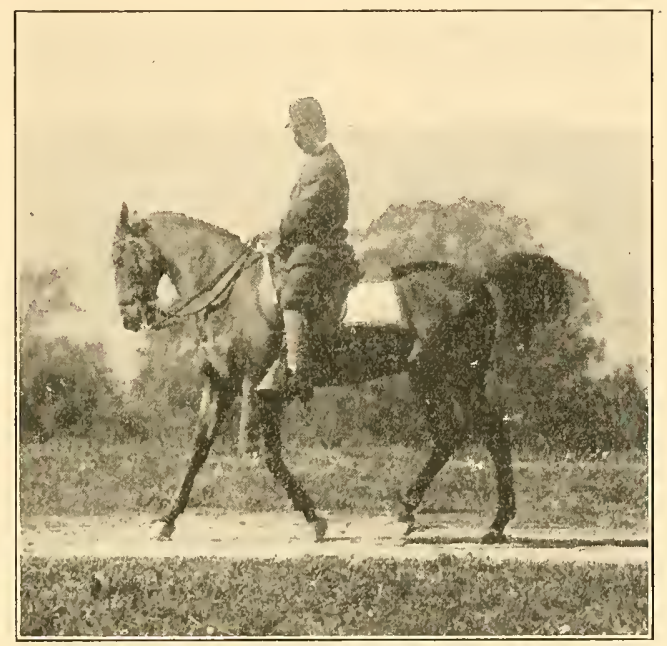

Fig. 40.- Fox-trot.

slower, and the beats are often separated. This is also called a slow gait (Fig. 40).

The slow pace. - While similar to the pace of the harness horse, this gait differs in that both feet on the same side of the body do not strike the ground at the same time. There is just enough break in the impact to introduce a short interval, thus making it a four beat gait similar in this respect to the running walk and fox trot. It is a slow gait. 
The jump. - While not a gait, properly speaking, hunters are required to perform the jump, and it is here described. Most horses take the hurdles at the gallop or rum by shortening the steps and advancing

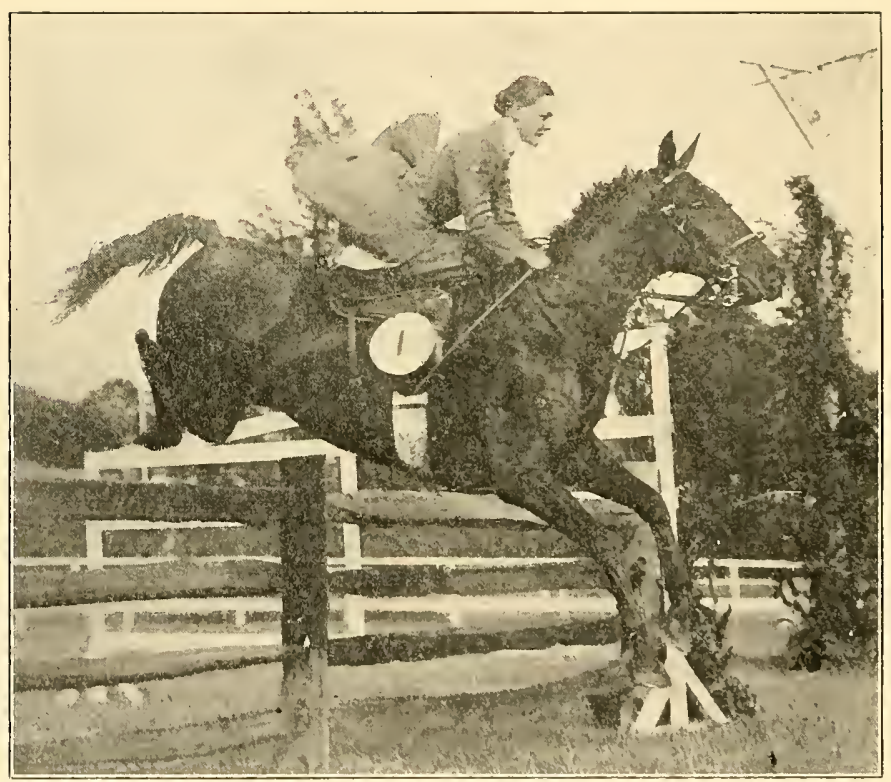

FIG. 41. - The jump.

with both hind feet nearly simultaneously until sufficiently near to take off. They bring the hind feet well under the center of gravity, and instantly the forequarters are raised, and this action is immediately followed by an energetic propulsion of the 
hind legs sufficient to lift the weight and carry the long body of the horse entirely over the hurdles. As soon as the obstacle is passed, the forelegs separate, so as not to make contact with the earth at the same time. Thus the forefeet come in contact with the earth in rapid succession, and they are immediately followed by the hind feet landing separately, in such a manner as to deaden the shock. All the feet are now free to gallop off as before the leap (Fig. 41).

\section{CLASSES OF SADDLE HORSES}

There are three classes of saddle horses: the walking horse; the walk, trot and canter horse; and the five-gaited saddle horse, to which may be added two others, the hunter and the high-school horse. The walking horse is one well trained at the running walk gait. This is the business horse, and is in demand on ranches, plantations, large farms, and the like. The walk, trot, and canter horse is an animal well trained in the three gaits and is in demand wherever saddle horses are used. The gaited saddle horse is required to go five gaits. He must be able to walk, trot, rack, and canter, and for the fifth gait he may choose any one of the three slow gaits, the running walk, fox trot, or slow pace. This horse is in demand for pleasure and show purposes. The hunter is usually able to go most of the saddle gaits, and in addition is well trained at the jump, while 
the high-school horse, in addition to going all the saddle gaits, is well trained in many fancy steps. From time to time there is still another class of saddle horses for which there is much demand, and is for use in the army. These horses, in addition to doing the ordinary saddle gaits, must be trained to stand gun-fire, and some of them, more particularly the scouting horses, to lie down when commanded.

\section{TRAINING TO THE GAITS}

Now that the horse is thoroughly familiar with the use of the bit, - both snaffle and curb, - with whip and spurs, and with the rider's legs in aiding and controlling the movements, and that we have a clear understanding of the movements of the various gaits, we are prepared to teach the horse how to perform the gaits. Let no one attempt to teach the gaits until all of these requirements, on the part of both rider and horse, have been met, for failure will surely result, since the rider eannot teach that which he does not understand, and the horse cannot learn until means of communication have been established between the rider and his mount.

The walk. - Training to a true or collected walk is a very important part of the saddle horse's education, although it is perhaps the most neglected of all gaits. To train the horse to walk, take the snaffle rein in hand in such a manner as just to feel the ani- 
mal's mouth, and allow the hand to be slightly influenced by the movements of his head. Apply the unspurred heel in such a way as to induce the horse to increase the length of his stride, without breaking into a jog. If he shows any inclination to break, immediately steady him by a slight increase of the pressure on the bit, and by the voice. After a few breaks, the rider can tell when the horse is on the verge of breaking, and should hold himself in readiness to gently prevent him from doing so. It is important to remember, in teaching the horse to walk fast, that he must be allowed the freedom of his head, and that the reins must not be held in a firm hand. If the reins are held firmly, it causes him to shorten his steps and to go into the air instead of moving rapidly forward. As the lesson progresses, the blunt spurs may be applied to stimulate the horse to greater effort.

It is not advisable to continue the walking lesson. After going a couple of miles, carrying the horse well up to his limit at the flat-footed walk, he may be quietly urged into a trot for a quarter of a mile, making him do his best as to style and action all of the way. Steady down to the walk, and continue as before. To prevent the horse from acquiring a slovenly or uneven gait, always make him do his best at each gait. To perfect the horse at the flat-footed walk may require months, but we should keep at the task, always urging him to the mark. 
The trot. - In teaching the horse to trot, take him on the snaffle reins and hold tolerably firm on the bit. Gently urge him into a slow, collected trot, and as he prepares to start begin to post - that is, rise in the saddle. As a rule, the saddle-bred horse will go to trotting the instant you post in the saddle, if urged at the same time. If the horse should make a mistake and start on a "jiggle," bring him to a walk and try again. - As you give him the word this time, reach forward, and with the right hand grasp him by the mane, well up on the neck. It seems instinct for the young horse to trot when you do this. Sometimes if you bear a little weight and rather shove his head down, the green horse will go off on the trot. With a difficult horse some excellent horsemen recommend reaching forward and taking hold of one ear. They state that it is a very rare case where this will not work. After the horse knows what you want him to do, then work back to his neck, and eventually by just touching his neck in front of the saddle he will go on the trot. It should be said, however, that the ear method is condemned by many saddle-horse trainers.

To develop style and action urge the horse forward by such gentle means as a light tapping with the whip ; by the judicious application of the spurs and by the voice; but the rider must not allow the animal to pull on the bit. The head must be retained in the correct position by a gentle see-saw action 
with the reins. In the latter stages of the training, the curb-rein may be brought into play to improve the style and increase the action. Because of the extra exertion, the trotting lesson should always be of short duration, and the horse kept well within his strength.

'The horse should be taught to lead with either foreleg at the discretion of the rider. To teach the animal to lead with the right foreleg, gently pull his head to the right, inclining the body somewhat to the right and at the same time cautiously apply the right spur just behind the girth, as the prick there causes the animal to move his right foreleg. Some horsemen gently strike the right elbow with the toe of their boot, and at the same time tap the horse as far back on the left quarter as possible with the whip. This causes the horse to bring the left hind leg forward, and as the right front leg moves in unison the desired action is obtained. To teach the horse to lead with the left front leg, just reverse the procedure. This training should be given in the paddock, and should be repeated until the rider can control the leading leg at a given signal.

The canter. - With the horse at the walk, take him on the curb-rein, pull him together until his legs are under him, lean slightly to the front and urge him forward by the gentle application of the spurs, restraining him at the same time with the curb- 
bit. As the horse starts, salute him with the right hand; if he fails to notice this, snap the fingers to attract his attention. This is the signal to be used in later life when you wish him to canter. After cantering a quarter mile steady him down to the walk, and then repeat until the horse understands what he is expected to do.

Speed is not sought at the canter, simply stylish and comfortable action. This must be attained by inducing the horse to bring his hind legs well under the body, and at the same time by keeping his head in the proper position by slight pressure on the curb-bit.

Teach the horse to lead with either foreleg as suggested in training to trot. To facilitate this, when teaching to lead with the right foreleg circle to the right, and when teaching to lead with the left foreleg circle to the left. Teach him to lead with alternate legs by riding him in the outline of the figure 8 . First use a large figure, but gradually decrease it until it is as small as possible. The horse will thus learn to change his leading leg in accordance with the direction in which he is required to circle.

The running walk. - With the horse at the' walk, take him lightly on the curb reins, urge him just out of the walk by a gentle touch of the spurs and as he starts reach over and touch him on the withers. As he breaks from the walk hold him steady and do not allow him to go into a trot or rack, or to fall back into a walk. This is a very delightful gait 
to ride and one in which the horse keeps time to his steps by the nodding of his head, hence the term "nodder" which is sometimes applied to horses of this class.

Fox trot. - With the horse at the walk, take him on the snaffle rein and urge him into a slow "dog trot" or "shog." As with the running walk, do not let him forge ahead into a trot or rack or slow down to a walk, but when he strikes the desired gait hold him steady. After going a short distance slow down and then repeat. Next practice urging the horse, alternately, from the walk to the running walk and from the walk to the fox trot. Repeat until the horse will obey the signals without the slightest confusion. This may take months, but it is essential to a well-trained saddle horse.

The slow pace. - This gait is taught in much the same manner as the fox trot, some horses taking naturally to one, some to the other, depending on whether they have a natural inclination to trot or pace. Take the horse mildly on the curb-rein and urge him just out of the walk by pressure on the legs and a slight side to side shuffle of the reins just sufficient to work on the bit. When the horse takes the gait hold him steady. Slow down to a walk and then repeat. Later alternate with the running walk and fox trot.

The rack. - In teaching this gait, choose a road with rather hard, smooth surface. The rack is a rather 
difficult gait on the horse. If the road is soit, he fatigues rapidly, while if rough the gait is difficult to perform. With the horse at one of the slow gaits, preferably the slow pace, take him on the curb-rein and urge him forward by gripping the knees so that he will feel the clasp, and give him the spurs. A horse is taught to rack by spurring him forward and curbing him back. Should he start to trot, sometimes a side to side shake of the reins just sufficient to work on the bit will encourage the green horse to start off on a rack. Sit firm in the saddle and urge the horse up against the curb. Do not allow him to slow down into a pace; if he falters, touch him with the spurs and lift him gently on the bit to steady him. After racking a short distance steady down to the walk and repeat. Continue the process until he will rack the moment you draw up on the curb and apply the pressure with the knees. Each of the saddle gaits should now be repeated until the horse will take any one at the given signal. This may require much time and patient effort, but such is essential to the saddle horse's education.

The jump. - Some horses are born jumpers and require practically no training, but jump efficiently at the first attempt, while others appear to have no idea of jumping whatever. While opinion is divided as to the proper age to begin training the hunter, many excellent horsemen think the jumping exercise cannot begin too early if properly conducted. 
This training may well begin during colthood while he is running with the dam by arranging a couple of fences, such as the dam can easily step over, say eighteen inches or two feet high, and so situated that both mare and foal must pass over them when leaving the stable and when returning. To avoid acciclent these fences should be made of movable boards placed one upon the other, thus avoiding cracks, and the top should be padded with burlap. As soon as the foal learns to jump easily, the boards may be removed for a month and later replaced.

Exercise of a similar nature should be provided from time to time, gradually increasing the height of the hurdles up to say three feet by the time the horse is three years old. It is not considered safe to go beyond this height, as it is very easy to sprain the young horse or to cause the development of bony growths such as curbs, splints and the like.

At three years of age, the hunter may be trained to the uses of the bit much as suggested for the saddle horse (p. 150). Now with the long lines drive the horse about an inclosure similar to the small track described for the trotter (p. 111), but provided with high, well-padded fences on either side, and with two hurdles on one stretch and one on the other. For the first two rounds place the bars on the ground and if the horse has been trained as suggested, he will jump them. This serves to fix the idea as to what he is supposed to do. When the 
horse goes steadily around at the canter, arrange the hurdles about one foot high, then lead him toward one of them and when near quietly encourage him to jump. If he refuses, lead him back and punish him as he moves away from the hurdles, then turn and try again, never punishing as he approaches the object, as this distracts his attention and he will refuse again. When he jumps, caress him.

During the second lesson approach the hurdles from the opposite direction, and alternate from day to day. Do not hurry the horse, and do not run risks by asking him to jump when the earth is wet and slippery, or when there is the slightest danger. Continue this exercise until the horse is four years old, when he may be mounted and ridden about the farm. At first, to inspire confidence, have him jump easy objects. If you do not overdo the work, he will soon acquire courage and carry you wherever you may wish to go.

Training to stand. - The saddle horse should be taught to stand whenever the reins are thrown over his head. This is done by fastening a bag to the reins in such a way that when the horse steps forward he steps on the bag, and gives himself a jerk at the bit. Very soon he learns that when the reins are over his head and the bag on the ground, he is to stand. After a while the bag may be removed, and the horse will stand simply by throwing the reins over his head and on the ground. 
If he should acquire the habit of stepping forward, attach the bag for a time.

\section{TRAINING HORSES FOR THE ARMY}

In preparing horses for use in the army, whether for cavalry, scouting or artillery work, one of the first lessons should be to train the animal to stand gun-fire. Some horses are so nervous that they seem unable to become reconciled to such noise, and if the animal is of this class, it is of advantage to know it at once, since further training is useless.

There are two methods of training horses to stand gun-fire, the Rarey and the Galvayne. In the Rarey method (p. 212) the horse is laid on the ground while firecrackers are shot off over his body, first at some distance, but gradually approaching. After he becomes reconciled to the noise, he is let up and the use of the crackers continued; then a revolver is used, and lastly the gun. If at any time the horse becomes unsteady, he is laid down again and the entire process repeated until he becomes so familiar with the gun that he will stand while it is being fired from his back. In the Galvayne method (p. 219) the head and tail are tied together so that the horse goes round and round until the excitement passes away. Only a few crackers are used at first, and as soon as the horse becomes familiar with the noise his head is freed, and the noise continued as 
in the Rarey method. If at any time the horse becomes unsteady, his head and tail are tied together again and a new start is made. This is continued until he becomes perfectly familiar with the firing of guns.

The cavalry horse. - The work of the army is often carried out under rough conditions, and it is important that the cavalry horse be trained at the jump as well as at the walk, trot and canter. He should be so thoroughly educated that the rider can control the horse's movements by the legs and voice in case both hands should be engaged in operating the guns. As soon as the horse will perform the movements alone, he should be placed in the ranks and taught to act in unison with the other mounts.

The scouting horse. - In addition to the training suggested for the cavalry horse, the scout's mount should be taught to lie down at the command of the rider and permit him to fire over his reclining body. Some horses are very easily taught to lie down. This is accomplished by the Rarey method (p. 212), or by some modification of it. The horse is laid down gently as described, and while down is caressed. Then he is let up and the process repeated; this time he is commanded to "lie down" or tapped on the back of the front legs with the whip, and an instant later his feet are drawn up by the ropes and he goes down again. Caress him as before. The process is repeated until the horse will 
lie down when commanded to do so. This may require tact and patience. If the horse seems rather obstinate, give him a few hard falls, but caress him when down.

Picketing. - There are two methods of picketing army horses, one by the low rope, lying on the ground and secured by pegs, the other by the high rope. In the former method the animals are secured to the ground-rope by one or both heels, preferably both, while in the latter method the rope is arranged taut, nearly breast high, and does away with the necessity for heel-ropes, which have a tendency to chafe the pasterns, even though soft, pliable hobbles are used. The heels, in consequence, become sore, and when on the march it is very difficult to keep the abrasions clean so as to give them an opportunity to heal (p. 375). Both methods are extensively used.

TRAINING SADDLE HORSES FOR SPECIAL IVORK

Polo game. - In the making of a polo pony it is very important that he possess a good temper and be well trained in the uses of the bit, and to the walk, trot and canter. He should be taught these gaits as thoroughly as the cavalry horse, for the rider's hands are constantly engaged in manipulating the polo stick. It is essential that the polo pony be taught to lead (p. 171) with either foreleg at a given sig- 
nal from the rider, and it is even more important that he be taught to stop instantly, no matter how fast the gait. As we have seen, much exercise in the outline of the figure 8 is beneficial in teaching the horse to lead with either foreleg. The pony must stop with his head up rather than down, and to do this properly he should be taught to stop from his hind legs. When the stopping is done with the shoulders, the head is likely to be lowered, which is objectionable.

The next step is to familiarize the pony with the polo stick. This can be facilitated by some such methods as suggested in poling (p. 69). When the pony shows no fear, the rider may take the stick in hand and with the animal at the walk, slowly, go through much the same motions as in playing the game. Gradually increase the movements of the stick, first in one hand and then in the other. Much care should be exercised never to hit the pony with the stick during this familiarizing work.

When the pony is sufficiently familiar with the stick to permit all the strokes at the walk, continue the practice at the trot, and lastly at the canter. Next take a soft india rubber ball and gently knock about until the pony is used to it. If perchance such a ball should strike the animal it will not injure or frighten him. In training the pony to follow the ball it is best to have several balls, and when the rider misses one he may take another. It discour- 
ages the pony to be constantly returning after missed balls.

Now that the pony will follow the ball, you are ready to teach him to mix with other polo ponies. To do this use a pony that knows the game and begin at the walk. The green pony is ridden alongside the trained pony, with the head turned away so that the shoulder will be turned in toward him. The green pony should be encouraged to brush up against the other by pressure from the rider's outside leg (p. 157). This training must be continued on both sides. When the pony understands it at the walk, it must be repeated at the trot and at the canter. Next procure two well-trained ponies and accustom the green pony to being squeezed and bumped, at first gently, but increasing the roughness from day to day. The green pony should be made familiar with all of the movements likely to be met before he enters the practice game.

High-school gaits. - The high-school horse is required to do a great variety of fancy movements, such as the Spanish walk, the Spanish trot and similar gaits. To illustrate the method of teaching such movements, we will consider the Spanish walk. This walk is characterized by the peculiar manner in which the forelegs are extended during the step. The foreleg is raised without bending the knee and extended straight out in front of the body as nearly parallel with the ground as possible, and held there 
for a brief moment until the body is brought forward, when it is lowered without bending the knee. Then the other foreleg is raised similarly.

In teaching the Spanish walk, the first lesson is to train the horse to extend his foreleg to the front. To do this place the animal with his right side toward a wall, then standing in front and facing him, grasp the reins under the chin with the left hand, slightly raise the head and turn it toward the right side so as to relieve the weight on the left foreleg. Tap the horse gently on the cannon or forearm of the left foreleg to induce him to raise it and extend it to the front. Caress him for doing as you wish. Encourage him to extend it as far as possible. When he understands that tapping the left foreleg means to extend it to the front, in a similar way teach him to extend the right foreleg.

Having taught the horse to extend either foreleg at the tap of the whip, let us try the Spanish walk. Take your position in front as before and have him extend the left foreleg, bring him forward by the reins so that he will take a step. While he is doing this you must prevent him from bending the leg at the knee by applying the whip. Reward him for obeying and repeat the process with the other front leg. By diminishing the interval between the steps and by inducing him to raise his forelegs higher we arrive at the Spanish walk. It will take much practice standing in front and aiding the horse by alter- 
nately moving the head from right to left, and occasionally tapping the legs to encourage extension, in order to bring out this walk. Later you may mount the horse and by aiding with rein and whip perfect the gait.

The Spanish trot is similar to the Spanish walk except that the movements are quickened and when the gait is perfected, there is a brief moment between each step when all four feet are off the ground, which gives the horse a very spectacular appearance. Similar methods are employed in teaching each of the high-school movements and gaits.

Circus tricks. - Teaching a horse circus tricks is not a difficult task. The most essential things are tact, patience and self-control on the part of the horseman. The teaching of tricks is merely the forming of what may be called unusual habits, and establishing signals to excite the horse to execute them. The circus horse is required to do a great variety of these tricks, and to illustrate the method of training we will take a case, as teaching the horse to bow and shake his head, or to say "yes" and "no," as the circus man puts it.

In teaching the horse to bow or say "yes," stand a little to one side and in front of him, and with a pin prick him slightly on the breast. The horse will think the slight pain was caused by a fly and will put his head down to frighten it away. When he makes the move toward his breast with his head, caress 
him. Repeat and caress, giving the command "bow" or "yes" just as you prick him. Soon he will go through the motion at the command alone, in anticipation of the caress. To teach the horse to shake his head or say "no," stand on the left side and with a pin prick him lightly on the crest above the shoulder. As before he will think this a fly, and shake his head to remove it. The moment he shakes his head caress him. Repeat and caress, giving the command "no" just as you prick him. Soon he will shake his head at the command as before, in anticipation of the caress.

To illustrate another method, let us consider the case of teaching the horse to stand erect on his hind legs. To teach this trick, the surcingle and back band, a common bridle, and the pulley bridle (p. 193) should be used. Place the pulley bridle under the common bridle, and rein the horse up as high as convenient. Take a position in front of the animal, hold the pulley bridle lead rope in the left hand and the whip in the right. Gently jerk with the lead rope and flick the whip in front of the horse. Repeat until he makes an effort to raise his front feet from the ground and then caress him. If he refuses to rise, rein his head a little higher and continue as before. As this trick is very hard on the muscles of the animal's back, it should not be continued for too long a time. With a little patient effort the animal can be taught to stand erect at the command "up." 
Training Saddle Horses for Special Work 185

If he is a teachable one, he can be encouraged to step forward at the command "come here" or "get up." Should he attempt to drop on his front feet before commanded to do so, touch him gently under the chin with the whip. Not all horses can be taught this trick as the muscles of the back are too weak to permit the animals to stand erect. 


\section{CHAPTER VI}

\section{TRAINING WILD AND SUBDUING VICIOUS HORSES}

THe training of stubborn, refractory and wild horses, or the subduing of vicious horses often calls for more strenuous methods than have hitherto been suggested. Before deciding upon the method to be employed, one should make a careful study of the horse to determine, if possible, the cause of his obstinacy. One source of indifference is improper training while young. The colt has probably had his nerves deadened by severe bits or some similar treatment. Accidents are a second source of indifference. The horse may have been well trained and under excellent control, but in an accident may have become frightened and perhaps injured, thus leaving a bad impression upon his mind, and under similar circumstances he becomes unmanageable. In such cases, absolute subjection by either the Rarey or Galvayne method will serve to bring the horse back under control, as he learns that man is his superior, and that if he does as commanded no injury is to come to him. 
TEMPERAMENT IN THE HORSE

Perhaps the greater number of wild, refractory and vicious horses owe their faults to inequalities of temper. It is therefore of much importance that the temperaments be studied carefully. Horses may be divided into four general classes according to their temper: teachable, nervous, stubborn and treacherous. The horse with a teachable temper is kind and docile. He is easily taught and readily adapts himself to various conditions. $\mathrm{He}$ is very seldom frightened, excited or provoked to bad habits. The horse with a nervous temperament is ambitious and determined. He is quick to learn and acts with all his power. If he is properly directed he rapidly develops into the best type of horse. On the other hand, if he is improperly directed, he is quickly spoiled. He is easily frightened and has a natural tendency to develop such habits as shying, running away and the like. He seldom balks, and when he struggles he does so with all his power. 'Though this class resists hard, it is easily conquered, after which it will do anything that it understands.

The horse with a stubborn temperament is willful and difficult to conquer. He calls for patient effort and tact on the part of the horseman, as the horse of this class is persistent and does not give up. The horse with such a temper often becomes sullen, his senses seem to have become blunted and he 
apparently has no feeling. When he is excited the most severe punishment may be administered and he will not move in the least. If he does not respond to the first few strokes of the whip, it is useless to punish him further. He must be put through the Rarey or Galvayne course of subjection.

The horse with a treacherous temper is very resentful. He acts without apparent cause and when least expected. He may balk, fight, kick, strike, bite, bolt or run away. Often he seems to be conquered and works freely, when of a sudden all his former viciousness returns. The other classes, when once conquered, remain obedient, but not so with the treacherous horse. While some horses of this class become fairly trustworthy after long usage, they seldom develop into steady work horses. In fact, one must be prepared to repeat the subjugation course at any time.

\section{TRAINING AND SUBDUING APPLIANCES}

In echeating wild, stubborn and vicious horses, it is often necessary to have at hand a variety of training appliances. To save space later on when describing methods, we will consider the appliances first. Several kinds of halters, bridles, twitches, as well as many kicking, hobbling and throwing rigs, are described, as it may be necessary to try more than one hitch in order to bring about the desired results. 
Rope halter. - The simplest way to make a rope halter is from a soft rope about half an inch in diameter and about fifteen feet long. Double the rope at one end for about four feet, and tie a knot in the doubled part so as to form a large stationary loop about three and one half feet long. In this large loop make a small one for the lead rope to pass through. The second knot should be so tied as to leave one third of the large loop on one side and two thirds on the other, the short part to form the noseband, the long part the headpiece. Now place the free end of the rope through the small loop and the halter is ready for use (Fig. 42). A knot may be made in the lead rope under the chin to prevent the halter from squeezing the jaws together, otherwise the halter will draw tightly around the jaws.

Yankee bridle. - To make this bridle, choose a soft rope three eighths of an inch in diameter and about twenty feet long. Tie one end of the rope around the horse's neck, close to the head, in such a way that the loop thus formed will not rum. Pass the free end through the horse's mouth from the right side and up through the loop on the left side, and the bridle is completed (Fig. 43). The principle upon which this bridle acts seems to be that the horse obtains relief from the painful pressure of the rough rope on the corners of the mouth the instant he approaches the man who is pulling, and consequently follows to avoid the pain. 
190 Training Wild and Subduing Vicious Horses

Yankee bridle modified. - With the right hand take hold of the lead rope near the horse's left jaw, with the left hand pass the free end of the rope over the head just back of the ears, down the right side,

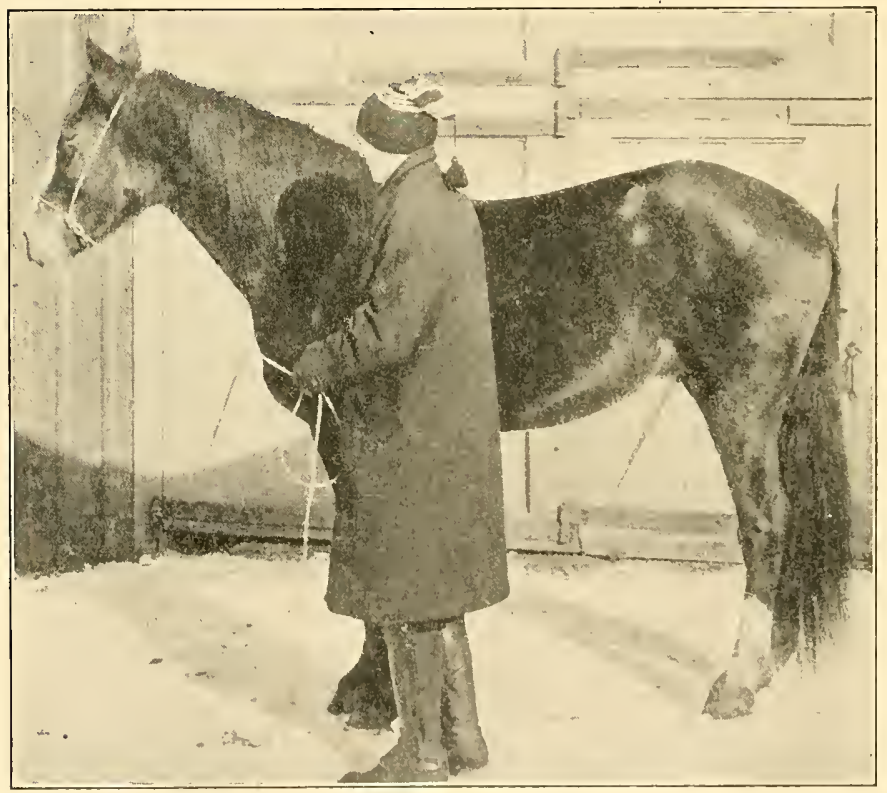

FIG. 42.- Rope halter.

through the mouth again and then up the left side and through the portion of the rope held in the right hand, and you have the bridle completed (Fig. 44). To increase the severity of this bridle, instead of placing the latter rope in the mouth as a bit, place 
it just under the upper lip and on top of the teeth, then draw tight. You now have one rope in the horse's mouth as an ordinary bit, and a second under the upper lip as a twitch, which forms a very efficient bridle for controlling refractory horses.

War bridle. - To make this bridle, choose a rope similar to the one described in making the Yankee bridle (p. 189), tie a small loop in one end just large enough to go in the horse's mouth and around the lower jaw. Now place this in the animal's mouth as described, with the knot and free end on the right side, bring the

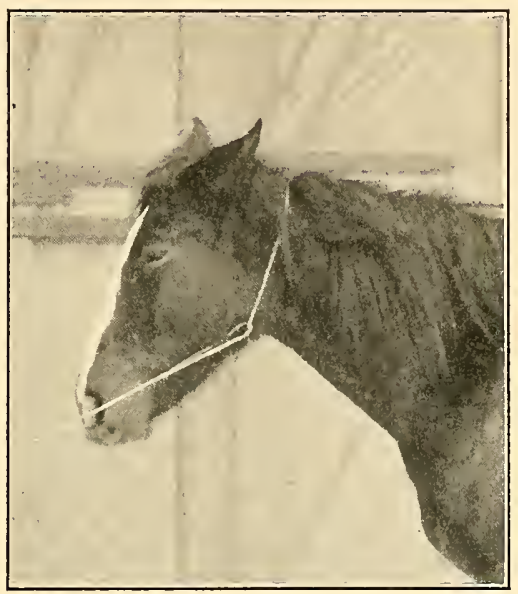

FIG. 43. - Yankee bridle.

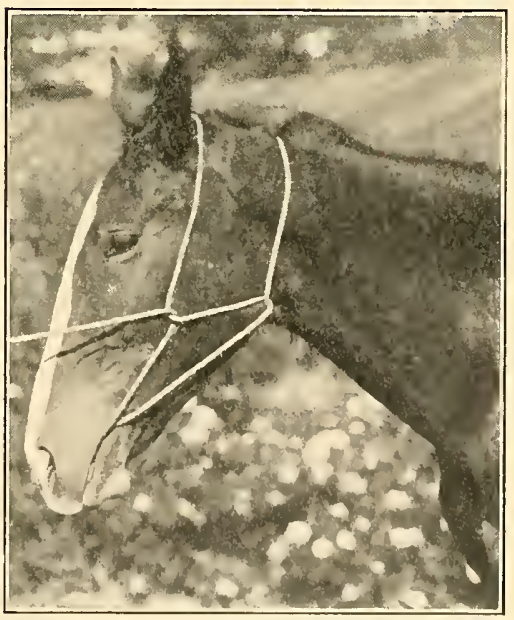

FIG. 44. - Yankee bridle modified. 
192 Training Wild and Subduing Vicious Horses

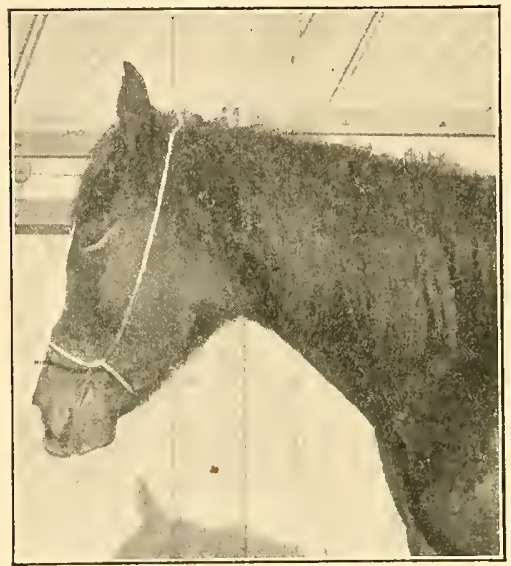

FIG. 45. - War bridle.

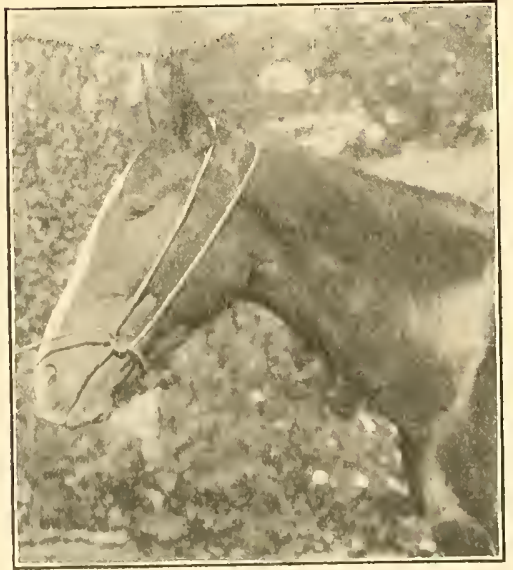

FIG. 46. - W ar bridle modified. free end up over the head, down the right side and through the loop at the mouth, thus completing the bridle (Fig. 45). In Europe this bridle is often referred to as the Comanche bridle.

War bridle modified. - Pass the free end of the rope over the horse's head, just back of the ears, down the right side, through the mouth, and then through the part which passes over the head and the briclle is completed (Fig. 46). The severity of this bridle may be increased as suggested in the Yankee bridle modified, by passing the latter rope just under the upper lip, thus forming a twitch. 
Many horsemen prefer this to the Yankee bridle because it is more convenient in arranging and removing.

Excelsior bridle. This bridle is made in exactly the same way as the war bridle modified, except that the first rope, instead of being placed over the head immediately back of the ears, is arranged well down on the neck, almost halfway to the withers (Fig. 47). This bridle is very effective in causing a horse to lower his head in case he insists on holding it up when teaching to take the bit.

Pulley bridle. - In addition to the rope, two rings and a

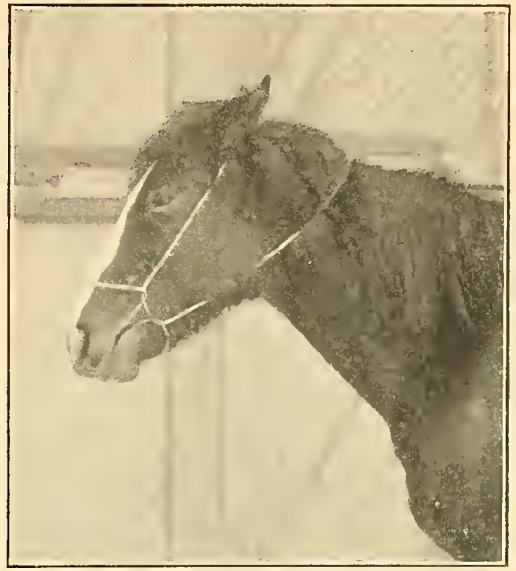

Fig. 47. - Excelsior bridle.

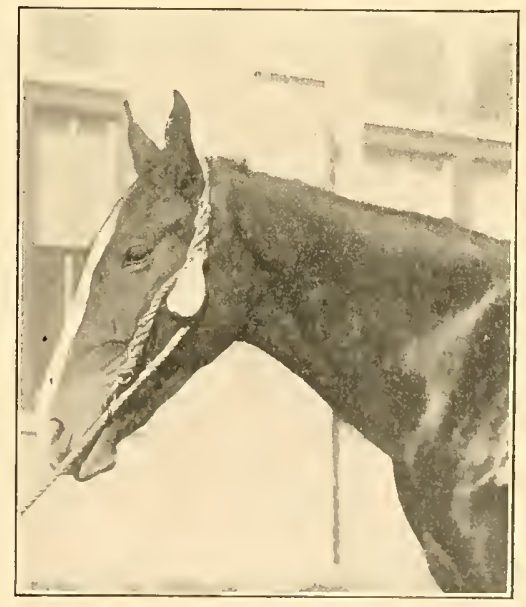

FIG. 45. - Pulley bridle. 


\section{Training Wild and Subduing Vicious Horses}

pulley are needed in making this bridle. Secure a short piece of rope and weave the two rings in so that when completed they will be about six inches apart, and you have a rope bit very similar to a common rubber-covered bit. With another piece

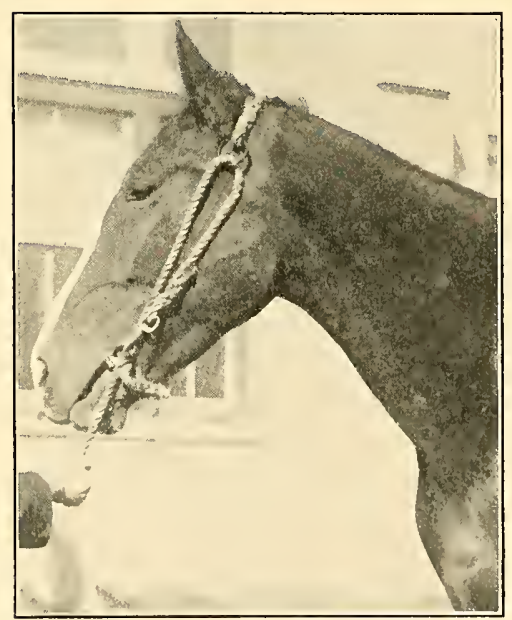

FIG. 49. - Pulley bridle with three rings. of rope, weave one end to one of the rings, and the other end to the eye of the pulley, so that when completed it will be about eighteen inches from ring to pulley. Perhaps this should be measured on the animal's head, as the pulley should be about even with the left eye when the bridle is in position on the head. Now weave one end of the lead rope to the other ring. Place the rope bit in the horse's mouth with the lead lope on the left and the pulley rope on the right side, carry the latter over the head just back of the ears and hold the pulley on the left side of the head while you slip the free end of the lead rope through it; next pass the lead rope down through the ring on the left side and the bridle is complete (Fig. 4S). This makes 
a very efficient bridle for controlling stubborn and refractory horses. Sometimes this bridle is made by using a third ring instead of a pulley (Fig. 49).

Pulley bridle modified. - In making this bridle, neither rings nor pulley are used. Use a rope similar to that suggested in making the Yankee bridle (p. 189), and tie a small loop in one end and insert in the horse's mouth as in the war bridle (p.191). Now carry the free end over the head two inches back of the ears and down the left side just a little below the eye; with the right hand hold the rope here, and with the left

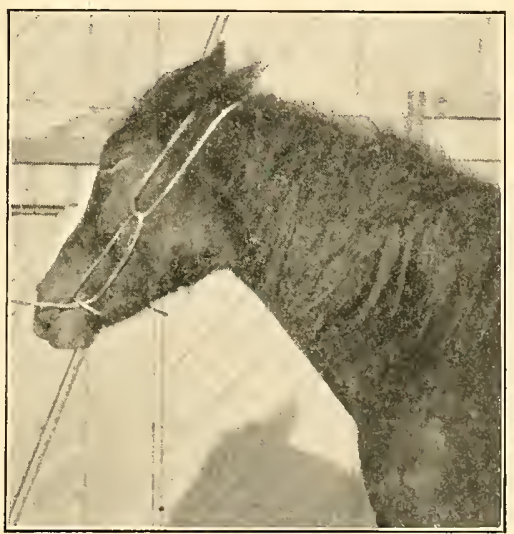

Frg. 50. - Pulley bridle modified. double the free end back over the head again immediately back of the ears, carry the free end down the right side and through the mouth, then up and through the rope you are holding with the right hand, then down through the loop in the mouth, and the bridle is completed (Fig. 50). As with the other modified bridles, the severity of this one can be greatly increased by placing the last rope just under the upper lip, thus making a twitch. 
Hackamore bridle. - To make an Indian Hackamore, take a soft, three-eighths inch rope about twenty feet long, tie a running loop in one end, put it around the horse's neck just back of the ears, pull the loop open, and with the part with which the loop is made

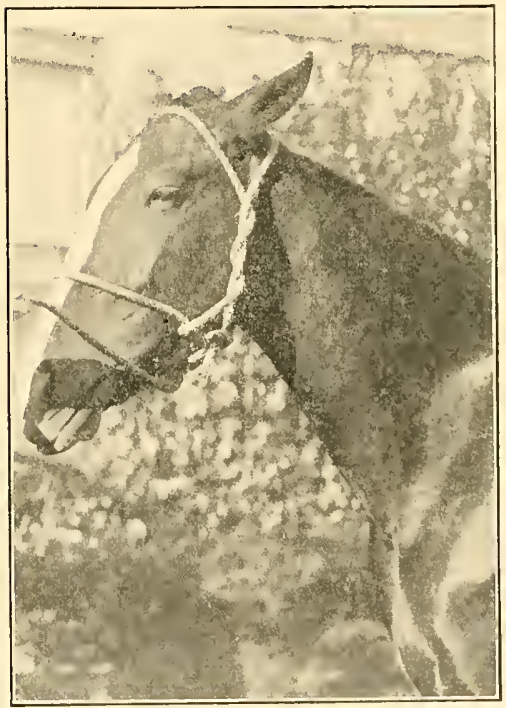

Fic. 51.- Hackamore bridle. take a half-hitch about his nose. Now with the free end make a second halfhitch about the nose. Grasp the middle of the second hitch where it passes over the nose and run it through the first hitch twice, pulling it out far enough to pass over the head. This completes the Hackamore bridle as made by some, while others pass the latter rope twice around the rope already at the top of the head and bring it out around the forehead, making a brow band. This makes a substantial hitch, and is much used by the Indians, Mexicans and plainsmen (Fig. 51).

Cavesson halter. - This consists of a common leather halter with a heary, leather-covered noseband 
made of metal to which the lead rein is attached so as to inflict blows on the nose by light jerking. While this appliance is much used in Europe, especially in the riding-schools, its use is not recommended, as it often renders the horse difficult to handle about the face and head. Better results can be obtained from some form of twitch.

Lip-twitch. - This is made by tying a loop in a small rope, such as sash-cord, through a hole in the end of a stick. The loop should be about nine inches long, while the stick may be from one to five feet long, according to convenience. The loop is slipped over

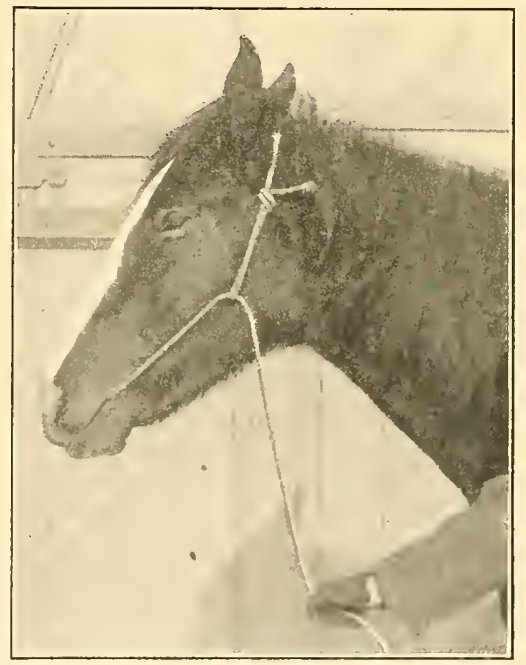

Fig. 52. - Noose-twitch. the upper lip of the horse, and the stick, which forms the handle, twisted until his attention is attracted. As the horse's lip.is very sensitive, the twitch should not be used more frequently nor tighter than is necessary.

Noose-twitch. - To make this twitch, use a small rope, such as sash-cord, and at one end tie a small 
stationary loop. With the right hand hold this loop on the left side of the horse's head, and with the left hand place the free end of the rope over the head just back of the ears, down the right side and in the mouth just under the upper lip and on top of the teeth, and then up through the loop being held in the

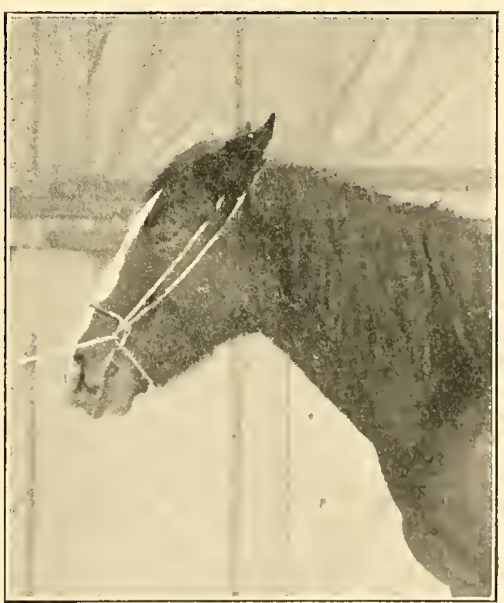

FIG. 53. - Halter-twitch. right hand, and the twitch is completed (Fig. 52).

In case the horse is very wild, it will require some manipulation to get this twitch in place. One can of ten facilitate the work by employing a crooked stick, especially if the horse strikes or bites at the operator.

$$
\text { Halter-twitch. - To }
$$

make this twitch, use

the rope halter described (p. 189), or any common rope halter; with the right hand hold the lead rope close to the halter, and with the left hand pass the free end over the head just back of the ears and down the right side, through the mouth just under the upper lip and then up around the rope in the right hand, and the twitch is complete (Fig. 53). This makes a very 
convenient and efficient appliance for leading and handling a refractory horse.

Headstall-twitch. - This twitch is made from a common leather halter by passing the lead rope through the lower ring of the halter on the left side of the head, then over the top of the head just back of the ears, down the right side and through the mouth under the upper lip and then up through the upper ring on the left side. This makes a very powerful twitch. In case the lead rope is not sufficiently long to go over the head, a fair twitch can be made by placing the lead rope through the lower ring on the

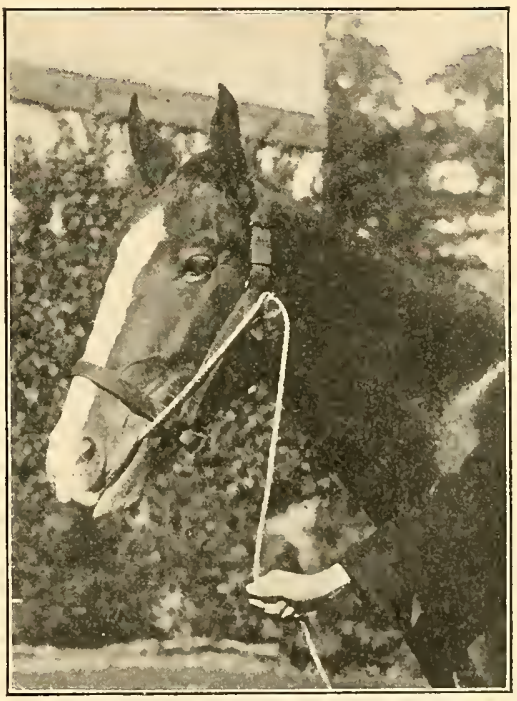

Fig. 54. - Headstall-twitch. right side of the head, then down and through the mouth, under the upper lip, then up through the lower ring on the left side of the head, and the twitch is completed, though this is not so efficient as where the rope passes over the head, and the rope extends to the upper ring of the halter (Fig. 54). 
Bridle-twitch. - In making this twitch, the right snaffle-rein is passed under the upper lip and drawn tightly to the left side. This is often employed in training the horse to stand quietly after he has been bridled, and while you mount.

Rearing-twitch. - This twitch is suggested for the horse that rears in the saddle. Secure a small rope the size of a sash-cord and about ten feet long, tie a knot in it about six inches from one end and draw it tightly, tie another knot about six inches from the first, but leave it open. Pass the knotted end of the rope through the horse's mouth, and bring it around the lower jaw and pass through the open knot, and work it up tightly against the lower jaw. Pass the free end back through the breast-plate, if there is one attached to the saddle, then between the forelegs, through a ring arranged in the middle of the girth, and then up to the right hand, or the end may be secured to the saddle. Now when the horse shows an inclination to rear, immediately pull the cord.

Wooden-gag. - This gag is made from a block of hard wood, five or six inches long, and about two inches square. The colners should be rounded to prevent severe injury. A hole is bored through the center, longways, for a chain which is attached to a headstall. Some persons tack leather guards on each end to prevent the horse from getting the gag out of his mouth. This gag is used to prevent the horse from biting, and for curing him of the habit. 
The guy rope. - This is a lead rope for controlling wild, refractory and vicious horses. To make it, use a soft, three-eighths inch rope about twenty feet long and make a small stationary loop in one end. Place this loop under the left jaw, carrying the free end over the neck from right to left, then down the left side of the head through the loop and to the mouth, then through the mouth, back under the lower jaw, and between the jaw and the rope coming from the neck, thus forming a loop around the neck, and a half-hiteh around the jaw (Fig.

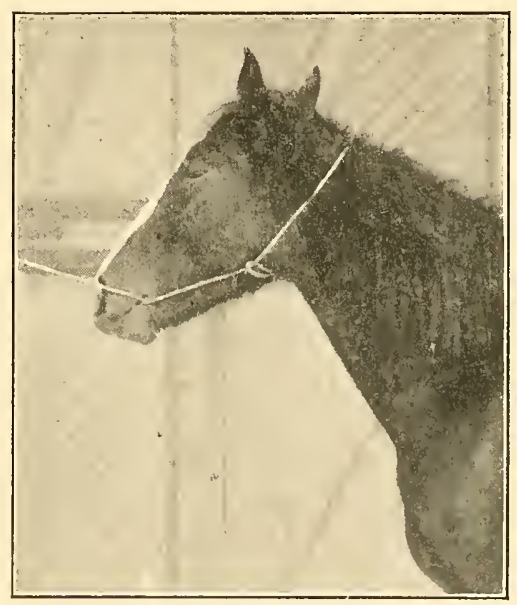

Frg. 55.- Guy rope.

55). This makes a very efficient lead, though it should never be used in prolonged pulls, but in short, quick jerks.

Combination bridle. - To make this, choose a small rope or sash-cord about thirty feet long, put the middle of it in the horse's mouth, pass both ends up toward the forehead, knotting them in front and a little above the eyes (some slip the foretop in this knot before drawing tight), pass both free ends over 
the head between the ears and bring one end down either side just back of the jaws, twist the ropes together, then bring each end forward and around the rope in the mouth, one on either side; next pass the free ends back through the rings in the surcingle, and then carry them on back behind the horse, and you have a very efficient combination bridle and lines for controlling a wild horse (Fig. 56).

Kicking strap. - This is used to prevent the horse from kicking when in the shafts. It is made from leather, which always should be of the very best and should not be less than two inches wide, and of such length as will reach from one shaft over the horse's rump to the other shaft (Fig. 17). When the strap is fixed in its keepers there should be practically no play in the strap between the shafts and the rump of the horse.

Kicking reins. - These reins are useful in controlling the horse that bucks as well as the one that kicks. To make them, secure two small ropes or sash-cords about eighteen feet long. Put an overdraw check on the horse with a ring just back of the ears. Take one of the small ropes, tie one end in the ring on the overcheck just back of the ears, pass the free end down through the ring at the top of the surcingle, then forward and through the ring of the bridle bit, then back through the ring on the side of the surcingle. Put the other rope on the other side in a similar manner. These cords can be used as lines, 


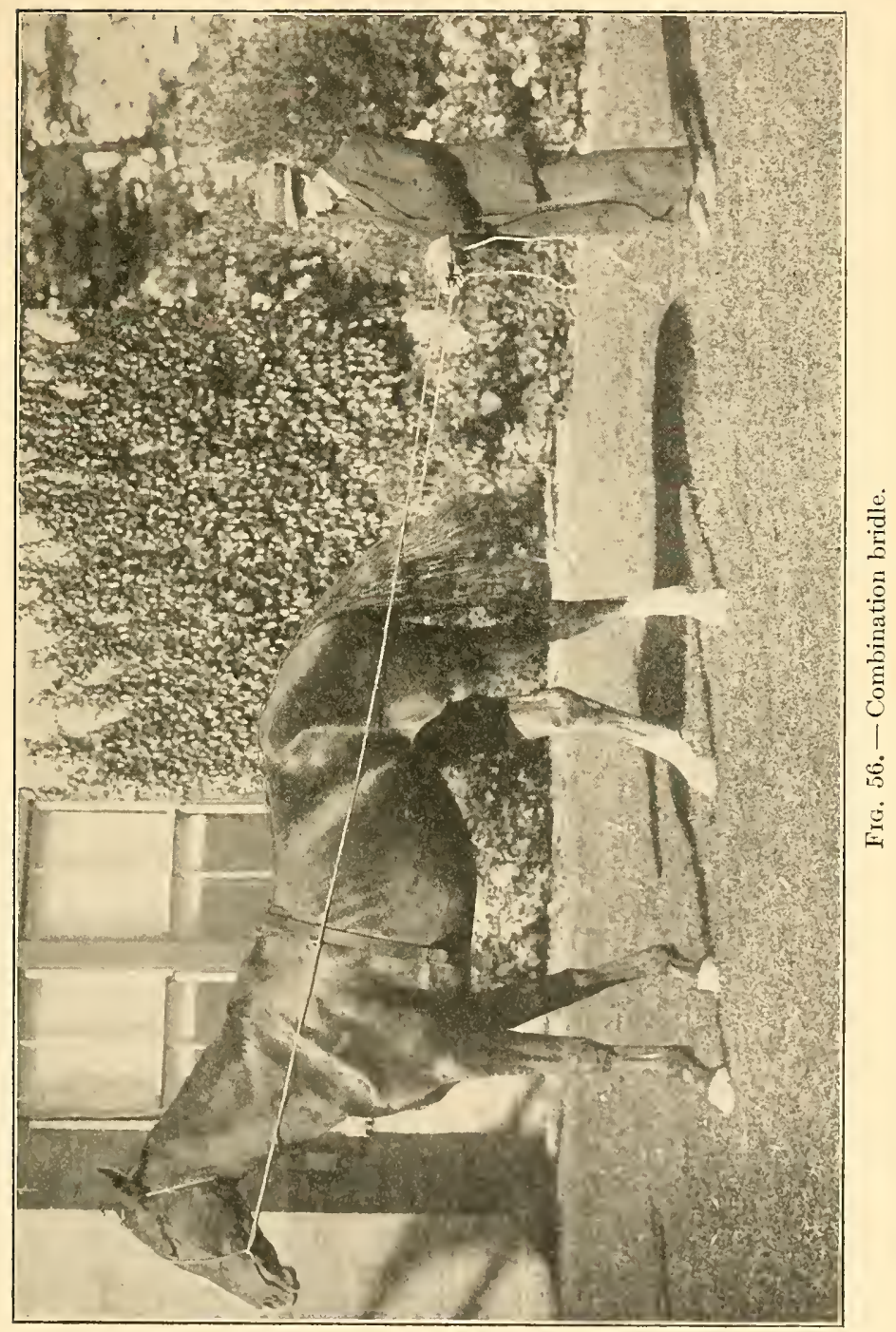


and they are very effective, particularly on the horse that has a tendency to get his head down against his breast, thus making it impossible to control him with ordinary lines. If the animal attempts to buck or kick, pull on the cords, thus raising his head and preventing him from either kicking or bucking, as he cannot do either without lowering his head. As these reins are very severe, they should never be used with more force than is necessary to secure obedience.

Kicking harness. - To make this harness, it is necessary to have a very substantial overdraw check provided with a ring just back of the ears, two pulleys and a small rope. The pulleys should be secured to the shafts, one on either side, about where the kicking strap is fastened. Attach the rope over the rump similar to the kicking strap. Pass the free ends of the rope down through the pulley on either shaft, then up through the terrets at the saddle, and attach to the ring in overdraw check just back of the ears. If the horse attempts to kick in this harness, he jerks his head up, thus preventing him from kicking, as he cannot kick without lowering his head. This is a very effective harness for curing chronic kicker's, as they are punished each time they attempt to kick.

Self-punishing harnesses. - While there are many methods of arranging self-punishing harness, perhaps the following is as simple and efficient as any. 
Choose a sash-cord or soft quarter-inch rope about twelve feet long, a soft three-eighths inch rope about six feet long, a light pulley, four straps one inch wide and about two feet long, and two rings two inches in diameter. Place the long rope through the eye of the pulley and the short rope through the pulley

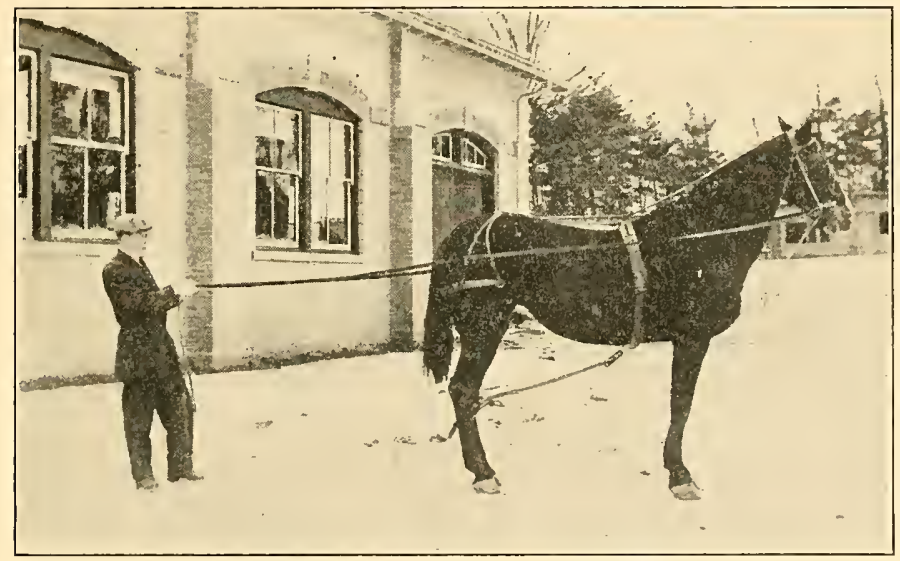

FIG. 57. - Self-punishing harness.

itself. Draw the short rope backward from the front under the girth so the pulley will rest just back of the girth (Fig. 57). Buckle the straps above and below the hocks and through the rings; tie, by half-hitches, the short rope into these rings. Next grasp the ends of the small rope, pass each to the rings of the bridle bit, at either side, passing through the rings from the outside, then pass the small ropes up over the head, 
under the head-stall of the bridle, then down the opposite side and fasten to the bridle rings by a halfhitch, so that the rope can be easily unfastened no matter how tightly it may be drawn. If there is danger that the straps will slip down over the hocks, they should be supported by a light strap placed over the rump and down to the hock on either side.

When this harness is properly made of substantial material, it may be used to correct many bad habits, such as kicking, rearing, bolting, running, and the like. Should a horse kick in such a harness, the rope over the head draws the bit up into the angles of the mouth and holds it there until relieved by the trainer. This should be done gently and with patience. The advantage of such a harness is that the horse deals out his own punishment at the instant he violates his master's will.

Hobbles. - These are used to prevent the horse from kicking. They are often used on a mare at time of service to prevent her from kicking the stallion. To make the hobble, use a soft rope one inch in diameter, and about eighteen feet long, four straps about one and one half inches wide and two feet long, and two rings two inches in diameter. Double the rope at the middle and tie a knot forming a stationary loop about three feet long. Buckle the straps above and below the hocks and through the rings. Now place the large loop over the horse's head and slip it back to the shoulders much as a 
collar, pass the free ends between the forelegs and tie off in the rings at the hocks by half-hitches, thus completing the hobbles (Fig. 58). As buckling the straps about the hock entails much risk, it is a better plan to have the rings sewed to the straps, which

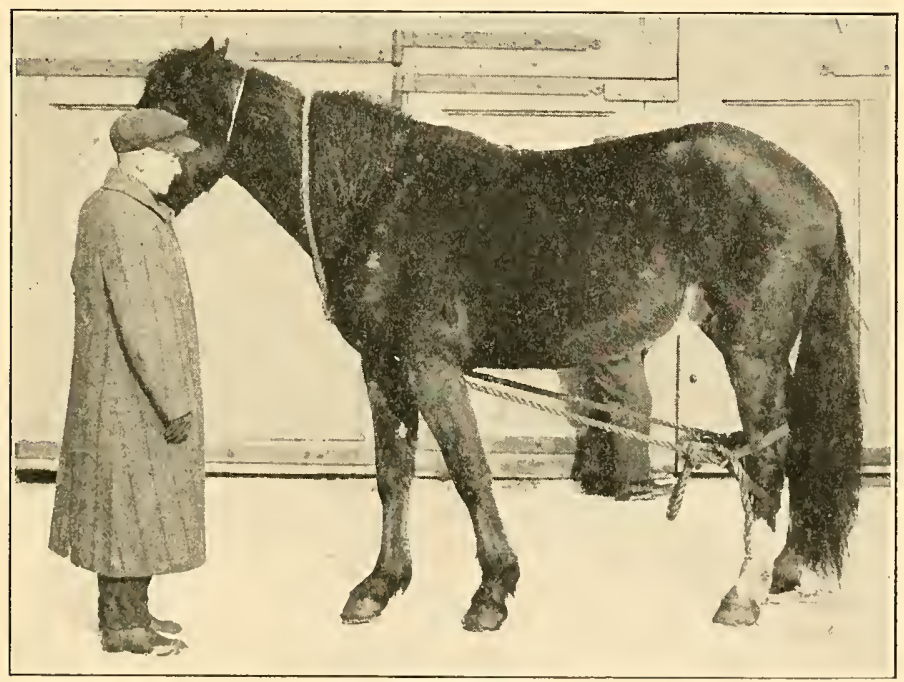

Fig. 58. - Hobbles.

calls for four rings instead of two, the ends of each pair of straps being attached to a ring and the rope passing through both rings on either pair.

Rarey's leg-strap. - This is a strong strap used for fastening up a horse's foreleg. It should be approximately three feet long, two inches wide and at one end of it there should be attached a heavy buckle with a 


\section{Training Wild and Subduing Vicious Horses}

keeper. Now place a free running keeper on the strap and the leg strap is completed. To adjust the strap, pass it around the pastern of the horse and through the running keeper. Then draw the foreleg up until the heel touches the elbow, pass the free end of the strap around the forearm, then

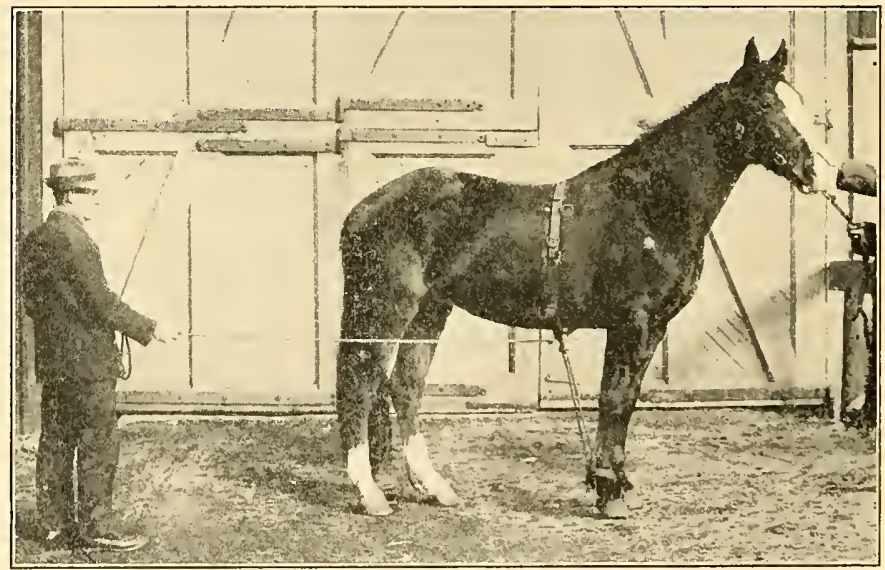

Fig. 59. - Rarey's single safety.

through the buckle, and draw tight. The horse is now unable to get his front foot to the ground and must walk about on three legs. As a cautionary measure it is a good plan to put on a soft knee-pad, otherwise should the horse come down on his knee he may injure it permanently.

Rarey's safety harness. - This harness was devised by Rarey for use in training wild, stubborn and 


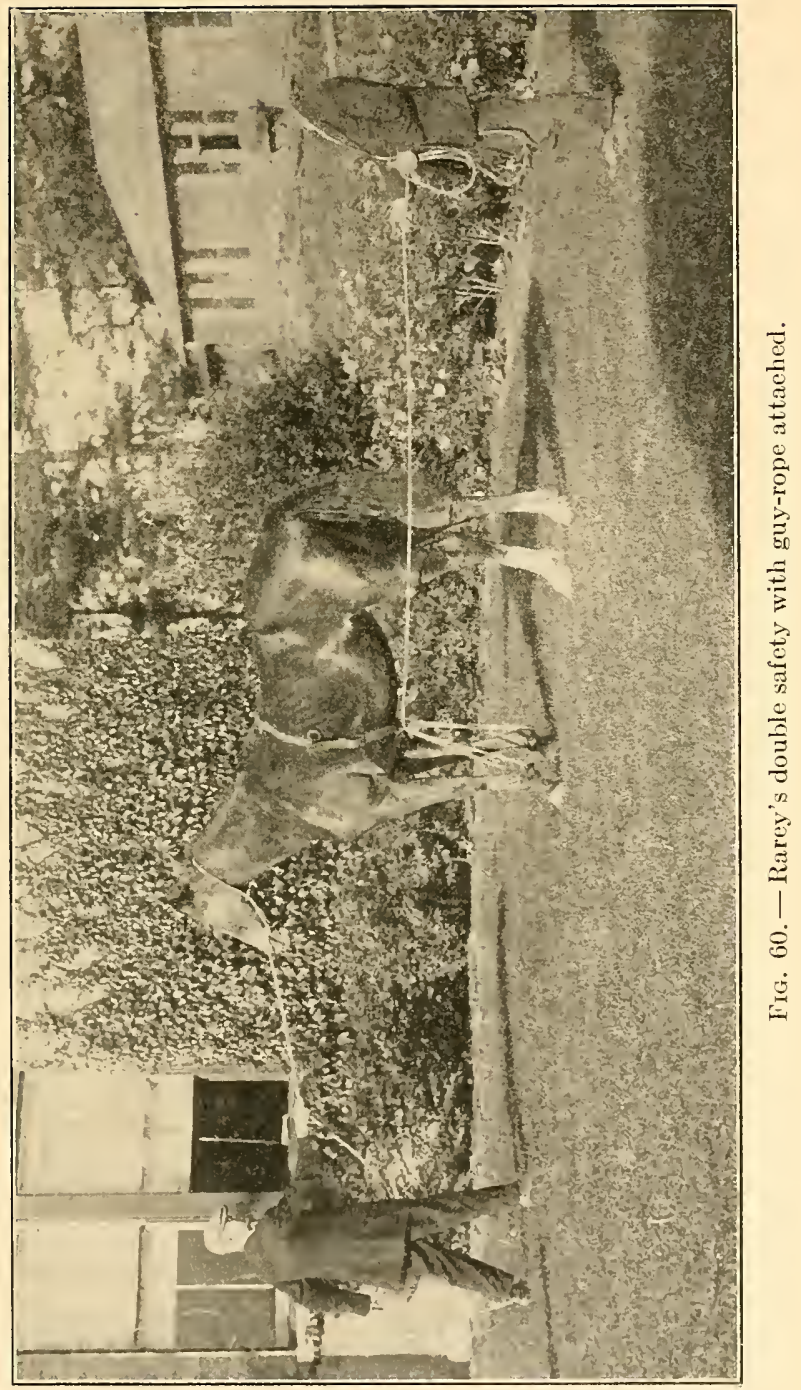


vicious horses. There are two forms, the single and the double safety; in the former one front leg only is under restraint, while in the latter both front legs are under control. This harness consists of two straps about one foot long and fitted with D-shaped rings, a surcingle fitted with two rings on the belly, three on either side and one over the saddle and a long rope

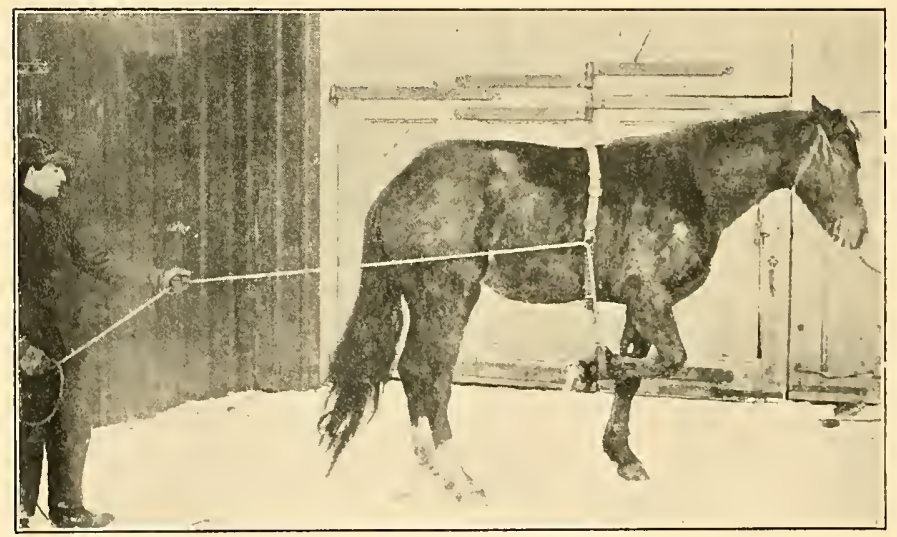

FIG. 61.- Rarey's single safety, restraining one foreleg.

(Figs. 59 and 60). The straps are buckled around the front pasterns and the surcingle around the body. The straps should be padded to protect the pasterns in case the animal struggles, and the knees should also be provided with pads. In arranging the double safety, one end of the rope is passed through the ring at the belly, then down and through the ring at the left pastern, then up to and through the other ring 


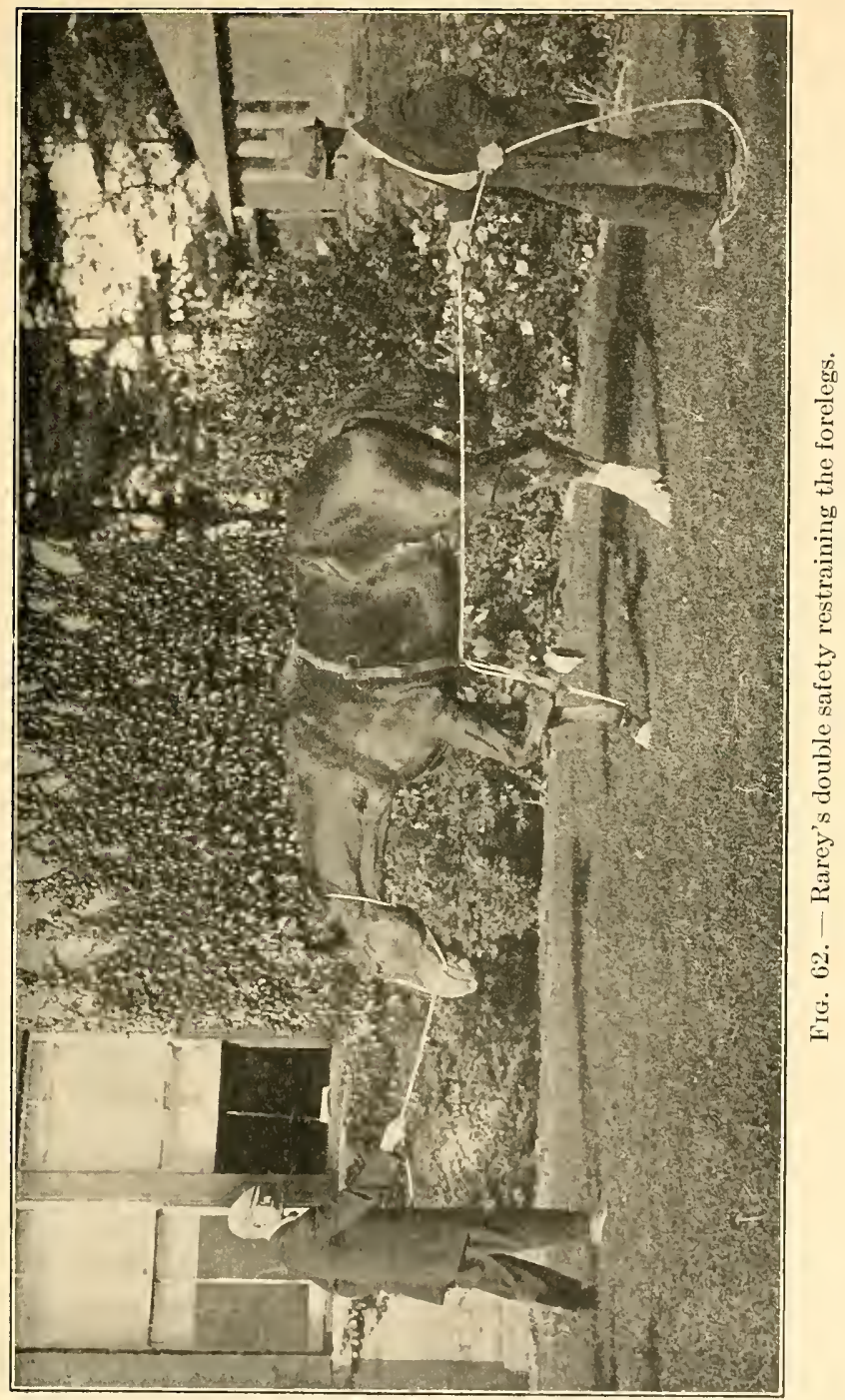


at the belly, then down and through the ring at the right pastern, then up and tied off at one of the rings at the right side. Now by taking hold of the free end of the rope we have the harness as illustrated(Fig. 60).

In case the horse is difficult to manage, put on the guy rope in addition (p. 201). Should he begin to

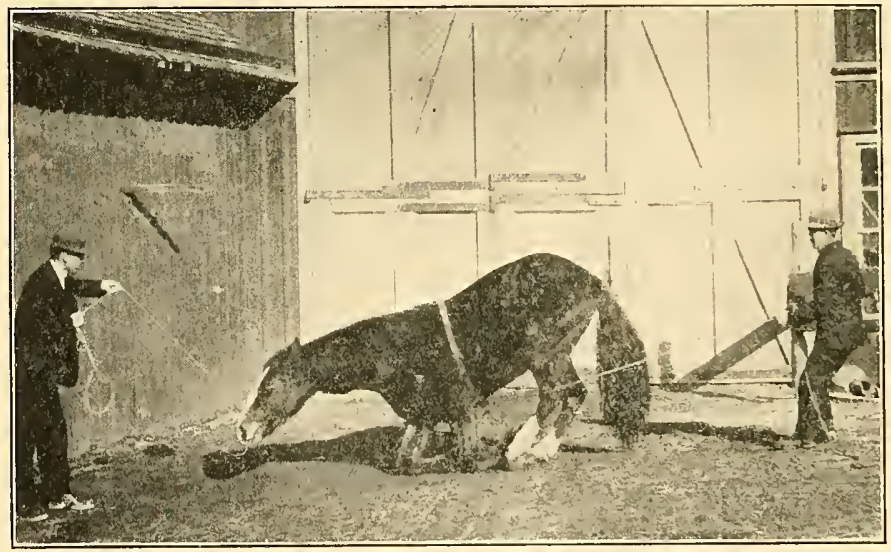

FIG. 63. - Rarey's double safety, horse on knees.

rear, bolt or back, pull on the safety rope and restrain his forelegs (Fig. 62). If he continues to act up, pull his forelegs up by a jerk on the safety rope, and he will come down on his knees (Fig. 63). A few hard falls will usually teach the most incorrigible, as such is a very humiliating position.

Rarey's throwing harness. - In the case of some vicious horses it is necessary to lay them on the 


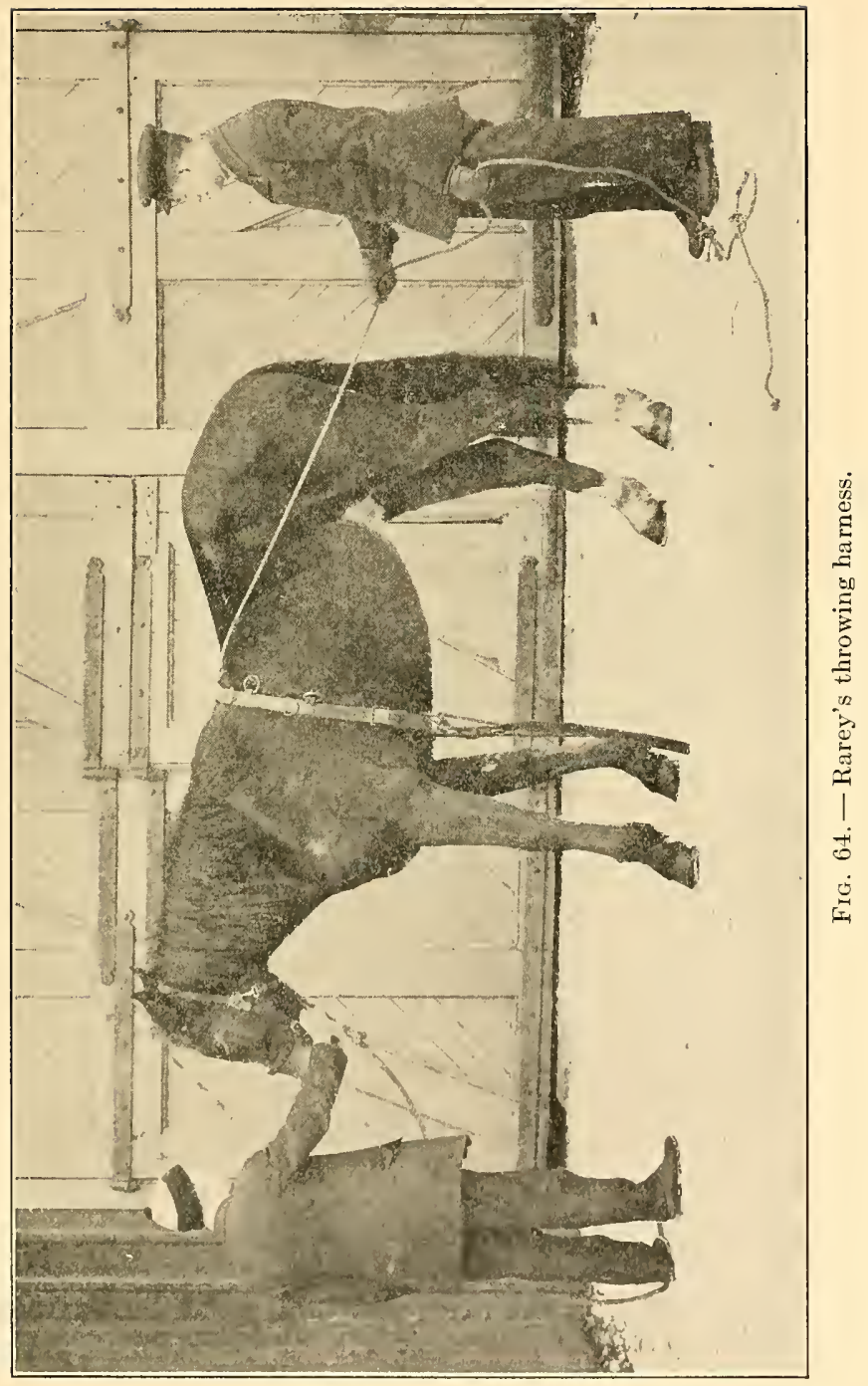




\section{Training Wild and Subduing Vicious Horses}

ground to teach them that man is their master. Rarey also devised a harness to accomplish this. It is practically the same as the safety harness, with the addition of a heavy strap similar to the Rarey leg-strap, which is attached to the surcingle

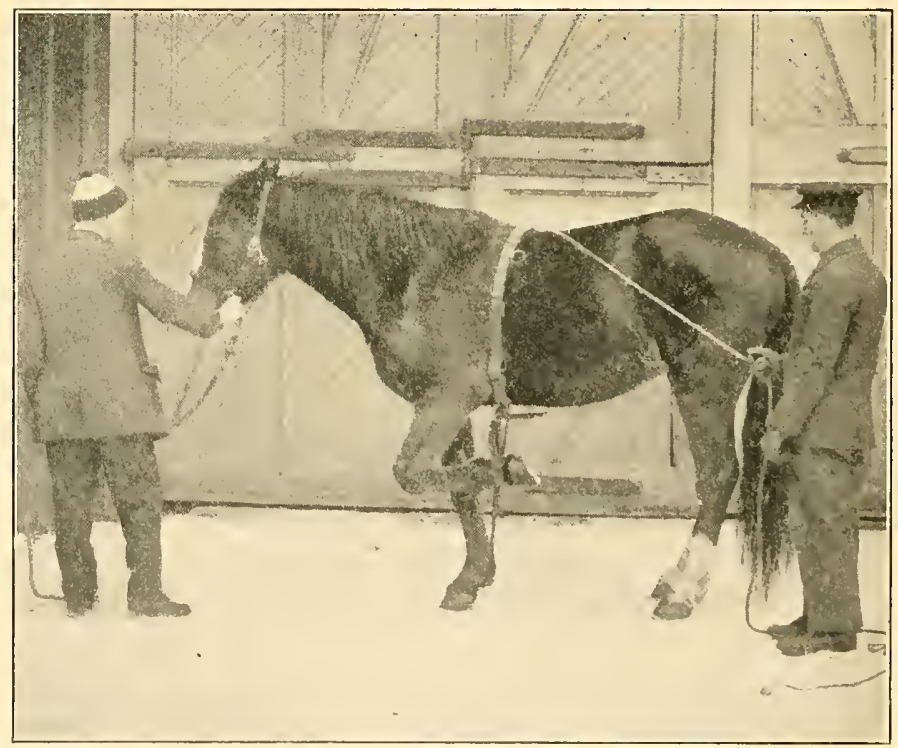

Fra. 65. - Rarey's throwing harness, first position.

on the left side. The surcingle is put on as before and the strap buckled about the right pastern only. One end of the rope is tied in the ring at the belly, the free end passed through the ring at the right pastern, then the rope is passed up through one of 
the rings on the right side, then on up and over the back, and the harness is completed (Fig. 64).

When ready to throw the horse, first strap up the left foreleg (Fig. 65). Next have the assistant lead the horse a step forward and as he lifts his foot draw it up against the breast by pulling on the rope (Fig. 66). Pull steadily on the rope; if the horse rears,

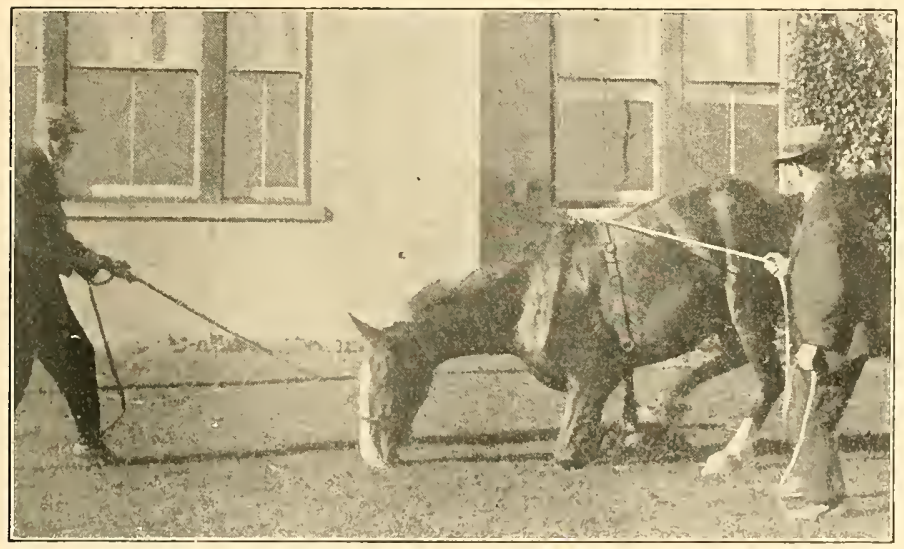

FIG. 66.-- Rarey's throwing harness, second position.

keep his foot drawn up and he will come down on his knees, when to lay him down is simply a matter of pushing him over (Fig. 67). Keep pulling on the rope, otherwise he may surprise you by quickly jumping to his feet. While in this position you can do anything you like. Shoot fire crackers, guns, rattle cans, run up to him with an automobile or traction engine or the like. He soon learns that if he 
216 Training Wild and Subduing Vicious Horses

remains perfectly quiet he will not be injured. Many excellent horsemen put all horses through this course, as it tends to make them steady in case of an accident.

Rope throwing. - There are two common rope

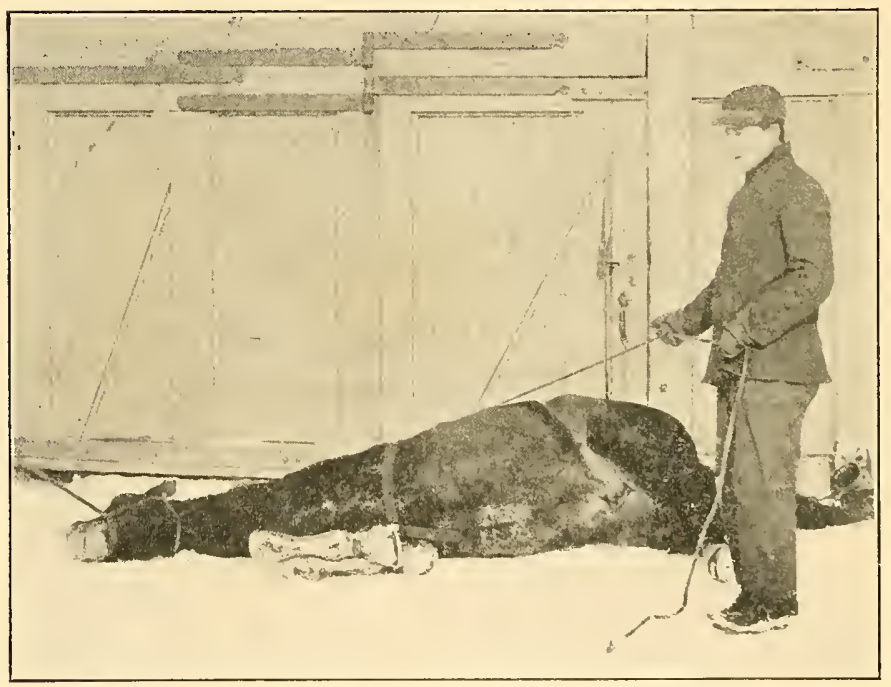

FIG. 67. - Rarey's throwing harness, third position.

hitches used in throwing the horse. In one the rope only is used, while in the other, two straps, about one foot long and provided with buckle and ring, are needed. In the first method take a long rope, double it at the middle and tie a knot forming a loop about three feet long. Slip this loop over the 


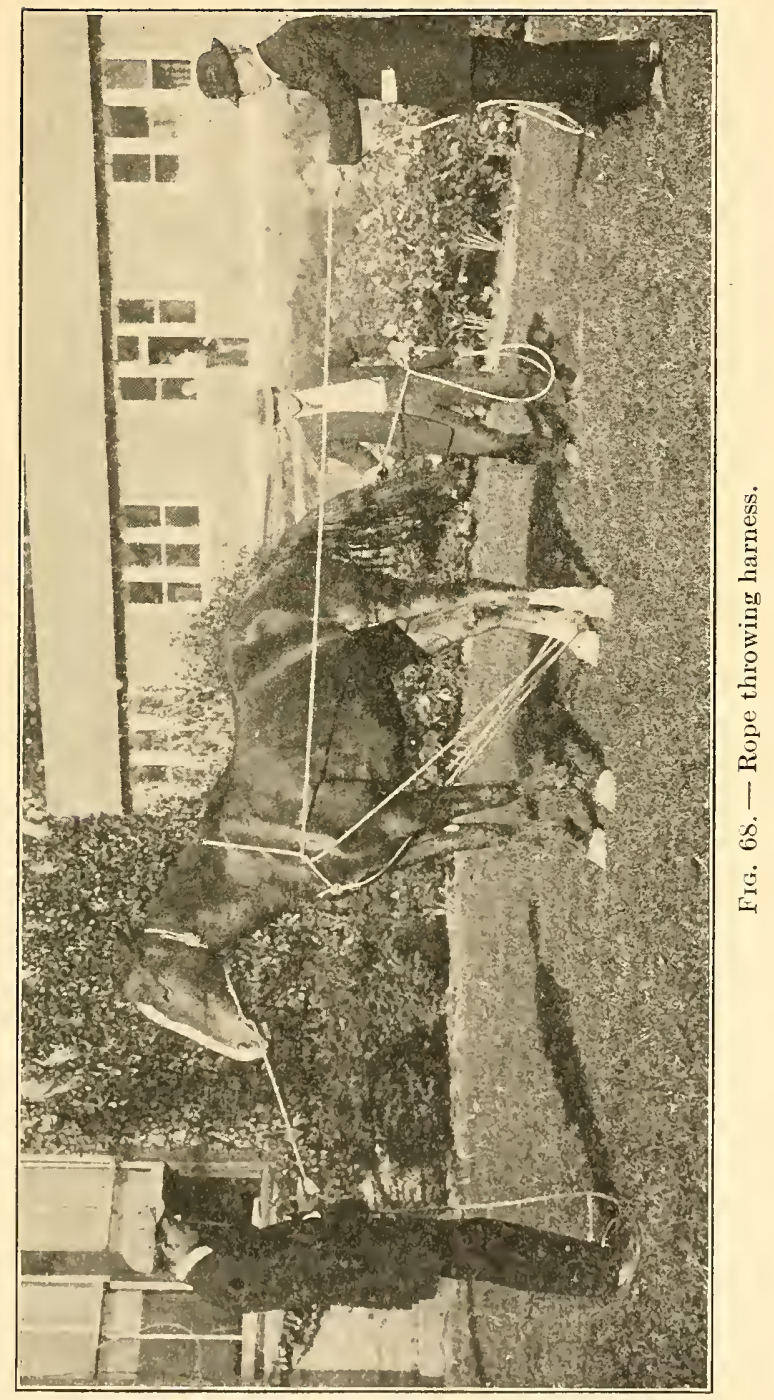


head and down to the shoulder, similar to a collar. Pass the free ends down between the front legs, back and around the hind pasterns from the outside, then up and through the loop at the horse's shoulder. Three men are needed to use this appliance, two to pull the rope, one at either end and one to hold the horse (Fig. 68). When ready let the two men holding the rope pull vigorously, which draws the horse's hind feet under him, and when he goes down let the man at the head hold it firmly on the ground, as a horse with his head flat cannot get up. The objection to this method of throwing is that the ropes may burn the hind pasterns as the hind legs are being drawn forward.

In the second hitch secure a short rope about five or six feet long, tie a large loop to slip over the horse's head and down to the shoulders as in the first hitch. Buckle the straps around the hind pasterns. Tie a rope around each fore pastern, pass the free ends back and through the rings at the hind pasterns, then up and through the loop at the shoulders, one on either side, and then backward (Fig. 69). This hitch requires three men, as in the first, two to pull the rope, one at either end, and one at the head. When ready have the men pull strongly on the ropes, which pulls the horse's fore and hind feet together and he goes down. The instant he goes down the man at the head should hold it flat as in the first hitch. This has the ad- 
vantage that there is no danger of burning the pasterns joints with the ropes.

Galvayne's training harness. - This consists simply of an appliance for tying the horse's head and tail together so that he will go round and round until he goes down or becomes steady. It was devised by

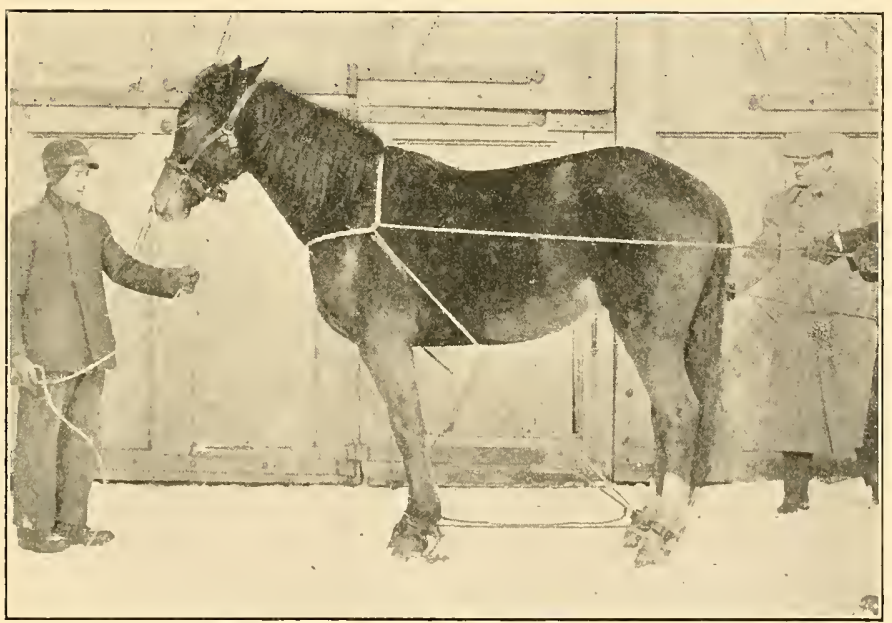

FIG. 69. - Rope and ring throwing harness.

Galvayne, and consists of a tail-rope provided with a loop or snap so as to be readily attached to the halter or lead strap. There are several ways of securing the tail-rope to the tail. Where the tail is provided with long hairs it may be tied up in the ordinary way and the tail-rope tied into the loop similar to Fig. 88. If the tail has been docked or 
contains few hairs, this cannot be done. When such is the case, grasp the tail-rope, double it at the middle and pass it around under the tail from left to right, and through the doubled part. Pass it

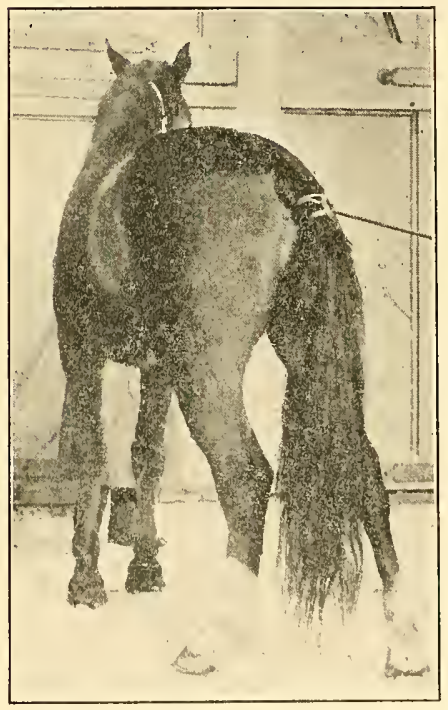

FIG. 70. - Method of securing rope to tail. down the tail two inches, then back around from right to left and under the rope that extends downward, and you have a tie that will not slip if properly attached (Fig. 70). This rope may be provided with a snap which may be snapped directly into the halter ring, or in the absence of the snap it may be tied to the halter (Fig. 71). This is a very effective appliance for subduing vicious horses.

The difficulty with this harness comes when we approach the vicious horse's hind quarters to arrange the tail-rope, as he is likely to kick. To avoid this danger take hold of the halter with the left hand. near the head, and by pulling the head toward you swing the horse round and round, making yourself the center around which the horse revolves. A few 
sharp turns will stupefy him, when the cord may be looped about the tail with perfect safety, providing you keep the head turned well toward you.

Shackles. - These are sometimes used in training wild western horses. This appliance consists of a strong ring about four inches in diameter, to which are welded four strong chains about eighteen inches long and provided with heavy straps, well protected, at the other ends to buckle around the horse's pasterns. The wild horse is snared (p. 225), thrown, bound, and the shackles buckled to his pasterns, and then he is

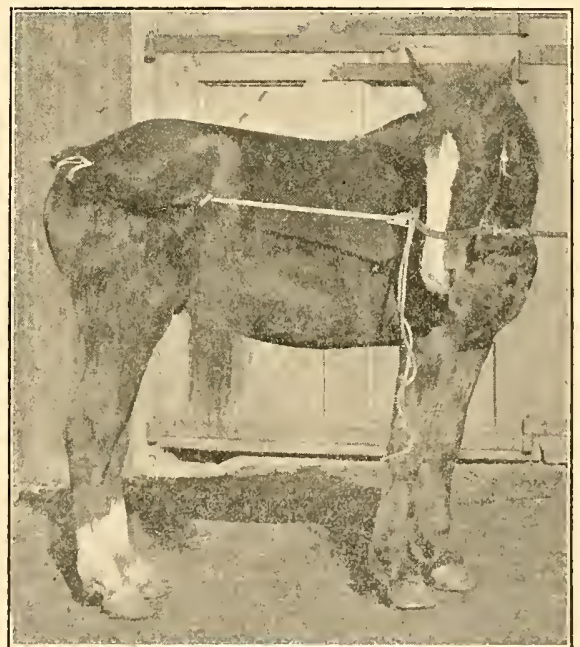

FIG. 71. - The Galvayne appliance in use. released and left alone to thrash it out with the shackles until he calms. This appliance should be made very strong, and the straps going around the pasterns should be well protected, otherwise the horse will injure himself.

Straight-jacket. - This appliance is also used in 


\section{Training Wild and Subduing Vicious Horses}

training wild and vicious horses. It consists of a strong breast-band and breeching provided with a heavy ring on either side and supported by two

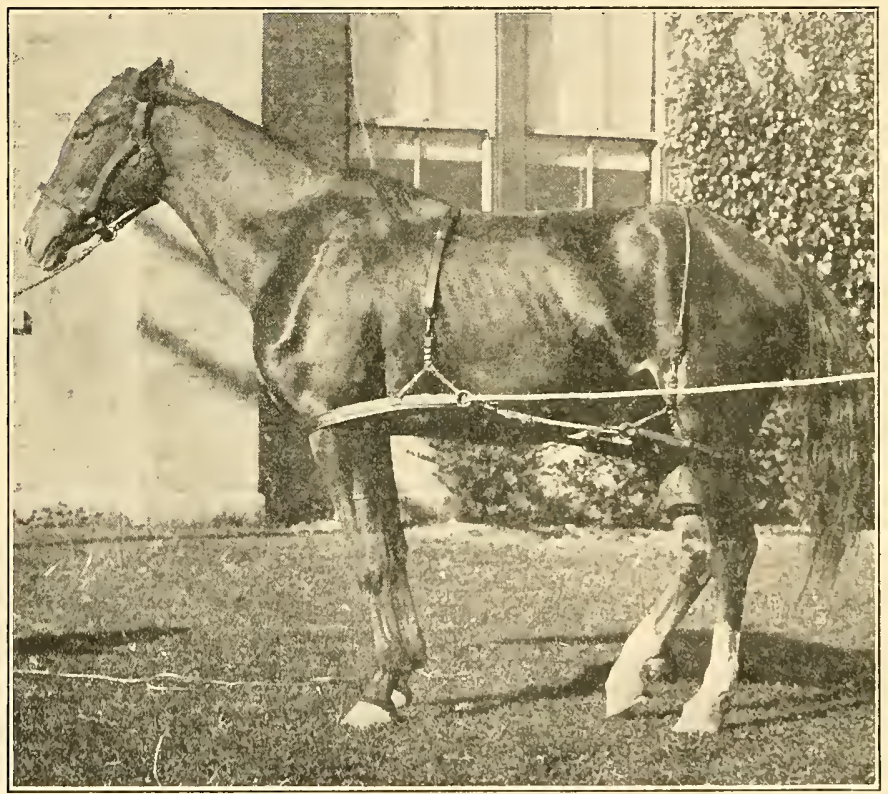

Fig. 72. - The straight-jacket. This appliance must be made very strong.

straps, one passing over the back at the withers, the other in front of the hips. The breast-band is lowered, passing around the forelegs close to the chest, while the breeching is lowered, passing around the hind legs below the quarters. At first the breast- 
band and the breeching on either side are drawn tight and secured by a strong strap or rope passing from breast-band to the breeching. In this harness the horse can make but slow progress, and this by low and very fatiguing jumps. He is now turned loose to get used to the restraining harness, which he usually does in about one quarter of an hour. After the horse has calmed, some persons take a long rope, secure it in the ring on one side of the breeching, say the left, then pass the free end forward and through the ring on the left side of the breast-band, and back through the ring at the breeching. Next remove the straps, securing the breast-band and breeching on the left side. Now the horse can walk, but if he should begin to jump around, all they have to do is pull on the rope, which compels him to make the short, tiresome jumps as before (Fig. 72).

\section{TRAINING THE WILD OR STUBBORN HORSE}

Having considered the more important and more useful appliances used in training wild, refractory and stubborn horses we will pass at once to the education of these classes of animals.

Catching a wild horse. - When it comes to training the wild horse, the first thing, of course, is to get hold of him and to get our training appliance attached. While cowboys and ranchmen do this with the lasso, only a few of us can manipulate a rope so 


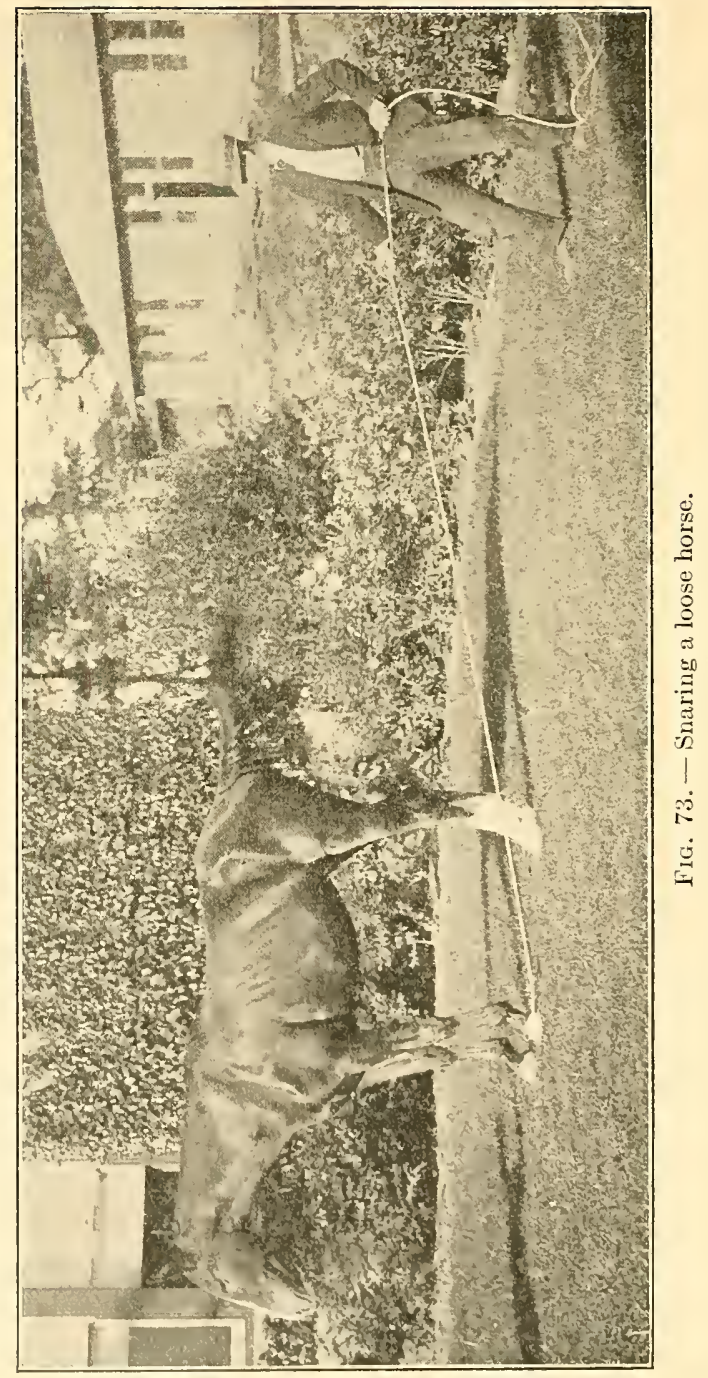


dexterously, and besides, the method is not considered a good one by horse trainers generally, as it often results in injury to the animal. To catch the wild horse, drive him into a small inclosure. It is a very easy matter to drive a wild horse if gentle horses are turned loose with the wild one and all are driven together. Secure a soft, three-eighths inch rope and tie a running loop in one end. Enter the inclosure with the horse. He will try to get away by running to the farthest corner, and as you walk in one direction he will walk in another. Place the loop upon the ground and walk the horse around until he steps into it with his left front foot (Fig. 73). Pull the rope quickly, so that it will slip up to the pastern, and then hold fast. When the horse feels the rope on his pastern he will try to shake it off, but do not let him, for once he gets it off he will spend half his time thereafter trying to get it off again. Pull his foot toward you and do not let him put it down squarely, but make him put it down eight to ten inches from where it would be normally. If he refuses by shaking his head and running about, do not punish him, but pull his foot again. After a time he will become tired and place his foot at the place you have selected.

After the horse becomes submissive to having his foot pulled about, approach him and put your hand on his shoulder, but not on his head. If he refuses to let you touch his shoulder, pull on the 
rope. If he struggles, pass behind him, bring the rope up over his back and pull his left foot off the ground (Fig. 74). He will soon see that he must choose between having your hand on his shoulder and his foot off the ground. As soon as he becomes

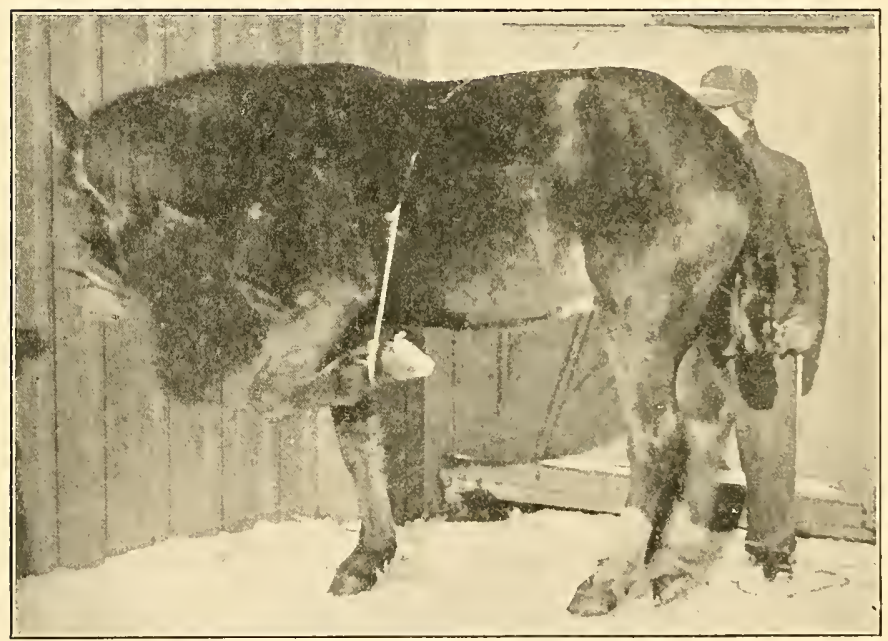

FIG. 74. - Gentling a loose horse.

submissive to having his shoulder handled, take a position standing on his left again, gather up the rope, keeping it tight all the time, so the horse cannot get it off, and throw it over his back. When the rope goes over his back he will run out from under it, but pull on the foot as before. Again he must choose between having the rope orer his back and 
having his foot drawn out from under him. While the hor'se is doing this running about, you stand in the center of the inclosure and keep him on the outside. When he will permit the rope over his back, bring the free end under his body, and pass it in front of the perpendicular rope leading to the foot. This is important. If you pass the free end behind the rope leading to the foot and the horse should succeed at any time in getting in front of you, it would pull off over his tail and you would have to begin over again.

Now you have a hitch somewhat similar to the single safety (p. 208). If the horse starts to act up, to calm him pull the rope which holds up one front foot. As soon as he quiets let the foot down. He rapidly learns that he must choose between standing quiet and having his foot drawn up. As he does not like to have his foot suspended he will let you caress him, when he may be haltered without risk.

Haltering a loose horse. - The precautions necessary to be taken in haltering a loose horse will depend on his vice. A good plan for haltering one not too wild is as follows. Drive him into a small square inclosure. Have a long pole and enter the inclosure with him. He will, of course, rush into the farthest corner and try to get away. When he is measurably quiet, touch him gently on the crest with the long stick; as a horse likes to have the top of the 
neck rubbed, this has a quieting effect. Soon he will let you place the pole anywhere along his neck. Take the rope halter described (p. 189), twist the chin piece three times around the end of the pole, and the lead rope two or three times around to pre-

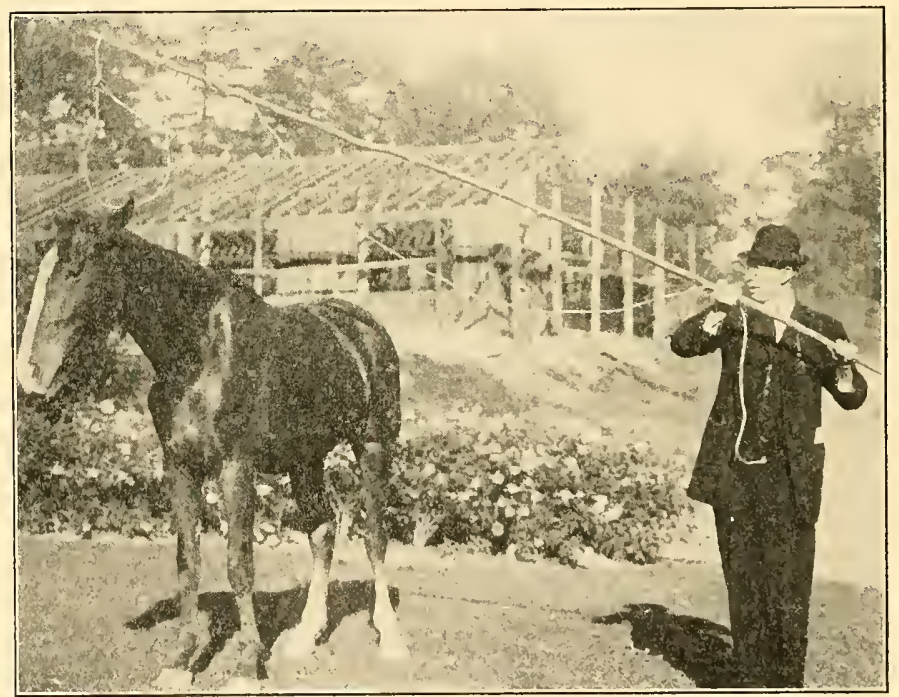

FIG. 75. - Haltering a loose horse, first position.

vent it hanging too low. Now bring the crownpiece of the halter behind the ears while holding the end of the pole slightly above the forehead (Fig. 75). Rapidly bring the pole down in front of the horse's nose and then under the lower jaw, which brings the halter into its proper place (Fig. 76). The horse 
will run to another corner, when he should be quieted with the pole again by caressing the top of the neck. Some recommend tying the lead rope to a chunk, and permitting the horse to drag it around on the assumption that it aids in teaching him to lead.

Gentling the wild horse. - After catching the horse and before proceeding further, it is necessary to

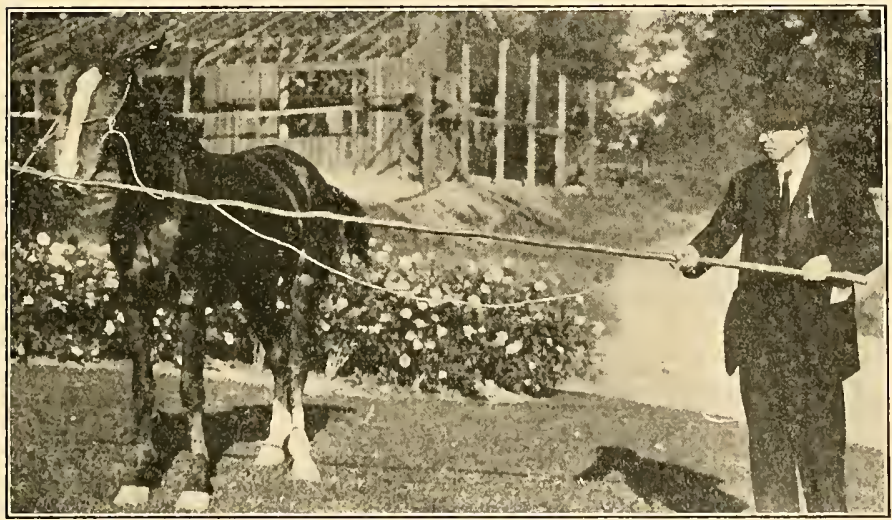

F1G. 70. - Haltering a loose horse, second position.

make him gentle to being handled. If the horse is a wild one, this may require tact and patience, particularly to get him to submit to pressure along the back of the forelegs, the front of the hind legs and along the abdomen, as such parts are very sensitive. The method to be pursued will depend on the temper of the horse. If he will submit to having the top of his neck rubbed with a long pole, the 
method may be much simplified (p. 50). If he resents all efforts while standing, then he should be thrown, bound and the shackles (p. 221) attached, when he may be released and left to worry himself fighting the appliance. When he gives in, caress him along the neck. As soon as he will let you, offer him a dainty, as a carrot, apple, potato, or sweets of some kind. At first, do not touch his abdomen or legs, but work with his neck and body. Caress him often and he will soon learn that you do not mean to hurt him. Keep at this until he becomes submissive. The next day repeat the entire process if need be. As this is the first lesson it is important that the wild horse thoroughly understand it before proceeding further. Take extra care to see that the shackies are strong and well protected, so as not to injure the animal's pasterns. Everything possible must be done to teach him that no harm is to come to him if he obeys, therefore the harness must not chafe his legs.

If preferred, either the Rarey or the Galvayne method may be used in the gentling process. The left front foot may be snared and held up, the throwing harness arranged (p. 212) and the horse laid on the ground. Begin at once to gentle him by rubbing his crest and giving sweets as soon as he will take them. After he becomes docile let him up and handle him standing. If he resists, lay him down again and begin over. Soon he will understand that he must 
choose between permitting you to handle him while standing, and being laid on the ground to be handled while down. If it is desired to use the Galvayne method, snare the foreleg and hold it up as before, while you arrange the tail-rope and attach it to the lead-strap (p. 219). Now let the horse loose and he will go round and round until he becomes stupefied. Then handle the crest, and caress as before. When he becomes docile remove the tail-rope, but continue to handle him. If he resists, replace the tail-rope and let him go around again. After a few repetitions he will understand what is wanted, and will stand quietly while you handle any part of his body.

Teaching the wild horse to lead. - If the horse will not respond to any of the methods suggested heretofore (pp. 37 and 52), but bucks, rears, runs or balks, then more severe methods must be adopted. Above all things do not punish him. If he fights the halter, tie the lead-rope to a heavy chunk and let him worry himself until he ceases to resist. Then place the guy rope (p. 201), to be held by an assistant, on his head and attach the double safety (p. 208). Now if he rears, bucks, runs forward or backward, pull his front feet up with the double safety and let him come down on his knees. After a few hard falls he will stop running and bucking, but may balk. Do not lose your temper and punish him, but let the assistant quickly take a po- 
sition ten or fifteen feet in front of the horse and give a sharp jerk on the guy rope (Fig. 60). Never pull the guy rope steadily. At the jerk the horse will move forward, and if he goes along nicely have the assistant walk in front, and do not trouble his legs with the safety. If at any time he acts up, pull him to his knees, or if he balks, have the assistant jerk him forward with the guy rope.

If the horse seems very active and you find it necessary to pull him to his knees more than you think best, remove the safety and place the tail-rope (p. 219) on him and let him go round and round until he becomes stupefied. Release his head, replace the double safety and continue as before. If the horse is very game, put the throwing harness (p. 212) on him and give him a few hard falls. After a few hard falls, after being stupefied by the Galvayne method a few times, and after being pulled to his knees several times, the most vicious of horses will get the idea that they must follow where you wish or suffer accordingly. Do not be too severe in this work, and when the horse does as you wish caress him. Be firm, give him to understand that you are his master and that he must do as you command, but when he does obey be equally as sure to give him some evidence of your pleasure.

Sometimes it is quite a struggle, but the horse conquered in this way usually gives right up and seldom causes further trouble. It is well, however, 
to continue the use of the double safety for a time, to be prepared to meet any emergency, since occasionally such a horse does act up without giving warning even after going nicely. Do not rush through this part of the training, but give the horse sufficient time to adjust himself to the new conditions. As soon as he gets the idea that you are his friend and that no harm is to come to him, the victory is half won.

Teaching the wild horse the uses of the bit and to drive with lines. - The stubborn, refractory and wild horse should be taught the uses of the bit much the same as suggested for the work horse (p. 56) modifying the method to meet the needs of each individual. Use a bridle with a mild bit in connection with the bitting harness. If the horse fights the bit, do not use a severe one, as is the usual practice, but try a bitless bridle for a time. After a few lessons in the bitting-harness and bitless bridle, try the mild bit again. Soon he will cease to fight it. Patience on the part of the horseman is the principal requirement in training a wild horse.

After the horse becomes familiar with the bit, the side-reins of the bitting-harness may be substituted for lines preparatory to driving and teaching the commands. If the horse promises to give trouble, place the double safety (p. 20s) on him before attempting to drive him, so as to be prepared to steady him should he attempt to act up. Have an assistant 


\section{Training Wild and Subduing Vicious Horses}

manage the safety rope. Now teach the commands as suggested (p. 65). If the animal rears, bucks or runs either forward or backward, pull him to his knees with the safety. If he balks, do not punish him, but put the guy rope (p. 201) on under the bridle, and while you manage the safety rope and lines have the assistant jerk him forward. If he is very game and fights too long, remove the harness and attach the tail-rope (p. 219), and let him go round and round until he becomes stupefied. Release his head, replace the bitting harness and double safety, and continue with the commands. With the wild horse it is very important that he thoroughly understand the uses of the bit and the commands before attemptins to hitch to a vehicle.

Teaching the wild horse to drive in harness. - After the horse becomes perfectly familiar with the uses of the bit and obedient to the commands, he should be harnessed preparatory to hitching. In rendering him submissive to the harness he should first be poled (p. 69). If he resists, attach the double safety (p. 208), pull him to his knees and continue the poling process, or if preferred, attach the tailrope (p. 219) and let him go round and round until he becomes stupefied, and then continue with the pole as before. As soon as he becomes familiar with the pressure of the pole, harness him. If he bites, strikes or kicks, use the appliance suggested (p. 254 and 292), in order to overcome such habits. It is 
often a good plan to remove the harness and replace it, until he becomes submissive to being harnessed.

After harnessing and before hitching drive him about, guiding him to the right and left and putting him through the various commands. Next familiarize him with the shafts (p. 77). Then attach the double

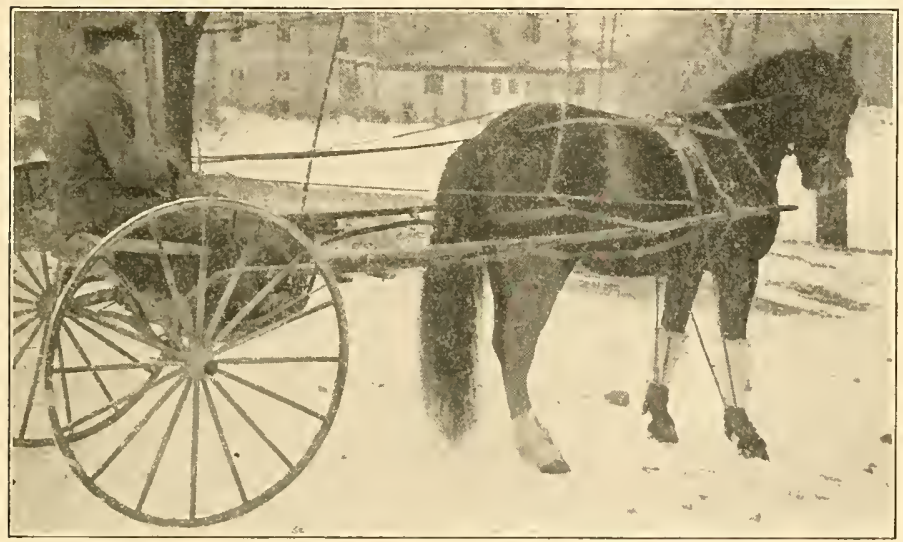

Fig. 77. - Method of arranging the double safety when hitched to a vehicle.

safety and hitch him to the rig (Fig. 77). If he promises to give trouble it is well to attach the guy rope (p. 201) under the bridle and have an assistant manage the rope. Now if he acts up pull him to his knees, or if he balks, do not punish him but have the assistant jerk him forward with the guy rope. If he offers to kick attach one of the kicking appliances (p. 202), or better still, attach the appliance at the 
time of hitching, so as to be prepared to meet any emergency that may arise. If one has a training cart provided with long shafts and the appliance properly arranged, he is prepared to offset anythin? the horse may attempt. If he rears, bucks or runs either forward or backward, pull him to his knees; if he balks, have the assistant jerk him forward; if he attempts to kick, the kicking appliance will restrain him, and if he lies down, the shafts are so long that no injury is likely to result.

If the horse is very game and fights incessantly, unhitch, remove the harness, then attach the tailrope and let him go round and round. If this appliance has been applied about two times previous to this, keep him going round and round until he drops. Now begin over again, taking the same precaution as before. If he insists on lying.down, attach the throwing harness (p. 212) instead of the tail-rope and give him several severe falls. Then continue as before. Such treatment will bring the most incorrigible animal under subjection. He will understand soon that it is useless to resist, as you are using his own strength to steady him. It is only in very rare cases that two or three such lessons at most will not serve to subdue the horse.

This work should be continued daily for some months, even though the horse does seem perfectly obedient. It is necessary to teach these lessons very thoroughly. The horse has been ruming wild 
up to this age, perhaps he has seldom seen man and then only to be punished or injured by him, as in corralling, branding and castrating. During the animal's wild life he has learned to look upon man as his greatest enemy and it may require much time and patient effort to gain his confidence. After he becomes perfectly obedient in single harness, hitch him double, much as suggested (p. 84), with such alterations as are necessary to insure safety.

Training the wild horse to unfamiliar objects and to noise. - While in general the wild horse is not so difficult to bring under subjection by the methods herein described, he is, as a rule, very sensitive to unfamiliar objects and to noise, though occasionally one will find a wild horse that seems to fear no objects other than men and dogs. In training the wild, refractory or stubborn horse to objects of fear, pursue much the same course as suggested in training the work horse (p. 85). If he resists, attach the double safety (p. 208) and pull him to his knees as he begins to act up, but continue with the noise as suggested. If preferred, one may attach the tail-rope (p. 219) and continue the noise as the horse goes round and round. Do not rush through the work, but give the animal ample time to become familiar with the racket. It may be necessary to begin the noise in the distance and gradually approach him, exercising due care when the sound is to the rear, as he cannot see its source. 


\section{Training Wild and Subduing Vicious Horses}

If the horse continues to resist when the noise approaches him, attach the throwing harness (p. 212) and lay him down. Then begin the noise again, moving round and round him, but gradually coming nearer, until at last the noise is over his body (Fig. 78). During this time it is necessary for the man holding

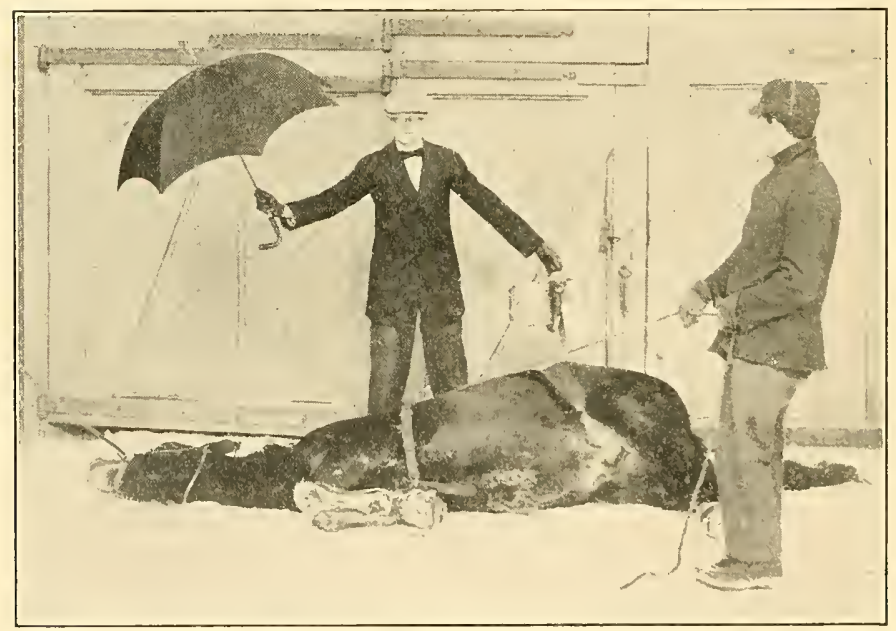

Fig. 78. - Familiarizing the wild horse with strange objects and with noise.

the safety rope to keep it tight, or the horse may surprise him by bounding to his feet. After the animal becomes perfectly submissive to the racket while lying on the ground, let him up, but continue the noise. If he still resists, lay him down again. Repeat until he becomes submissive while standing. Now familiarize him with such objects as bags 
lying in the road, robes on the fence, umbrellas in women's hands, the waving of flags, and the firing of crackers, guns and the like in much the same manner. If he cannot be driven or coaxed up to such objects, lay him down and wave the objects over his head. Repeat until he will walk right up to them and feel them with his nose. When he refuses to be driven up to the object never punish him, as this only frightens him all the more. Either put the throwing harness on him and lay him down, then bring the object to him; or attach the tail-rope and let him go round and round until he becomes stupefied, and then bring the object to him as before. Soon he will understand that he must either face the object of his fear when asked to do so or be placed on his back and have the object brought to him. When he faces the object be sure to caress him, to help fix the idea that he is not going to be injured.

To familiarize the wild horse with the automobile, place the double safety and guy rope (p. 201) on him and approach the machine, standing, preferably in the training inclosure. Make him walk right up to it and touch it with his nose, or if he refuses to do this lay him down and run the machine up to him. After he becomes familiar with it while not in motion have it started while he stands near by. Stop it and drive him up to it again. Keep the horse following the machine in this way until he becomes steady. Next turn the machine around and have 


\section{Training Wild and Subduing Vicious Horses}

him meet it; if he becomes frightened, stop it and drive him up to it again. Repeat until he will let the machine pass first to his left and then to his right; each time drive him directly up to it as it passes. Now that he will pass the automobile on either the right or left, have the machine come slowly from the rear. Do not pass too closely, but keep it well to the other side of the road. As it passes, drive slowly up to it. Gradually increase the speed of the machine and have it pass on both the right and left side of the horse. Now stand the horse while the automobile is being driven around him, thus familiarizing him with it at all angles.

In familiarizing the wild horse with steam or electric cars, pursue the same general course suggested for the work horse (p. 89). If he is very refractory, do not attempt the work hitched to a vehicle. Attach the double safety and the guy rope, then proceed as suggested for the work horse. Do not hurry about this part of the work and do not punish the horse in case he acts up. After he gets fairly well accustomed to the cars, then hitch to a vehicle and begin over again. To avoid risk, leave the double safety and guy rope on the horse. If he rears, bucks or runs either forward or backward pull him to his knees, and if he balks, have an assistant jerk him forward with the guy rope. Continue the work until he becomes perfectly reconciled to the cars from before and behind and from either side. 
In a similar manner familiarize the wild horse with any and all objects and noise that cause him fright. Be very quiet about the work and employ every means in your power to secure the animal's confidence. Once he learns that he can trust you and that he can go wherever you command without risk, the victory is won. After that you will have no trouble in driving him past unfamiliar objects, noise, and in fact anywhere you may wish him to go. On the other hand, if you are careless, punishing him when frightened or when confused, and permitting him to get injured, he will lose confidence in you and resist your every effort to train him. It is, therefore, of the utmost importance that the wild, refractory and stubborn horse be treated gently, yet firmly; that he be asked to do nothing unreasonable, but that he be made to do whatever is attempted and then caressed by giving a dainty, as a carrot, apple, potato or sweets for doing as you wish.

\section{SUBDUING THE VICIOUS HORSE}

There are a few horses, fortunately a very few, that do not seem to respond to any method of training. Perhaps the most historic case of which we have record is that of the wild horse "Cruiser." It was the training or subduing of this horse that made Rarey famous. This horse fought every effort of man to overcome him. Punishment only served 
still further to increase the rebellious state of his mind. He was known as the "man-eater," and successfully resisted all attempts to bring him under subjection until Rarey succeeded in taming him by means of his throwing and safety harness. In reality this horse was never trained, but had to be tamed by the Rarey appliance whenever he was required for use. Hence the statement often made by horsemen that they can train any horse, no matter how vicious, is absurd. There are, however, only a few horses of this class. The great majority of them can be rendered subservient to man's will if the proper means are employed.

In the subduing of the vicious horse it is difficult to give general advice that will be of value, as each individual must be dealt with according to his peculiarities. The requirements on the part of the trainer are patience, perseverance and tact, but of greater importance than any of these is an innate love for the work. It is essential to be cool-headed, and never fly into a rage and punish the animal, as such treatment only serves to increase his determination not to submit to man's will. There are more horses made vicious by ill treatment than from all other causes combined.

In the training of the vicious horse, the first thing is to get hold of him. This can usually be done by snaring (p. 225). For the next step one may choose between two appliances, the throwing harness (p. 212) 
and the tail-rope (p. 219), attaching whichever the exigencies of the case will permit. In case the throwing harness is attached, you must be prepared for a struggle, as the horse may resist every move. He may bite, strike and kick; he may go to his knees and rear up and leap forward, refusing to leave the ground with his hind feet; he may kick while on his knees, or he may bite, and kick with either or both hind feet while lying on the ground. If he does this, however, you may be sure he will soon wear himself out. On the other hand, while he may fight desperately on his feet, he may be quiet while down, thus saving his energy to wreak vengeance when he regains his feet.

If you succeed in attaching the tail-rope instead of the throwing harness, he may bite, strike and kick as he goes round and round, or he may go round a few times, then drop to his knees and refuse to get up until his head is released. If you should free him, however, he may be even more ferocious than before. Whichever appliance you succeed in attaching, keep working at him until he goes down. While down make him submit to the most severe tests that you can give, such as the rattling of tin pans, ringing of sleigh bells, grinding of horse fiddles, firing of firecrackers, shooting of guns, sounding of automobile gongs and the like. After he becomes perfectly submissive to this let him regain his feet, but keep the appliances attached. If he begins to 


\section{Training Wild and Subduing Vicious Hórses}

act up, repeat the entire process, this time making even more noise than before, covering him with old papers, waving robes over his head, opening umbrellas in front of his eyes and doing everything in your power to excite him. After he becomes submissive while down, let him regain his feet and continue with the noise and strange objects. Continue this until he becomes perfectly reconciled. Unless he is indeed a demon he will unconditionally surrender. When he gives in, caress him and give him a dainty to assure him that as long as he obeys your wish he will be treated kindly.

As a rule, it is not a good plan to continue this battle for more than two hours, and perhaps better results would be secured from one. In the first place, this is exceedingly hard work for a man and he will probably be exhausted after one hour's struggle, and in the second place the horse ceases to resist, not because he is conquered, but because he too is exhausted. The horse that ceases to fight because he is exhausted will put up just as severe a battle when he gets rested as he did in the beginning. What we must do is conquer him and impress him with his helplessness when in our power. Therefore, if the battle is not won at the end of one hour's severe struggling, declare a truce until the next day. Repeat the entire process as on the first day. When he surrenders, put him through a similar course as that suggested in training the wild and stubborn horse. 
The course suggested is a combination of the Rarey and Galvayne methods and is a very effective one. Many vicious horses have been subdued, hitched and driven in less than two hours' time. It is so effective because it impresses the horse so forcibly with his utter helplessness, and uses his own energy to overcome him. 


\section{CHAPTER VII}

\section{OUTDOOR VICES AND WHIMS}

BroAdLY speaking, the chief cause of all the bad habits of a horse is poor management at some stage of his career. Such habits may have been formed during colthood, when the youngster is very sensitive to his surroundings, and when he is only too often made to do things that seem "cute." In later life these very things may serve to lessen his usefulness. They may be formed during the training period; frequently the animal's mouth is spoiled by the use of a severe bridle-bit'or an improperly fitting one; and his shoulders, back and tail are made exceedingly sensitive to pressure by improperly fitting harness; or simply by lack of proper training. Again, such habits may be due solely to the inability of the horse to do that which is required of him. This may depend on some unknown physical impediment that makes it impossible for the horse to act as we desire. It is seldom if ever that a hor'se is really born vicious. While it may be true that temper is transmitted, and that certain tempers are more predisposed than other's to develop vice, yet vice itself is not a hereditary character. 
Of all the kinds of vice, treachery and stubbornness are the most difficult to overcome, as animals possessing them often deliberately oppose our efforts. Vice due to nervousness or impatience can be readily overcome, as the cause soon passes away. Vice due to excessive sexual excitement is often very difficult to overcome. Castration or spaying is the most efficient means for overcoming vice from sexual causes. Very rarely, one will meet with a vicious horse which seems to have the source of viciousness in an unsound mind. Such an animal, of course, cannot be subdued.

Since vice owes its origin to many and varied causes, it is important to study each case to ascertain the cause and, if possible, remove it. In overcoming or subduing vice we must establish a new habit that will have a stronger influence on the horse's mind than the old one which impairs his usefulness. At first it will be largely a question of supremacy, and we must impress upon him that we are physically and mentally superior. From the beginning we must use such appliances as will give us the advantage. This can be accomplished in two ways: first by the employment of such appliances as will use the animal's strength in overcoming him, and second by the use of self-punishing harness, which will inflict the punishment at the instant he violates our wish. He must be given to understand that he is to obey us or suffer accordingly. Next we must 
impress him with the fact that we are his friend. This can be accomplished by feeding him a dainty when he obeys our commands. To aid in securing his confidence we should abstain from all forms of punishment likely to cause him pain. While the use of the self-punishing harness, by which he deals out his own punishment, is recommended, yet we should never use the whip or spur in overcoming vice, as the pain thus inflicted provokes further rebellion.

Perhaps the most efficient means for punishing the horse in overcoming vice is by humiliating him, as this seems to have a greater effect than any form whereby he is caused pain. There are three common methods of humiliating the proud and vicious horse: first by pulling him to his knees and holding him there until he becomes calm; second by tying his head and tail together and letting him go round and round until he becomes stupefied; and third by throwing him to the ground and holding him down until he gives in. The great advantage of each of these is that they do not cause the horse physical pain.

We may divide bad habits into two general classes: vice and whims; the former comprising the more serious moral defects, and the latter imperfections of less importance. 
OUTDOOR VICES, THEIR CAUSE AND HOW TO OVERCOME THEM

Balling. - This is a vice in which the horse refuses to obey the commands of his master. It varies in degree, sometimes the animal merely refusing to go in a certain direction or along certain roads and to pass certain objects; sometimes refusing to go to the right, to the left, forward or backward, and at other times stopping, notwithstanding the driver's energetic efforts to get him to go; or he may lie down and refuse to get up.

The causes which excite the horse to balking are many and varied, chief of which are sore mouth, due to a poorly fitting bit or bridle; sore shoulders and neck, due to dirty or improperly fitting collar, to excessive weight on the collar or to backing; sore back, due to poorly fitting harness; sore tail, due to dirty or improperly fitting crupper; overloading; exhaustion; and to discontent with the treatment of the driver.

As balking seems to be largely a nervous trouble, it is useless to punish the horse; in fact, such treatment only increases the difficulty. First of all we must divert the animal's attention from his fixed determination not to obey. In mild cases this can be accomplished by quietly arranging the collar or bridle, by giving a bite of grass, or by picking up one front foot and gently tapping the shoe as if there were 
something wrong, which serves to attract the animal's attention, when he will move on without further trouble.

The confirmed balker, however, must be put through a more strenuous course, as he is not to be out-generaled in any such manner. Before attempting to overcome the vice, see that he thoroughly understands and is obedient to the commands. It is not possible to make much progress until he obeys such commands as "whoa," "get-up" and the like. If he does not know these simple commands, teach them to him much as suggested in training the wild horse (p. 233). Do not rush through this part of the work, but make him thoroughly obedient.

Now that the horse is perfectly obedient to the commands, harness him, and with both the guy rope (p. 201) and double safety (p. 208) attached, hitch him to a vehicle. Have an assistant manage the guy rope while you drive and tend the double safety. Drive the horse first in the training inclosure and then in the open field, continuing the commands. If he shows any tendency to balk, such as laying back his ears, looking to the rear and the like, give the command "whoa" at once, and before he has time to stop of his own accord. This will serve to nonplus him. In starting, the assistant should quickly take a position in front of the horse and smartly jerk him forward with the guy rope (Fig. 60) at the same instant you give the command "get-up." 
As a signal you should snap the whip to the right, but without touching the animal, as the command is given. In a similar manner repeat the process of stopping and starting three or four times. Do not wait until the horse gets stubborn, but use the guy rope and use it severely, on the slightest intimation that the animal does not want to go when commanded. Continue this work for half an hour each day for three or more consecutive days, unless the horse shows by his submission that he is willing to do as you wish.

If the horse is rather game and fights the guy rope, unhitch him, attach the throwing harness (p. 212) and lay him down. While down, snap the whip to the right and left and over his body but do not touch him. After he becomes submissive, let him up and proceed as before. If desired, the tail-rope (p. 219) may be used and the animal made to go round and round until he goes down. While down, snap the whip about him, then let him up and proceed as suggested.

During this training process, rely less and less on the appliance and more and more on the lines, whip and voice. The object should be to dispense with the guy rope and double safety as soon as possible. This can be accomplished gradually by attaching the guy rope to the bit and lastly by removing it altogether. It is a good plan, however, to carry the appliance for some time. Should he refuse to go, 
upon arriving at a special place or circumstance that formerly caused him to balk, give him a severe lesson. After a few such lessons there should be no further trouble. If at any time the horse seems confused, stop him at once by the command "whoa." Then as you give the command "get-up," snap the whip at his right. This serves to remind him of his former lessons in subjection and he will obey your command.

Occasionally one meets with a very stubborn horse that lies down and refuses to get up. In such a case something must be done to attract the animal's attention. Some persons advise violently blowing the breath into his ear and at the same time striking him a severe blow across the hind quarters with the whip. This seems to nomplus the horse and he leaps to his feet at once. Another plan is to pour a pint of water into the animal's nose while you hold his nose up. Such treatment diverts his attention and he bounds to his feet.

Jibbing. - This is a vice in which the horse refuses to go in a certain direction though he may be perfectly willing to go in some other one. In America the habit is usually classed with balking, while in England, where it is considered a more serious vice than balking, it is always classed separately. The causes that tend to produce it are very similar to those that produce balking.

To orercome the vice it is first essential that the 
horse be trained thoroughly to the uses of the bit, to the commands, and more especially to guide to the right and to the left. In teaching these lessons, proceed as suggested for the balker (p. 249). If the horse refuses to go in any desired direction, pull him to his knees and hold him there until he calms. If he refuses again, have the assistant take up a position in the direction you desire to go, and as you pull the line have him jerk the horse in the desired direction with the guy rope. If the horse is game and still resists, remove the double safety, attach the throwing-harness and lay him down, holding him there until he becomes aware of his helpless position and gives in. Try again as before. If he still refuses, attach the tail-rope and stupefy him. Free his head and proceed as before. This alternate lying down and going round and round soon convince the most incorrigible horse of his absolute helplessness.

If the horse viciously refuses to turn in a certain direction, say to the left, lay him down on the right sicle with the throwing harness, then place a rope halter on his head, pull his head around on his left shoulder, and secure the lead-rope to the tail in such a manner as to hold his head over his left shoulder. Keep him in this position a few minutes, but watch him closely to see that he does not injure himself, as he will struggle violently to regain his feet. When he becomes submissive free his head, let him up and 
proceed with the bitting as suggested. This treatment seldom if ever fails to have the desired effect.

As soon as the horse thoroughly obeys the commands and reins, hitch him to a vehicle and continue the work. If he seems obstinate, pull him to his knees; if this does not suffice, unhitch him, alternately lay him down and make him go round and round until he falls. As a rule, one half hour of such treatment for three consecutive days will overcome the most stubborn case.

Kicking. - This is a very dangerous vice, though formerly it was the horse's principal means of defense. While the horse usually kicks backward with one or both hind legs, he can kick outward and forward like a cow, to reach an object near his forelegs. The causes which excite the horse to kick are very numerous, chief of which are touching him in some tender place, as the tail over the line, the crosspiece of the vehicle striking his quarters and the causes named above for provoking the horse to balk (p. 249). Lack of proper training is also an important cause. The horse that is not properly educated to pressure, as suggested in poling (p. 69), is the most likely to develop the kicking habit; thus if a horse kicks because he gets his tail over the line, or the cross-piece strikes his quarters, it indicates that his hind quarters were not properly educated.

In training to overcome the habit of kicking, give the horse a thorough course in poling. Attach the 
double safety (p. 208) and guy rope (p. 201), or some prefer the war bridle (p. 191) to the guy rope. At first refrain from touching the hind legs until you are satisfied that progress has been made. As soon as he will let you rub the body as far back as the quarters without any indication or disposition to kick, then pass the pole gently toward the hocks. If he shows a disposition to kick, work the pole up toward the quarters, then begin to work down gradually as before. If possibje do not entirely remove the pole from the horse. Continue until he becomes submissive. If during the poling lesson he offers to resist, pull him to his knees and continue the work. If he is exceedingly game, attach the throwing-harness (p. 212), lay him on the ground and pole him while down. When he becomes submissive while down, let him up and continue the poling as before. After his hind legs are submissive, crupper him as suggested (p. 70), employing the appliance if necessary to control him.

Now harness the horse, arranging the breast-band and breeching rather loosely and placing the traces through the rings on the breeching, so that the ends will flap about the hind legs and quarters. If he resents the pressure from the loose harness and kicks, stop him instantly and attach the war bridle and double safety, or better still, attach the appliance at the time of harnessing if the animal promises to give trouble. Now try him again, and if he kicks, 
give the command "steady" and pull him to his knees rather severely. Hold him in this position until the excitement passes away. Continue the process until he submits.

Next take two long poles, secure one end of each on either side at the shaft tug, and allow the other end to drag on the ground behind the horse. Now drive him about, and if he offers to kick, command "steady," and if he continues, pull him to his knees and hold him there a moment. If he fights this appliance too much, attach the throwing-harness and lay him down or use the tail-rope (p. 219) to stupefy him. After he becomes submissive to the poles dragging on either side of him, then place them between his hind legs and continue as before. Care should be exercised at this time, for the animal may injure himself. Do not continue to drive him with the poles between the hind legs, for the poles will rub the legs sore. If he resents this or kicks, give him the same treatment as before. Continue until he submits.

If the horse is a very stubborn and confirmed kicker, if he bucks as well as kicks, or if he has a tendency to get his head down on his breast so as to render the lines ineffective, then attach the kicking reins (p. 202) instead of common lines. These reins provide good leverage and are very efficient in controlling such a horse.

After the horse becomes perfectly submissive to the poles dragging both on the outside and between 
his hind legs, he should be hitched to a vehicle. At first the double safety and war bridle should be retained and one of the kicking appliances suggested (p. 202) should be provided, so as to be able to meet any emergency. If the horse shows any tendency to kick, give the command "steady" and pull him to his knees. Repeat this two or three times, and about the fourth time, instead of using the safety rope, give the animal a severe set-back with the lines by having the left line tight and giving a severe pull with the right. This gives him the impression that you have the same power over him with the lines that you have with the safety rope. Continue this, removing the ropes as soon as it is safe, though they should be carried along for some time.

Shying. - This is a very dangerous habit and usually results from two causes, a natural nervous or timid temperament and defective eyesight. As the latter is beyond the field of the trainer, requiring the attention of a veterinary surgeon, we will not consider it here. We are more especially interested in shying as the result of a nervous temperament, as much can be done to overcome it if the proper means are employed. With this class of horses the habit is largely due to improper handling. Perhaps no other single cause results in so much shying as the improper use of the whip. The timid horse comes to some object that frightens him, and true to his instinct he pauses, or he may notice the object 
just as he gets even with it, and again, true to his nature, he jumps in an endeavor to get away. In either case, instead of permitting the horse to get acquainted with the object, the driver takes the whip and by punishing the animal forces him past and may continue the punishment long after the object is passed. It is in some such way as this that the habit of shying is formed.

The very nervous horse will sometimes shy at the most trifling objects and no doubt occasionally imagine the object of his fright. The sudden rustling of the leaves or a piece of paper caused by the wind, stumps, stones, logs, pools of water, flashing light and the like are common objects. The automobile, electric and steam cars and the traction engine often excite the horse to shy. Few horses are so steady but that they will show alarm at a pig that runs and grunts, particularly after night. Whatever the cause of the horse's fear, he must be made familiar with it and taught that it will do him no harm.

To overcome the habit of shying it is absolutely necessary that the horse understands and obeys the commands. Next familiarize him with strange objects, as suggested for the work horse (p. 85) and the wild horse (p. 237). After working with a rather familiar object, as old papers, which were suggested for the work horse, then take an object that causes the animal special fear and with the appliances suggested for the wild horse thoroughly educate the 
timid horse that such objects cannot do him injury. Do not rush through this work, but give him ample time to adjust himself to the new condition. After he is perfectly familiar with this special object, take another and repeat the lesson. To inspire confidence in your commands, caress him often and soon he will go any place you wish.

Now that he has learned to face strange objects and has confidence that you will not ask him to do that which will cause him injury, you are ready to hitch him to a vehicle. For the first few times leave the safety ropes attached. If convenient, drive him past some object that formerly caused him special fright. As you approach the object, caress him with voice and whip to assure him that no injury is to come to him. Drive up on the opposite side of the road until a few feet in front of the object, then face him toward it, and stop at the command "whoa," if necessary using the safety to assure him that you have perfect command. Now make him walk right up and feel it with his nose as you did the objects in the training paddock. As he moves toward it, caress him to give him confidence. If at any time you wish to square him, pull his head away from the object, as this straightens the head and neck and gives much better control. To leave the object, carefully pull the horse away with the line farthest from it and give the command "get-up." Should he show alarm, immediately stop him at the command 
"whoa" and allow him to stand until he becomes steady. If he seems frightened, turn around and approach the object as before. Continue this process until the timid horse will face everything that formerly caused him fright, and shows no fear either in approaching or leaving.

Running away. - This is a vice in which the horse usually breaks suddenly into a gallop and rushes forward with all the speed of which he is capable. Once started he seemingly no longer sees, hears or smells. Blind to objects likely to injure him, deaf to threats, insensible to blows and to pulling on the bit, he no longer realizes danger. Efforts made to stop him only serve to increase his fright and he stops only when utterly worn out in strength and wind, or when he is checked by colliding with a telephone pole, fence or vehicle.

The habit often results from bad education, such as the improper use of the bit, or from the use of severe bits which destroy the natural sensitiveness, and from vicious tempers. It is excited in much the same manner as shying. On the other hand, one will occasionally meet with what seems to be an extremely gentle and high-spirited horse that is addicted to this habit, due to some internal impulse not clearly understood. In such cases it is probably lack of exercise, and when the horse is driven he becomes intoxicated at the chance to extend himself. He begins as in play, but soon "loses his head" and be- 
comes deaf to all restraint. It often happens that the driver removes the bridle to give the horse a drink by the roadside. This is an unsafe practice, as the horse may become frightened, especially if he is driven with blinds, as removing them increases the range of his vision and he sees objects in the rear which he had not noticed before, and in his excitement runs away.

To overcome the habit of running away, it is necessary to put the horse through much the same course as in balking, kicking and shying (p. 249). First of all make him thoroughly obedient to the commands and uses of the bit. After familiarizing him with objects, such as papers, flags, umbrellas, robes and the like; and to sound, as pans, sleigh-bells, steam cars and the firing of guns, hitch him to the vehicle with the safety ropes attached. After driving him about for a time, give him the opportunity to run away. When he gets down to a good run command "steady" and begin to restrain his front feet with the ropes. Slacken him gradually until slow enough to permit a sudden stop, then give the command "whoa" and bring him to his knees. For this work it is necessary to pad the knees (Fig. 27), otherwise he will injure them. Repeat this a couple of times, and about the third, instead of using the safety rope to bring him to his knees, give him a severe set-back with the lines by having the left line tight and giving a severe pull with the right, thus giv- 
ing him the impression that you have the same power with the lines that you have with the safety rope. Continue this work, driving him past objects that formerly excited him to run, until perfectly submissive.

Running back. - This is a very dangerous habit, as the horse may cramp the vehicle and upset it, thus throwing the occupants to the ground, or he may back into other vehicles, or people passing by or the like. The causes which provoke a horse to run back are quite numerous, chief of which are improper training to back, and inexperienced or unskillful drivers. The habit is not uncommon among spirited horses, in which it is often provoked in the following way. As the horse approaches some object to which he has not been properly trained, say an automobile, he slackens his speed at the strange sight; the driver at once becomes frightened and begins to pull back on the lines. The horse, of course, thinks this means to go backward, and as he starts to obey, the driver strikes him severely with the whip. Now the animal's confusion is complete; he is restrained in front by the pressure of the bit, and spurred on behind by the blows from the whip, with the object of his fear approaching him, and to avoid the strange object he backs up, as best he can. To avoid all such trouble, teach the horse to have confidence in the driver, and train the animal to all such objects before driving, or at least abstain from punishing him at both ends simultaneously. 
To overcome the habit, be sure that the horse is obedient to the commands. Then with the double safety rope (p. 208) attached, command him to back. After backing a few steps, command him to stop, and at the same time pull him to his knees. Continue this until he understands that "whoa" means to stop, whether going forward or backward. Now hitch him to a vehicle and put him through the same course. Next drive him to some object that formerly provoked the habit and repeat the process. It is a good plan to carry the safety rope for a time, and if he promises to repeat the habit attach the rope and pull him to his knees at the command "whoa" as before.

Difficult to back. - Occasionally a horse will be met with that resists all efforts to get him to back; he stiffens his muscles, stretches his forefeet forward and his hind feet backward, and will often lie down on his belly in an effort to keep from backing. This habit results from confusion at the time of teaching the horse to back. He has perhaps been punished at both ends and lies down in an effort to escape his tormentors. In overcoming this habit, attach the pulley bridle (p. 193) under the leather bridle, and take a position near the horse's left shoulder while an assistant holds the lines. Now as you give the command "back" have the assistant give a severe see-saw pull on the lines and simultaneously give a sharp jerk on the pulley bridle. This will 
surprise the horse and he will take a step backward, when he should be caressed. Do not ask him to back very far at a time, and caress him for doing as you wish. Repeat the process until he will obey the lines and voice, remove the pulley bridle and continue with the lines until he will obey the voice alone.

Rearing and plunging. - Since these habits are somewhat similar, they will be considered together. Both invariably result from defective training and are usually traceable to bad mouthing. They are provoked in much the same manner as balking, kicking and the like (p. 249). In overcoming either vice, first train the horse to the proper uses of the bit (pp. 56 and 134). This may require patience and tact, but is essential in overcoming such habits. If the mouth has lost its natural sensitiveness by the use of harsh bits, use the Yankee bridle (p. 189) in the bitting process. As soon as he understands the uses of the bit, teach him the commands. By the proper application of the double safety (p. 208) in pulling him.to his knees every time he rears or plunges, he should be taught the meaning of the command "whoa" so very thoroughly that he will stop and stand quietly at the command.

Now with the Yankee bridle and double safety still attached, hitch him to a vehicle and continue as before. Each time he starts either to run or plunge, give the command "whoa" and bring him to his knees. Hold him down until he quiets. About 
the third time, instead of using the safety give him a severe set-back with the lines, to impress him that you have the same power with the lines as with the rope. Now drive him to those objects that formerly caused him to rear and plunge, and continue until he becomes perfectly submissive and quiets at the command.

Breaking and prancing. - Occasionally a highspirited but nervous horse, because of his eagerness to go forward, becomes addicted to the habit of breaking and prancing when we wish him to walk or trot. This often becomes very aggravating and may lead to more serious vice, as he is especially liable to rear and throw his head up and down. To overcome the habit, attach the double safety (p. 208) and thoroughly educate him to the commands, especially to the term "steady." If he seems very game, apply the throwing-harness (p. 212) and lay him down until he becomes quiet, or if preferred attach the tail-rope (p. 219) and stupefy him. When he becomes obedient to the commands and will walk or trot as you like, then hitch him to a vehicle, and continue the work as before. The horse that is exercised regularly is less likely to acquire such habits than one that stands in the stable much of the time.

Switching tail. - Some horses have the very aggravating habit of constantly switching the tail. The causes for this are quite numerous and much the same as in producing kickers (p. 254). In fact, 
the switching of the tail indicates a predisposition to kick. To overcome the habit, put the horse through the course suggested to overcome kicking. While such a course may seem long and tedious, it is essential, as both kicking and switching the tail are due to vicious tempers, and the horse must be subdued beforeeither habit can be permanently overcome.

There are several appliances that are very effective in preventing the horse from switching his tail, particularly in the case of a mild-tempered animal. Secure a strap about one inch wide and of sufficient length to reach from the crupper to the breeching. On one end have a loop made so that the crupper can be run through it. On the other end arrange a buckle so the end may be buckled around the breeching. This end should be buckled rather loosely, so as to permit it to slide easily on the breeching. "Get two short straps, of sufficient length to buckle around the tail under the hair, and sew these crossways of the former strap, the upper one about four inches from the top loop and the second four inches below the upper. With the former strap placed around the crupper, under the tail and buckled to the breeching, buckle the two short straps around the tail under the hair, and you have an appliance that will keep the horse from switching the tail far enough to catch the lines (Fig. 79).

Another appliance that is fairly effective in preventing the horse from switching his tail is made as 
follows: Secure a piece of leather about five inches wide and about as long as the tail-bone. At one end of this attach a crupper, at the other sew a bag sufficiently large to hold two pounds of shot, and about four inches apart near the middle attach two short straps at right angles to the broad leather band to buckle about the tail. Fill the bag with shot, suspend it under the tail and buckle the crupper to the back-band and the small straps about the tail-

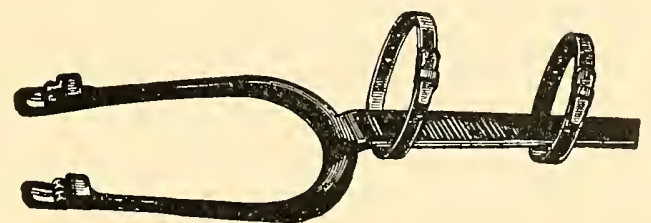

FıG. 79. - Anti-switehing appliance, in the form of crupper and breeching.

bone, and you have an appliance that cannot be seen, as well as one that will prevent the horse from switching his tail. Still another plan for preventing the horse from catching the lines with his tail is to gather part of the hair a little above the end of the tail-bone, extend toward the tug on either side and tie securely by means of a string. Thus by drawing the tail down tight the animal is unable to switch it. Some prefer to take a strap, attach it to the hip-strap, pass it around the quarters, and secure the tail to it (Fig. 80). This arrangement is objected to because it is exposed to view, although it is very efficient in preventing the animal from switching his tail. Now 
we may gently lower the line on either side, and gradually accustom the animal's hind quarters to the slight pressure of the lines, and eventually he will cease switching his tail when the lines touch his quarters.

Tail over line. - Occasionally a horse will be met with that becomes very much excited when he gets his tail over the line. He clamps the line so firmly

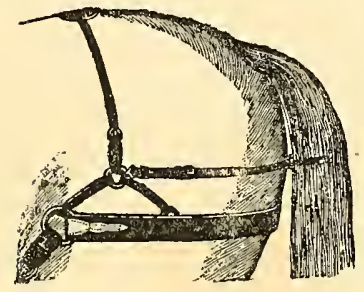

Fig. 80. - Hip-strap antiswitching appliance. beneath his tail that it is freed with great difficulty and often not without injuring the tender parts, which may provoke kicking, backing or running away. While there are many causes for this habit the two chief ones are improper training, particularly the cruppering, and tender tail, the result of irritating sores produced by poorly fitting harness. The tight, dirty crupper causes a sore tail and the line by some chance gets under the tail and into the sore, causing the horse much pain. This he remembers always and when the line gets under the tail he thinks only of the pain it once gave him, and hence the excitement.

To overcome this habit, carefully pole the tail as suggested in poling the work horse (p. 69) and in overcoming kicking (p. 254). Do not rush through the work, but give the horse sufficient time to become familiar with the pressure of the pole. With the 
pole work back toward the tail very gradually, and if he shows much excitement slip the pole up his back and then start toward the tail again. Continue this work until he becomes perfectly submissive. Raise the tail and place the pole from buttock to buttock under the tail. As much care should be used in removing the pole as in placing it under the tail. After he becomes perfectly familiar with the pressure of the pole, with the double safety still attached, place the harness on him and drive him about the paddock, managing to get the line under the tail. If he shows excitement, quiet him at the command "steady," as in poling. If he refuses to quiet, go over him again with the pole. Soon he will learn that the line is no more likely to cause him pain than the pole. When he becomes submissive to the line under his tail, he may be hitched to a vehicle and the work continued as before.

Halter-pulling. - This is a very aggravating habit and one that is easily acquired. It is usually due to faulty training, the horse being tied up by the head before being educated to the pressure of the halter. The strange object on his head annoys him and he tries to shake it off, and failing in this he tries to free himself by pulling. Now he finds himself in a trap and becomes frantic in his efforts to get free. The pressure of the halter hurts his head and he may pull so hard as to deform the face lines or injure his neck, or he may break the strap that secures him; in any 
event, the foundation for a confirmed halter-puller is laid, and in the future he will pull at the least provocation. To avoid this, familiarize him with the pressure of the halter before tying.

To overcome the habit of halter-pulling, or to train the horse to stand tied, secure a half-inch rope

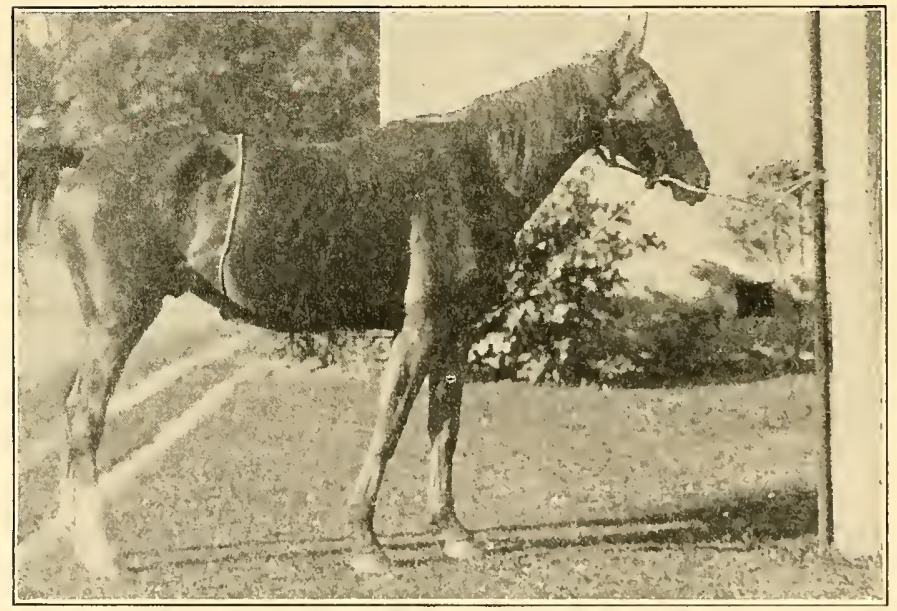

FIG. 81. - Loin-hitch to ovarcome the habit of halter-pulling.

about fifteen feet long and tie a loop that will not run in one end. Place the rope about the horse's body just in front of the hips with the loop under the abdomen and run the free end through the loop, then forward between the forelegs, up through the ring at the halter, then around a solid post and back and tie into the ring at the halter (Fig. 81). Now excite 
the horse to pull. The instant he feels the pressure about the body he bounds forward and stands close to the post. To avoid any possibilities of his pulling in the future, with an umbrella, flag or other strange object force him back into the rope rapidly so as to cause him sufficient pain to fix it in his mind. Since it is natural for him to flee from pain, he springs forward to relieve himself from the pain around the body. After two or three such pulls he will crowd the post so closely that a string will probably hold him as securely as a chain.

Occasionally one will meet with a confirmed halter-puller that is reluctant to give up. He will go back into the rope, and notwithstanding the pain about his body he pulls stubbornly. He may pull until he falls and spring to his feet and try again. After he struggles for a time, force him back into the rope severely by tapping him across the nose with the whip. This throws him into the rope with such force as to increase the pain about the body which, coupled with the fright caused by the whip at the nose, never fails to bring him forward. Caress him and treat him kindly while he stands by the post. Should he start to pull again, force him into the rope severely as before but as soon as he comes forward, caress him. After a few such struggles it will be difficult to get him away from the post. Three or four lessons on as many days will overcome the most stubborn of halter-pullers. 
This treatment is sometimes recommended for the horse that balks. He is first tied to a post and forced back into the rope until he learns its use and to spring forward as it presses him. Then he is hitched by the side of a gentle horse with the halterpulling rope still about his body, and the other end is tied to the hame of the gentle horse. It should be tied of such length as to cause no pressure so long as the balker walks along even with the other horse, but the instant he refuses to go the pressure is brought to bear about the body, when he springs forward as at the post.

In overcoming the habit of halter-pulling, some horsemen think they get better results from slightly different hitches. Some prefer to tie a stationary loop in one end of the rope sufficiently large to go about the tail similar to a crupper, passing the free end forward through the turret at the top of the surcingle, then through the ring at the halter on to the post and back, and tie to the ring at the halter (Fig. 82). Now when the horse pulls back, the pressure is brought to bear at the tail, a very sensitive part, and he springs forward as before. Other horsemen prefer to tie one end of the rope about a pastern, some choosing a fore pastern, others a hind one, then pass the free end of the rope through the ring at the halter and on to the post, then back to the halter and tie as before. With this hitch when the horse pulls, he jerks one leg out from under him, which surprises 
him so greatly that he soon ceases to pull back. Whichever one of these hitches is employed, it is important to force the horse back into the ropes until he fully understands that pulling back causes

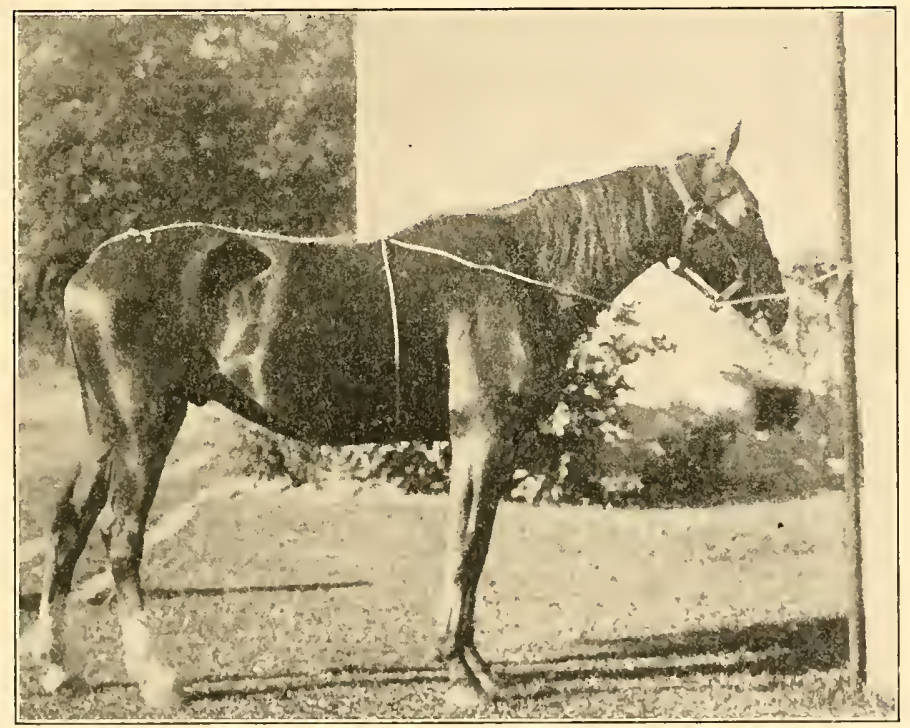

Fig. 82. - Tail-hitch to overcome the habit of halter-pulling.

him pain, thus associating the act of pulling back with pain. To avoid the pain he ceases to pull back.

Unsteady under whip or spur. - While this nervousness or impatience is not a vice, it is very aggravating to drive a horse that will not permit a whip to be held over his back, or to ride one that will not obey the spurs. This is particularly true in the . 
saddle horse as the spurs are used in perfecting the gaits. To overcome this habit, pole the horse much as suggested for kicking (p. 254). After he becomes perfectly familiar with the pole applied to any part of the body, then take the whip and rub it over him in a similar way. If he resists, attach the throwing harness, lay him down and rub him with the whip; when he becomes steady, let him up and continue as before. Repeat until he becomes thoroughly submissive to the whip and will let you flick it about his body.

To overcome the habit of resisting the use of the spurs give special attention to poling the flanks, then touch him gently with the blunt spur and next with the rowel. If he resists, lay him down and familiarize him with it on the ground, caressing him frequently. When he becomes steady, let him up and continue the work until he becomes submissive.

Difficult to mount. - Some horses are exceedingly difficult to mount. While this habit may be due to many causes, the two chief ones are improper training and tender or sore back. In the latter case, the first thing to do is to heal the sore. To overcome the habit when due to lack of training or nervousness, give the horse a thorough lesson in submission. Attach the throwing-harness (p. 212), lay him down and hold him there until he becomes quiet, then place an empty bag across his body. After he becomes accustomed to the empty bag, fill it half 
full of earth and replace it. As soon as he becomes submissive to the half-filled bag, let him up and replace it while standing, and secure it so he cannot get it off his back. Drive him about for a time. If he acts up, attach the double safety (p. 208), and pull him to his knees. As soon as he goes steady with the bag on his back, remove it, saddle him and mount. If he resists, attach the tailrope (Fig. 83) and make him go round until he drops. Free his head, and while in this stu-

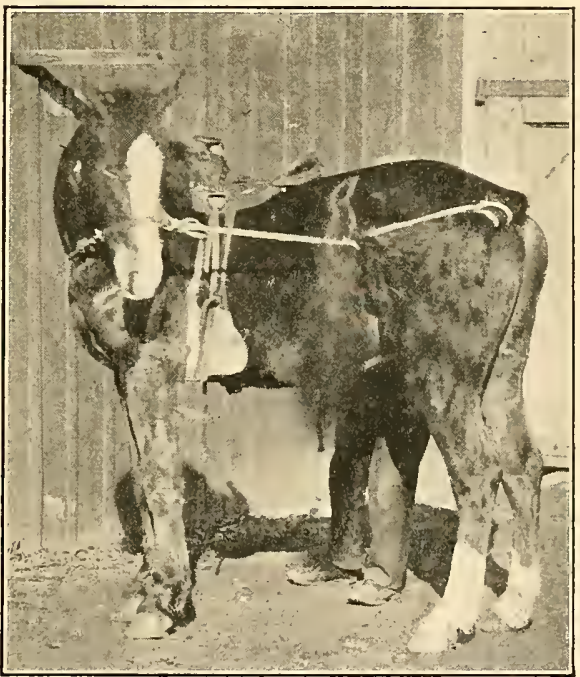

Fig. 83. - Galvayne tail-rope, arranged to overeome the horse difficult to mount. pefied condition he will stand as you mount. Caress him for doing as you wish. Some horsemen recommend placing the tail-rope under the saddle-girth and mounting as the horse goes round and round. While this is a good plan it is somewhat dangerous unless you are a good horseman and can ride in a small circle or dismount quickly in case the horse falls. 
Buck-jumping. - This is a very dangerous vice of riding horses. Sometimes they buck and run away as horses in harness do. They get their chins down on their breasts, arch their backs and bound, buck or jump along in such a way that it requires an expert rider to remain in the saddle. To overcome this habit, put the horse through a similar course to that suggested above for the horse difficult to mount. Spend much time in driving him about with the bag of earth secured to his back and the double safety attached. Each time as he starts to buck, bring him to his knees severely and hold him there for some time. Soon he will understand that if he jumps or bucks, he must come to his knees and remain there as a punishment. Now do all you can to make him buck, pulling him down each time that he does. When he positively refuses to buck, stupefy him with the tail-rope and then mount.

Rearing. - This is also a very dangerous habit for a riding horse to possess, as he is likely to throw his head up and strike the rider, or in some cases, he may fall over backward, thus exposing the rider to the greatest of danger. To orercome the rice, put the horse through the same course suggested above for the horse difficult to mount and the buck-jumper. When he seems perfectly submissive and you are ready to mount, as a further precaution attach the rearing-twitch (p. 200) to prevent any possibility of danger. Now if perchance he should start to rear 
or even throw his head up, you can give the twitch a jerk which will force him to lower his head.

Jumping fences. - Many horses have the very aggravating habit of jumping the fence when turned to pasture. While there are many causes producing this habit, the principal one seems to be a faulty temper. Many contrivances have been devised to prevent horses from jumping fences. Yokes of all descriptions have been manufactured with the central thought of punishing the animal when he approaches the fence, with the result that horses are often injured, sometimes fatally, by such contrivances. The yoked horse in fighting flies sometimes injures himself or others standing near by. A contrivance free from all such dangers, and equally if not more efficient, is made as follows: Procure a surcingle with a ring at the bottom, a short piece of rope, and two leg-straps provided with rings. Place the surcingle on the horse and buckle the straps about the forelegs just above the knees. Next tie one end of the rope in the ring at the back of the left knee, then pass the free end up through the ring at the bottom of the surcingle, then down, drawn medium tight, and tie in the ring at the back of the right knee. This will permit the horse to walk naturally, lie down, get up, and, in fact, do almost anything except run or jump, which it most effectively prevents. The principal advantages are that there is no risk attached to its use and the horse's head and neck are perfectly free. 
OUTDOOR WHIMS, THEIR CAUSE AND HOW TO OVERCOME THEM

Tongue-lolling. - Some horses have the disagreeable habit of protruding the tongue from the mouth, usually either to the right or left, but sometimes in front; others place the tongue on top of the bit, and still others fold the free part backward and underneath without protruding it from the mouth. Each of these abnormal positions of the tongue lessens the sensitiveness of the mouth and, in addition, the lolling tongue is exposed to injury, which may become very serious. The principal cause of such habits is improper mouthing. The tongue-lolling bit was devised to overcome these habits. This bit is similar to a straight bar-bit with guards at either side and with an oval, flat piece of steel attached to the bar. This steel is about two and one half inches wide and three to four inches long (Fig. 94, 5 and 6). The bit is placed in the horse's mouth with the flat piece resting on the tongue. As this extends up into the mouth about two inches back of the bar, it is impossible for the horse to get his tongue back far enough to get it over the steel, and the guards at the sides effectively prevent him from protruding it at either side.

To make a tongue-lolling bit, use an ordinary straight bar-bit (Fig. 94, 1 and 2), and file three inches of the middle flat. Sew an oval piece of sole 
leather, about two and one half inches wide and four inches long, over the flat place. The flat place in the bit prevents the leather from turning, which makes a very good tongue-lolling bit. Now take two circular pieces of leather about three inches in diameter and attach to the bit ring on either end, thus preventing the horse from protruding the tongue at the sides.

Striking lips. - Certain horses have the habit of continually moving the lower lip in such a way as to cause it to strike against the upper lip. Sometimes this is done with sufficient force to make a characteristic noise. The cause which tends to produce it is lack of proper training in permitting the horse to fight or play with the bit. While the habit is not as dangerous as tongue-lolling, it is very unpleasant to drive or ride such a horse. To prevent the habit, make a lip-strap conforming to the lower lip and chin, and attach this to the bit in such a way as to limit the descending movements of the lower lip.

Grasping bit. - The habit of seizing the bit between the teeth or with the lower lip is quite common. This is rather dangerous since, when the bit is so held by, the horse, it is not possible to control his action. The habit is usually caused by improper methods of bitting, the horse grasping the bit to gain relief from unnecessary pain. Usually a light jerk of the rein will compel him to let go, but when the habit is confirmed, other methods must be employed. It is on horses of this class that the curb bit is permissible. 
If he is persistent, have the branches curved backward. With the lines attached to the long lever of the curb and the branches curved backward, one can easily compel the most stubborn horse to let go of the bit (Fig. 94, 34 to 36).

Gnashing teeth. - This is a habit somewhat similar to grasping the bit with the teeth and is caused in like manner. To overcome the habit in case it is confirmed, employ the same kind of curb bit, attaching the lines to the long lever of the curb. Then by a slight see-saw motion of the lines one can compel the horse to desist.

Tossing and shaking the head. - Certain horses have the very aggravating habit of jerking the lines by continually tossing the head up or down, or by throwing it from side to side. Such horses are difficult to drive properly, as they pull the lines through the hands and may throw the lines over the end of a shaft and an accident result. Either habit is due to improper bitting and is often difficult to overcome. The best method of prevention is to obtain a short strap about six inches long provided with a loose ring and a snap at either end, to secure in the bit ring on either side so the loose ring will remain under the lower jaw. Now secure a strap to this loose ring under the jaw, pass it down between the front legs and attach to the belly-band similar to a standard martingale. This is a very effective appliance for preventing either habit. 
Lugging. - The horse that continually pulls on the bit is spoken of as a lugger. The habit is very common and exceedingly difficult to overcome. It is usually due to improper bitting, the use of a severe bit having paralyzed the muscles of the mouth to such an extent that as a rule no matter what kind of bit is used, it has no effect whatever. Occasionally, however, a change of bits will prove beneficial. To overcome the habit, it is necessary first that the horse be perfectly obedient to the commands. As his mouth has lost its sensitiveness, it will be necessary to teach commands by employing the double safety rope and either the guy line or Yankee bridle, much as suggested in overcoming balking (p. 249). Continue the work as suggested until he becomes obedient to the commands without the use of the lines. Next, with the double safety rope still attached, hitch to a vehicle. Now instead of pulling on the lines to steady him give the command "steady," and if he does not obey, begin to interfere with his legs by pulling on the rope. Do not pull on the lines in every event; if he is stubborn and will not steady, pull him to his knees, at the same time giving a see-saw pull on the lines. Continue this until he understands that the slight see-saw motion of the lines means to go steady. If he is very game, use the throwing appliance or the tail-rope to subdue him.

Boring. - The horse that lugs or pulls more on one rein than on the other is said to "bore." The causes 
that tend to produce it are similar to those that cause lugging, and in fact the two habits are much the same; in one case the horse pulls straight forward, while in the other he pulls to one side. To overcome the habit, put the horse through the course suggested for lugging.

Crowding and pulling away. - These are very troublesome habits often met with when horses are hitched double, one horse often crowding the other so hard as to push him out of the road, or pulling away so far as to pull the other out of his path, either of which is very aggravating. The principal causes tending to produce either habit are lack of proper training, especially bitting, and poorly fitting harness, which chafes the horse, thus producing irritating sores. When the trouble is due to the latter cause, the first thing to do is to obtain properly fitting harness and heal the sores. When the habit is due to improper bitting, the horse must be put through a course of subjection and then educated to the proper use of the bit, and to obey the command similar to that suggested for the balling horse (p. 249).

After the horse becomes obedient to the commands and familiar with the uses of the bit, he may be hitched double with the double safety still attached. Now, if he crowds or pulls away, command him to "take care," and begin to interfere with his legs by pulling on the rope, at the same time giving a slight jerk with the line. If he continues to crowd, pull 
him to his knees, stopping the other horse at the same time. Continue this until he obeys the command and the jerking of the line.

In certain kinds of work, such as plowing, when the single line is used on the leader, it is necessary to employ a "crowd stick" to prevent the off horse from crowding the near one. This stick is attached to the lower end of the hame on the leader and to the right ring on the bit of the off horse, and is of such length as to hold him in his proper place. To overcome the confirmed crowder, some horsemen take an inch board about six inches square and drive several eightpenny nails, with sharpened ends, through it, then suspend the board on the side of the steady horse in such a way that when the other crowds, he comes in contact with the sharpened nail ends, and the punishment thus inflicted teaches him to stay over on his own side of the path.

Stripping bridle. - Certain horses have the habit of stripping the bridle whenever the opportunity presents itself; thus when tied to a post or rack, if their bridles are the least bit too large, they slip them off their heads, and when they find themselves free they start to walk away, breaking the lines and perhaps getting into greater difficulty. The chief cause tending to produce this habit is poorly fitting bridles, either too small or too large. When too small, the bridle fits so tightly about the forehead and at the corners of the mouth that the horse rubs 
his head on the post to get relief, and perhaps breaks some part, which gives him relief and permits the bridle to slip off. Thus he learns that when the bridle annoys him he gets relief by rubbing it off. When too large, the bridle hangs so loosely that in moving the head about, the bridle catches on the rack and the horse slips his head out. To avoid this habit, use a properly fitting bridle (p. 325). To overcome it when once established, use a properly fitting bridle with both a nose- and chin-band fitted snugly, as such a bridle cannot be stripped off without great difficulty, though to avoid any risk use a neckstrap fitted snugly and with the tie strap run through the ring at the bit, and secured to the post or hitching rack.

Refusing to stand. - Some horses have the very aggravating habit of refusing to stand while you get in the vehicle and arrange the robes. This is due simply to lack of proper training, and to overcome the habit it is necessary to teach them to obey the commands thoroughly. The horse must be taught that "whoa" means to stand quietly until ordered to move on. If he fails to respond to gentle treatment, put him through the course suggested in overcoming balking (p. 249). Then with the double safety still attached, hitch him to a vehicle, and if he moves while you are arranging things, severely jerk him to his knees and hold him there a few minutes. Continue until he obeys. 
Troublesome to catch. - This refers to the horse out at pasture refusing to come when called, or refusing to allow one to approach him. It is very annoying to corral such an animal. The habit is due to improper treatment, usually when young. It is not uncommon for boys or thoughtless persons to throw sticks or stones at young colts to make them run. In this way the horse learns that by fleeing when any one comes near, he avoids such objects as are thrown at him. To overcome the habit, treat the horse gently, take an ear of corn, an apple or a little sugar to the field when you go after him and be sure to give him the dainty and caress him when he comes to you. If you catch him by offering the corn, then refuse to let him have it, he is not likely to let you "catch him again; hence give him the dainty each time and he will soon reward you by coming when you call him. 


\section{CHAPTER VIII \\ STABLE VICES AND WHIMS}

Many a young horse has been spoiled the first day he spent in the stable, by the treatment he received. Many persons seem to think the green horse should stand much the same as a work horse. Thus if he fails to stand over when commanded, or if he will not permit his sensitive abdomen and legs to be curried, or if he objects to having heavy harness with flapping bands thrown over his back, then a whip, fork handle, club, lip twitch, or anything that the excited attendant can lay hands on, is used to punish the horse, with the result that a habit is established which may be exceedingly difficult to overcome. All such excitement and resulting bad habits easily can be avoided by a little patient effort in properly training the horse. The stable education should take place simultaneously with the training in the pardock.

STABLE VICES, THEIR CAUSE AND HOW TO OVERCOIIE THEM

Refusing admission into stall. - The horse that has not been trained properly sometimes refuses to let the attendant enter the stall, or crowds him against 
the partition once he gets inside. This is a very dangerous habit, as one is likely to be injured either by being kicked, or by being squeezed against the side of the stall. To train the horse to permit admission to his stall, secure a three-eighths inch rope about ten feet long, and two rings with staples attached. With the staple secure one of the rings to the left stall partition about as high as the horse's head, and over the manger. Secure the other ring to the rear of the stall where it can be reached handily without exposure to injury by the horse. Now grasp the rope, tie it into the ring at the halter, pass the free end up through the ring over the manger, then back to the ring at the rear of the stall and tie, leaving the rope slack enough so the horse can lie down or reach to the right side of the manger. When ready to enter the stall, catch hold of the rope at the rear ring, and as the command "stand over" is given, pull the horse's head over against the left partition, simultaneously giving a slight push on his hind quarter. This appliance pulls his fore quarters to the left and as you push his hind quarters to the right you have him in such a position that you can enter to his left with perfect safety. Continue to hold his head close to the left partition so he cannot either turn his hind quarter toward you or squeeze you with his left shoulder.

As soon as the horse becomes familiar with one entering the stall on the left, change the appliance 
to the right partition, and in a similar way train him to admit the attendant on the right side. This is important, for the horse that is trained only from one side is very likely to cause trouble when one attempts to enter the stall from the opposite side. Repeat this work until the horse will stand over and admit one to either the right or left at the command.

Difficult to groom. - Not only are some horses difficult to approach, but they resist grooming by arching the back, stamping and striking with the forefeet, trying to lie down, pressing the groom against the stall, and when loose in a box stall by turning around and kicking. This is a very dangerous habit, and one often difficult to overcome. In most cases, it is due to lack of proper training. To punish the animal only increases the difficulty. Gentleness, caresses, kind treatment and the feeding of some dainty will have a much better effect on the animal with such a disposition.

To overcome the habit when once established, give the horse a course in general submission by taking him from the stable and using either the tail-rope (p. 219) to st upefy him, or by laying him down with the throwing harness (p. 212). Next pole him thoroughly as suggested for the kicker (p. 254), exercising due care about the abdomen and legs. If he fights the poling process, either stupefy him or lay him down and continue the work while in the helpless condition. After he becomes perfectly 
submissive to the pole, arrange one of the twitches suggested (pp. 190 to 199), and with the twitch in the left hand, the currycomb in the right, gently go over the entire body, exercising due care about the

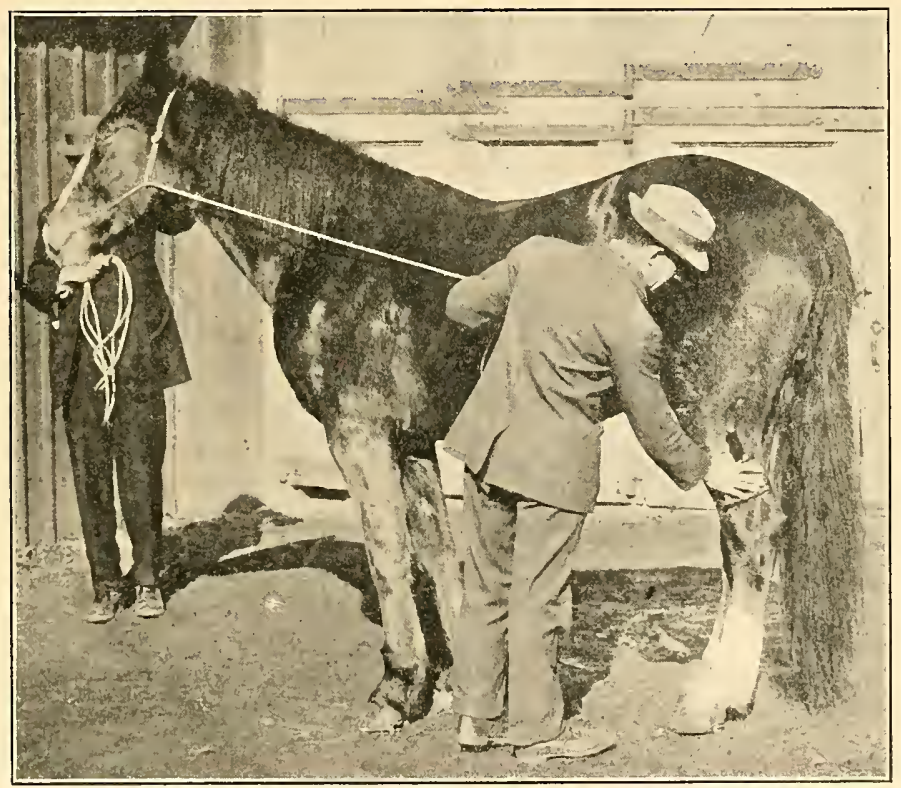

FIG. 84. - Noose-twitch on a horse difficult to groom.

sensitive parts (Fig. S4). If he flinches or stamps, jerk him with the twitch; if he is stubborn and very game, subdue him with the tail-rope or lay him down and continue the work until he becomes calm. Repeat until he becomes perfectly submissive to the use of the comb. 
In the sale stables one frequently observes a vicious horse being curried while an assistant quiets him with the lip-twitch. This twitch causes the horse such pain on the upper lip that he does not notice the currycomb and hence does not resist currying, but it does not overcome the habit, for when the twitch is removed, the horse becomes as bad as before, if not worse.

Difficult to harness. - This may become a very dangerous habit, as some horses kick with the hind feet, strike with the forefeet, bite, rear, or try to lie down as one approaches to harness them. As in most other forms of vice, it is largely due to lack of proper training, and the correct way to overcome it is to do the training over again. To begin with, the horse should be made thoroughly familiar with the uses of the bit and obedient to the commands, much as suggested for the balker (p. 249). In the second place he should be made perfectly familiar with pressure applied to all parts of the body, as suggested for the kicker (p. 254). In this poling work, give special attention to the top of the head, the back, the abdomen and the tail, as these are the parts where the harness presses. Next attach the war bridle modified (p. 192), and after permitting the horse to smell and feel the harness with his nose, gently place it on his back. Do not throw it over his back, as the loose straps dangling about his abdomen and legs may excite him to kick, 
strike or bite. If he resists as you place the harness over the body, punish him with the war bridle. Continue until he becomes perfectly submissive to being harnessed. To complete the work, in a similar way educate him to stand while being harnessed from the right side. If he is very game, attach the tail-rope and continue the work after he becomes stupefied.

Where the horse does not too stubbornly resent being harnessed, very good results are secured by tying his head very short to the manger or hayrack before harnessing, as this prevents him from biting or kicking the attendant while placing the harness over the animal's back.

Difficult to bridle. - This is a very common habit and one that is often difficult to overcome, the horse either holding his head very high or positively refusing to open his mouth. As with horses difficult to harness, this habit is due to improper methods of training, to the use of severe bits or to tight-fitting bridles." To overcome it, give the same treatment as already suggested for the hórse difficult to harness. If the horse has the habit of throwing the head up as you attempt to bridle, attach the excelsior bridle (p. 193), placing one of the ropes well back on the neck and the other just back of the ears. Now as he raises his head give a severe jerk on the excelsior bridle, thus causing pressure on the top of the neck and both pain and pres- 
sure just back of the ears, and the horse naturally lowers his head, when he should be caressed and fed a dainty, as sugar or an apple. Next work the bridle up toward the top of the ears, and if he raises the head jerk it down as before. Do not forget to caress him when he lowers his head, as this is what you wish him to do. Continue until he becomes submissive to having the bridle placed over his ears without raising the head. In case he refuses to open his mouth, part the lips at the left side and with the fingers reach in between the bars and tickle the top of the mouth, when he will immediately open his jaws and you can slip the bit into his mouth.

Difficult to crupper. - This is a very aggravating habit, as the horse clamps his tail down on his quarters so firmly that the crupper is placed in position with much difficulty. The causes of the habit and the methods of overcoming it are similar to those described for the horse that throws his tail over the lines (p. 268).

Biting. - This is a habit usually caused by irritation and rapidly develops into a confirmed and dangerous vice. Improper grooming is the most frequent cause of the irritation, hence the most gentle treatment is essential in animals with sensitive skins.

In confirmed cases, the vice is exceedingly dangerous, the animals sometimes plunging ferociously upon their victim, trampling him underfoot or 
bruising him in many ways. As dealers do not hesitate to put such animals on the market, especially when the vice is not very marked, it is a good plan for the prospective purchaser to be on his guard. Such a horse can usually be told by the manner in which he sets back his ears, puckers his nostrils, curls his lips, stretches out his head and shows his teeth when any one passes within his reach. Occasionally, however, such a horse appears very docile when in the care of his regular groom, due no doubt to his being cowed by the remembrance of past punishment or the fear of a future one.

When the horse is troubled only mildly, simply nipping now and then, the habit can be overcome by the use of the pulley bridle (p. 193). Place this on him and when he attempts to nip, punish him severely with the bridle. Tempt him to nip and then punish him if he does. Soon he will associate the punishment with nipping, and will cease. To keep the horse from reaching around and biting as you enter the stall, arrange a rope to pull his head up to the side of the stall, as suggested in refusing admission (p. 286).

If the horse has the habit too well developed to be overcome with the pulley bridle, try the war bridle modified (p. 192). Each time he attempts to bite, punish him severely with the bridle. If he still persists, apply the wooden gag (p. 200) and if neces- 
sary tie up one foreleg or put him in the straightjacket (p. 221). After placing the gag in his mouth give him every opportunity to bite, for as he does so the sharp corners on the gag cut his gums. Keep nagging him until he ceases to bite the gag. A few lessons, one each day, will serve to overcome most biters. In case the horse is a confirmed biter, it is a good plan to put him through a course of subjection with either the tail-rope or throwing harness as suggested for the kicker (p. 254), and teach him to be thoroughly obedient to the command "steady."

Tying the horse up short by the head, or the use of such appliances as the muzzle, necklet or neckcradle (Fig. 91), effectively prevent him from biting, but in no manner serve to overcome the habit. Such methods may be useful in protecting the attendant while he curries, harnesses or gentles the horse, but they are not severe enough to effect a cure.

To prevent a horse from biting his mate when hitched double, attach the modified war bridle under the common bridle and run the lead rope back to the vehicle. When the horse attempts to bite, punish him severely with the war bridle, at the same time giving the command "steady." Continue the method until he ceases the habit and quiets at the command. If he fights the method, attach the double safety and severely jerk him to his knees at the same time you jerk the war bridle. Striking. - This habit is acquired in much the 
same manner as biting and may become very dangerous. Another prolific cause of striking is the arranging of the bit too high in the mouth, especially when the mouth is tender, as the horse naturally throws his head down and strikes out with a front foot in an endeavor to remove the source of pain. When the vice is due to the latter cause, the first thing is to use a properly fitting bit and bridle. When the vice is due to infirmities of temper, other means must be employed. The horse should first be given a general course in subjection by the use of the tail-rope (p. 219), or by the throwing-harness (p. 212). Teach him to obey the commands thoroughly, and especially "steady." Then place him back in the stable, attach the war bridle modified (p. 192) and gentle both forelegs. If he strikes, punish him severely with the war bridle. Continue until he becomes perfectly submissive and will not raise either foreleg until commanded to do so.

Kicking in stable. - The horses that are given to this vice may be divided into two general classes: those that kick at persons who may be entering the stall or passing by, and those that kick to hear the noise; the latter usually kick at night and are spoken of as "night kickers." The former may prove very dangerous and the latter very annoying. The causes that produce the vice of kicking at persons are practically the same as those that make the horse difficult to groom (p. 288). To over- 
come this habit in case it is confirmed, remove the horse from the stall and give him a complete course in subjection with either the tail-rope or the throwing-harness. Thoroughly teach him the commands, especially "whoa" and "steady." Place him back in the stall, attach the war bridle modified (p. 192) and when he kicks punish him severely with the bridle. Endeavor to make him kick, then punish him for doing so. Continue until he becomes perfectly submissive while you pass around him and handle his hind quarters.

As a precaution, arrange an appliance to pull his head up to the side of the stall whenever you wish to enter, similar to that suggested for refusing admission (p. 286). Another device that some persons prefer in teaching the horse to stand over is made from a surcingle and long rope. The surcingle is placed about the horse and one end of the rope tied in the ring on the left side of the halter; the free end is then passed back and through the ring at the top of the surcingle, and tied at some convenient place near the rear of the stall. Now by pulling the rope we pull the horse's head to the left and his hind quarters to the right, thus enabling one to enter the stall without risk.

There are several ways of overcoming "night kicking," or kicking to hear the noise. A rery simple yet effective plan is to suspend from the ceiling a bag of hay in such a position that when 
hanging, it will clear the floor by about three feet and be about one foot to the rear of the horse's quarters. Each time he kicks the bag will swing back and strike his quarters. Soon he will tire of kicking it away and will stand quietly, when the bag will cease to annoy him; but as soon as he begins kicking, it will strike him again. In this way he quickly learns that by standing quietly he avoids the annoyance of the bag striking his quarters. Another plan is to pad the stall, using hay or straw and burlap, which prevents the horse from making a noise. With this arrangement he hears no report and soon gives up the habit. Another simple and yet very effective plan is to place an elastic around the horse's leg just above the hock joint. Now as he raises the leg to kick, the elastic causes extra pressure on the tendons, which serves to divert his attention from kicking. Still other horsemen prefer the single shackle, which is made from a heavy piece of leather provided with a buckle and keeper at either end. This is of sufficient length that, when buckled about each hind pastern just above the fetlock joints, the horse can stand naturally. With the hind legs thus fastened together the horse is unable to kick. The fastening of a short chain to one leg so that when the horse kicks it will strike the other leg is not to be recommended, as it is likely to injure him.

Hanging back in the stall. - This habit is rather 
common and sometimes develops into halter-breaking. The principal cause of the habit is that the flooring in the stall is too high in front. The horse cannot rest if his forefeet are elevated much higher than the hind ones. There is another rather common cause that is often overlooked. It is the usual practice in erecting stall-partitions to have them much higher at the horse's head than at the rear. Often the high part is not carried sufficiently to the rear, and the horse hangs back in order to get his head over the low part and play with the horse in the adjoining stall. To overcome the habit, level the floor and raise the partition. Then arrange a rope across the rear of the stall so that when the horse backs the rope will come in contact with the quarters, which will stimulate him to move forward. If he has contracted the habit of pulling on the halter, adapt any of the hitches suggested for overcoming halter-pulling (p. 269).

Difficult to lead into a doorway. - Some horses are exceedingly difficult to lead into a box stall, a doorway or other dark places. This habit is caused perhaps by low doorways, in which the animal has had a few hard bumps on the top of his head, which of course makes him rather timid about entering any doorway. The simplest and most efficient method of overcoming this habit is to adapt one of the hitches suggested for teaching a horse to lead (p. 51). Do not rush him through, but 
stop him as he enters, caress him and in every way possible teach him that no harm is to come to him in passing through the door. Continue the work until he walks through the door without the least alarm.

Cribbing. - This habit is commonly defined as one in which the horse gnaws at the stable fittings, such as the mangers, hay-rack, halter-strap, sides of the stall and occasionally the ends of the shafts when he is hitched. While it is not necessarily dangerous, there are few habits that are more objectionable. Further, it is often accompanied by wind-sucking, which makes it all the more disagreeable. The causes do not seem to be well understood, a few horsemen stating that it is due to a disordered stomach, but most of them agreeing that it is due to comparative idleness and bad companions, principally the former. When once developed and confirmed there seems to be no cure that will work in every case.

Many plans have been suggested for overcoming cribbing, such as smearing the fittings, mangers, hay-racks and sides of the stalls with aloes or other bitters ; removing fittings and feeding off the ground ; providing muzzles (Fig. 85, 1); supplying rocksalt for the horse to lick, and the use of a strap tightly drawn around the neck (Fig. 85, 2), all of which seem to fail with the confirmed cribber. Since idleness seems to be the principal cause, the 
best way to avoid the trouble is to keep the horse at work or exercise him regularly. A very tired horse seldom cribs.

Wind-sucking. - This habit is commonly defined as one in which the horse sucks wind. He begins by moving his lips in an up and down motion, then he suddenly lowers his head, sometimes to the level
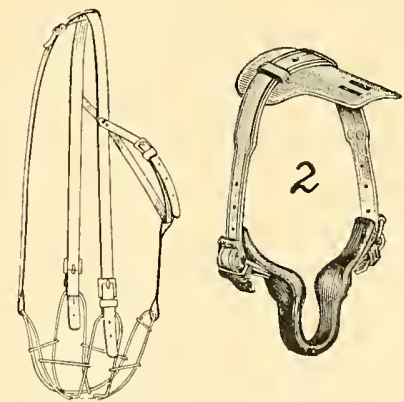

Frg. 85. - Appliances to prevent cribbing. 1 , muzzle ; 2 , neckstrap. of his knees, and then swallows a mouthful of air. As a rule, the wind-sucker may be told by the gulping sound that he makes, this being very loud in some cases but in others so slight as to be scarcely noticeable. The cause and the suggestion usually recommended to overcome the habit are very similar to cribbing. As a matter of fact, both habits seem to be so closely allied that many veterinarians speak of them both as cribbing. In one case they say the horse "cribs with support" ; that is, that he grasps some object with his teeth while sucking the air, commonly understood as cribbing. In the other case they say the horse "cribs in the air" ; that is, he swallows the air without grasping an object with the teeth, commonly called "sucking wind."

Difficull to shoe. - $\mathrm{A}$ horse difficult to shoe is a great 
inconvenience to the owner and too often a cause of accident to the blacksmith. The habit is usually due to lack of proper training or to injury received in the blacksmith shop. With animals that have

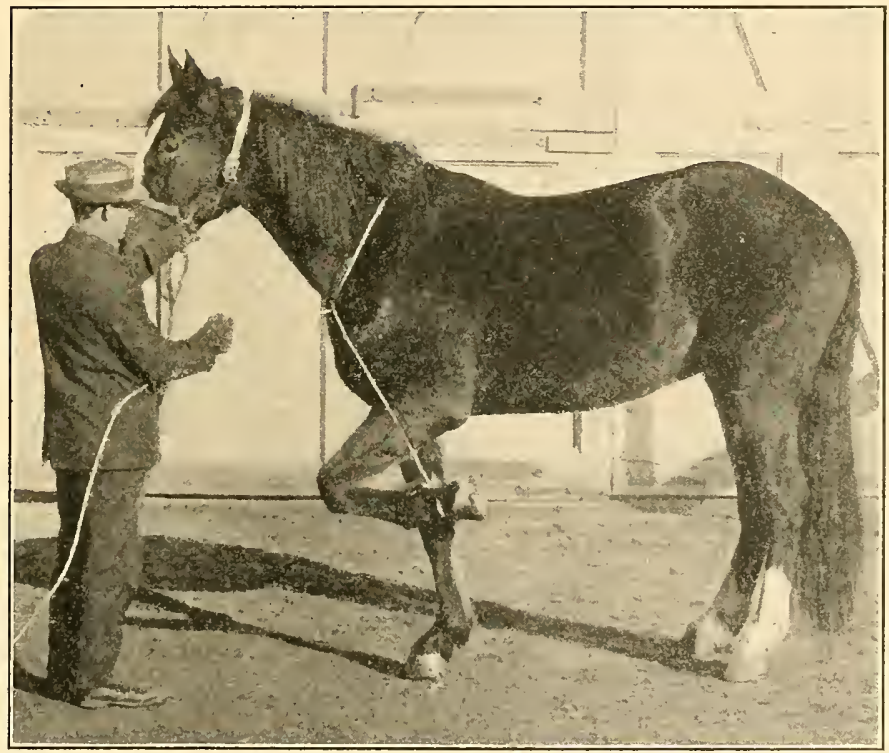

FIG. 86. - Gentling front foot with rope.

the feet gentled there is little or no difficulty (p. 101). When the horse is confirmed in the habit, other means must be employed. First his legs should be thoroughly poled as in overcoming the licker (p. 254). Next attach the pulley bridle (p. 193) and gently run your hand down the left shoulder toward 
the leg. If the horse resists, punish him with the bridle. Continue to work with the leg, punishing with the bridle when he resists, until he becomes submissive to the hand at the pastern. Lift the foot; if he resists, tie one end of a rope about

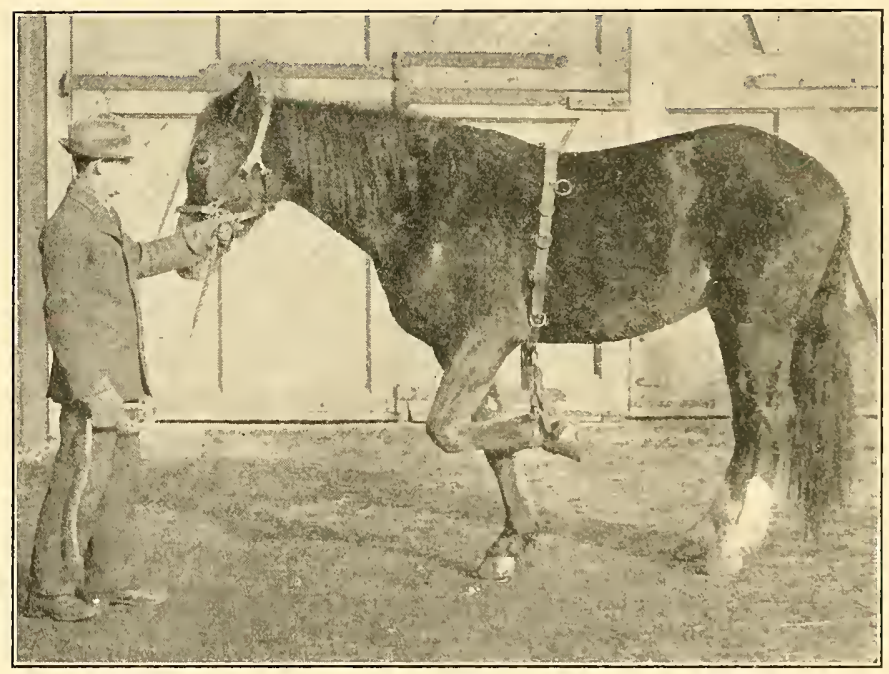

FIG. 87,- Gentling front foot with leg-strap.

the pastern, pass the free end around the neck just in front of the withers, draw the foot up and hold it (Fig. 86). If he is game and fights this method, strap up the left front foot as in throwing, by using the surcingle and leg-strap (Fig. S7). Now lead him about for a few minutes on three feet to teach him to balance properly. If he attempts to settle down on 
the one front knee, punish him with the pulley bridle.

As soon as the horse understands how to balance himself and becomes submissive, take hold of the leg and push it backward and pull it forward, and then to the side as far as convenient. If the horse resists, punish by jerking the bridle. Remove the strap and gentle the other forefoot in a similar way.

To gentle the hind foot, rub the hand along the horse's body, over the hip, and down the hind leg to the hoof, punishing with the bridle as before if he resists. Attach the rope to the left hind pastern. If he attempts to kick, tie up a front foot while you attach the rope. Should he attempt to kick while in this position he will throw himself out of balance. As soon as you have the rope secured to the hind foot, unstrap the front one. Now have an assistant take this rope and attempt to lift the foot with it, at first standing well to the front and out of the horse's reach should he attempt to kick (Fig. 88). If the horse resists, give several sharp jerks with the pulley bridle, when he will usually raise his foot. If he struggles to replace the foot, tie the rope to a collar. If he attempts to settle down, punish with the bridle. Continue until he learns to balance on three legs and becomes submissive.

Next have the assistant take a position in the rear and try to lift the foot as before, standing well back behind the horse and out of reach should he attempt 
to kick (Fig. 89). If the horse refuses to lift his foot, give a few sharp jerks on the bridle, which will induce him to raise it. Should the horse refuse to hold the foot up, tie a knot in his tail as high as

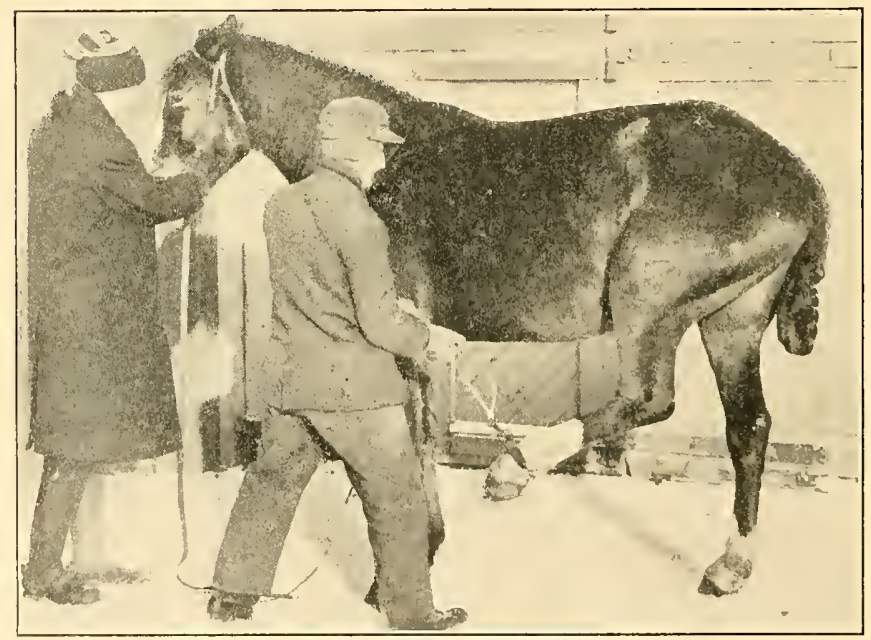

FIG. SS. - First position in gentling hind foot.

possible and pass the free end of the rope through the loop in the tail. Now the assistant can hold the hind foot up with ease, even though the horse should resist. Some prefer to tie the rope to the tail and run the free end through a ring at the pastern (Fig. 90). With the latter arrangement the assistant can work the foot up and down or backward and forward until the animal becomes submissive. If at 


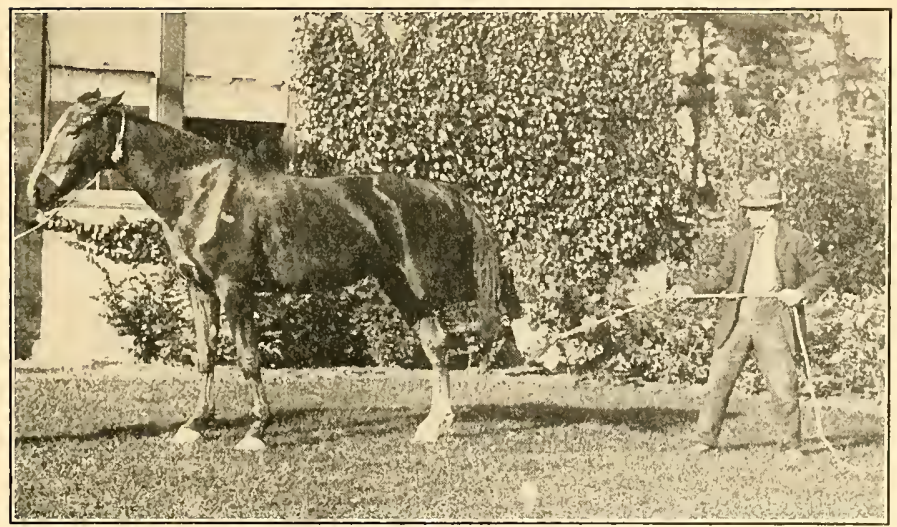

FIG. 89. - Second position in gentling hind foot.

any time he should resist, punish with the pulley bridle. Gentle the other hind leg similarly.

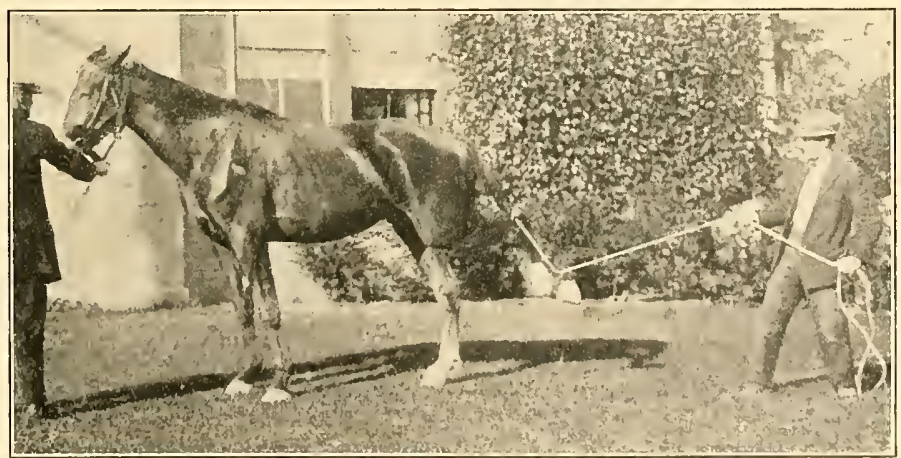

FIG. 90. - Third position in gentling hind foot.

After the horse becomes perfectly submissive to the rope method, go over each foot by hand, punish- 
ing with the pulley bridle if he resists. While this requires considerable patient effort and tact, it should be done before taking the difficult horse to the shop. It is a good plan to take the appliance along the first few times and attach it to remind the horse of his helplessness. After putting the most difficult horse through such a course, usually a few sharp jerks of the pulley bridle while at the shop will serve to quiet him while the blacksmith is working with his feet.

STABLE WHIMS, THEIR CAUSE, AND HOW TO OVERCOME THEM

Rolling. - Many horses have the habit of rolling in the stable. This is somewhat dangerous for the horse as he is likely to get fast, particularly if his stall is rather narrow. When the horse attempts to roll and stays over on his back, the stall is too narrow for him to go on over, so he cannot get up, and as it is often impossible for him to roll back, he gets fast. The longer he struggles, while lying on his back, the worse his condition becomes. This habit is due perhaps to lack of opportunity to roll. The horse should be turned to a paddock for a few minutes each evening so that he may frolic. To overcome the habit, secure a small ring and sew it in the top of the halter. Suspend a small rope from a beam or the ceiling so that it will hang directly over the horse's shoulders when standing at the manger. 
Attach a snap to the lower end of the rope, and snap into the ring at the top of the halter. This rope should be of sufficient length to allow the horse to get his nose to the ground about where his front feet usually stand. This appliance will permit the horse to lie down, get up and do much as he likes, but he cannot place the top of his head to the ground. As he cannot roll without first placing the top of his head on the ground, this is a very efficient arrangement for overcoming the habit. To lead the horse from the stable, it is only necessary to unsnap the rope at the top of the halter and untie the halter.

Tearing blankets. - There are horses that have the habit of biting and tearing their blankets. There are at least two rather common causes for the trouble: first, an itching skin, and as the blanket prevents the horse from biting the itching part he bites and tears the blanket in order to get at the part; and second, the salty taste that is found in the blanket, due to the sweating and other exudates from the skin. The salty taste induces the horse first to lick the blanket and later to tear it. To overcome the habit, attach one end of a bar to the halter and the other end to the surcingle, or construct a neck-cradle (Fig. 91). As these prevent the horse from turning the head to either side, he cannot reach the blanket with his teeth. Another and perhaps more desirable device is made by using a noseband and suspending small, short chains from the 
front, back and sides in such a form that when the horse turns his head to get hold of the blanket with

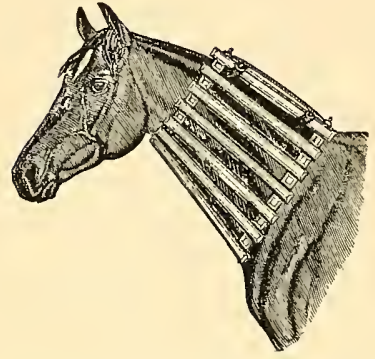

Fí. 91. - Neck-cradle for preventing the horse from tearing his blanket and biting his attendant. his teeth the chain appliance prevents him from doing so (Fig. 92). The muzzle is often recommended, but the objection to it is that the animal cannot eat with it attached.

Stripping the halter.Often a horse contracts the habit of slipping the halter off over his head. The causes are much the same as those that provoke stripping the bridle (p. 283). It often results in the horse getting an over-feed, which occasionally brings on fatal indigestion. To overcome the habit, use a snugly fitting neck-strap in addition to the halter, with the tie-strap run through the ring of the halter and fastened to the manger. A common halter with a tight throat-latch will not overcome the trouble as some confirmed halter-strippers have a head of such con-

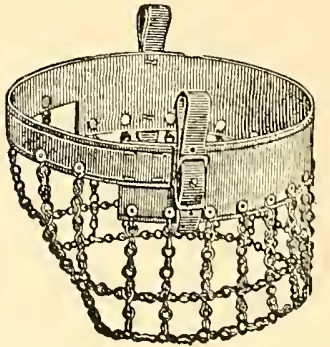

Fig. 92. - Muzzle to prevent tearing the blanket. formation that it is easily possible for them to strip the halter, notwithstanding the throat-latch. 
Pawing with the forefeet. - This is a disagreeable habit, usually due to insufficient exercise or to restlessness when the animal is left alone in the stable. It causes useless fatigue and a rapid wearing out of

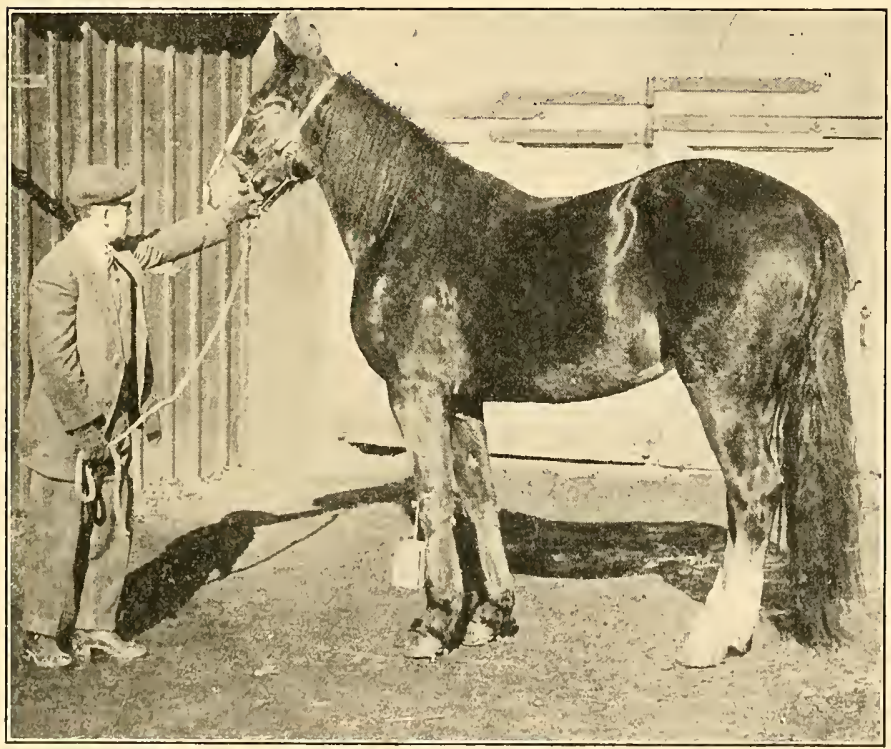

FIG. 93. - Appliance to prevent pawing.

the shoes. The noise that the horse makes while pawing is almost unbearable, especially at night. To avoid the habit, exercise the horse regularly. To overcome it, buckle a leg-strap around the foreleg just above the knee, and from it suspend a block of wood, about two inches square and four inches 
long, so that it will hang about the middle of the cannon (Fig. 93). When the horse attempts to paw, the block strikes him. In case the horse is very sensitive, substitute a corn-cob for the block. Another good plan is to use a heavy strap provided with a buckle at either end and buckle the two forelegs together. This strap should be of the proper length to permit the horse to stand normally. With this appliance he can lie down, get up, move backward and forward, but is unable to paw. Some horses that paw badly in a common stall will cease if placed in a box stall, particularly if bedded with sawdust.

Rubbing the tail. - Many horses acquire the habit of rubbing the tail against the sides of the stall or other surrounding objects. This is very undesirable as the hairs soon become tangled, break off and disfigure the tail. While there may be several causes for it, the principal ones are intestinal troubles, mange or unclean skin, causing intense itching, and infirmities of temper. To overcome the habit the treatment will vary according to the cause. If due to intestinal worms they must be removed, when the horse will cease to rub his tail; if due to mange or dirty skin, the disease must be cured and the skin kept clean; whereas if due to temper other means must be employed. Some horsemen recommend the applying of a bandage around the dock, while others suggest tying two or three separate 
pieces of tape or ribbon around the tail, one near the tail-head, a second near the middle of the tail-bone and a third near the lower end of the bone.

Rubbing harness. - Many horses have the annoying habit of rubbing the harness while standing in the stable during the noon meal. While this may be due to many causes, the principal ones are improperly fitting harness, which often causes sores; mange, which causes intense itching, and unclean skin. To overcome the habit, search out and remove the cause. If it is due to poorly fitting harness and sores, change the harness and heal the sores; if it is due to mange, cure the disease, and if it is due to unclean skin, cleanse the animal. Perhaps no greater service can be done the tired horse than to remove the harness and let him consume his midday meal in quiet.

Lying down cow-fashion. - This is a habit in which the horse doubles his forelegs back under his chest when lying down in such a way that the heels press against the elbow. The constant friction of the heels against the elbows causes boils or tumors, usually called shoe-boils, to develop at the elbow joint. Such boils are very unsightly and may become painful. There are several rather common methods of overcoming the habit, such as protecting the foot with a boot, shortening the inside heel of the shoe to prevent it from rubbing against the elbow, and securing a scantling two inches square across the stall just back of where the horse normally stands 
with his front feet. The scantling hurts the cannons when the horse doubles them back under him, and to avoid the pain he ceases to practice the habit.

Lying down in harness. - This is a very annoying habit, as the horse soils and may even break the harness. It is due perhaps to insufficient exercise. To overcome the vice, when in harness tie the horse up by the head so very short that he cannot lie down, but as soon as the harness is removed lengthen his tiestrap to the normal.

Chewing tie-strap. - Occasionally the horse contracts the habit of chewing his tie-strap. It is probably due to the salty taste of the leather, as he usually begins by licking and finally takes to chewing the strap. To overcome the habit some horsemen recommend to keep rock salt before the horse for him to lick, although the best plan seems to be that of substituting a chain for the leather strap.

Eating the bedding. - This is a very aggravating habit and a rather common one. In fact, the horse does not always stop with eating his bedding, but may eat certain kinds of earth as well, or plastering from the stable walls. The causes of the habit are not well understood, as it often occurs in horses that are receiving what is considered a balanced ration. It seems to be a craving for certain minerals. It may give rise to serious consequences, as the horse often suffers from colic, the result of overfeeding on such material. When once confirmed, the habit is rather 
difficult to overcome. It is often necessary to remove the bedding during the day, and sometimes the muzzle must be resorted to after he has had his night feed.

Resting one hind foot upon the other. - It is very common to see a horse standing with one hind foot semiflexed and resting upon the front surface of the other. The principal causes perhaps are fatigue and unevenness in the stable floor. The habit may result in serious consequences to the horse, as he often wounds the coronary band, particularly if sharply shod. Sometimes the walls of the foot become so much thickened as to change the direction of the foot entirely. The only means of preventing these defects is by protecting the exposed parts with leather boots. To overcome the habit, do not work the horse to excess, or if due to unequal footing, level the stable floor.

Sleeping standing. - There are horses that never lie down, a habit that seriously detracts from their capacity for work. The principal cause, no doubt, is nervousness, especially in the case of heavy horses. To overcome the habit, change the horse from a common stall to a large box stall deeply bedded with fresh straw. If he still refuses, give him two or three days' extra hard work, feeding him in a common stall and on the night of the second or third day bring him in late, when the stable is quiet, and turn him loose in the box stall bedded with fresh straw up to his knees and hocks. He will usually eat his 
feed and lie down at once, and he should not be disturbed until he gets up of his own accord. It has been suggested to suspend a five-pound weight securely fastened to the tail, so that it will hang about four inches above the hocks. It is stated that the strain of the weight impels the horse to lie down.

Trotting in stable. - This is a habit in which the horse executes a movement somewhat similar to the trot; that is, he moves from one pair of diagonal feet to the other. While the habit has no serious consequences, the noise is rather annoying and the horse uses up energy, which lowers his efficiency as a working animal. The principal cause is lack of regular exercise, as hard working horses are never troubled, and it is of rare occurrence among those given sufficient exercise.

Weaving. - This is a habit somewhat similar to trotting in the stable, the horse wearing from side to side, sometimes raising his feet at the same time. It is brought on by lack of exercise and standing in the stable. It uses up much energy and lessens working efficiency. It is overcome by regular exercise and hard work.

Switching tail in stable. - This aggravating habit is caused by improper training, particularly poling. To overcome the habit, give the horse a thorough poling as in overcoming kicking (p. 254). Then with the pulley bridle (p. 193) attached, go over him carefully with the brush. If he resists, punish with the bridle. It has 
been recommended to make the horse's tail sore, by tying it up over his back as follows. Double a small piece of rope about eight feet long, at the middle, and tie the doubled part to the tail. Now pull the tail up over the animal's back and tie the free ends of the rope to the collar, one on either side at the hame tugs, drawing down rather tight, so as to make considerable strain in the cords of the tail. To hold the ropes in place, it is a good plan to use the surcingle, placing it over the ropes. This appliance should not be left on more than an hour. It will make the muscles and tail so very sore that the horse will be unable to switch it for some time.

Gorging grain. - Many horses have the disagreeable habit of gorging their grain and swallowing it without mastication. This may result in fatal colic. To overcome the habit, give the horse a drink and feed some hay before feeding the grain. Another very good plan is to feed the grain in a rather large, flat-bottomed grain box provided with pockets, as this arrangement prevents the horse from getting much grain at a mouthful. Some horsemen recommend placing round stones in the grain-box, but the confirmed grain gorger is usually an adept at throwing stones out before eating the grain.

Difficult to drench. - Many horses are rather difficult to drench, resisting all attempts to get the morsel down their throats. A very good plan to make the refractory horse take his drench is to apply 
the noose-twitch (p. 197), and jerking slightly as the morsel is being poured into the cup formed by pulling out the lower lip as the horse's head is being held up. It has been suggested to mount the horse, and sitting well forward draw the head around to the off side by the head-stall with the left hand and give the drench out of a bottle with the right hand. In stables where there are many horses to be cared for, a drenching bit should be procured, as the task of drenching is much more easily accomplished by the use of such a device. 


\section{CHAPTER IX}

\section{HARNESSING THE COLT}

IN harnessing the colt for the first time or subsequently, it is important that the various parts of the harness should be properly adjusted, as a perfectly fitted harness adds much to the animal's comfort, efficiency and future usefulness. The young horse's skin is very tender, and unequal pressure due to poorly fitting harness is likely to abrade the parts. This is well emphasized by the sore mouth, shoulders, neck, back and tail produced by such harness. These are the parts that come in contact with the harness, and as they are very tender they are the places likely first to become sore. As the poorly fitting harness irritates these sores, they become a source of much pain and may provoke vicious habits. In this manner a severe bit may irritate the mouth until the parts become numbed and the animal be provoked to running away; a poorly fitted collar may produce a sore neck or shoulders and the horse be provoked to balking; and a tightly drawn backstrap may cause the crupper to abrade the tail and the horse be provoked to kicking. As the comfort, efficiency and future usefulness depend so largely 
upon the proper adjustment of the bit and bridle, collar, saddle and crupper, each will be considered separately.

\section{THE BIT AND THE BRIDLE}

The proper adjustment of the bit and bridle is of first importance. A responsive mouth contributes much to the efficiency and safety of the horse. A good mouth is to a large extent natural to a colt, and if properly treated will remain good. When we recall the extreme tenderness of the mouth, the cruel manner in which it is often bitted, the excruciating pain resulting from the irritation of the sores by a poorly fitted bit, we can understand why a horse may lag behind until the parts become numbed, then begin pulling on the bit, bearing down, holding the head to one side, going with mouth open, lolling the tongue, slobbering, tossing the head, crossing the jaws, rearing, mixing the gaits, hitching or hobbling, interfering, plunging or rushing when starting, balking, as well as being very restless when standing and in many other ways showing evidence of the discomfort he is suffering.

The bit. - As a general rule, in the control of the horse, too much is expected from the bit alone. Many otherwise excellent horsemen imagine that by using a heavy and severe bit they are or ought to be able to do anything they like with a horse, even though the animal has not been properly trained. 
Such is not the case, for no matter what kind of bit is used it cannot act as a substitute for effective training.

Because of the feeling that any defect, whim or vice may be overcome by the use of the proper bit, many types have been devised to meet the various and peculiar habits of horses, most of which have been designated to punish the horse and irritate the sensitive parts, thus defeating the object they were devised to accomplish. The horse soon learns that by constant pulling the resulting pain gradually becomes less, due to the parts becoming numbed, and as a result the animal develops a hard mouth lacking in sensitiveness. If the bit is to remain effective in horse training, it is essential that the bars of the mouth retain their natural sensitiveness; that the bit be an easy and light one, and that it be handled with care.

The several makes of bits may be classified in two ways: first according to their form, such as straight bar, jointed, and curb ; and second, according to their function, as mild, medium and severe. The straight bar bit is one with a solid mouth-piece and without lever action (Fig. 94, 1 to 8 ). It is sometimes made with cheek-pieces (Fig. 94, 2 and 4), and sometimes without (Fig. 94, 1 and 3). With this form of bit there is a minimum amount of pressure on the bars of the horse's mouth and a maximum on the tongue. This is the mildest form of bit. 


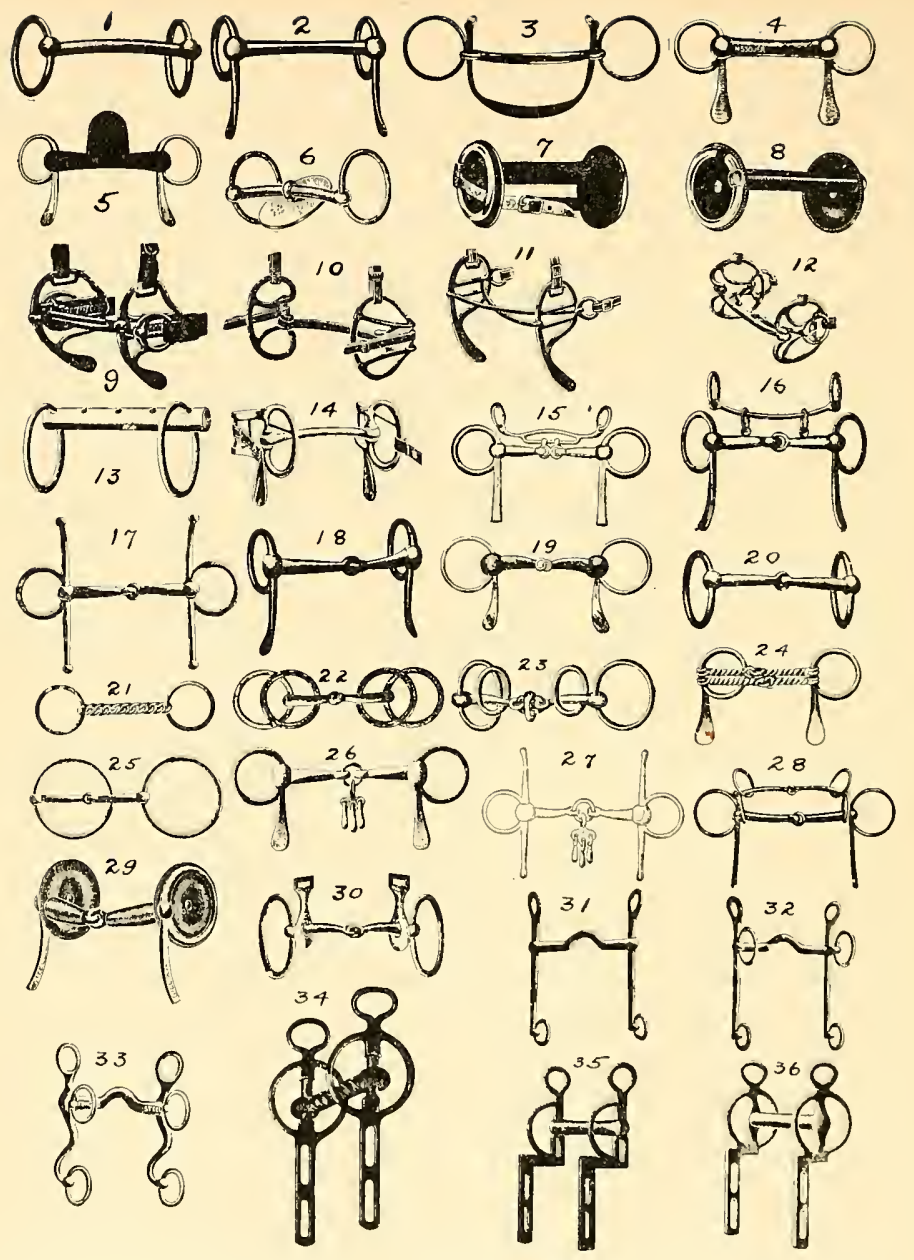

FIG, 94. - Bits. 1, Plain bar : 2, Half cheek bar ; 3 , Humane ; 4, Chain center, rubber covered ; 5 . Rubber tongue lolling; $b$, Tongue lolling; $\%$. Detroit leather; $S$, Straight cushion; 9, Racine spring; 10 , Success; 11, J. 1. C.; 12, Imperial ; 13 , Wind sucking; 14. Triumph ; 15, Victor; 16. Perfection; $1 \%$, Cheek riding; 18 , Half cheek jointed; 19, Nodine, rubber covered; 20, Plain jointed; 21, Chain; 22 , Wilson 4-ring; 23 , Sanborn; 24, W-wire; 25 , Racing; 26 , Half check mouthing; $2 \gamma$, Full ehcek mouthing ; 28 , Norton ; 29 . Jointed cushion ; 30 , Rockwell; 31,2 -ring riding; 32, 4-ring riding; 33, U. S. Army riding; 3., Liverpool coach; 35 , Elbow coach; $S 6$, Full ring elhow coach. 
As a matter of fact, a smooth, good-sized straight bit slightly enlarged at the ends near the rings or covered with rubber or leather cannot be improved upon in most cases. It is essential that the straight bit be of proper length for the horse's mouth. It is not uncommon to observe a bit of this type that is too long for the animal (p. 60). One important matter that must always be taken into account when fitting the straight bit is that the jaws of some horses are much narrower than those of others. The bit, therefore, should be of correct length for the particular horse in hand and properly adjusted.

For animals with very tender mouths, the straight bar is 'often covered with leather or rubber (Fig. 94, 4, 7 and 8). To make the bit still more mild, oftentimes the rubber surrounds a chain instead of a bar, thus making a very yielding bit (Fig. 94, 4). Not only are bits of this type used on animals with tender mouths, but they are very efficient in overcoming some bad habits, such as lugging (p. 281).

The jointed or snaffle bit is one with a jointed mouth-piece and also without lever action (Fig. 94, 17 to 31 ). Like the bar bit, the jointed bit is sometimes made with cheek-pieces (Fig. 94, 17 and 18), and sometimes without (Fig. 94, 19 and 20). With this form of bit there is a minimum amount of pressure on the tongue and a maximum amount on the bars of the horse's mouth. This is a very useful type of bit, and many horses work more agreeably with 
it than with the bar bit. It not only gives more room for the tongue, but the pressure is more evenly distributed on the jaws than with the bar bit. When properly arranged this is a mild or medium bit and a most useful one, but when drawn too tightly by the lines it has a tendency to pinch the jaws and may cause the horse much pain. This pinching effect is made use of in devising severe bits; thus we have bits of the jointed type containing a double mouthpiece (Fig. 94, 9, 11, 12 and 24). Perhaps these are the severest kind of bits.

The severe bit should never be used unless it is absolutely necessary. While there are many kinds on the market, they each have for their main object that of punishment, which is always to be avoided, as it destroys the natural sensitiveness of the mouth. Such a bit often provokes the horse to lugging. This habit often can be overcome by changing from a severe bit to a mild one. With the former the animal was in constant pain, and hence very nervous and excited. Being excited, his only desire was to go, which suggests that the severe bit should be discarded whenever possible. This is especially true of animals with tender mouths. In training and controlling horses, the bit should be regarded as a means of conveying to the animal our wishes and not as an instrument of torture.

While the mild or medium bit is the one to use as a general rule, there are times when a severe one 
is needed. Because of this, several attempts have been made to construct a bit that can be variously applied, so as to form either a mild or severe bit as desired (Fig. 94, 9, 10, 11, 12, 22, 23 and 30). Perhaps the Beery bit furnishes as good an illustration of this principle as any. This bit can be applied in four ways: As a very mild and easy bit (Fig. 95, 1) ; as a most powerful bit (Fig. 95, 2); as a very severe bit (Fig. $95,3)$ and as a bit to *ure the side-reining horse (Fig. 95, 4).

Curb bits are made in a number of styles, but each bit consists primarily of a solid mouthpiece connecting two cheek-pieces
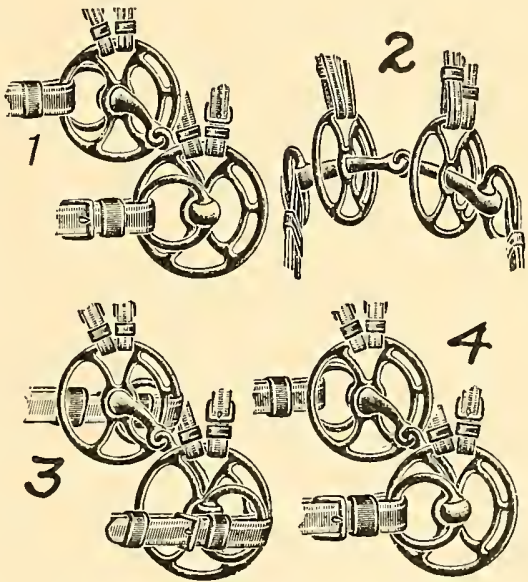

FIG. 95. - Beery bit. 1, Easy ; 2, Powerful ; 3 , Very severe; 4, Side reining.

(Fig. 94, 31 to 36). The mouth-piece may be straight or curved, the more common form having an upward curve at the center (Fig. 94, 31 to 33). This bit is often used with the curb chain or strap which extends from one side around to the other beneath the lower jaw. When the curb chain is used, a lever action is obtained, the efficiency of which depends on the man- 
ner in which the bit and chain are arranged. If the curb chain is too tight, causing pain on the surface of the chin, the horse will project his head forward and fret. Much care should be exercised in adjusting the bit and chain so as to get sufficient power on the bars of the mouth without pain on the chin. A double chain worked flat is best for general use. While many persons prefer a leather strap to a chain, yet leather is subject to stretching and contracting and is likely to become stiff and harsh.

The curb bit is used to advantage to improve the action in training and driving the high-acting coach horse. The horse properly bitted with a curb bit gets his head up and nose in and shows himself to better advantage than with any other kind of bit. The curb bit should be used only by those who are familiar with it, as it may become an instrument of torture in the hands of the inexperienced.

In training a colt to the uses of the bit, a mouthing bit is often used. This consists of an ordinary jointed bit provided with keys at its center (Fig. 94, 26 and 27). The keys hang upon and tickle the tongue, and cause the colt to champ the bit, and tend to keep his mind occupied while he is in training. It should not be used on nervous horses (p. 58).

A sympathetic feeling should always exist between horse and driver, and the proper bit to secure this relationship can be determined only by trial, and several changes are often necessary. When it has 
been determined which bit best serves the purpose, no further change should be made. The horse does not take kindly to a change of bits after becoming used to a certain kind. Such a change makes him uncomfortable and may interfere with his efficiency, particularly his action.

Head-stall. - The cheek-straps should be properly adjusted so as to keep the bit in its proper place, that is, right across the bars of the mouth just above the tushes. This is very important. If the cheekstraps are too long, the bit drops so that the rings are drawn into the mouth. The horse becomes careless and unmindful of our wish. On the other hand, if they are too short, the bit is drawn upward into the angles of the mouth and becomes a constant source of annoyance to the animal and may produce a sore mouth. It is a common mistake among horsemen to draw the bit up into the corners of the mouth, so as to cause slight wrinkles. The brow-band and throat-latch should be carefully observed, to see that they are neither too loose nor too tight, as the former arrangement is very annoying to the horse and the latter rather painful, either of which may provoke certain kinds of vice or whims (p. 249).

Blinds. - There is diversity of opinion as to the advisability of using blinds on the bridle, particularly during the training period. Some horsemen contend that blinds are of benefit, while others are just 
as certain that it is a detriment to limit the range of vision while training. While much depends on the individuality of the animal, it is true that most colts train better in the open bridle. As a matter of actual fact, this is very important in the education of a driving horse. No horse can be said to be trained until he is familiar with objects at all angles, and to accomplish this the open bridle must be used. After training, however, there is no important objection to the use of blinds, although even then they add weight, are warm in summer and very annoying to the horse; but many horses work better when blinds are used, in which case they should be attached to the bridle. If blinds are used, they should be firmly adjusted to the bridle so they cannot swing back and forth. They should be of the same height on the horse's head, as it is very unsightly as well as annoying to the horse to have one placed low and the other high on the face.

Centerpieces, earbobs, tassels and brass fixtures. Such fixtures add to the general appearance of the turnout. While fashion and custom seem to demand a certain amount of unnecessary fixtures to worry and annoy the horse, the use of them is not recommended. Such parts are costly and add nothing to utility. It would be more economical to use harness of a better quality without such fixtures. On the other hand, brass fixtures are often of indirect benefit, as they promote interest in caring for the harness, 
the driver taking delight in having the harness and fixtures shine. However, it requires much rubbing and polishing to keep the brass in presentable condition. When all the metal parts of the entire harness are brass (Fig. 29), it requires at least one hour after each drive to keep the fixtures shining and from turning green, as they will if not polished often. Compare with Fig. 98, where the metal parts are black and the harness much less expensive.

The check-rein. - The adjustment of the checkrein deserves special consideration, as the efficiency of the horse depends much upon the way in which his head is held. In common practice there are two general methods of checking the horse's head by means of the side-rein and by the overdraw check-rein. The former is used largely on work horses, the latter on driving horses. The side-rein is used with and without check hooks at the throatlatch. Though the side-rein is not so effective in compelling the horse to hold his head up, it is much more comfortable to the animal and enables him to perform his work more efficiently. Horses checked with the side-rein are not so likely to stumble as those with the overdraw check-rein and will pull a much heavier load. This is because they have more liberty with the head, thereby enabling them to see the ground immediately in front, and to lower the head, and thus throw more power into the collar.

The overdraw check-rein was devised and first 
used by the old-time driver, Hiram Woodruff, on the trotting horse Kimball Jackson, and it was formerly known as the "Kimball Jackson" check-rein. It was devised to prevent that once famous trotter from getting his head down when he made a break, as he could not be brought back to a trot again with his head down on his breast. The rein proved very effective for trotting and pacing horses on the track and its use became almost universal.

Although the overdraw check-rein was devised for trotting horses, it has become so popular that it is used almost exclusively for driving horses. Though originally devised for use on the track, where the surface is as smooth as a floor, and for short periods of time, at present it is used on roads of all kinds and for indefinite periods of time. There are many strong objections to its use on the driving horse, especially if drawn too tight. It holds the horse's head in such a position that he is unable to see the ground immediately in front of him, so that he is very likely to stumble on obstacles in the road. Further, it holds the animal's head in such a direction that he cannot pull efficiently. This is particularly true in ascending a steep grade. The horse is unable to lower his head, and hence can put little power into the collar. The horse that is stalled when thus reined can often pull the load if unreined or if the driver will ride him, thus bringing forward the center of gravity and enabling the animal to put more 
pressure into the collar. The overdraw check-rein is also very hard on the horse's back and front limbs in descending a grade. When drawn too tight it holds the head and neck in such an unnatural position that they soon become numbed and the horse is seen to toss his head from side to side and to take other characteristic attitudes in search of relief.

After the horse has become thoroughly familiar with the uses of the bit, he should always be reined mildly. Without the rein he is likely to become careless in his habits, shambling in his gait and to yield to the temptation to eat grass when standing. When the horse lowers his head and neck, the lines, collar or breast harness slip down and he is likely to become tangled in the harness and may get into difficulty.

\section{THE LINES}

The arrangement of the lines adds much to the appearance of the turnout and to the comfort of the horse. The spread line should be so adjusted as to enable the horse to travel straight to the front. It is a common practice in the cities to lengthen the spread lines so that the horses in a team travel wide apart or are well spread. This spreading, if carried to excess, may be objectionable, and under certain conditions should be avoided. Driving horses, whether in training or subsequently, should never be spread so wide apart that they cannot travel 
straight to the front without turning their heads outward. It often happens, especially in the country, that the roads are not well broken, the worn track narrow, and if spread too wide the horses must turn their heads outward in order to travel in the worn track. On the other hand, we sometimes meet the other extreme: the horses are checked too short and must turn their heads inward in order to travel in the worn track.

Multiple hitch. - Occasionally we desire to hitch three or more horses abreast, and the arrangement of the lines becomes important. While there are many ways of arranging the lines in a four-horse hitch, the following is as simple and effective as any: Use a pair of common check lines and attach to the outside horses just as if hitching two horses; that is, snap the spread line in the ring in the bit next to the outside horse, on either side. Secure three straps about eighteen inches long. Make them so they can be adjusted to any length with a buckle and have a snap in each end. Snap one end in the right side ring of the outside near horse's bridle and the other end in the left sicle ring of the horse next to him. Snap all four bits together in like manner. This makes a very neat arrangement and has the advantage that it works equally well with three, four, five, or as many horses as we choose to work abreast. 
Since the service of the horse is so largely accomplished by the shoulders, it is of the utmost importance that the collar fit the neck and shoulders perfectly. A poorly fitted collar causes the horse much pain, results in sore neck and shoulders, and is a common cause of viciousness, particularly balking. Collars of many types have been devised to meet the needs of the horse, chief of which are various styles of the common leather, the pneumatic, the metal and the humane, each asserting superiority over the others.

The pneumatic collar consists of a metal frame lined with rubber, which is inflated similarly to a bicycle tire (Fig. 96, 2). Some of the points made for it are: that it presents to the horse's shoulder a soft, pliable cushion; the pressure is always evenly distributed over the pulling surface; no sweat-pads are needed; always cool; and that it prevents all forms of sore neck and shoulders.

The bearing surface of a metal collar is shaped somewhat like that of a leather collar, and all the parts are of metal (Fig. 96, 3). Some of the statements in its favor are: that the metal parts keep the shoulders hard and cool ; the shoulders do not sweat, first preventing scalds and then sores; its surface is smooth; it fits correctly, as it can be adjusted in either width or length; and it never wears out. 
The humane collar differs in shape from any of the others. It consists of a metal frame and two broad leather pads, one for either shoulder (Fig. $96,1)$. Some of the points made for it are: that the pulling surface is properly distributed; the horse can pull a load easier because the pulling surface is greater than in the old-style hame collar; the burden

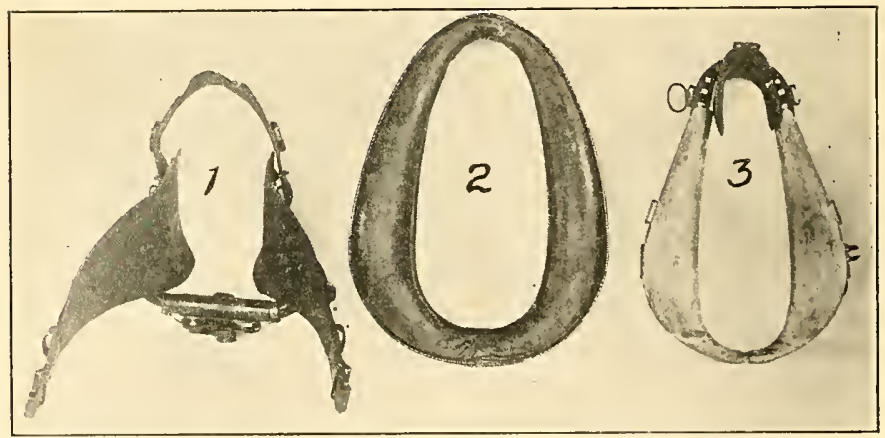

Fig. 96. - Patent collars. 1, Humane ; 2 , Pneumatic ; $s$, Steel.

of pulling comes about the lower shoulder joint, giving the horse a chance to step without bruising the joint where most bruises come; there is no pressure on the thin skin and flesh over the shoulder-blades, where so much trouble is caused with old-style collars; there is no pressure at all on top of the neck, on the wind pipe or breast to shut off the horse's breathing; and that it is less trouble to put on and take off as well as to fit any horse perfectly at all times by simple adjustment. 
Notwithstanding all assertions made by the adherents of these patent collars, the leather collar still holds first place among horsemen generally. To meet the various needs of the horse, the leather collar

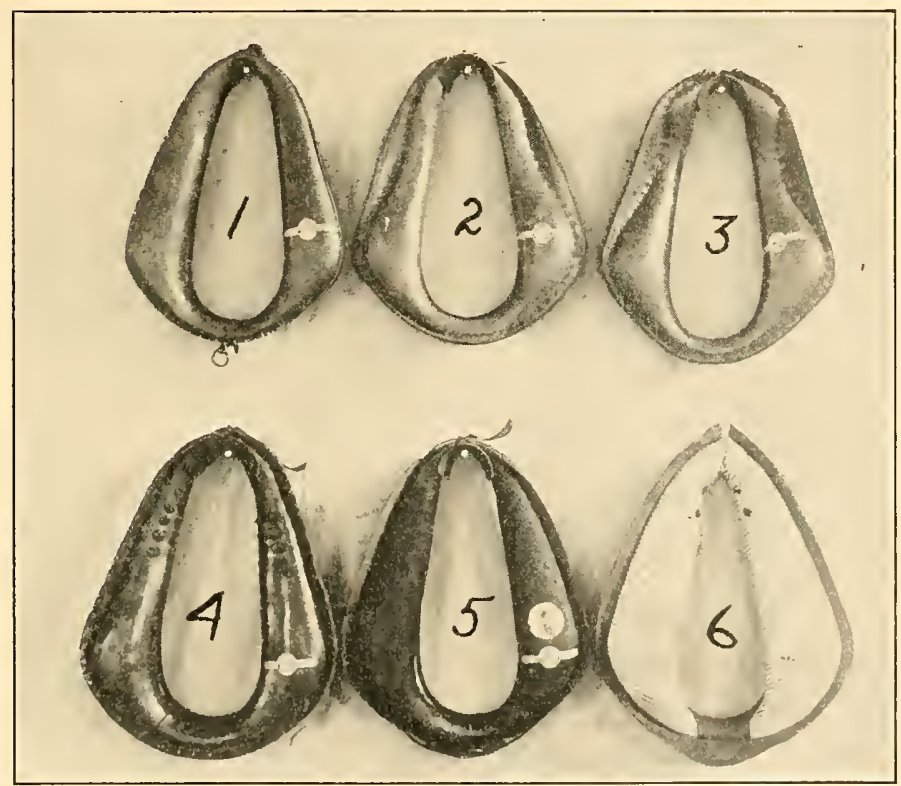

FIG. 97. - Leather collars. 1, Conmon leather; 2, Half sweeny; 3 , Full sweeny ; 4, Double ribbon seam; 5 , Kangaroo lined; 6 , Irish collar.

is made in many shapes, as the full sweeny, half sweeny, Irish or cloth-faced, kangaroo leather face, common leather face and the like (Fig. 97). The sweeny collar is intended for use on the horse suffer- 
ing from sweenied shoulder, the Irish and the kangaroo leather-faced for the horse with tender shoulders, and the common leather for ordinary work.

The fitting and adjusting of the leather collar should receive careful attention. In the manufacture. of collars the leather is soaked until it is limp as a rag and then fitted over a metal form representing the shape of the horse's neck. When dry, these collars are so firm and stiff that usually it is impossible to buckle the harness tight enough to bring it to the shape of the animal's neck, and the shoulders are therefore adjusted to the collar rather than the collar to the shoulders, with sore shoulders as the result. The neck and shoulders of no two horses are alike. To avoid this soreness it is essential that the stiff collar be adjusted to the shoulders of the horse for which it is intended. To do this, take the poorly fitting collar, new or old, wrap it round and round again with a thoroughly wet cloth or sacking; or place the unwrapped collar in three inches of water and let it remain overnight. In the morning put the collar on the horse, and with hame straps draw it snugly to the sides of the neck; be sure that the hame straps are properly adjusted, then work the horse moderately through the day. After working in this way, the collar will adjust itself to every inequality of the shoulder and the horse will seldom be troubled with soreness.

Since the shoulders of no two horses are alike, each 
should have his own collar. It should fit closely to the neck along its entire length and should never be tight in some places and loose in others. The hamestraps should be properly adjusted at top and bottom ; be sure at all times that the lower hame-strap is buckled as tightly as the thickness of the neck will permit, otherwise the harness may slip off the collar when the horse is backed.

Sweat-pads. - A collar that will fit in the early spring when the horse is fat may be too large later, when he is worked down, so that it may be necessary to use sweat-pads or get another collar. Sweatpads, however, should not be used unless it is necessary, as they are very warm and the neck and shoulders can be kept in a more healthy condition without them, providing a properly fitted collar is employed. When the pads are used they should be cleaned and dried daily. To remove the dirt, some dip them in gasoline or benzine, though a thorough washing with soap and water is equally as efficient. After washing they should be thoroughly dried before using.

Breast harness. - For light driving, such as runabouts, buggies and the like, breast harness is preferred to the collar. In fitting breast harness care must be exercised in adjusting the neck strap, for if too long, the harness will drop and interfere with the action of the fore limbs, or if too short, the harness will be drawn up and choke the animal, 
particularly in ascending a grade. The breast harness is intended for light work only, and if the load is heavy, the horse may choke.

The hame-tug. - The proper adjustment of the hame-tug adds much to the efficiency of the horse and is an important factor in preventing sore shoulders. If the draft is too low, the action of the shoulder while walking gives too much back-andforward motion to the collar. This is noticeable by the motion at the tops of the hames as the horse walks. This constant motion is likely to cause sore shoulders either at the points or at the top. If the draft is too low, the likelihood to injury is equally as great. Further, the tugs should be of equal length. It is not uncommon to observe one tug hitched longer than the other, which materially lessens the horse's efficiency and is likely to cause sore neck and shoulders.

\section{THE CRUPPER AND BACK-STRAP}

Next in importance perhaps to the bit and collar is the crupper. In training as well as for subsequent use, the large stuffed crupper free from folds is recommended. In fitting the crupper extra care must be exercised in adjusting the check-rein and backstrap, for if either are too short the crupper will be drawn tightly against the tail. Since the under part of the tail is very tender, this is likely to cause soreness and thus lessen the reliability of the horse. The 
horse with a sore tail is often difficult to manage, as he may at any time get his tail over the line, become excited through fear that the abraded part will be injured, clamp his tail down on the line and be difficult to control (p. 268). On the other hand, if the back-strap is too long and the crupper too loose it may result in the back-strap, crupper, hipstrap and breeching all slipping off to one side of the horse. It is important, therefore, that the checkrein and back-strap be so adjusted that the saddle remain in its proper place on the back and the crupper fit snugly under the tail, then there will be little or no trouble from soreness.

\section{THE SADDLE AND BACK-BAND}

While the saddle is of less importance than either the bit or collar, there are so many differently shaped backs that it is important to give the fitting of the saddle extra attention. Often this is neglected and a poorly fitting saddle is used, which results in a sore back, particularly if the harness is heavy. Further, the saddle should be kept clean and smooth. When properly adjusted, clean and smooth, there is little or no danger that the horse's back will become sore or abraded. In the case of single harness, where there is extra pressure on the saddle, due to the weight of the shafts or the like, a saddle pad should be used. 
THE BREECHING AND HOLD-BACKS

When there is much backing to be done, or in sections that are mountainous or hilly, the breeching and hold-backs assume much importance. As a rule, very little attention is given either the breeching or hold-backs, yet their absence frequently results in sore necks and sore backs, particularly among work horses. If the breeching is too loose or the hip-straps too long, allowing the former to hang low, it will wear the hair off the horse's hind legs, and in addition, the vehicle will have a jerky motion. On the other hand, if the breeching is too tight, it will interfere with the animal's action and efficiency. In mountainous sections the "Pennsylvania" breeching is preferred. This breeching differs from the common in passing over the top of the rump just above the tail instead of around the quarters.

For heavy work, care should be exercised in choosing and adjusting the hold-backs. While there are many makes of hold-backs and backers on the market, they can all be divided into four general classes; namely, breeching and shaft hold-back, yoke and collar hold-back, breeching and belly martingale hold-back, and Boston hold-back. These hold-backs and backers may be attached in a variety of ways. The breeching is used with each except the yoke and collar backer. Often the saddle is discarded in the breeching and belly martingale and 
Boston hold-backs, in which cash the crotch backstraps and hip-straps are usually employed.

The breeching and shaft hold-back is used only with single rigs. With this hold-back the breeching is attached directly to the shaft by means of the holdback straps (Fig. 19). After the breeching is properly adjusted, the main point to be noted is that the hold-back straps are of the proper length. If too short, they draw the horse forward, thus interfering with his action and efficiency; whereas if too long, the breeching hangs loose and the rig will have a jerky motion and be annoying to the animal. As this hold-back increases the draft on the belly-band, the latter should be of good quality and properly adjusted.

The yoke and collar hold-back is intended only for light vehicles. With this hold-back the backing is accomplished very largely with the neck by means of the yoke and collars (Fig. 98). Sometimes a martingale-band passing from the lower end of the collar, the breast-strap or the yoke between the forelegs to the belly-band is used, and a part of the backing is accomplished by pulling down on the saddle. With this attachment it is very important that the saddle fit properly and that the back be well protected by the use of a saddle pad or housings. One reason for the popularity of this holdback is that no breeching is needed, and it is becoming a fad among owners of light harness horses to 
discard the breeching. As a result, this backer is much misused. While intended for light vehicles and light loads, where it constitutes a very neat and efficient hitch, it is often used for heavy vehicles and

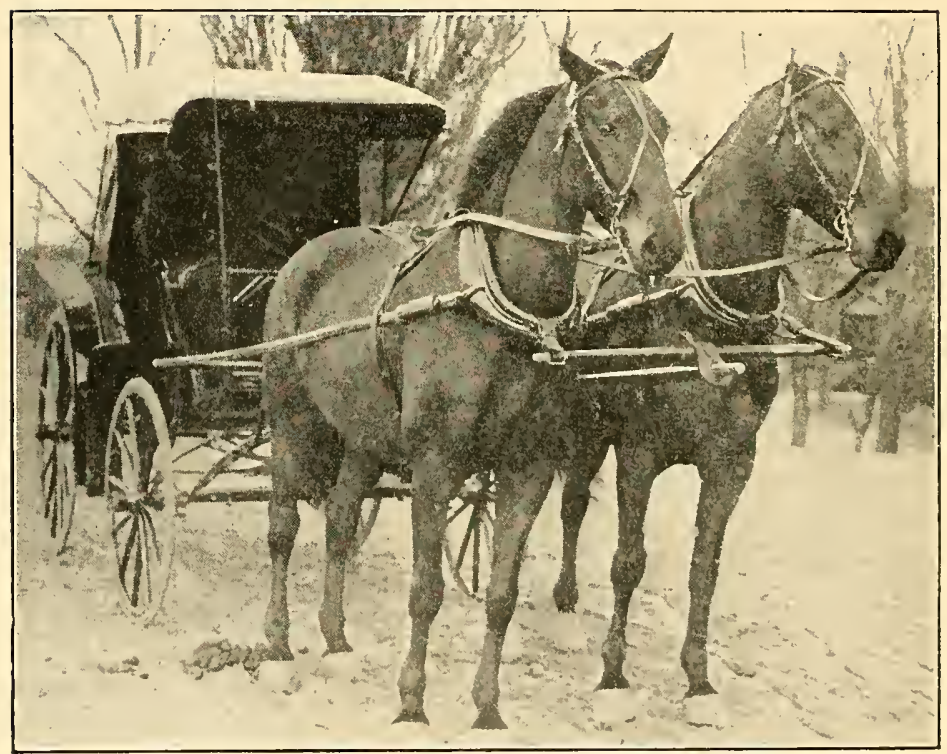

Fig. 98. - An inexpensive but neat driving harness.

heavy loads, where it is a frequent cause of sore necks and sore backs. When thus used it often provokes vicious habits, such as balking, kicking, rumning away and the like. With this form of backer the wagon tongue has a tendency to rise, and one may occasionally see a driver hanging on the tongue to hold it 
down and beating his team backward, which of course cannot be too strongly condemned.

In the case of the breeching and belly martingale hold-back, much of the backing is accomplished by means of the martingales and breeching, though

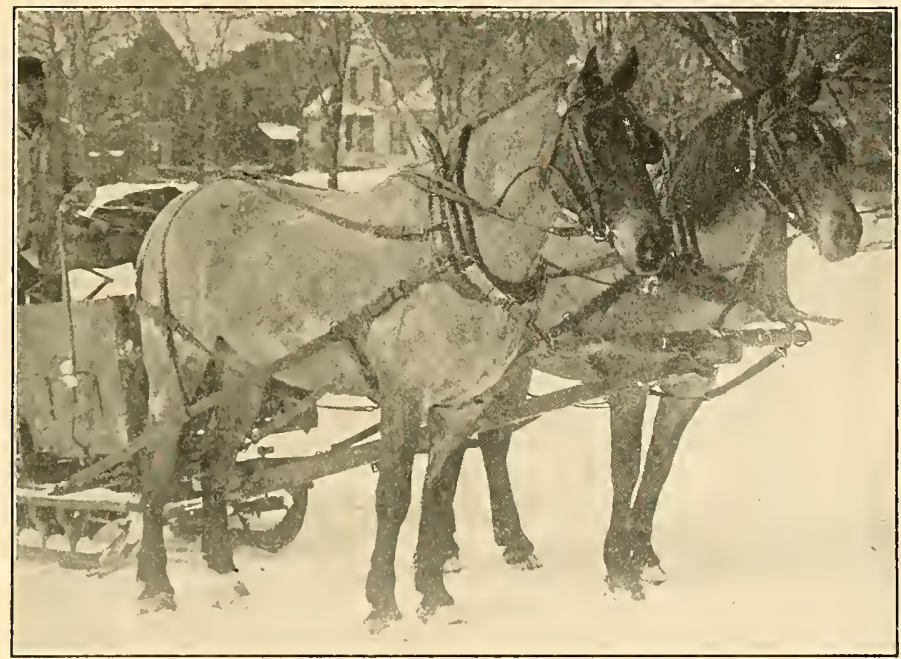

FIG. 99. - Light-work harness, showing belly martingalls and crotch-back and hip-straps.

extra pressure is often brought to bear on the top of the neck in addition (Fig. 99). While this is a more efficient backer than the yoke and collar, it is open to the same general criticisms in respect to producing sore neck. As the saddle is often discarded, it does not of course injure the back. 
When the loads are heavy and there is considerable backing to do, the Boston hold-back and backer is recommended. With this form of hold-back the backing is accomplished with the breeching by means

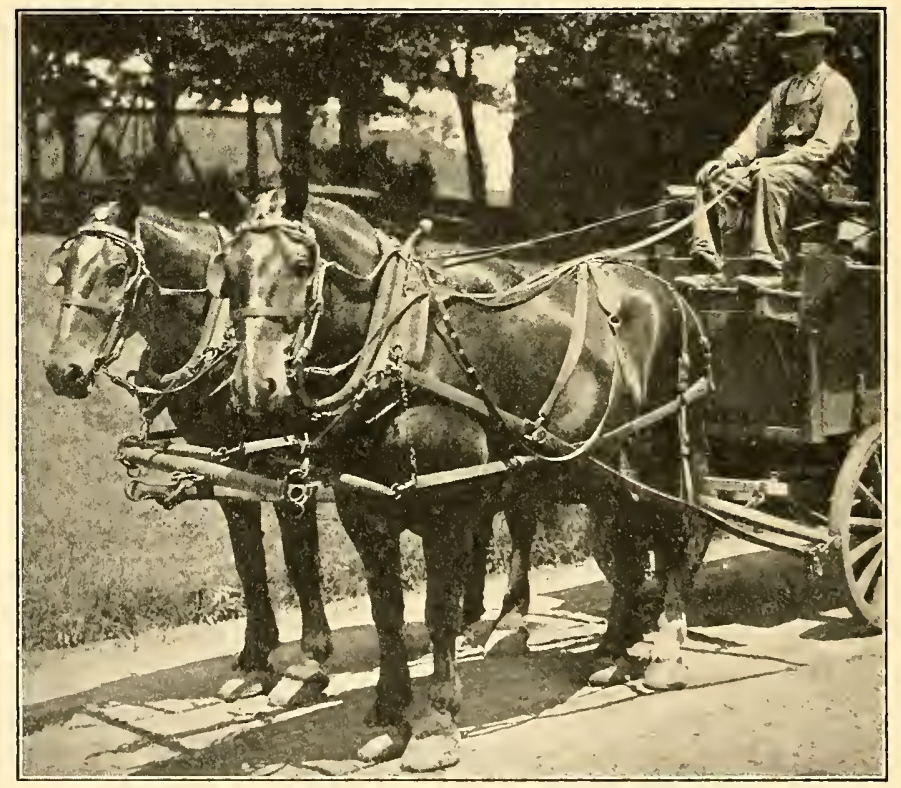

Fig. 100. - Heavy work harness, with Boston backer.

of tugs extending from the breeching to the jockey yoke, which is attached directly to the neck-yoke (Fig. 100). The draft is in a straight line from the end of the tongue to the quarters, thus giving the horse his maximum efficiency in backing. This is 
the easiest on the horse, as there is but little pressure at the top of the neck and none on the back.

\section{CHOOSING HARNESS}

When it comes to choosing harness, there are so many items to be taken into account that the task is often a difficult one. When we visit the harness store or examine the harness sale catalogue, we are rather bewildered by the great variety of styles black leather, polished leather, russet leather and woven web, cut into all imaginable shapes and styles. No attempt is made here to go into the matter in detail; only a few of the general difficulties are noted. The purchaser should first consider the kind of service to which the harness is to be put, - whether it is intended for light driving, heavy driving, light work, heavy work or for fancy and fashionable turnouts.

In choosing useful harness, the fewer trimmings the better. While white rings, brass trimmings and extra fixtures may add much to the appearance of the turnout and serve as an advertisement, especially if they are kept clean and shining, they do not add to the usefulness of the harness. Extra fixtures hanging here and there annoy the horses and in warm weather often prove to be uncomfortable. Further, as has been stated in fitting the bit and bridle (p. 327), these brass trimmings require much 
work to keep them presentable. This extra time might more profitably be utilized in grooming the horses (p. 357). Nothing is so inappropriate as wellpolished harness on poorly groomed horses. In choosing work harness, therefore, discard the extra fixtures, trimmings and the like. On the other hand, in choosing harness for fancy or fashionable turnouts, for display, for advertisement and the like, the more trimmings and brass fixtures it contains the better it serves the purpose intended.

There is an arrangement in connection with the use of heavy harness that would result in much comfort to the horse and in a saving, if it could be attained. It is to secure light parts where light parts will serve, as in the bridle, reins, lines, back-straps and the like, and to use heavy harness only where needed, as in the tugs, hold-backs, breeching and breast-straps. There is no need of having heavy, wide-leathered bridles, heavy reins, lines, backbands, even on heavy harness, as they play no part in bearing the load and are often a hindrance to both horse and driver, and in addition they are rather expensive. Lighter harness where it bears no part of the load will serve every purpose.

\section{CARING FOR HARNESS}

Harness should be properly cared for, as this will increase the length of its usefulness and lessen the 
liability of its injuring the horse. It is very important that the bearing parts be kept scrupulously clean at all times. This applies especially to the parts in constant contact with the animal, as the collar, saddle, crupper and the like. It is, not possible to prevent sore shoulders, sore back and sore tail, if these parts are permitted to become dirty, which they will, because of the sweat and dandruff, unless they are carefully watched and frequently cleaned. These parts should be thoroughly cleaned each morning before harnessing, or better still, immediately after removing the harness.

The entire harness should be thoroughly cleaned and oiled at least once each year. The simplest way of doing this is to take the harness apart and soak the parts for fifteen minutes in a wash-tub of luke-warm water containing a handful of washing soda; then scrub the parts with a scrub brush, and when dry, oil with neat's-foot oil to which a small amount of kerosene and a little lampblack have been added; next hang up to dry, taking care not to dry in the sun or by the fire, and finally sponge with castile soap and buckle the parts together. Yet there can be no denying the fact that water injures the harness, particularly the polished and fancy parts. In the case of fancy harness, the mud and dirt should be permitted to dry. Then it should be removed with a brush stiff enough to answer the 
purpose but not so coarse as to injure the grain of the leather. It is important that the straps be rubbed with the grain, which lays down the fiber and gives a smooth edge. Next, the harness should be taken apart and cleansed with a sponge dampened with soapsuds, using only as much water as is necessary. When cleansed, wipe dry and oil with a little neat's-foot oil applied with the sponge, then apply some good harness blacking, and polish. Harness treated in this way will neither turn red nor become gummy, and if often sponged with white castile soap, can be kept looking like new.

When not in use, the harness should be covered with a sheet and hung in a room constructed especially for it, as dust, dampness and vermin tend to injure the leather and tarnish the fixtures. It frequently happens that the harness is hung on hooks just back of the horse in the stable. This is very objectionable. In the first place, gases escaping from the manure are very destructive to the leather, and in the second place, the harness is often knocked down under the horse's feet and becomes soiled with manure. It is much more desirable to have a harness-room convenient to the horse stable where all harness can be kept, as it is much less difficult to keep in order, and if we have a hanger for each horse's harness and hang it there each time, the work will be much lighter than otherwise. 
It is often very convenient and sometimes economical to be provided with a repair kit to mend harness whenever needed, as it often saves delay in sending to the shop. To make simple repairs is not difficult, and the repair kit is inexpensive. We should provide a wood clamp for holding the leather to stitch; round knife, gage knife, square point trimming knife; four-tube punch; paper of needles; ball of thread; ball of wax; three different sized awls; collar awl; rivet set; box of assorted rivets and a pair of pliers; all of which can be obtained for approximately five dollars. With such a kit of tools on hand, one can keep his harness in the best of repair at a very small cost.

\section{FLY-NETS AND FLY-BLANKETS}

The proper use of fly-nets or fly-blankets often brings much confort to the horse. In the summer, therefore, when the flies are troublesome, the horse should be provided with either a fly-net or a flyblanket, as they are more effective than any of the "fly-killer" preparations that have been compounded. The fly-blanket, though not advised by many persons, because it is not so presentable and is much warmer than the open net, nevertheless is very effective in keeping out the flies and retains the natural color of animals that fade on exposure to the sun. Leather fly-nets are the most presentable, and 
therefore the most desired by horsemen generally. The horse should always be provided with a throatlatch cloth when the bot-flies are present, as these. pests are very annoying, and the animal in fighting them will often become excited, with a consequent lessening of his usefulness. 


\section{CHAPTER X}

\section{CARE OF THE COLT IN TRAINING}

Having considered at some length the various methods of bringing out the best there is in the colt, we will now discuss the more important factors influencing his general development. No matter how efficient the method of education, it is not possible to bring out that which the animal does not possess; hence the general development should receive much consideration in training. This is often sadly neglected, with the result that the colt runs down in condition and loses courage. In reality, he is "broken" in spirit and obeys, or more accurately does not resist, because he has not sufficient energy to do otherwise. Such a colt is not educated, but is simply worn out instead. It is the horse thus treated that frequently gives his owner a surprise, when the animal regains his former condition, by rearing, kicking, running away and the like. It is highly desirable, therefore, to keep the colt in the pink of condition from the time of foaling, so that he may develop both mentally and physically. 


\section{EXERCISE AND DEVELOPMENT}

The idea is somewhat prevalent that colts brought up roughly, permitted to rough it through all sorts of weather, and on scant, coarse food, develop hardness and endurance, and that high feeding and good care will cause an otherwise good colt to grow into an unsound horse, lacking hardiness and endurance. Practical results in many cases have been such as to warrant this belief, not that there is anything bad in generous and liberal feeding, or good in starvation and exposure, but that the colts that roughed it always had pure air and abundant exercise, without which there can be no sound and healthy development.

An abundance of fresh air and exercise are factors in the raising and developing of a colt second to no others. It is for this reason that we recommend working the brood mare both before and after foaling, working the stallion when possible and permitting the foal to follow the dam into the field when convenient. The colt needs abundant opportunity for exercise in the fresh, pure air, uncontaminated by stable odors, as this is essential to a healthy development in all young animals. It is not sufficient that he be led out for exercise at stated intervals. He needs the opportunity to romp and play, that he may extend his muscles to their utmost capacity, expand his lungs to their very depths and send the blood 
coursing through his veins with much vigor. This is essential to a healthy, robust development of heart and lungs, bone and muscle, and nowhere can it be obtained in so great perfection as in the freedom of the open field.

The colt that is kept in the stall and fed highly on heating grains is seldom given an opportunity for this health-giving exercise. He grows up a stiff, clumsy animal, deficient in stamina and vigor, with his endurance greatly reduced and this all for the want of what is so free - fresh air and exercise. The best plan is to promote the growth of the colt by an abundance of nutritious food, and to secure a healthy and perfect development by permitting him to romp, race and play at will. If this practice is followed, all that is good in roughing it will be attained and all that is bad or dangerous in generous feeding will be avoided.

In the summer the required exercise may be obtained by permitting the colt the run of a pasture or paddock, while in the winter it is a good plan to fit up a box stall with the outside door opening to a lot or paddock. This door may be left open at all times, except in the severest of weather, though even then the colt should be let out a few hours each day. As winter comes on he will grow a heavy coat of hair, which will afford him ample protection. When convenient, it is a good plan to let two colts run together. Colts cared for in this manner will spend much of 
their time out in the lot at play and will get the much needed exercise. While there is always more or less risk attached to permitting the colts to play on slippery or frozen ground, it must be borne in mind that it is not possible to raise horses of quality and endurance unless they are vigorously exercised at all times irrespective of climatic conditions.

\section{FEEDING AND DEVELOPMENT}

To encourage maximum development, the colt should be liberally fed from the time of foaling. As a general rule, it is not possible to get him too fat before he is two years old. There are two periods in the colt's early life when much care must be exercised in feeding him. The first one is from foaling up to say three weeks of age, and the second immediately after weaning. Many mares are very poor milkers at best, and the youngster is often stunted before he is old enough to eat. On the other hand, some mares are very good milkers and provide more milk than is good for the colt. If he is permitted to take it all, he is likely to suffer from indigestion, which usually produces scours or constipation and if not attended to may prove fatal. When the colt is attacked with such troubles, it is very important to cut down his supply of milk and draw a part of the milk from the dam by hand. This should be continued until the colt can take it all with no ill 
effect. When the mare does not supply sufficient milk, the colt should be fed a small amount of fresh milk from a cow. When this is done, one should choose milk rather low in percentage of butter-fat, as milk too rich is likely to cause indigestion. This should be given in very small amounts at first, not to . exceed a pint twice daily when the younster is one week old, and in smaller quantities if given younger. This may be increased slowly as the colt becomes able to take it. If it seems necessary that the colt have extra milk after he is six weeks old, skimmed milk should be substituted for whole milk. The change should be made very gradually. In feeding milk, it is important that it always be fed sweet.

As soon as the colt is old enough, he should be encouraged to nibble at grain, preferably oatmeal. As a rule he will begin to munch in the grain and hay at two or three weeks of age and should be encouraged to eat. It is a good plan to arrange a grain box for the colt's convenience, though some prefer to lower the dam's grain box so the colt can eat from the mother's supply. In this way the colt may be taught to eat, so that when taken from the dam at weaning time he will not miss his mother so much.

In choosing the ration for the growing colt, it is important that much protein be supplied, as this constituent is essential in the formation of bone, muscle, blood, nerve, hair and hoof. The food should be palatable and easily digested. Such foods $2 \mathrm{~A}$ 
as oats, bran, peas, linseed meal and perhaps a little corn may constitute the grain, while alfalfa, clover and mixed hays, which should always be sweet, may constitute the roughage. Perhaps the following grain mixture cannot be materially improved upon for the growing colt: 45 pounds ground oats, 35 pounds bran, 10 pounds corn meal and 10 pounds linseed meal. The exact amount of the mixture that should be fed will depend largely on the individual. On the average, however, excellent results will be obtained by feeding the weanling 4 pounds of grain daily and all the sweet clover, alfalfa or mixed hay he will consume, which will be from 6 to 10 pounds each day; by feeding the yearling 6 pounds of grain daily and all the hay he will take, which will vary from 12 to 15 pounds each day, and by feeding the two-year-old 8 pounds of grain daily and all the hay he will consume, which will vary from 15 to 20 pounds daily.

Many excellent horsemen prefer to feed whole oats once a day, preferably in the morning, and the mixed feed at noon and night. For best results the colt should be fed the grain ration three times daily, though many feed but twice, morning and night. It is not necessary to feed the hay three times unless equally as convenient as feeding twice. To develop strong and thrifty colts, grain should be fed in summer as well as winter, particularly in the early spring, when the grass is very succulent, and in 
the fall, when the grass is rather short and flies troublesome. In the summer, shade of some kind should be provided in the absence of trees.

The ration for the trotting colt in training will vary somewhat from that fed other colts. Perhaps nothing excels oats as the principal grain ration, though they should be supplemented from time to time with bran and barley, if convenient. A good night ration is made from three parts ground oats, one part of barley and a handful of bran, mixed and steamed, and fed as a mash. For the colt in training most horsemen prefer old, sweet, clean timothy hay, as new timothy, clover and alfalfa have a loosening effect upon the bowels of the hard-working colt. Give the colt all he will clean up, then keep him in good physical condition by exercising him regularly.

The colt should be fed, watered and exercised regularly and uniformly at all times. He becomes accustomed to a certain order, which should be followed. To change the order for even a single meal oftentimes produces digestive disturbance. There is much difference of opinion as to the order of supplying food and water, as well as to the number of times the colt should be watered each day. Because of the small size of the horse's stomach, it must fill and empty itself two or three times for each meal. During the fore part of the meal the material is pushed into the intestines almost as soon as it enters the stomach by the food that follows, while toward the 
end of the meal the passage is slow and the digestion in the stomach more perfect; hence it would seem that the more nutritious foods should be fed toward the end of the meal. Were this true, first of all, we should water the colt, then feed the hay and lastly the grain. On the other hand, it is stated that this method of watering affects the appetite, and the horse will not consume so much food as he otherwise would. Again, it has been very clearly demonstrated that if a horse is fed his grain first and then watered, much of the food is carried by the water into the intestines. From this it would seem that there are theoretical objections, at least, to either method.

The most successful practice in the order of supplying food and water is to water the horse the first thing in the morning, then feed the grain and lastly the hay. Then water again as soon as the horse has consumed his morning meal and before going to work. At noon water both before and after feeding, and at night water before feeding and then again in about two hour's after feeding, or just before bedding the horse for the night. Colts thus managed will never become so thirsty as to drink enough water to affect their appetite materially. After they become accustomed to this order they will not gorge themselves before the meal, as they know they will be watered again before going to work or before being bedded at night.

Sudden changes in the food should be avoided, 
as the colt is often unable to accommodate himself at once to such changes, and digestive disorders follow. Such changes sometimes result in scouring, other times in constipation and occasionally permanently weaken the digestive system, as when the colt unaccustomed to grain is too quickly put on a full feed. If it is necessary to make a change, let it be made gradually, so that the digestive system can adapt itself to the new condition without injury.

The successful horseman will make a special study of each individual and modify the ration according to the needs; one colt may require a little more than the regular allowance and the next possibly a little less, because it is well recognized that some youngsters are much more difficult to keep in condition than others doing the same amount of work and under similar conditions.

\section{GROOMING AND DEVELOPMENT}

Efficient grooming, in some respects, is almost as essential as feeding and watering. The cleaning and rubbing of the skin stimulate the secretions and improve the general tone of the entire system, but more important than this is the good effect upon the feet and legs. The cleaning and rubbing of the feet and legs are very important factors in preserving soundness. As a general rule, grooming is sadly neglected. As soon as the colt is old enough to put 
into harness, the object seems to be to wear him out or to break his spirit. He is worked until late in the evening, hastily put in the stable, fed his evening meal, blanketed without being permitted to cool off and left for the night without cleaning the body or feet. The sweat saturates the blanket and the colt remains damp all night, the mud chills the legs and lessens the circulation, and the foreign materials collected in the bottoms of the feet heat and keep the sole in a feverish condition. The next morning the driver comes to the stable, feeds, removes the blanket and with the comb curries the body a very little, the legs practically none and entirely neglects the feet, then harnesses the colt and goes to work. At every step the colt betrays his care; he is stiff, his joints are sore and his courage gone. He is indeed "broken," to use the common term. Soon the colt becomes foot-sore, side-bones, ring-bones, splints and the like make their appearance and the animal is sold or traded as part payment for another and the process is repeated. The owner often wonders why his horses do not stand the work as well as those of his neighbor.

In grooming, the principal tools needed are a curry-comb, body-brush, flannel cloth, mane and tail comb, a half-worn broom for use on the legs, and a hoof-hook (Fig. 101). The curry-comb is used to loosen the hair which has become matted with sweat and dirt and to remove splashes of mud, thus 
preparing the way for the body-brush, which it also serves to keep clean. Much care should be exercised in currying the horse with a sensitive skin, as carelessness often provokes kicking, striking, biting and the like. Follow the curry-comb with the - body-brush, and with the cloth rub the hair free
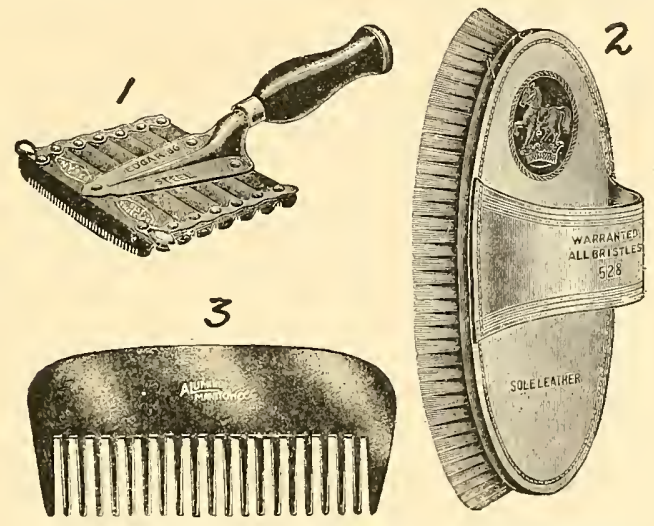

FIG. 101. - Principal tools for grooming. 1, Curry-comb ; 2, Bodybrush; 8, Mane- and tail-comb.

from dandruff. Straighten out the snarls and tangles in the mane and the tail with the comb. The hoof-hook, which is somewhat similar to a hay-hook, is used in cleaning the materials from the sole of the foot. When the colt arrives at the stable with legs covered with loose mud, a half-worn broom is a very convenient tool for removing it.

While the driver often takes much interest in rubbing the body and in keeping the hair well 
brushed out, the care of the legs is really of more importance. They are subject to severe strain and concussion, and if they are to be kept sound, they must be thoroughly cleaned and well rubbed so as to encourage the circulation and keep the parts warm and dry. The legs are the most exposed to water, mud and ice in winter, often remaining soaked the entire day, and to the ever-present dust of summer, and it is little wonder that they become unsound and often useless. To make them last as long as possible, they should be thoroughly cleaned and well rubbed each evening after the day's work is done, so that they will have the night in which to recuperate. Nothing contributes more toward producing diseased and unsound limbs than allowing the animal to remain all night with damp legs covered with mud, especially in damp or cold stables. The practice of not cleaning the legs and feet until morning should be severely condemned, for it is practically useless to cleanse them at six-thirty, when at seven they will be as muddy as ever.

If the animal is working in the mud, it is desirable that the hair be clipped from the legs as far up as the knees and hocks, as by so doing the animal's limbs may be kept clean with much less difficulty. In case the legs are clipped, it is all the more important that they should be thoroughly cleaned and rubbed each evening after work.

In grooming, a very good order to pursue is as 
follows: On arriving at the stable, if the horse's legs are muddy, they should be roughly cleaned with the half-worn broom. He should be placed in the stall, fed, unharnessed and covered with a sweatblanket. When he has measurably cooled, remove the sweat-blanket and let the hair dry. Then give a thorough grooming, spending extra time rubbing the legs in order to dry them and stimulate the circulation. Now the horse should be blanketed with a stable blanket. In the morning give the horse a complete rubbing to remove the dandruff and stimulate the circulation. Horses cared for in this way will repay for the extra care many times over in the satisfaction of seeing them come from the stable in the best of spirits, as indicated by the pleasing appearance, the snap and vigor with which they lift their feet and by the complete absence of any stiffness in the joints. Such care will decrease the unsoundness and greatly increase the animal's efficiency and prolong his usefulness.

Clipping and blanketing. - There is much difference of opinion as to the wisdom of clipping a colt in training as well as to the time of year it should be accomplished. It is stated that clipping improves the general appearance, renders the coat more easily kept clean and that a clipped horse is less liable to take cold than a long-coated one, because the evaporation is more rapid and the animal does not get so warm. While these statements 
are true in a way, it must be admitted that it is not possible to make a clipped coat show the luster of an unclipped one. Some horsemen practice clipping rather early in the fall, perhaps about the middle of October, stating that they wish the hair to attain some length before cold weather; while others delay the work until November, preferring the later clipping, as the hair has its growth and will not grow out again, whereas if clipped early, it will grow out again and sometimes necessitate a second clipping in two or three weeks.

There are many excellent horsemen who would dispense with clipping altogether and keep the coat in condition by blanketing and proper grooming. By the proper use of stable and outdoor blankets it is possible to keep the coat rather short, and by judicious grooming to keep it from becoming too thick, thus avoiding the necessity of clipping. Coats thus cared for can be made to carry a luster that it is impossible to obtain when clipping is practiced. When this is the practice, warm boiled feed given one or two evenings each week materially adds to the luster. Horses thus fed will shed very early in the spring. When blankets are used, we should provide two for summer as well as winter use. One should be employed as a sweat-blanket to be used immediately after the horse returns from work and while he cools out, then to be removed and in a few minutes to be replaced by the second, to remain on 
the animal overnight. Both should be kept scrupulously clean at all times, particularly the summer blankets, as it is sometimes preferable to discontinue their use rather than to use those laden with dirt.

During the cold weather, when the horse is allowed to stand outdoors, he should be well protected with a blanket, otherwise he may chill. During very inclement weather it is a good plan to secure the blanket around the abdomen with safety pins. As warm weather approaches, the heavy blanket should be substituted for a lighter one, and in summer its use may be dispensed with entirely, and a light fly-blanket employed in case the animal is of a color to fade on exposure to the sun.

Care of the colt's feet. - The feet of the growing colt should receive much attention. If left to nature, the feet will not always grow out full, strong and perfect in form. On stone or gravel soil, the foot wears off as fast as necessary to keep it in fair proportions, but the wearing is not even. For this reason the colt's feet should be carefully inspected at least once each month. It is often necessary to shorten the toes. This should be done with a rasp, which is the only instrument that should be used for this purpose. As a rule, when the toes are kept short, the quarters will care for themselves. The frog needs special attention, for if it gets out of contact with the bearing surface, the foot will very rapidly lose its shape, the heels will contract 
and the walls at the quarters become brittle, weak and easily split both from above and below. When a split occurs from above, it is especially difficult to stop without blistering or firing; hence it is important to protect the walls. Keep the toes of the proper length, the walls rounded at the ground surface, and the frog prominent.

It often happens that a piece is broken from the side of the hoof, throwing the weight of the body in such a way as to bring a strain upon the joints of the leg, which often causes deformity and disease. When such a break occurs, the hoof should be leveled with a rasp. Equal distribution of weight-bearing and other functional activities is possible only when the form of the foot and the direction of the limbs are correct. Any deviation from the proper standing position will cause a proportionate overtaxing of certain parts, resulting in unsoundness. Sound feet are best produced by feeding nutritious food. Sudden changes of the food, periods of sickness, exposure to cold, damp weather for months at a time, all have an injurious effect upon the feet. While the food and climate influence the rate of growth of the hoof, on the average it will grow one third of an inch a month. Hind hoofs grow faster than fore hoofs and unshod ones faster than shod. Thus if the top of the hoof is injured at the toe, it will take something like twelve months to grow out, if at the side, six to eight, 
and if at the heel three to five months, depending somewhat on the length of the hoof.

Care of the colt's teeth. - The teeth of the growing colt should be watched closely to see that they appear regular and uniform. Soon after foaling, or usually within two weeks, the central pair of incisors makes its appearance in both the upper and lower jaws; the second or intermediate pair appears in two to four weeks, and the third pair or corners makes its appearance about the fifth or sixth month of age. Colts often suffer from teething and it is very important that they receive extra attention at this time or they will run down in flesh. Because of the increasing size of the colt's jaws, at about two years and nine months of age the central pair of milk teeth is replaced by permanent ones in both the lower and upper jaw; at about three years and nine months the intermediate pair is replaced, and at about four years and nine months the corner pair of milk teeth is replaced by the permanent ones. It is very important that the teeth be closely observed at this time, as the first or milk teeth often persist, causing the second or permanent teeth to grow in crooked or irregular. To avoid this, the persistent milk teeth should be removed with forceps.

The upper jaw of the horse is somewhat wider than the lower and the teeth are not exactly opposite, thus the wear is not equally distributed and 
as a result sharp edges are often left unworn on the inside of the lower molars and on the outside of the upper, which may cut or lacerate the tongue or cheeks, which become sore. When the horse attempts to eat, the food irritates the sores and he will not feed well. This condition can readily be felt by the hand, and these sharp edges when found should be taken down with a guarded rasp.

In all cases in which a horse quids his food, slobbers or otherwise evinces pain in mastication, as shown by holding his head to one side while chewing, the teeth should be carefully examined. In addition to not feeding well, a horse whose teeth have unduly sharp edges, or which are otherwise irregular, is likely to drive badly, to pull to one side, not to bear on the bit, or to bear on too hard, to toss the head and start suddenly when a tender spot is touched.

\section{ACCIDENTS LIKELY TO OCCUR IN TRAINING}

While in training, the colt is more or less exposed to injury. The amount and severity of injury will depend much on the activity of the animal as well as on the methods of the driver. The high-strung, nervous and refractory colt is more likely to be injured than a mild, teachable one, and the driver who is careless and indifferent, or who uses severe methods, is more likely to cause injury than one who exercises the utmost care at all times. 
The following list contains the more important of the common injuries that a colt is likely to sustain in training, and the suggestions given are intended largely as a first aid until more expert advice can be obtained, particularly if the injury is a severe one.

Bruised knee. - In training a colt the knees are very much exposed to injury, particularly if the double or single safety (p. 208) is used. It is therefore very important that knee-pads be provided whenever the safety rope is attached, though even then the knee may be bruised in case the fall is a severe one. The injury may vary in extent from a mere scratch to a serious fracture of the bones; in any case it should receive immediate attention, as a slight bruise, if not cared for, may result in a permanent enlargement of the knee-joint, which is often exceedingly difficult to reduce, sometimes necessitating blistering and firing. In case the knee is simply bruised, bathe it freely with warm water night and morning, then put on a muslin bandage which has been soaked in a liniment composed of two ounces of tincture of arnica to a pint of cold water.

Broken knee. - This term is variously applied to injuries in which the skin is slightly abraded or broken, to others in which the tendons and sheaths, the ligaments and even the bones may be involved. If the skin is simply abraded, the hair scraped off 
and a little blood oozing from the surface, bathe the parts freely with warm water to which a little carbolic acid has been added, about one tablespoonful to the quart. Next dress with a white lotion made as follows: Zinc sulphate, one ounce, lead acetate, one ounce, and water, one quart, to which add one teaspoonful of carbolic acid to increase its antiseptic properties.

Where the skin is cut, bathe thoroughly to remove dirt and foreign substance, clip away the hair, bring the edges together and apply a muslin bandage around the knee. In all cases the leg must be kept as free from motion as possible. To do this, tie up the animal's head so he cannot lie down for a few days, and where he will not be likely to strike his injured knee against the manger. If pus forms, free exit must be allowed, and hot baths applied until it subsides, after which the healing process may be encouraged. A pad or compress made of wool or tow, covered with the white of egg and placed over the wound, and a wet pad bandaged lightly over this will exclude the dirt.

Bruised fellock. - The young horse very frequently interferes with the hind feet in such a way that a hind foot strikes the opposite fetlock, often bruising, abrading or scratching the surface. This is very likely to happen when the colt is fatigued or improperly shod. Injury is sometimes caused by a poorly clinched nail. The injury is usually in- 
dicated by the colt flinching, or if badly struck he may carry the injured leg off the ground for several steps. Rest and proper shoeing is the best remedy. If the horse continues to interfere, boots must be placed on the fetlocks to protect them from injury (p. 114). If the part is badly bruised and sore, bathe freely with cold water and dress with cold compresses.

Calking. - This is the name applied to injury at the top of the hoof or coronet and is usually inflicted by the shoe of the other foot or by the shoe of another horse. It is of quite common occurrence among colts in training, particularly when there is much short turning. As a rule, when the colt gets settled into a regular system of action, this trouble will cease; if not, boots must be worn to protect the exposed parts. If the parts are seriously injured, remove any jagged edge, bathe freely with warm water and apply tincture of arnica or iodine. Keep the wound clean, and bathe three times a day with white lotion (p. 368).

Puncture of the foot and frog. - This may be caused by the colt stepping on a nail or other sharp object, or it may be due to the nails not being properly driven when shod. Occasionally the nails are actually driven into the sensitive laminæ lining the interior of the horny substance of the foot. When the sensitive sole is injured, inflammation usually occurs, which results in the formation of pus. This 2 в 
may work its way up and form a running sore at the top of the hoof. Any injury of this kind, whatever its cause, should be promptly treated, as it may result seriously, sometimes producing lockjaw.

The injured spot must be found, and if still remaining, the object removed. Wash with an antiseptic and rest the animal until it heals. On the other hand, if inflammation has begun, freely pare out the puncture, so as to afford an easy exit for any matter which may form. Thoroughly bathe the part and soak the foot in warm water for one hour. Keep the parts clean and dress with an ointment. Perfect rest must be given until the sole grows out again.

Puncture of the frog is similar to that of the sole and requires similar treatment. When taken in time it yields to careful treatment more readily than puncture of the sole. On the other hand, if it is neglected, it is likely to lead to disease of the frog, and canker may result.

Wounds and stabs. - The refractory colt is often wounded while in training. The wound may be clean cut, in which the edges are smooth; lacerated, in which the skin is torn or broken, with edges more or less ragged and uneven; and punctured, in which the depth is greater than the entrance. The treatment will, of course, vary according to the class. In general, however, attention should first be directed to cleaning the wound from all foreign bodies, such 
as splinters, gravel and the like. This may be done by permitting lukewarm water to fall in a stream over it, as the surface should be touched as little as possible. The water should be made antiseptic by adding one tablespoonful of carbolic acid to each quart. In case there is much bleeding, immediate attention must be given to stopping it. This may be done with astringents, cold, or pressure. Common salt is a very good astringent for stopping a hemorrhage. Cotton, tow or oakum bound over the wound is also good.

In case the wound is deep, it may be necessary to hold the parts together by stitches. Separate stitches answer better than continuous ones. In case a bandage is used to hold the parts together, it should be adjusted very evenly and extra care exercised not to draw it so tightly as to obstruct the circulation. The bandage should be applied so as to encourage union from the bottom, and prevent accumulation of pus.

During the following days, syringe the wound out once a day with an antiseptic wash made by adding one tablespoonful of carbolic acid to a quart of water. The wound may be gently cleaned with a soft sponge and castile or carbolic soap and hot water. If proud flesh forms, it must he held in check by applications of some caustic, such as nitrate of silver.

In treating wounds it is very important to keep 
the animal as quiet as possible. While in some parts a certain degree of motion cannot be avoided, an endeavor should be made to lessen it to the minimum. In some cases the colt will have to be tied up to prevent his moving, while in others it will be necessary to place a cradle about his neck to prevent him from gnawing the wound with his teeth (p. 308).

Sprains. - In training the colt, sprains of the muscles, tendons and ligaments are of rather common occurrence. Severe lameness usually comes on suddenly soon after the injury. The joint becomes inflamed, swollen and tender, and is often moved with much difficulty. The animal should be kept quiet on a level floor. Hot or cold applications should be applied to the parts; hot water if there is severe pain, to soften; sooth and relax the parts, and cold applications in the form of water or bags of ice, if there is inflammation. If the pain is severe, a warm application of one quart of water with four ounces tincture of opium and two ounces of acetate of lead added, made several times daily, will prove beneficial. If the parts remain large and swollen after the inflammation is reduced, tincture of iodine should be rubbed in twice daily. If this fails to reduce the part, try a light blister. A part that has been severely sprained should have a long period of rest, as complete recovery from a sprain is a very slow process. 
Wind-galls, wind-puffs, blood-spavin, bog-spavin and thorough-pin. - These appear as soft, rather symmetrical bunches, wind-galls occurring on the back of the fetlock joint; wind-puffs along the tendons, usually on either side of the leg, but more particularly on the outside just above the fetlock joint, between the back tendons and the bones; blood-spavin and bog-spavin in front and a little inward of the hock; and thorough-pin is located at the back and on the top of the hock in that part known as the "hollows." They often make their appearance on the young horses as the result of strains due to heavy pulling, fast driving, jumping and the like. The treatment is to cause the swelling to absorb. This can usually be done by handrubbing, followed by pressure and cold, applied by means of wet bandages. An elastic bandage is good. Later iodine ointment may be rubbed in once a day. A small amount of red blister rubbed over the growth sometimes proves beneficial, but a severe one should not be used.

Capped hocks. - The colt in training frequently injures his hocks in kicking or by striking them across the cross-bar, which results in a growth over the parts, known as capped hocks. Sometimes the injury is brought on in the act of lying down and getting up. The treatment is similar to that suggested for sprains (p. 372).

Harness galls. - The young horse in training is 
very subject to harness galls, particularly along the shoulders under the collar, at the back under the saddle and under the tail, caused by the crupper. The parts are soft and tender and sweat easily from the excitement of training. In this condition the colt chafes under the harness, especially if it is hard and poorly fitting. This chafing causes abrasions of the skin, which prepare the way for abscesses or chronic blemishes unless attended to very promptly. This may involve only the skin or it may work down into the muscle and even the bone. When the ligament is involved there may be a dry slough, commonly called "sit-fasts."

Abrasions are best prevented by bringing the young animal gradually into working shape, so as to harden the muscles and toughen the skin. The harness should be well fitted, cleaned and oiled to remove all dirt and to make it soft and pliable (p. 345). The parts likely to be abraded should be cleaned and brushed free of dirt.

In treating the sore, bathe the parts freely in warm water, then apply an astringent, such as cold salt water ; carbolic acid and glycerin, one part of the former to fifteen of the latter; one pint of alcohol in which are well shaken the whites of two eggs; a sugar of lead lotion made by adding one teaspoonful of the lead to a quart of water; or a nitrate of silver solution, one half teaspoonful to the quart of water. Continue until cured. 
If a horn-like slough or sit-fast has developed, it must be carefully dissected out and the wound treated with antiseptics. Allow the animal rest until the wound is healed.

Chafed legs. - It often happens that the friction caused by improperly fitting hopples and boots chafes the legs, and constant irritation causes the horse much pain. It is the common practice of horsemen to dust the injured parts with lampblack or to apply charcoal and boracic acid. The trotting horsemen assert excellent results from the use of these materials. 



\section{INDEX}

Accidents, blood-spavin, 373 ; bogspavin, 373 ; broken knee, 367 ; bruised fetlock, 368; bruised knee, 367 ; calking, 369 ; capped hocks, 373; in training, 366; sprains, 372 ; stabs, 370 ; thoroughpin, 373 ; to foot, 369 ; windgalls, 373 ; wind-puffs, 373 ; wounds, 370 ;

Acquainting, with buggy, 77 ; with objects of fear, 85 ; with umbrellas, etc., 87.

Action, 132; bitting for, 139 ; bitting to improve, 134 ; brushing, 145; cause of heavy going, 133 ; clicking, 143; conformation favoring, 133; conditioning to improve, 142 ; condition favorable, 134 ; curb-bit, 136 ; cutting, 145; defective, corrected by shoeing, 141 ; exercise improves, 147 ; faulty, 143 ; faulty bitting, 146; faulty causes, 144, 145; faulty overcoming, 144,146 ; feeding to improve, 143 ; forging, 143; high, 131; importance of a good mouth, 136 ; improved by curb-bit, 137 ; interfering, 145 ; length of hoof, 141 ; over-reaching, 143; shoeing to improve, 139,146 ; striking, 145 ; weight on shoe, 141.

Age, by tceth, 364 ; to train coacher, 109 ; to train foal, 27 ; to train horses for work, 46 ; to train to jump, 174 ; to train roadster, 109; to train saddle horse, 150 ; to train trotter, 109.

American Saddle Horse Breeders' Association, 163.
Appliances, 188; anti-switching, 267 ; bridle twitch, 200 ; cavesson halter, 196; combination bridle, 201 ; excelsior bridle, 193 ; fence-jumping, 277; gag, 200; Galvayne's training harness, 219 ; guy rope, 201; Hackamore bridle, 196 ; halter-twitch, 19s; headstall twitch, 199; hobbles, 206 ; kicking harness, 204; kickingreins, 202; kicking strap, 202 ; lead rope, 201; lip-twitch, 197 ; muzzle, 308; neck-cradle, 308; pulley bridle, 193; pulley bridle, modified, 195; Rarey's leg-strap, 207 ; Rarey's safety harness, 208; Rarey's throwing harness, 212; rearing twitch, 200; rope halter, 189 ; rope throwing, 216 ; shackles, 221 ; straight-jacket, 221 ; twitch, 191; war bridle, 191 ; war bridle, modified, 192; Yankee bridle, 189; Yankee bridle, modified, 190; wooden-gag, 200.

Army horse training, 177.

Artillery horse training, 177.

Association of ideas, 3.

Automobile, familiar with, 239.

Back-band, 337.

Backing, by pressure, 39 ; difficult, causes, 263; difficult, overcome, 263 ; foal, 38 ; in stall, 297; in stall overcome, $29 \mathrm{~S}$; vehicle, 80 ; when to teach foal, 38 ; with lines and pressure, 81 .

Back-strap, 336.

"Back," teaching foal, 42; teaching borse, 67 ; what it stands for, 100. 
Balancing, 139, 303.

Balker, how produced, 95.

Balking, 249; causes, 249; overcome, 250, 272.

Bandaging legs, 126.

Bar-bit, 320 ; half check, 320.

Bedding, eating, 312.

Beery bit, 323.

Bit, 56, 318 ; bar, plain, 320 ; Beery, 323 ; chain, 320 ; chain center, 320 ; classes, 319 ; coach, 320 ; curb, 136; Detroit, 320 ; fitting, 60 ; fitting curb, 137 ; grasping, 279; humane, 320; Imperial, 320 ; importance of fitting, 318 ; J. I. C., 320 ; jointed cushion, 320 ; kinds, 320 ; Liverpool coach, 320 ; mouthing, 320 ; nodine, 320 ; Norton, 320 ; perfection, 320 ; plain jointed, 320 ; Racine, 320 ; riding, 151,320 , Rockwell, 320 ; Sanborn, 320 ; straight cushion, 320 ; success, 320 ; teaching wild horse uses of, 233 ; training, 58; tongue lolling, 320 ; triumph, 320 ; U. S. Army, 320; victor, 320 ; wind-sucking, 320 ; Wilson 320 ; w-wire, 320.

Biting, 292 ; causes, 292 ; overcome, 292.

Bitting, to curb-bit, 139; first time, 59 ; the horse, 57 ; to improve action, 134; refractory horse, 233 ; stubborn horse, 233; uses of bit, 61; wild horse, 233.

Bitting-harness, 60, 139; "elastic" reins, 62 ; " fixed" reins, 62 ; " running" reins, 62 .

Blanket, saddle, 153.

Blanketed, 121.

Blanket-fly, 347 .

Blanketing, advantages, 362 ; and clipping, 361 ; the trotter, 126.

Blankets, tearing, 307 ; tearing, overconie, 308 .

Blinds, 325; on training bridle, 9.
Blood-spavin, 373.

Body-brush, 359.

Bog-spavin, 373.

Boils, shoe, 311 .

Boots, 114.

Boring, 281 ; causes, 282 ; overcome, 282.

Boston hold-back, 338.

Brass fixtures, 326.

Breaking, 265.

Breaking $v s$. training, 1.

Breast harness, 335.

Breeching, 338; "Pennsylvania," 338.

Breed, on training, 47.

Bridle, 318 ; adjusting, 59 ; blinds, 325 ; check-rein, 327 ; combination, 201; difficult, 291; excelsior, 193 ; fixtures, 326 ; Hackamore, 196; pulley, 193 ; pulley, modified, 195; riding, 151 ; stripping, 283; tassels, 326 ; too tight, 59; too loose, 59; war, 191; war, modified, 192 ; Yankee, 189; Yankee, modified, 190.

Bridle-twitch, 200.

Bridling first time, 59.

Broken knee, 367.

Bruised fetlock, 368. Bruised knee, 367.

Brushing, 145.

Brush system, 119, 124.

Bucking, 276; causes, 276; overcome, 276.

Buck-jumping, 276.

Buggy, aequainting with, 77 .

Calking, 369.

Canter, 160 ; training, 171 ; threefooted, 161.

Cantle, 151.

Capped hocks, 373.

Care in training, 349.

Caressing with whip, 83.

Cars, familiar with, 240.

Cart, familiarizing with, 77 ; for training, 74 ; how to make, 74 . 
Catching a wild horse, 223; foal, $28,29$.

Catch, troublesome, 285.

Cavalry horse training, 177, 178.

Cavesson halter, 196.

Centerpieces, 326 .

Chafed legs, 375 .

Chain bit, 320 .

Chain center bit, 320 .

Check-rein, 327 ; disadvantages, 328.

Children handling foal, 31.

Children's pony, 91.

Circus tricks, 183.

Classes of saddle horses, 167.

Clay mud pack, 127.

Clicking, 143.

Clipping and blanketing, 361 .

Coach bit, 320.

Coach, horse training, 108.

Coacher, action, 132 ; bitting to improve action, 134; brushing, 145; clicking, 143 ; conditioning to improve action, 142 ; curb-bit, 136; cutting, 145; defective action corrected, 142; driving, 129; exercise improves action, 148 ; faulty action, 143 ; forging, 143; high action, 134 ; interfering, 145; over-reaching, 143; shoeing to improve action, 139 , 146 ; striking, 145 ; training yard, 111.

Collar, 73, 331; adjusting, 334; fitting, 334; humane, 332 ; Irish, 333; metal, 331 ; pneumatic, 331; Sweeny, 333.

Combination bridle, 201.

"Come here," teaching horse, 55.

Commands, teaching, 65 .

Confidence of foal, 31 .

Conformation for action, 133.

Confusing a colt, 32 .

Cradle, neck, 308.

Cribbing, 299 ; causes, 299 ; overcome, 299; sce Wind-sucking.

Crowding, 282; overcome, 253.

"Cruiser," 241.
Crupper, 336.

Cruppering, 70; difficult, 292.

Curb-bit, 136, 320 ; advantages, 137 ; disadvantages, 137 ; familiarizing the horse, 138.

Curry-comb, 359.

Cutting, 145.

Daily program for a trotter, 125.

Detroit bit, 320.

Development, and exercise, 350 ; and feeding, 352; and grooming, 357.

Difficult, to back, 263 ; to crupper, 292 ; to bridle, 291; to groom, 288 ; to drench, 315 ; to harness, 290 ; to mount, 274 ; to lead in doorway, 298; to shoe, 300.

Domestication of horse, 30 .

Double, hitching, 84.

Draft horse, how to drive, 94; "steady," 96 ; signals, 96 ; training for, 93.

Drenching, 315,

Driving, 68, 129; careless effect, 131; efficient effect, 132 ; foal with lines, 40 ; guide left, 65; guide right, 65; holding lines, 131 ; horse with lines, 63 ; how acquired, 130 ; position of lines, 132; surcingle, 64 ; when to teach foal, 40.

Dumb jockey, 139.

Earbobs, 326.

Farly training, advantages, 110, 117; effect on coacher, 110 ; effect on disposition, 117; effect on roadster, 110 ; effect on trotter, 110 ; in harness, 118 ; objections, 43 ; value, 42.

Educating, foal to back, 38 ; a loose horse to follow, 55 ; by the special senses, 7 ; to come under shafts, 82.

"Elastic" reins, 62.

Endurance, increasing, 124. 
Examine the horse, 49.

Excelsior bridle, 193.

Exercise, and development, 350 ; improves action, 147 ; irregular, 147 ; value of, 350 .

Eyes, 49.

Familiarize with vehiele, 77.

"Family broke," 90.

"Family horse," 90.

Fast walking, advantages, 92 ; train to, 91 .

Fatigue, 116, 122 ; impairs memory, 6.

Faulty action, 143.

Fear, 85 ; and sight, 9.

Feed for one day, 354.

Feeding, eolt, 353; and development, 352 ; night ration, 355 ; order of, 355 ; requires training, 7 ; the trotter, 125 ; to improve action, 143.

Feeling and fright, 8 .

Feeling $v s$. smelling, 8 .

Feet, 49, 101; advantages of handling, 106 ; care, 127,363 ; gentling, 101, 301, 304.

Fence jumping, 277 ; overeome, 277.

Fetloek bruised, 368 .

First lessons short, 33 .

Fitting, collar, 334 ; halter on foal, 36.

Five-gaited horse, 167.

"Fixed" reins, 62.

Fly-blankets, 347.

Fly-killer, 347.

Fly-net, 347.

Foal, training, 26.

Following when loose, 54.

Foot, aceidents, 369 ; gentling, 301, 304; gentling a front foot, 102 ; a hiud foot, 104; handling, 101 ; holding a hind foot, 105; how to pick up, 103; injuring, 313; trimming, 140 ; shocing to improve action, 140.

Forging, 143.

Fox trot, 165; training, 173.

Frightened horse, never whip, 89.

Frog, puncture, 369 .

Gag, wooden, 200.

Gait, diagonal, 160.

Gaited horse, 167.

Gaits, 158; training to, 168.

Gallop, 160 ; hand, 161.

Galls, harness, 373.

Galvayne's appliance in use, 221; method, 12; training harness, 219 ; tail rope, 219.

"Gee," teaching a horse, 97 ; what it stands for, 100 .

Gentling, a front foot, 301 ; a hind foot, 304; a wild horse, 226, 229.

"Get up," teaching foal, 42 ; teaching horse, 67 ; what it stands for, 100.

Girth, saddle, 153.

Gnashing teeth, 280.

Gorging grain, 315.

Grain, gorging, 315 .

Grasping bit, 279; eauses, 279; overeome, 279 .

Groom, 357 ; difficult to, 288 ; difficult to, overcome, 288 .

Grooming, advantage, 360 ; tools, 359 ; and development, 357.

Guiding by legs, 158 .

Gun-fire, training, 177.

Guy rope, 201.

Habits, bad, 4; easily formed, 4; good, 4 ; transmitted, 4.

Hackamore bridle, 196.

Hackney coach horse, 4.

Halter, eavesson, 196; fitting on foal, 36 ; leather for the horse, 51 ; for colt, 35 ; web, 35.

Haltering a loose horse, 227.

Halter-pulling, 269; causes, 267 ; eonfirmed, 271; overcome, 270 .

Halter, rope, 189.

Halter-twiteh, 198. 
Hame-tug, 336.

Hand-gallop, 161.

"Hands," how acquired, 130 ; in driving, 130.

Handling, colt, 26; foal, 28; feet, 101 ; horse, 44, 50; vicious horse, 242 ; wild horse, 226 .

Harness, 188, 317 ; back-strap, 336 ; bit, 318 ; bitting, 60 ; bits, 322 ; blinds, 325 ; breast, 335 ; breeching, 338 ; bridle, 318 ; caring for, 344 ; check-rein, 327 ; choosing, 343 ; cleaning, 345 ; collars, 331 ; combination bridle, 201 ; crupper, 336 ; difficult to, 290 ; early training in, 118 ; excelsior bridle, 193 ; galls, 373; Galvayne's training, 219; Hackamore bridle, 196 ; hame-tug, 336 ; head-stall, 325 ; hobbles, 206; hold-backs, 338 ; kicking-reins, 202; kicking-strap, 202 ; leather, 343 ; lines, 329; lying down in, 312 ; oiling, 345 ; pulley bridle, 193 ; Rarey's safety, 208; Rarey's throwing, 212; repairs, 347 ; room, 346 ; rope halter, 189 ; rubbing, 311 ; rubbing overcome, 311 ; saddle, 337 ; shackles, 221; self-punishing, 205 ; straight-jacket, 221 ; sweat pads, 335; trimmings useless, 343 ; twitch, 197 ; Yankee bridle, 189; war bridle, 191 ; web, 343.

Harnessing, 68, 317; collar, 73; cruppering, 70; difficult, 290 ; difficult to overcome, 290 ; difficult to bridle, 291; difficult to crupper, 292 ; examine shoulders, 73 ; fitting collar, 334 ; kind of harness, 72; parts likely to abrade, 74 ; placing harness over back, 72 ; poling, 69 ; .pressure, 69 ; smelling harness, 73 ; a wild horse, 234; work horse, 72.

"Haw," teaching a horse, 97 ; what it stands for, 100 .

Head, tossing and shaking, 280 .
Head-stall, 325.

Headstall-twitch, 199.

Hearing, 49; confusion, 9 ; requires training, 9.

Heavy draft, training for, 93.

Herds of wild horses, 6 .

High-school horse, 167 ; training, 181.

Hitching, 68, 78; double, 84; kicking-straps, 78; single, 74; tandem, 98.

Hitching-rack, 45.

Hobbles, 206.

Hocks, capped, 373.

Hold-backs, 338.

Horse training, 44.

Humane, bit, 320 ; collar, 332.

Humiliating the horse, 248.

Hunter, 167.

Imperial bit, 320 .

Inclosure for training, 48.

Individuality on training, 47.

Intelligence, of the horse, 3; of mule, 7 .

Interfering, 145.

Irish collar, 333.

Jibbing, 252 ; causes, 252 ; overcome, 253.

J. I. C. bit, 320.

Jockey yoke, 342.

Jump, 166; age to train, 174; training while young, 174 .

Jointed cushion bit, 320 .

Jumping fences, 277.

Kicking, 254, 295; causes, 254; in stable, 295; overcome, 255.

Kicking-harness 204.

Kicking-reins, 202.

Kicking-strap, 202.

Kicking-straps, 78.

Kimball Jackson, 328.

Knee, bruised, 367; broken, 367 .

Lassoing a wild horse, 223.

Leader, 97. 
Leaders, how to train, 97 ; kinds, | Metal, collar, 331. 97.

Leading, foal with loin-hitch, 38 ; the foal, 34 ; the horse, 51 ; when to teach foal, 34 ; wild horses, 231 ; with halter, 45.

Leather collar, 333.

Legs, bandaging, 126 ; chafed, 375 ; clipping hair from, 360 ; guiding with, 15s; leading, 162, 171; pressure of, 157.

Leg-strap, Rarey's, 207.

Lessons, in regular order, 34 ; useful, 33 ; short, 33.

Light horse training, 108.

Lines, 329 ; arranging on foal, 40 ; holding, 131 ; multiple hitch, 330 ; under tail, 268.

Lip striking, 279.

Lip-twitch, 197.

Liverpool coach bit, 320 .

Loin-hitch, how made, 37; in teaching foal to lead, 37 ; on horse, 52.

Loose horse, following, 54 ; haltering, 227.

Loose ring strap, 45.

Lope, 160.

Lugging, 281 ; causes, 281 ; overcome, 281.

Lying down, cow-fashion, 311 ; in harness, 312 .

Mane-comb, 359.

Martingale, 338.

Master, of the horse, 2; personal habits, 2 ; qualities of, 2.

Memorizing, and flocking together, 6 ; and number of ideas, 6 ; both sides of the horse, 6 ; fatigue, 6 ; imitation, 7 ; out of condition, 7 ; rapidity depends on, 5; while young, 5 .

Memory, good, 4 ; how trained, 4; in foal, 27 ; repetition, 5 ; vividness of impression, 4.

Mental capabilities of the horse, 3 .
Methods, effective, 13; Old WTorld, 15 ; rapid $v s$. slow, 12 ; safe, 15 ; selecting, 12; of training, 11.

Mounting, 106, 155; difficult, 274; steadying, 107.

Mouth, before bitting, 56 ; "hard," 57 ; how to examine, 57 ; in good condition, 49; importance of a good one, 57; "spoiled," 57; "tender," 57 ; unresponsive, 63.

Mouthing, bit, 320 .

Mouths, difference in, 136.

Movements of foal, 28.

Mules, intelligence, 7 .

Multiple hitches, 98 .

Muzzle, 308.

Natural law, 28.

Neck-cradle, 308.

Nervous types of foals, 30 .

Nets, fly, 347.

“Night kicking," 295 ; causes, 295; overcome, 295.

"Nodder," 173.

Nodine bit, 320 .

Noise, 85; acquainting with, 86 .

“Noise kicking," sce "Night kicking."

Noose-twitch, 197.

Norton bit, 320 .

Obedience, 16; and reward, 17.

Objects, acquainting with, $s \overline{\text {; }}$ of early training, 27; of fear, 85 ; strange, 237; of training, 11.

Old World methods, 15 .

Orders, few, 16 ; make them understood, 15; patienee, 16; simple, 16.

Over-reaching, 143.

Pace, slow, 165.

Painful lessons long remembered, 4.

Pawine, 309 ; overcome, 309.

"Pennsylvania" brecehing, 338.

Perfection bit, 320 . 
Permanent methods, 13.

Personal influence in training, 21.

Petting the horse, 17.

Physicked, 121.

Picketing, 179.

Plain jointed bit, 320 .

Plunging, 264 ; causes, 264.

Pneumatic collar, 331.

Poling, 69; advantages, 71 ; legs, 72 ; wild horse, 229.

Polo game, 179.

Pommel, 151.

Pony for children, 91.

Position, while harnessing, 45 ; while leading a horse, 44 .

Prancing, 265.

Pressure, 69; in backing, 81.

Principles, exaggerate horses' ideas, 22 ; fatigue, 23 ; obedience, 24 ; of training, 22 ; study horse, 24 ; train while young, 22 ; use appliance to give advantage, 24; various methods, 23.

Program training a trotter, 125.

Pulley bridle, 193; modified, 195 ; three ring, 194.

Pulling away, 282.

Punishiug harnesses, 204.

Punishment, and the voice, 18 ; and the whip, 19 ; in training, 17.

Quarters, examine, 73.

Quarters-hitch, how to make, 53; on horse, 53 .

Race, conditioning, 128 ; driving, 129; examining before, 127; preparing for, 129; training for, 127 ; working out for, 129.

Racine bit, 320 .

Racing bit, 320 .

Rack, 163; training, 173.

Rapid methods, 12; effective, 13 ; safe, 15.

Rarey's, double safety, 210 ; double safety and guy rope, 209; legstrap, 207 ; method, 12; safety harness, 208; safety in use, 210 ;

single safety, 210 ; throwing harness, 212; throwing harness in use, 215 .

Ration, daily, 353.

Rearing, 264, 276; causes, 264, 276 ; overcome, 264, 276.

Rearing-twitch, 200.

Refractory horse, hitched, 235 ; subduing, 236.

Refusing to stand, 284.

Repair-kit, 347.

Repetition, 14; and memory, 5.

Reward, and taste, 10 ; and the whip, 19; food, 17 ; in training, 17 ; patting, 17 ; voice, 17.

Riding bit, 151,320 ; bridle, 151 ; saddle, 151.

Right, make easy, 11.

Roadster, action, 132; bitting to improve action, 134; brushing, 145; clicking, 143, conditioning to improve action, 142 ; cutting, 145; defective action corrected, 142 ; driving, 129 ; exercise improves action, 148; faulty action, 143; forging, 143; interfering, 145 ; over-reaching, 143 ; shoeing to improve action, 139, 146 ; striking, 145; training, 108; training while young, 110 .

Rockwell bit, 320 .

Rolling, 306 ; causes, 306; overcome, 306.

Rope-halter, 189.

Rope-tail, 220.

Rope-throwing, 216.

Rubbing harness, 311 .

Run, 160.

Running away, 260; causes, 260 ; overcome, 261.

Running back, 262 ; causes, 262; overcome, 262.

Running foal about, 31 .

"Rumning" reins, 62.

Running walk, 164; training, 172. 
Saddle, 151, 337 ; cantle, 151 ; fitting, 151 ; men's, 151 ; pommel, 151 ; women's, 151 ; stirrup, 152. Saddle-blanket, 153.

Saddle-girth, 153.

Saddle horse, army training, 177 ; Breeders' Association, 163; canter, 160 ; circus tricks, 183; classes, 167 ; "dog trot," 173 ; fox trot, 165 ; fox trot training, 173 ; gaits, 158; gallop, 160 ; guiding, 158; hand gallop, 161; high-school, training, 181 ; “"jiggle," 170 ; jump, 166 ; jump, training, 174 ; lope, 160; mounting, 155, 156, 157 ; picketing, 179 ; polo training, 179; pressure of legs, 157 ; rack, 163; rack, training, 173; riding bridle, 151 ; run, 160 ; running walk, 164 ; running walk training, 172; saddle for, 151 ; "shog," 173; single-foot, 163 ; slow pace, 165 ; slow pace training, 173; Spanish trot, 183; Spanish walk, 181 ; special work, 179; three-footed canter, 161; training, 150, 171 ; training equipment, 151; training to stand, 176 ; trot, 160 ; trot, training, 170 ; walk, 159 ; walk, training, 168.

Safety harness, 208; in horse training, 14 .

Sauborn bit, 320 .

Score, 128.

Seouting horse training, 177.

Scraped, 121.

Scraping trotter, 126.

Secure foal's confidence, 31 .

Self-punishing harness, 204.

Senses, feeling, 7 ; hearing, 9 ; sight, 9 ; smell, 10 ; taste, 10.

Senses and training, 7 .

Shackles, 221.

Shackling a wild horse, 230.

Shafts, teaching horse to come under, 82 .
Shoe-boils, 311.

Shoe, fitting, 140.

Shoeing, 101, 122; difficult, 300 ; fitting the shoe, 140 ; to improve action, 139 ; weight, 140.

Shoulders examine, 73 .

Shying, 257 ; causes, 257 ; overcome, 258.

"Side wheelers," 164.

Sight, limited, 9 ; requires training, 9.

Signals, few, 16 ; make them understood, 15; patience, 16; simple, 16.

"Single foot," 163.

Single, hitching, 24.

Sit-fasts, 374.

Sleeping standing, 313 .

Slow methods, 12.

Slow pace, 165 ; pace training, 173.

Smelling vs. feeling, 8 .

Smell requires training, 10.

Snaring a loose horse, 224 .

Sores, eare of, 74 .

Sore mouth, 57.

Spanish trot, 183.

Spanish walk, 181 ; described, 182.

Special senses and training, 7 .

Speed-making lessons, 124.

Sprains, 372.

Spurs, 154; army, 154; English, 154; familiarizing, 154 ; patent, 154 ; plain, 154 ; racing, 154 ; rowel, 155 ; unsteady under, 273 ; uses, 154 .

Stable, switehing tail, 314 ; trotting in, 314 ; vices, 286 ; causes, 286 ; overeome, 286 ; whims, $2 \$ 6$.

Stabs, 370; treatment, 371.

Stall, hanging back in, 297 ; refusing admission, 286 .

Stand, refusing, 2S4; training, 176 .

"'Steady," four uses, so; teaching horse, $\mathrm{S0}$; what it stands for, 100 .

Stirrups, 152; military, 153: Oxhow, 153; safety, 153; slipper, 153; straps, 153; Texas, 153. 
Straight cushion bit, 320 .

Straight-jacket 221; in use, 222. Strange objects, 8 .

Strength of foal, 27.

Striking, with foot, 145, 294 ; causes, 295; striking-lips, 279; causes, 279 ; overcome, 279, 293.

Stripping bridle, 283 ; causes, 283 ; overcome, 284.

Stubborn horse, driving, 233; hitched, 235; leading, 232; teaching uses of bit, 233 ; training, 223.

Study individual peculiarities, 121.

Stupefying, 231.

Success bit, 320 .

Sugar for foal, 32 ; for gaining confidence, 32.

Sugar-of-lead-laudanum lotion, 126.

Surcingle, for driving, 64 ; for foal, 40.

Sweated, 121.

Sweat pads, 335.

Sweeny collar, 333.

Switching tail, 265; in stable, 314.

Tail, rubbing, 310 ; rubbing overcome, 310 ; sore, 268 ; switching, 265; causes, 265; overcome, 266.

Tail-comb, 359.

Tail-hitch, how to make, 52; on horse, 52.

Tail over line, 268; causes, 268; overcome, 269.

Tail-rope, 219; attached to tail, 220.

Tassels, 326 .

Taste, and reward, 10 ; requires training, 10.

Teeth, 49; care of, 364 ; gnashing, 280 ; in telling age, 364 .

Temper, 187 ; nervous, 187 ; stubborn, 187; teachable, 187 ; treacherous, 187.

Temperament, 187.

"Third hand," 51.
Thorough-pin, 373.

Throwing harness, 212.

Throwing ropes, 216.

Tie-strap chewing, 312 .

Time required for early training, 43 .

Timidity, of foals, 30 ; overcome by handling, 30 .

Toe-weight, 122 .

Tongue, 49.

Tongue-lolling, 278; bit, 320 ; causes, 278; overcome, 278.

Tossing and shaking head, 280.

Track, exercise on, 113 ; small construction, 111; small training, 111.

Trainer, personal influence, 21 ; requirements, 20.

Training-cart, 74 ; advantages, 76 ; driving, 79 ; backing, 82 ; familiarizing with, 77 ; hitching to, 78 ; how to make, 74 ; kicking-straps, 78 .

Training defined, 1.

Training vs. breaking, 1.

Train within an inclosure, 48.

Tricks, 183.

Triumph bit, 320 .

Trot, 160; fox, 165 ; Spanish, 183 ; teaching to lead, 171; training, 170 ; action, 132; advantage of early training, 117 ; advantages of early work in harness, 123; balancing, 139; blanketed, 121 ; bandaging legs, 126 ; blanketing, 126; boots for, 114; brush system, 119; brushing, 145; care, 112, 125 ; elicking, 143; cutting, 145; do not tire, 115; driving, 129 ; exercise, 113 ; exercise in1proves action, 148; exercise on small track, 113; fatigue, 116 ; feeding, 112; forging, 143 ; increasing endurance, 128 ; interfering, 145; in harness, 118 ; in single harness, 119 ; in stable, 314 ; length of exercise, 116 ; night care, 127 ; objection to 
cart, 118; order of feeding, 125; over-reaching, 143; physicked, 121; plan for training, 112 ; rest two days a month, 116 ; scraped, 121; scraping, 126 ; shoeing, 122; shoeing to improve action, 139, 146; small training track, 111; speed-making lessons, 124; striking, 145 ; study colt, 116; study individual, 121 ; sugar-oflead-laudanum lotion, 126 ; sweated, 121 ; training, 108; training to use track, 113 ; training vehicle, 118; training while young, 110 ; toe-weight, 122 ; two- and three-year-old, 123; watering, 112,125 ; young exercised twice daily, 120.

Troublesome to catch, 285.

Trusting horses, 44.

Tug, hame, 336.

Twitch, 191, 192, 195, 197; and bridle, 191, 192, 195; bridle, 200 ; halter, 198; headstall, 199; lip. 197 ; noose, 197 ; rearing, 200.

Tying to post, 45 .

Unsteady under whip and spur, 273.

U. S. Army bit, 320 .

Useful lessons only, 33 .

Uses of the bit, 56 .

Value, depends on training, 2 ; of early training, 42 .

Vehicle, backing, 80 ; familiarizing with, 77 .

Vices, 246, 286; backing in stall, 297 ; balking, 249 ; biting, 292 ; breaking, 265; bucking, 276; causes, 247; eribbiug, 269; difficult to back, 263; difficult to bridle, 291 ; diffieult to crupper, 292; difficult to groom, 2Ss; difficult to harness, 290 ; difficult to shoc, 300; halter-pulling, 269; jibbing, 252; kicking, 254; kicking in stable, 295; outdoor, 246; outdoor, the cause, 249 ; outdoor overcome, 249; plunging, 264; prancing, 265; pulling-halter, 269; rearing, 264,276 ; refusing admission to stall, 286; running away, 260; running back, 262; shoeing, 300 ; shying, 257 ; stable, 286 ; striking, 295 ; study causes, 247 ; switehing tail, 265; tail over line, 268; wind-sucking, 300.

Vicious horses, 186, 241; causes, 186; "Cruiser," 241; handling, 242; Galvayne method, 242; objects of fear, 243; overcome, 244 ; Rarey method, 242; subduing, 241 ; temper, 157 ; training, 186.

Victor bit, 320 .

Vision, 49 ; limited, 9.

Vividness of impression, 4.

Voice, and punishment, 18; and reward, 17.

Wagon, skeleton, 119 ; advantages, 119.

Walk, 159 ; fast training, 91 ; running, 164 ; Spanish, 181 ; training, 168.

Walk, trot and canter horse, 167 .

Walking horse, 167.

War bridle, 191; modified, 192.

Watcring, 356 ; the trotter, 125.

Weaving, 314.

Weight in shoeing, 140.

Whims, 246, 278, 286; blanket tearing, 307 ; boring, 281 ; chewing tie-strap, 312 ; crowding, $2 \$ 2$; drenching, 315 ; eating bedding, 312 ; mnashing teeth, 2s0; gorging grain, 315 ; grasping bit, 279: lugging, 281; lying down cowfashion, 311; lying down in harness, 312 ; outdoor, 246 ; pawing, 309; pulling away, 2s2; refusing to stand, 254; rolling, 306 ; rubbing harness, 311 ; rubbing tail, 310 ; shaking head, 2s0; 
sleeping standing, 313 ; stable, 286 ; striking lips, 279 ; stripping bridle, 283; switching tail, 314 ; tail rubbing, 310 ; tearing blankets, 307; their causes, 278; tongue lolling, 278; tossing head, 280 ; trotting in stable, 314 ; troublesome to catch, 285 ; weaving, 314 .

Whip, 19 ; and spurs, 154 ; caressing with, 83 ; unsteady under, 273.

"Whoa," teaching foal, 41 ; teaching horse, 65 ; what it stands for, 99.

Wild horses, 223 ; acquainted with robes, 239 ; catching, 223 ; driving, 233 ; familiarizing with noise, 237 ; familiarizing with objects, 237 ; Galvaynizing, 230 ; gentling, 225, 229; harnessing, 234; hitched, 235; leading, 231; lassoing, 223 ; noise, 238; Rareyfying, 230 ; shackling, 230 ; snaring, 225; strange objects, 238; subduing, 236; teaching to lead, 231 ; teaching uses of the bit, 233 ; training, 223.

Wilson bit, 320 .

Wind-galls, 373.

Wind-puffs, 373.

Wind-sucking, 300 ; causes, 300 ; bit, 320 ; overcome, 300 ; see Cribbing.

Witch-hazel, 127.

Wooden-gag, 200.

Woodruff, Hiram, 328.

Words to use in training, 99.

Work horse, age to train, 46 ; driving, 129 ; training, 44.

Work performed on training, 47.

Wounds, 370 ; treatment, 371.

Wrong, make difficult, 11.

W-wire bit, 320 .

Yankee bridle, 189; modified, 190.

Yard training, 111.

"Yea," teaching a horse, 97.

Young colt, training, 5. 

THE following pages contain advertisements of a few of the Macmillan books by the same author or on kindred subjects 


\section{THE RURAL MANUALS}

\section{Edited by L. H. BAILEY}

\section{MANUAL OF FARM ANIMALS}

A Practical Guide to the Choosing, Breeding, and Keep of Horses, Cattle, Sheep, and Swine

By MERRITT W. HARPER, Assistant Professor of Animal Husbandry in the New York State College of Agriculture at Cornell University.

Illustrated, decorated cloth, t2mo, 545 pages, index, \$2.00 net; by mail, \$2.I8

"The work is invaluable as a practical guide in raising farm animals." - Morning Telegram.

"A book deserving of close study as well as being handy for reference and should be in the possession of every farmer interested in stock." - Rural World.

\section{MANUAL OF GARDENING}

A Practical Guide to the Making of Home Grounds and the Growing of Flowers, Fruits, Vegetables for Home Use

By L. H. BAILEY

Illustrated, cloth, Izmo, 517 pages, \$2.00 net; by mail, \$2.I7 This new work is a combination and revision of the main parts of two other books by the same author, "Garden Making" and "Practical Garden Book," together with much new material and the result of the experience of ten added years. Among the persons who collaborated in the preparation of the other two books, and whose contributions have been frecly used in this one, are C. E. Hunn, a gardener of long experience; Professor Ernest Walker, reared as a commercial florist; Professor L. R. Taft, and Professor F. A. Waugh, well known for their studies and writings on horticultural subjects.

\section{A STANDARD WORK REVISED AND ENLARGED}

\section{THE FARM AND GARDEN RULE BOOK}

By LIBERTY H. BAILEY

Illustrated, cloth, 12 mo, \$2.00 net

When Professor Bailey's "Horticulturist's Rule Book" was published nearly twenty-five years ago, the volume became a standard agricultural work running through sixteen editions. Taking this book as a basis the author has now made a wholly new book, extending it to cover the field of general farming. stock raising, dairying, pottltry rearing, horticulture, gardening, forestry, and the like. It is essentially a small cyclopedia of ready rules and references packed full from cover to cover of condensed meaty information and precepts on almost every leading subject connected with country life.

\section{IN PREPARATION}

MANUAL OF HOME-MAKING MANUAL OF CULTIVATED PLANTS

\section{THE MACMILLAN COMPANY}

Publishers

64-66 Fifth Avenue
New York 


\section{THE RURAL OUTLOOK SET}

\section{By Professor L. H. BAILEY}

Director of the New York State College of Agriculture at Cornell University Four Volumes. Each, clot/ I2mo. Uniform binding, attractively boxed. \$5.00 net per set; carriage extra. Each volume also sold separately.

In this set are included three of Professor Bailey's most popular books as well as a hitherto unpublished one, - "The Country-Life Movement." The long and persistent demand for a uniform edition of these little classics is answered with the publication of this attractive series.

\section{The Country-Life Movement}

Cloth, I 2mo, 220 pages, $\$ 1.25$ net; by mail, $\$ r .34$ This hitherto unpublished volume deals with the present movement for the redirection of rural civilization, discussing the real country-life problem as distinguished from the city problem, known as the back-to-the-land movement.

\section{The Outlook to Nature (New and Revised Edition)}

Cloth, I2mo, r95 pages, \$1.25 net; by mail, \$r.34

In this alive and bracing book, full of suggestion and encouragement, Professor Bailey argues the importance of contact with nature, a sympathetic attitude toward which "means greater efficiency, hopefulness, and repose."

\section{The State and the Farmer (New Edition)}

Cloth, I2mo; \$I.25 net; by mail, \$I.34

It is the relation of the farmer to the government that Professor Bailey here discusses in its varying aspects. He deals specifically with the change in agricultural methods, in the shifting of the geographical centers of farming in the United States, and in the growth of agricultural institutions.

\section{The Nature Study Idea (New Edition)}

$$
\text { Cloth, I2mo, \$I.25 net; by mail, \$T.3.7 }
$$

"It would be well," the critic of The Tribune Furmer once wrote, "if "The Nature Study Idea" were in the hands of every person who favors nature study in the public schools, of every one who is orposed to it, and, most important, of every one who teaches it or thinks he does." It has been Professor Bailey's purpose to interpret the new school movement to put the young into relation and sympathy with nature,- a purpose which he has admirably accomplished.

\section{THE MACMILLAN COMPANY}

Publishers 64-66 Fifth Avenue New York




\section{THE RURAL TEXT-BOOK SERIES}

\section{EDITED BY L. H. BAILEY}

A series of books primarily intended for the students in agricultural colleges, but exceedingly useful to any one who is willing to give the subject serious study.

NOW READY OR IN PRESS

\section{The Principles of Soil Management} By T. L. LYON and E. O. FIPPIN

An interesting, easily understood general discussion of soils, drainage, mulching, irrigation, manures, fertilizers, etc. A book which every farmer should study.

Cloth, 12mo, 53 I pages, illustrated, \$I.75 net

\section{Southern Field Crops}

By J. F. DUGGAR

Dec. cloth, illustrated, I2mo, 579 pages, \$1.75 net

\section{Plant Physiology}

BY B. M. DUGGAR

Dec. cloth, illustrated, I2mo, ${ }_{516}$ pages, $\$$ I.60 nel

TO BE ADDED TO THE SERIES LATER

Manures and Fertilizers

Animal Breeding

Cotton
BY H. J. WHEELER

BY F. B. MUMFORD

BY R. J. H. DE LOACH

VOLUMES ON PLANT BREEDING, PLANT PATHOLOGY, AND SPECIAL PIIASES OF FARM LIFE

WILL PROBABLY BE ARRANGED FOR AT AN EARLY DAY

\section{THE MACMILLAN COMPANY}

Publishers 64-66 Fifth Avenue New York 


\section{RURAL SCIENCE SERIES}

EdTED By L. H. BAILEY

On Selection of Land, ets.

Isaac P. Roberts' The Farmstead . . . . . . . . \$I 50

On Tillage, etc.

F. H. King's The Soil .

Isaac P. Roberts' The Fertility of the Land . . . . . . 150

F. H. King's Irrigation and Drainage . • . . . . . 150

Edward B. Voorhees' Fertilizers . . . . . . . . 125

Edward B. Voorhees' Forage Crops . . . . . . . 150

J. A. Widtsoe's Dry Farming . . . . . . . . 150

L. H. Bailey's Principles of Agriculture . • • • • • 125

On Plant Diseases, etc.

E. C. Lodeman's The Spraying of Plants - • . . . . 125

On Garden-Making

L. H. Bailey's Garden Making . • • . . . . . 150

L. H. Bailey's Vegetable-Gardening . . . . . . . 150

L. H. Bailey's Forcing Book • • • • • • • • 125

On Fruit-Growing, etc.

L. H. Bailey's Nursery Book · • • • • • . . 150

L. H. Bailey's Fruit-Growing • • • . • • . . 150

L. H. Bailey's The Pruning-Book . . . . . . . . 150

F. W. Card's Bush Fruits . . . . . . . . . I 50

On the Care of Live-stock

Nelson S. Mayo's The Diseases of Animals . . . . . . I 50

W. H. Jordan's The Feeding of Animals . . . . . . I 50

I. P. Roberts' The Horse . . . . . . . . . 125

George C. Watson's Farm Poultry . . . . . . . 125

On Dairy Work, Farm Chemistry, etc.

Henry H. Wing's Milk and Its Products . . . . . . 150

J. G. Lipman's Bacteria and Country Life . . . . . . 150

On Economics and Organization

I. P. Roberts' The Farmer's Business Handbook . • • • • 125

George T. Fairchild's Rural Wealth and Welfare . • . . 125

II. N. Ogden's Rural Hygiene . . . . . . . . 150

J. Green's Law for the American Farmer . . . . . . 150

THE MACMILLAN COMPANY Publishers 64-66 Fifth Avenue New York 


\title{
Cyclopedia of American Agriculture
}

\author{
Edited вy L. H. BAILEY \\ Director of the College of Agriculture and Professor of Rural Economy, \\ Cornell University.
}

With Ioo full-page plates and more than 2000 illustrations in the text; four volumes; the set, \$20.00 net; half morocco, $\$ 32.00$ net; carriage extra

\author{
Volume I - Farms \\ Volume II - Crops
}

Volume III - Animal

Volume IV - The Farm and the Community

"Indispensable to public and reference libraries . . . readily comprehensible to any person of average education." - The Nation.

"The completest existing thesaurus of up-to-date facts and opinions on modern agricultural methods. It is safe to say that many years must pass before it can be surpassed in comprehensiveness, accuracy, practical value, and mechanical excellence. It ought to be in every library in the country." - Record-Herald, Chicago.

\section{Cyclopedia of American Horticulture}

\section{Edited By L. H. BAILEY}

With over 2800 original engravings; four volumes; the set, $\$ 20.00$ net; half morocco, $\$ 32.00$ net; carriage extra

"This really monumental performance will take rank as a standard in its class. Illustrations and text are admirable. . . . Our own conviction is that while the future may bring forth amplified editions of the work, it will probably never be superseded. Recognizing its importance, the publishers have given it faultless form. The typography leaves nothing to be desired, the paper is calculated to stand wear and tear, and the work is at once handsomely and attractively bound." - New York Daily Tribune.

\section{THE MACMILLAN COMPANY

Publishers 64-66 Fifth Avenue New York



MAR IL 1912 



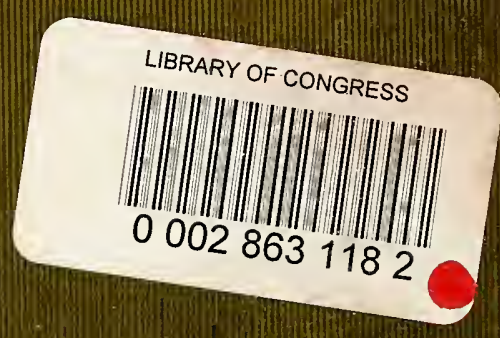

